\title{
V.A.
}

\section{Las nuevas narrativas, en el entorno social}

Editores: Vanessa Rodríguez Breijo, Milena Trenta, Samuel Toledano Buendía, Ciro Hernández, Alberto Ardèvol Abreu, Alejandro Álvarez Nobell, Lucas Morales, Tatiana Hidalgo-Marí, Almudedna Barrientos Báez

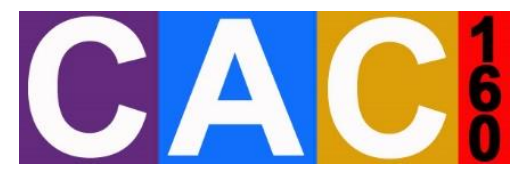

Cuadernos Artesanos de Comunicación / 160 


\section{CAC 160 - Las nuevas narrativas, en el entorno social}

\section{VV.AA.}

Editores: Vanessa Rodríguez Breijo, Milena Trenta, Samuel Toledano Buendía, Ciro Hernández, Alberto Ardèvol Abreu, Alejandro Álvarez Nobell, Lucas Morales, Tatiana Hidalgo-Marí, Almudena Barrientos Báez

Diseño: F. Drago

Ilustración de portada: Fragmento del cuadro "Mujer de Fuenteventura", de Vale (Bolonia).

Imprime y distribuye: F. Drago. Andocopias S.L.

c/ La Hornera, 41. La Laguna. Tenerife. Teléfono: 922250554 | fotocopiasdrago@telefonica.net

Edita: Sociedad Latina de Comunicación Social - edición no venal La Laguna (Tenerife), 2019 - Creative Commons * (http://www.revistalatinacs.org/2019/Sociedad/estatutos.html)

Catálogo $=$ http://www.cuadernosartesanos.org

Protocolo de envío de manuscritos con destino a CAC:

http://www.cuadernosartesanos/protocolo.html

Descargar el $p d f$ :

http://www.cuadernosartesanos.org/\#160

ISBN: 978-84-17314-10-1

D.L.: TF-997-2019

DOI: $10.4185 / \mathrm{CAC} 160$ 


\section{VV. AA.}

\section{Cuadernos Artesanos de Comunicación}

Coordinador editorial: José Manuel de Pablos - jpablos@,ull.edu.es

Comité Científico

Presidencia: José Luis Piñuel Raigada (UCM)

Secretaría: Milena Trenta (ULL)

- Octavio Islas (Unversidad de los Hemisferios, Ecuador)

- Ramón Zallo (Universidad del País Vasco, UPV-EHU)

- Núria Almiron (Universidad Pompeu Fabra, UPF)

- Francisco Campos Freire (Unioversidad de Santoiago de Compostela)

- José Cisneros (Benemérita Universidad Autónoma de Puebla, BUAP)

- Bernardo Díaz Nosty (Universidad de Málaga, UMA)

- Carlos Elías (Universidad Carlos III de Madrid, UC3M)

- Paulina B. Emanuelli (Universidad Nacional de Córdoba, UNC)

- José Luis González Esteban (Universitas Miguel Hernández de Elche, UMH)

- Marisa Humanes (Universidad Rey Juan Carlos, URJC)

- Juan José Igartua (Universidad de Salamanca, USAL)

- Xosé López (Universidad de Santiago de Compostela)

- Maricela López-Ornelas (Universidad Autónoma de Baja California, AUBC)

- Javier Marzal (Universidad Jaume I, UJI)

- José Antonio Meyer (Benemérita Universidad Autónoma de Puebla, BUAP)

- Ramón Reig (Universidad de Sevilla, US)

- Miquel Rodrigo Alsina (Universidad Pompeu Fabra, UPF)

- Xosé Soengas (Universidad de Santiago de Compostela)

- José Luis Terrón (Universidad Autónoma de Barcelona, UAB)

- José Miguel Túñez (Universidad de Santiago, USC)

- Victoria Tur (Universidad de Alicante, UA)

- Miguel Vicente (Universidad de Valladolid, UVA)

* Queda expresamente autorizada la reproducción total o parcial de los textos publicados en este libro, en cualquier formato o soporte imaginables, salvo por explícita voluntad en contra del autor o autora o en caso de ediciones con ánimo de lucro. Las publicaciones donde se

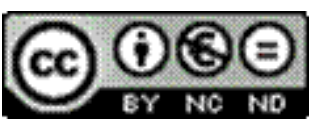
incluyan textos de esta publicación serán ediciones no comerciales y han de estar igualmente acogidas a Creative Commons. Harán constar esta licencia y el carácter no venal de la publicación.

Este libro y cada uno de los capítulos que contiene, así como las imágenes incluidas, si no se indica lo contrario, se encuentran bajo una Licencia Creative Commons Atribución-No Comercial-Sin Derivadas 3.0 Unported. Puede ver una copia de esta licencia en http://creativecommons.org/licenses/by-nc-nd/3.0/ Esto significa que Ud. es libre de reproducir y distribuir esta obra, siempre que cite la autoría, que no se use con fines comerciales o lucrativos y que no haga ninguna obra derivada. Si quiere hacer alguna de las cosas que 
aparecen como no permitidas, contacte con los coordinadores del libro o con el autor del capítulo correspondiente.

* La responsabilidad de cada texto es de su autor o autora. 


\section{Las nuevas narrativas, en el entorno social}

* 001 - La prensa española a través de la lengua: recursos para definir la identidad de género y la ideología lingüística - M. Belén Alvarado Ortega - Grupo GRIALE Universidad de Alicante - belen.alvarado@ua.es

En este trabajo pretendemos observar cómo algunos recursos lingüísticos, como la intensificación, son utilizados por los articulistas de la prensa española actual para expresar opiniones sobre la lengua, en general, y cómo, además, a través de ellos, podemos extraer conclusiones sobre la identidad de género y la ideología lingüística. La ideología lingüística del español ha sido un fenómeno estudiado por diferentes autores como Del Valle (2007), Schieffelin et alii (2012) y Marimón (2015), entre otros. Pensamos que realizar una construcción de la ideología lingüística del escritor es poner de manifiesto su pensamiento y actitud sobre la lengua a través de sus textos. Sobre el fenómeno de la identidad de género y la búsqueda de unas características propias del lenguaje de los hombres frente al de las mujeres, sabemos que ha sido estudio de numerosos investigadores a lo largo de la historia de la lingüística. Esta cuestión ya interesaba a R. Lakoff (1975), ideas que recoge de sus antecesores Jespersen (1922), Labov (1997), Trudgill (1972), entre otros. En nuestro corpus, que consta de 20 artículos de opinión, publicados en El País, observaremos si los autores, hombres y mujeres, tienen unas características concretas y particulares, según su identidad de género, sobre la manera de expresar su opinión.

* 002 - Consolidación del periodismo deportivo de nicho español: el caso de ElDesmarque.es - Cristian Ramón Marín Sanchiz - Universidad Miguel Hernández de Elche - crms74@gmail.com y José Luis González Esteban Universidad Miguel Hernández de Elche jose.gonzalez@umh.es 
Introducción. El periodismo deportivo de nicho se configura como una de las especialidades más innovadoras y activas en el terreno del emprendimiento periodístico español. Durante la última década, ElDesmarque se ha convertido en un proyecto de referencia para este sector gracias a su crecimiento en términos de audiencia y negocio hasta ser adquirido por parte del grupo Mediaset en 2019. Metodología. A través de un estudio de caso, este artículo analiza la situación actual del medio de comunicación en cuatro áreas: a) producto o servicio, b) procesos de producción y distribución, c) organización o equipo, d) acciones y estrategias de comercialización y marketing. Resultados y discusión. Se observa que ElDesmarque dispone de una propuesta de valor muy definida para su producto, basada en ofrecer la cobertura local desatendida por los medios tradicionales; además, su condición de nativo digital le permite lanzar, probar y distribuir nuevos productos periodísticos a través de metodologías ágiles, como el Lean Startup, que también otorgan un mayor dinamismo a nivel redaccional y comercial que el de las cabeceras tradicionales.

* 003 - La farmacopornografía desde la perspectiva de mujeres migrantes que ejercen el comercio sexual en la ciudad de Valdivia, Chile - Gabriela Edith Pérez lagos Universidad Austral de Chile lagosperezagabriela@gmail.com

La presente investigación analiza cuáles son los elementos de la farmacopornografía que influyen en las percepciones de mujeres migrantes que ejercen el comercio sexual en la ciudad de Valdivia. El concepto farmacorponografía fue acuñado por la filósofa Beatriz Preciado (2008) que define a la industria farmacéutica y la industria audiovisual del sexo como pilares fundamentales que sustentan el capitalismo de la segunda mitad del siglo XX.

La hipótesis consiste en que el trabajo sexual es un sustento de dicho modelo de control farmacopornográfico. De manera que el trabajo sexual está subordinado a estereotipos, fetiches y comportamientos característicos de los elementos de la sociedad farmacopornográfica. 
Junto con lo anterior, este estudio recoge el concepto de feminización de las migraciones. Concepto que acuña el fenómeno que se ha desarrollado a partir de los años 90 en Chile, donde migrantes llegan al país por su solvencia económica, pero sobre todo el mayor flujo de personas corresponde a mujeres provenientes de Perú, Colombia y Bolivia, las cuales se dedican a trabajos feminizados como la prostitución, trabajos domésticos, o el comercio a pequeña escala, etc. En este contexto, se realizará un estudio de caso, basado en el testimonio de cuatro mujeres trabajadoras sexuales migrantes, las cuales hayan tomado la decisión de dedicarse al comercio sexual por razones económicas, con el propósito de enviar remesas a sus familias.

Los resultados de esta investigación arrojaron que las entrevistadas son discriminadas por su color de piel, por ser extranjeras y por ejercer el comercio sexual. Además, su trabajo está supeditado a fetiches, comportamientos y estereotipos característicos de la sociedad farmacopornográfica.

* 004 - Transparencia de la información pública: Un análisis de las webs de los municipios de Ecuador - Narcisa Jessenia Medranda Morales - Universidad Politécnica Salesiana-nmedranda@ups.edu.ec

El acceso a la información pública permite que la ciudadanía se empodere de su rol de ciudadano, y se convierta en agente de cambio social. Este ejercicio de auditoria cívica, generará la prevención de la corrupción, de manera particular, en las instituciones públicas y aquellas que utilizan fondos del Estado. Es también cierto que, el acceso a la información pública, "Además de ser un factor preventivo frente a la corrupción, el acceso a la información de las administraciones públicas constituye un derecho necesario para profundizar y propiciar formas democráticas de implicación de la ciudadanía en la administración pública.”

Esta investigación tiene como objetivo: Determinar los niveles de transparencia de los municipios del Ecuador durante el periodo 2014 2019, a través de la metodología Infoparticipa. La metodología Infoparticipa fue desarrollada y aplicada en España desde el año 2012 
hasta la actualidad, esta metodología ha sido validada también en países latinoamericanos como Ecuador y Colombia donde se ha adaptado de acuerdo al marco legal de cada país, y a la estructura propia de las instituciones que hacen uso de los fondos del Estado. La metodología Infoparticipa cuenta con cinco grandes grupos de preguntas, desdoblados en 52 indicadores para los ayuntamientos españoles y en 53 para los municipios de Ecuador. Además, esta metodología tiene una cartografía digital que permite ver los resultados de las evaluaciones en abierto a través del Mapa Infoparticipa (http://mapainfoparticipa.com). Los principales resultados que se visibilizan en la plataforma del Mapa Infoparticipa son que el $90 \%$ de las webs municipales de Ecuador están por debajo de la media de transparencia según el infómetro del Mapa Infoparticipa. Como conclusión, se evidencia una falta de interés por parte de los representantes políticos en transparentar la gestión pública a la ciudadanía.

* 005 - El papel de las tecnologías transversales en la disrupción de la vida cotidiana - F. Javier Malagón Universidad Complutense de Madrid - fjmalago@ucm.es

La ponencia propone una explicación del papel de los smartphones como tecnología mediadora entre los cambios macrosociales y microsociales de la vida cotidiana, afectando a las mentalidades y pautas de conducta que acontecen en los espacios y tiempos familiares, laborales, de formación, consumo, ocio, participación social, cuidado de la salud, etc. Esta tecnología facilita la creciente virtualización de las interacciones comunicativas y las intensifica, fenómeno solidario con las transformaciones globales que apuntan a una nueva etapa en la expansión del capitalismo basada en una "economía de datos".

No solo estamos permanentemente conectados, sino que, gracias a ello, podemos flexibilizar la situación concreta en la que nos encontremos. Este tipo de tecnología transversaliza las acciones que podemos hacer con ella, distribuyéndolas de un modo mucho más abierto y flexible en los espacios, tiempos y ámbitos en los que discurre la vida cotidiana, en parte desorganizándolos y en parte transformando las reglas que los organizan. 
Todo esto sucede en el marco de un proceso sociohistórico en el que son condiciones socializadoras intensificar nuestra participación en interacciones comunicativas tecnológicamente mediadas, trasladar una parte considerable de esas interacciones al ciberespacio y aprender a gestionarlas en él.

No es un fenómeno totalmente nuevo, pues su genealogía puede rastrearse a través de las distintas etapas por las que transitan las sociedades industriales; pero sí puede afirmarse que la virtualización de las interacciones sociales es en la actualidad un proceso considerablemente más amplio, intenso, rápido y sofisticado que en el pasado como consecuencia de la aceleración, extensión y diversificación de las innovaciones.

El capitalismo ha encontrado en el ciberespacio un nuevo mundo a través del que expandirse ¿Hacia qué escenarios puede apuntar este proceso?

* 006 - Comunicación, orientalismo y superhéroes: la perpetuación de los estereotipos japoneses a través de turistas de película - Lucas Morales Domínguez Universidad de La Laguna lucasmoralesdominguez@gmail.com

La explotación que ha sufrido el género de los superhéroes en los últimos años se ha saldado con una inmensa producción de películas que han tocado diversos géneros y que se han rodado bajo diferentes sensibilidades creativas. Aunque es posible que tengan una estructura similar, es imposible cortarlas a todas con un mismo patrón, ya que los registros son tan variados como los temas sobre los que versan estas creaciones artísticas.

Para profundizar en esta materia, este texto se centra la película 'Lobezno: Inmortal' (Mangold, 2013), un caso donde se narra la visita que realiza un superhéroe a Japón, contando una historia que sirve como elemento de transmisión de estereotipos sobre este país que ya se han visto y estudiado por otros autores. Esta comunicación, que 
parte de los estudios sobre orientalismo de Edward Said (1978), se engloba bajo el paraguas de un estudio más amplio que recoge el retrato que se hace del País del Sol Naciente en las películas contemporáneas protagonizadas por turistas cinematográficos.

* 007 - ¿Quedamos o nos conectamos? La comunicación virtual de los milennials - Belén Casas-Mas - Univerisdad Complutense de Madrid - bcasas@ucm.es

Esta ponencia ofrece una visión de conjunto de los resultados de una investigación llevada a cabo por el Grupo Complutense "Identidades Sociales y Comunicación". Uno de los objetivos consistió en obtener información relativa a la virtualización de las actividades cotidianas entre los jóvenes denominados milennials y a los usos del tiempo relacionados con el empleo de las TIC. La metodología consistió en la aplicación de un cuestionario sobre una muestra representativa de estudiantes de la Universidad Complutense que pertenecían a diversos Grados, atendiendo a criterios de edad, sexo y ramas de estudio. La muestra fue de 810 alumnos pertenecientes a un total de 26 titulaciones que se imparten en la Universidad.

Los resultados específicos que se presentan en la ponencia se dividen en tres grandes bloques: el primero, abarca las actividades virtuales y las presenciales de los jóvenes, la simultaneidad de ambas tareas y los recursos informativos que más utilizan. El segundo, hace referencia a procesos de virtualización de las comunicaciones con diferentes Actores sociales, a saber: las administraciones públicas, instituciones privadas, familiares, amigos, conocidos, movimientos sociales o políticos. El tercer bloque comprende las preferencias de los jóvenes universitarios a la hora de elegir sus interlocutores en función de los temas de referencia. Los resultados de esta investigación han servido de base para el diseño de una investigación a escala nacional sobre los usos del tiempo relacionados con la virtualización.

* 008 - Ciberespacio y deporte: hacia la virtualización de los hábitos de vida saludables - María Cadilla Baz - Profesora Contratada Doctor Interina. Universidad Complutense de Madrid-cadilla@ucm.es 
Resulta difícil encontrar un ámbito de nuestra vida que no se encuentre mediado de algún modo por las TIC; más allá de eso, nos hallamos en un momento histórico en el que muchas de nuestras actividades cotidianas se están trasladando parcial o totalmente desde el espacio físico hacia el entorno virtual.

Este proceso de virtualización avanza de manera irrefrenable a la vez que irreversible, aunque a diferentes ritmos en función del tipo de actividades de que se trate; además, su penetración en la sociedad también parece guardar relación con ciertos perfiles sociales, económicos y culturales. Así lo muestra una $\mathrm{I}+\mathrm{D}+\mathrm{i}$ en curso sobre los usos del tiempo y las transformaciones generacionales relacionadas con la virtualización, parte de cuyos resultados se exponen en esta ponencia.

Concretamente, nuestra contribución se centra en la observación de cómo se está desarrollando la migración al ciberespacio de las actividades relacionadas con las prácticas deportivas. La vinculación entre la actividad física y la mejora de la calidad de vida hacen de este sector una oportunidad de negocio muy atractiva para la industria, pero también un reclamo interesante para la sociedad interesada en conocer, controlar y mejorar su estado de salud, así como para quienes recurren a las actividades deportivas como forma de socialización. Desde una perspectiva social, los usos de la tecnología vinculados a actividades relacionadas con el deporte también están provocando una transformación importante de hábitos, tiempos y espacios.

* 009 - Realidad Virtual para la innovación docente actoral Dra. Juana Rubio-Romero. IP Grupo de Investigación Nebrija Comunicación; Dra. Mar Sampedro. Directora Acting Studio Cinema Room. Dra y Amelia Meléndez. IP Grupo de Investigación Estudios Transversales de Creación Contemporánea.

Los rápidos avances tecnológicos de los últimos años están propiciando el auge tanto del hardware como del software dedicado a la Realidad Virtual (RV). Y aunque todavía es una tecnología en 
desarrollo, ya está siendo utilizada en campos muy diversos, como la ingeniería, la psicología, la medicina, el entretenimiento o el arte y el patrimonio. En el ámbito educativo la RV está además conociendo un amplio desarrollo debido a las posibilidades de inmersión e interacción que brinda esta tecnología al permitir la vivencia de experiencias imposibles en la realidad física. En la preparación de actores, en concreto, se están llevando a cabo experiencias interesantes como por ejemplo la propuesta del National Theater y The Royal Shakespeare Company de Londres o la del Kònic Lab barcelonés de acciones performáticas telemáticas e internacionales. El objetivo principal de este trabajo es determinar las posibilidades que ofrece la RV a la hora de desarrollar una docencia actoral, ya sea presencial u online, y el grado de innovación pedagógica o de beneficio que supone para la calidad y eficiencia de la formación de actores. En definitiva, se trata de descubrir las posibilidades de la RV como futura herramienta para proporcionar al actor vivencias referenciales en la construcción de su personaje a través de interacciones con espacios y temporalidades específicas en las que se situarán psicofísicamente durante su realidad en la ficción. Este trabajo forma parte de una investigación en curso de la Universidad Nebrija para la empresa Acting Studio Cinema Room, que ha sido beneficiada con el apoyo del Programa Cheque Innovación de la Comunidad de Madrid. Pretendemos conocer el nivel de desarrollo, los límites y el futuro previsto de la realidad virtual en el contexto de la docencia actoral. Se abordarán ventajas e inconvenientes del uso de esta tecnología con productos lifelike reactive que procuran el embodiement, la percepción de la corporalidad y si ésta potencia la empatía o, por el contrario, acontece una merma del ejercicio imaginativo o simbólico e incluso la desconexión emocional. La Metodología de investigación que estamos aplicando es la estructural o cualitativa, mediante entrevistas en profundidad a expertos en tres áreas bien diferenciadas: la tecnológica (productores y desarrolladores de realidad virtual), la docente y la de actuales usuarios de este tipo de tecnología, enfocándonos al área actoral y al de la psicología. Los resultados de esta investigación sobre las aplicaciones y dispositivos mejor adaptados a la inmersión en un contexto escénico servirán para valorar las posibilidades que ofrece la RV en la creación de referentes sensoriales, aprendizajes y experiencias virtuales con el objetivo de incrementar y potenciar las técnicas actorales futuras. 
* 010 - La resistencia a la virtualización de las tareas del cuidado de personas y hogares - José Antonio Alcoceba Hernando - Dpto. de Sociología: Metodología y Teoría. Facultad de Ciencias de la Información. Universidad Complutense de Madrid - jaalcoce@ucm.es

La incorporación de los procesos de virtualización al cuidado de personas y hogares en las sociedades contemporáneas occidentales, aparece como una necesidad social a la que habrá tener en consideración, habida cuenta de su relevancia por el envejecimiento poblacional.

Las TIC han venido transformando los usos y las relaciones productivos y reproductivos de las personas, con diferencias sustanciales en sus ritmos e incidencia. Mientras que los procesos productivos, concretados en la formación y el empleo, aparecen sometidos a una fuerte presión de virtualización, las tareas relativas el cuidado de personas y hogares están incorporando muy lentamente el uso de las TIC a los cuidados físicos, psicológicos y emocionales de las personas y hogares.

La virtualización de las tareas ayuda a otros hogares y de cuidado a personas corresponde en mayor medida a un grupo de personas, donde predominan las mujeres sobre los hombres (amas de casa), con bajos niveles de formación y con cargas familiares (generalmente sus progenitores mayores o enfermos). A pesar de que declaran una permanente conexión móvil y tecnológica en relación con las actividades de cuidado, ésta, está determinada por su implicación emocional y afectiva con dichas personas dependientes, concretada en visitas presenciales.

El incremento de hogares unipersonales de personas mayores (jubilados y pensionistas), está obligando a nuevas formas de relación y asistencia social (conexión móvil y servicios de teleasistencia permanentes); sin embargo, la presencialidad parece seguir siendo imprescindible en las relaciones entre cuidadores y sujetos de cuidado. 
* 011 - La compra online como símbolo y refuerzo del estatus social - Coral Hernández-Fernández - Universidad Complutense de Madrid - mclhernandez@ucm.es

Esta comunicación tiene su origen en la investigación Los Usos del tiempo relacionados con la virtualización. Transformaciones Generacionales (CSO2015-63983-P MINECO/FEDER) , centrándose en la virtualización de las compras de bienes de uso personal. Los resultados evidencian una tasa de virtualización de tipo medio, que si bien no alcanza los altos valores registrados por las actividades de ocio (entretenimiento, viajes y vacaciones) sí que se aproxima a las tasas de virtualización de los ámbitos productivos (empleo y formación).

Las personas que en mayor medida hacen uso de las TIC para la compra de bienes de uso personal, corresponden mayoritariamente a los denominados "cosmopolitas digitales". Se trata en su mayoría de individuos jóvenes (menores de 45 años), con un perfil claramente femenino, que cuentan con educación superior y que se consideran a sí mismos en situación económica favorable. Además, son personas a las que les gusta estar siempre conectadas a Internet, especialmente a través de sus dispositivos móviles, que forman ya parte integral de su forma de vida.

El artículo profundiza en la definición de este perfil de compradores online y en las correlaciones existentes con la brecha digital creciente que distingue y separa a los segmentos de población menos integrados en el entorno digital.

* 012 - Cambios generacionales en la virtualización de las actividades discrecionales - Francisco Bernete García Profesor Titular de Universidad - Universidad Complutense de Madrid - fbernete@ucm.es

La virtualización, entendida como traslado de actividades al ciberespacio, representa mucho más que un cambio de uso de las tecnologías informativas: es una transformación socio-histórica de la vida en el hogar y fuera del hogar. Se trata de aplicaciones de las TIC, 
en cuya adopción unas generaciones van por delante de otras. Estos early adopters (en terminología anglosajona), también son los primeros en cambiar los usos del tiempo y el espacio como consecuencia de la virtualización de actividades.

Las aplicaciones informáticas están incidiendo en la vida cotidiana, entre otros muchos ámbitos (la política, la economía, la educación, el arte, etc.). Una parte de la vida cotidiana está ocupada por actividades que se dejan a la discreción o libre albedrío de las personas. Situamos entre ellas, actividades relacionadas con el entretenimiento en el tiempo libre, las prácticas deportivas, las celebraciones y la asistencia a espectáculos.

En esta ponencia, se expondrán resultados -procedentes de un estudio $\mathrm{I}+\mathrm{D}+\mathrm{i}$ - sobre los rasgos que caracterizan a quienes más probablemente hacen uso de internet para actividades relacionadas con celebraciones y con la asistencia a espectáculos. Eventualmente, los datos sobre estos dos tipos de actividades serán comparados con los datos correspondientes a actividades relacionadas con el entretenimiento en el tiempo libre, o con la práctica de deportes.

* 013 - El organismo electoral en los procesos de democracia participativa a nivel local - Roxana Silva Chicaíza - Universidad de Coruña roxanasilvach@gmail.com

Ecuador es un Estado de derechos y de justicia, de conformidad con lo señalado en la Constitución del 2008, la misma que tiene como eje transversal la participación ciudadana.

El inicio de la novísima Función Electoral en el 2009 empeñó todo su esfuerzo para lograr transparentar una democracia justa y verdadera, en la cual se contemple la participación de las organizaciones sociales y movimientos políticos, en donde se respete la igualdad de oportunidades, transparencia e independencia y participación.

La participación es la base a una democracia incluyente y que se refleja ampliamente con iniciativas desarrolladas por primera vez en contextos 
socio-político-comunicacional, donde se plasman ideas innovadoras como: Observatorios de Redes Sociales de candidatos presidenciales en las elecciones presidenciales y de Participación Política Femenina.

La demanda de una democracia transparente, participativa, incluyente, eficiente y como resultado genere una gobernabilidad digna para el país, es un derrotero para el fortalecimiento institucional y empoderamiento ciudadano.

En los gobiernos locales la participación ciudadana puede resultar más fructífera debido a la cercanía de la autoridad con sus mandantes y por tanto se hace indispensable que se empiecen a analizar los mecanismos de democracia participativa, sus alcances a posibles problemas en aspectos como la gobernabilidad, la eficiencia de la gestión pública local, la comunicación política, y las competencias de las diferentes instituciones públicas en la concreción de estos derechos.

Este trabajo se centrará en el papel de una de las instituciones que conforman la Función Electoral, que es el Consejo Nacional Electoral; y, los organismos descentralizados en la promoción y goce de los mecanismos de una democracia participativa.

* 014 - La construcción de estereotipo de mujer a través del análisis de la metáfora en los avisos de la revista Cromos en 1922 vs 2016 - John Jairo León Muñoz - Universidad Santiago de Cali. Correo electrónico John.leon00@usc.edu.co y Ana María Diaz Jordán Universidad del Valle, Cali. Correo electrónico amdj04@yahoo.com

La presentación aborda un estudio comparado sobre la construcción de género en Colombia. Una manera de analizar ese cambio de la publicidad a lo largo de la década del 1920 y la segunda década de comienzos de milenio 2010, por medio de las publicaciones ininterrumpidas a través del análisis de la revista Cromos. Analizar las marcas existentes y que pautaban en un periodo de tiempo y el discurso que emitían y que reflejaban para conectarse con el consumidor. La investigación permitió evidenciar sobre cómo se hacían los mensajes 
publicitarios a comienzos de siglo XX y cómo fueron cambiando esos mensajes con la llegada de la imprenta, con la invención de la cámara fotográfica, con la llegada del cine, la radio, la televisión y la internet, etc. La investigación 100 años de frases Publicitarias: Análisis del texto en la revista Cromos 1916-2015, fue un proyecto aprobado por la Dirección General de Investigación (DGI) de la Universidad Santiago de Cali en el año 2015 y durante los dos años siguientes se investigó sobre la caracterización de los textos en los anuncios publicitarios aparecidos entre los años 1916 y 2015; además se alcanzaron los objetivos específicos que se enfocaron así: el primero en diferenciar los rasgos característicos de los anuncios publicitarios en el periodo de tiempo seleccionado. El segundo en exponer los aportes que la revista Cromos y los cambios sucedidos a través del tiempo hicieron a la escritura de textos publicitarios en Colombia, haciendo énfasis en la figura de significación -la metáfora- y su uso como forma de creatividad en el texto publicitario. El tercero consistió en identificar de qué manera los cambios políticos y socioculturales durante cien años han incidido en el ejercicio de la redacción publicitaria, evidenciados en el corpus analizado. $\mathrm{Y}$, finalmente, el cuarto, hace referencia a diferenciar la forma cómo los anunciantes les hablaban a los diferentes géneros; masculino, femenino y comunidad LGBTI.

* 015 - Ventanas a un tiempo de cambio rápido: la prensa internacional ante la transición a la democracia en Venezuela - Ángel Dámaso Luis León - Universidad de La Laguna-aluisleo@ull.edu.es

Venezuela experimentó un cambio político profundo a finales de la década de los cincuenta. La caída de la dictadura de Marcos Pérez Jiménez dejaba una situación de inestabilidad en el país que generaría inquietud no solo a los que allí estaban, sino también a los que se encontraban lejos. El papel del país sudamericano resultaba importante para otros por diferentes cuestiones, la dinámica política internacional hacía que despertara el interés de ciertos actores de peso en la comunidad internacional, su carácter de productor petrolero generaba atracción en otros países de la región que le observaban como lugar importante y el crecimiento económico que había experimentado había llevado al país una carga migratoria que hacía que muchas familias de 
diversas partes del globo tuvieran un ojo puesto en la situación venezolana. Debido a esta importancia adquirida, en esta comunicación, se tratará de estudiar y analizar cómo la prensa internacional, utilizando algunos patrones de referencia, observa y proyecta los acontecimientos que se producen en el país venezolano a finales de la década de los cincuenta. Poniendo énfasis en el trato al proceso en sí mismo, pero también a los actores que tienen un papel destacado en el mismo, así como a la incidencia que ello puede tener en sus países de origen.

* 016 - Inteligencia colectiva para el aprendizaje en red: Una exploración interdisciplinaria - María Isabel Villa. Universidad EAFIT. mvilla@eafit.edu.co, Luis Alejandro Cárdenas. Universidad EAFIT. lcardenf@eafit.edu.co y Mauricio Vásquez. Universidad EAFIT. mvasqu23@eafit.edu.co

La inteligencia colectiva es practicada por los seres humanos desde que disponen de lenguaje y cultura, pero Internet ha acelerado potenciado sus alcances debido a características como libertad, anonimato, ubicuidad y revisión constante de contenidos. La literatura sobre el campo muestra que la sociedad de la información y el conocimiento sería inviable sin inteligencia colectiva. Esta investigación tiene como propósito explorar la literatura académica publicada en Web of Science sobre inteligencia colectiva al servicio de la dinamización de comunidades de práctica y aprendizaje en red. Se parte de la necesidad de comprender los escenarios de interacción, participación y colaboración como factores clave de los aprendizajes contemporáneos.

Esta investigación se desarrolló en tres fases. En la primera se aplicaron indicadores bibliométricos para conocer las características de la producción académica sobre inteligencia colectiva teniendo en cuenta años, países, área de investigación, revistas, autores y citación en las publicaciones indexadas en Web of Science. En segundo lugar, se construyeron redes temáticas para identificar aspectos predominantes en su estudio; y en tercer lugar, se realizó un análisis cualitativo de los artículos de la muestra que abordan la inteligencia colectiva para facilitar el aprendizaje en red. 
Los resultados de esta investigación permiten identificar modelos teóricos y metodológicos significativos para el estudio de la inteligencia colectiva. El análisis provee importantes datos para el desarrollo de trabajos interdisciplinarios que impulsen la ciencia abierta y la educación. Los datos recabados pueden ser de especial utilidad para entidades sociales y gubernamentales interesadas en la adaptación, la implementación y/o el análisis de estrategias colaborativas.

* 017 - Redes sociales y relaciones públicas: un estudio bibliométrico de los artículos publicados en español en revistas indexadas en web of science y scopus - Marián, NavarroBeltrá - Universidad Católica de Murcia (UCAM) mnavarro2@ucam.edu, Susana, Miquel-Segarra - Universitat Jaume I de Castellón - smiquel@uji.es y Lorena, López Font Universitat Jaume I de Castellón - lfont@uji.es

Las relaciones públicas podrían definirse como una disciplina que se encarga de los procesos de comunicación entre las organizaciones y sus públicos con el propósito de crear y mantener relaciones mutuamente beneficiosas entre ellos. En este proceso las redes sociales poseen un papel de gran relevancia al fomentar la comunicación bidireccional entre las instituciones y sus stakeholders. Debido a la importancia de esta temática, el interés de las Ciencias Sociales por el estudio de las redes sociales cada vez es mayor. Ante este contexto, surge la necesidad de identificar y conocer las investigaciones existentes relacionadas con el tema de estudio. Así, el objetivo del presente trabajo se basa en recopilar, sintetizar y analizar la producción científica relacionada con las relaciones públicas y las redes sociales. Para ello se ha realizado un análisis bibliométrico. En concreto, se han localizado y examinado los artículos que se han centrado en el estudio de las redes sociales y de las relaciones públicas y que han sido publicados en español entre 1995 y 2018 en revistas indexadas en el área de comunicación de las bases de datos Scopus y Web of Science (WOS). Los principales resultados muestran que la producción científica sobre redes sociales y relaciones públicas parece haber aumentado en los últimos años. Además, aunque existen revistas especialmente interesadas en el tema de estudio, no parece haber una clara especialización al considerar a los autores y a las 
instituciones a las que estos pertenecen. Finalmente, resulta importante señalar que ninguno de los artículos analizados pertenece a revistas indexadas en la base de datos Journal Citation Reports (JCR). Por tanto, pese a la importancia de la temática tratada y aunque la investigación sobre redes sociales y relaciones públicas se ha incrementado en los últimos años, la producción científica examinada no parece ser de gran calidad.

* 018 - Retos comunicativos de estudiantes extranjeros en programas de estudios impartidos en lengua inglesa en universidades de países no angloparlantes - Dr. Mariana Sueldo - Universidad de Vilnius, facultad de Comunicación (Lituania) ISM University of Management and Economics (Lituania) marianasueldoluque@gmail.com y Dr. Beata Grebliauskiene Universidad de Vilnius, facultad de Comunicación (Lituania) beata.grebliauskiene@gmail.com

El creciente número de estudiantes que optan por estudiar en el extranjero está transformando la educación superior en una industria global. Instituciones de enseñanza superior (IES) de todo el mundo buscan afanosamente ampliar su oferta académica añadiendo programas impartidos en idioma extranjero, generalmente en inglés. Una mayor proporción de alumnos internacionales trae consigo la complejidad multicultural del aula universitaria que cada vez resulta un asunto más en el orden del día. Sin embargo, la diversidad cultural es un fenómeno complejo cuyos elementos impactan los procesos de enseñanza y aprendizaje de manera positiva y negativa.

Según datos empíricos, estudiantes extranjeros en universidades de países no angloparlantes se enfrentan a retos de índole predominantemente comunicativa. Uno de los mayores desafíos es la competencia lingüística. Aún admitiendo su propio insuficiente nivel de inglés, los estudiantes extranjeros esperan que sus profesores no angloparlantes nativos impartan sus asignaturas de manera clara y en perfecto inglés. Los profesores, por su parte, asocian los resultados académicos de estos alumnos con la experiencia previa en sus países de origen en cuanto a métodos de enseñanza y aprendizaje. En contraste, los estudiantes extranjeros se declaran abiertos ante innovaciones 
educativas, pero preocupados por la escasa o imprecisa información para realizar las tareas asignadas por el profesor. A esto se suma la exclusión ante la imposibilidad de interacción con los estudiantes locales con quienes no comparten la lengua materna, lo cual dificulta la adaptación a un nuevo ambiente cultural y lingüístico. Al no contar con el apoyo ni la cercanía de su familia y amigos, los estudiantes extranjeros tienden a procurarse una mayor atención y dedicación por parte de sus profesores.

Se perciben considerables discrepancias entre los puntos de vista de alumnos extranjeros y los del personal en la institución de acogida con repecto a estos problemas y sus causas.

* 019 - Diseño e implementación de un sistema de georreferenciación participativo SIGP - como estrategia de comunicación política y responsabilidad social universitaria para la promoción comunitaria de la E-participación política Alonso Cortina Acevedo - Universidad del Sinú Seccional Cartagena - acortinaa@unisinucartagena.edu.co y Bleidis Vanessa Quintana Pérez Universidad del Sinú Seccional Cartagena - bvannesaq@unisinucartagena.edu.co

En Colombia, existe una política pública para el fortalecimiento de los organismos de acción comunal, instituidos como expresión de participación ciudadana legal organizada, sin embargo, y pese a los recursos que en este sentido invierte el Estado, los organismos comunales no logran incidir políticamente en la gestión pública, esto debido al déficit de representación política, ocasionado entre otros factores, por la falta de procesos de comunicación política que promocionen la participación ciudadana.

Esta ponencia, presenta la responsabilidad social universitaria y la innovación social, educativa y tecnológica, como categorías que estratégicamente vinculadas, pueden coadyuvar en la solución del problema planteado. La reflexión, es producto de la sistematización de los avances del proyecto de intervención e investigación socio-jurídico, UNILAB Laboratorio de innovación social y educativa, de la Escuela de derecho de la Universidad del Sinú Seccional Cartagena, mediante 
el cual, se diseña e implementa, un sistema de georreferenciación participativo SIGP- a partir de las TIC y las TEP (tecnologías para el empoderamiento y la participación), como estrategia de innovación social y tecnológica, de responsabilidad social universitaria de la Escuela de derecho de la Universidad del Sinú seccional Cartagena, para motivar la e-participación ciudadana, estableciendo dinámicas innovadoras de comunicación política entre: los organismos de participación ciudadana, las comunidades, las autoridades públicas y la universidad, como actor político en el territorio local, con potencial para generar e impulsar procesos de cambio social.

* 020 - Las redes sociales, las aplicaciones móviles y las estrategias de transformación digital en la televisión pública: RTVE en el contexto europeo - Carmina Crusafon, Carlos González Saavedra y Marcial Murciano

Los medios de servicio público (MSP) se esfuerzan cada vez más por atraer y mantener a sus audiencias mediante nuevas plataformas y aplicaciones digitales, con la finalidad de fortalecer la interacción con los espectadores y diferenciarse de otras ofertas, mediante el conjunto de valores institucionales que le son propios. Como parte de este proceso de transformación digital, los MSP europeos y RTVE en particular, han incorporado numerosos mecanismos de acceso y participación basados en el establecimiento de comunidades de usuarios en las redes sociales y en la disponibilidad de aplicaciones para todo tipo de dispositivos móviles. La presente propuesta de comunicación plantea aportar datos actualizados y comparados sobre la presencia de la televisión pública española y europea en las principales redes sociales (Twitter, Facebook, YouTube e Instagram) y sobre el volumen de descarga de las aplicaciones para teléfonos inteligentes, que permitan evaluar la disposición de los MSP para afrontar los desafíos de la transformación digital en el ámbito de la televisión.

* 021 - Ítaca: Una estrategia educomunicativa para la alfabetización mediática de adultos - Adriana Patricia Garzón Forero - Corporación Universitaria Minuto de Diosadriana.garzon@uniminuto.edu 
Los acelerados cambios en las formas de acceso a la información, la convergencia de medios y tecnologías multimedia impone retos importantes a la sociedad en general, específicamente si se habla de los muros digitales que se erigen cuando no todas las personas tienen las competencias necesarias para leer críticamente las fuentes de información o ser al mismo tiempo creadores de contenido digital. La brecha digital se representa en la imposibilidad de acceder a internet y adicionalmente no adaptarse a las modalidades de participación que se van configurando dentro del escenario digital, en este sentido el analfabetismo digital se está convirtiendo en un nuevo formato de discriminación que puede agudizar la crisis en grupos sociales marginados. De acuerdo con lo anterior el objetivo principal de esta investigación es diseñar una estrategia educomunicativa para la alfabetización digital de adultos de la Escuela Piccolino Sede Lisboa ubicada en la localidad de Suba en Bogotá-Colombia cuyo trabajo se enmarca en la educación no formal de adultos. El trabajo se realizó bajo la metodología de Investigación Acción, el número de participantes del proyecto fue de 28 jóvenes y adultos entre los 30 y 70 años, estudiantes de la escuela y se utilizó la observación participante, la historia de vida y el grupo focal para la recolección de la información. Como resultado se generó una propuesta desde la comunicación/educación cuyo eje articulador es la construcción colectiva de relatos desde la cotidianidad y la historia de los adultos, contemplando el uso creativo de los diferentes lenguajes digitales y herramientas tecnológicas para el desarrollo de un producto transmedia que dé cuenta de las realidades y contextos de la comunidad.

* 022 - Leónidas Proaño, intermediador en la protección de los derechos humanos de América Latina - Julio Bravo Mancero Universidad Nacional de Chimborazo - jbravo@unach.edu.ec; Carlos Larrea Naranjo - Universidad Nacional de Chimborazo carloslarrea@unach.edu.ec y Ramiro Ruales Parreño Universidad Nacional de Chimborazo - rruales@unach.edu.ec

La presente investigación aborda la defensa de los derechos humanos en América Latina que realizó Leonidas Proaño. Desde el Frente de 
Solidaridad por Chimborazo, organismo al que llegaron cientos de denuncias, intervino a favor de quienes se sintieron vulnerados; recibió cartas de Argentina, Chile, Bolivia, El Salvador, Estados Unidos de Norteamérica, Colombia, Brasil, Ecuador, entre otros. La investigación de tipo cualitativa utilizó como técnica la revisión documental y el análisis de contenido a las evidencias que reposan en el Fondo Documental de la Diócesis de Riobamba; este trabajo analiza, ordenaclasifica e interpreta lo observado que, con carácter de relevante permanece aún invisibilizado, entregándole originalidad. Los resultados de su aproximación con: las Madres de la Plaza de Mayo, obreros, maestros, estudiantes, religiosos, seglares, indígenascampesinos, mujeres, y jóvenes, originó el ejercicio de la comunicación política y estrategias periodísticas para la difusión de las actividades de inter-acción, inter-relación e inter-mediación.

* 023 - Fortalecimiento de las competencias ciudadanas frente a la construcción de un territorio de paz: Reflexiones desde la incidencia de las competencias comunicativas como eje esencial de la reconstrucción de tejido social en aulas educativas Bleidis Vanessa Quintana Pérez Universidad del Sinú Seccional Cartagena-bvannesaq@unisinucartagena.edu.co

En la búsqueda de la redefinición de la Instrucción Cívica en Colombia se ha pensado en la inclusión de prácticas que fomenten el aprendizaje de los principios y valores de la participación ciudadana y la formación en el respeto a los derechos humanos, a la paz y a la democracia (MEN, 2006), como postulados teóricos del Programa de Fortalecimiento de la cobertura con calidad para el Sector Educativo Rural. Los esfuerzos se remontan desde el año 2004 como una apuesta por romper los esquemas de la educación siendo necesario el desarrollo de competencias que permitan ayudar a niños, niñas y jóvenes a manejar la vida en sociedad mediante las competencias comunicativas, permitiendo su expresión, entendimiento y diálogo a partir del reconocimiento del otro en términos de igualdad.

Conforme a lo expresado, se plantea la presente ponencia producto de la investigación social desarrollada al interior de una escuela rural en el municipio de Mahates (Bolívar, Colombia). A partir de esta reflexión, 
se establece el papel fundamental de las competencias comunicativas como el primer eslabón para la construcción de una sociedad que permita fraguarnos de manera individual y como ciudadanos participativamente activos, considerando las secuelas del conflicto armado en ciertas zonas del país. Así mismo, se establece la importancia del papel de las instituciones educativas en la construcción de espacios que permitan la consolidación y fortalecimiento de ciudadanos, en lugar de criminales.

El análisis resulta pertinente de acuerdo a los esfuerzos por la construcción de entornos de paz, en tanto que, se exige que el Estado actúe de manera eficiente en el fortalecimiento de las áreas rurales mediante entornos educativos que permitan la formación de una ciudadanía activa, lo cual es acorde a los objetivos de Desarrollo Sostenible en materia de Paz, Justicia e Instituciones sólidas planteado en la Agenda 2030.

* 024 - Análisis del tratamiento informativo en las ediciones digitales de Komsomolskaya Pravda, El País, The New York Times y The Sun sobre la detención de Julian Assange - Julio Bravo Mancero - Universidad Nacional de Chimborazo, Universidad Santiago de Compostela - jbravo@unach.edu.ec; Carlos Larrea Naranjo y Jessica Trujillo Mero - Universidad Nacional de Chimborazo.

El presente artículo aborda el tratamiento informativo desde que el activista australiano Julian Assange fue detenido en la Embajada ecuatoriana en Londres, el 11 de abril de 2019, tras permanecer 2.487 días con estatus de refugiado, luego de que el presidente de Ecuador Lenin Moreno hiciera pública el retiro del asilo político.

Este trabajo utilizó metodología cuali-cuantitativa; como técnica se escogió el análisis de contenido; como instrumento los investigadores diseñaron una matriz con la que se observó información con carácter de relevante; en los aspectos cuantitativos se obtuvo información sobre la temática, fecha, género, procedencia, emplazamiento, elementos de ayuda gráfica y elementos de ayuda audiovisual; en lo cualitativo, se estudió -que fue lo más importante- el qué dicen y cómo lo dicen. Para 
esta investigación se analizaron las ediciones digitales de los medios Komsomolskaya Pravda (Rusia), El País (España), The New York Times (Estados Unidos) y The Sun (Reino Unido), publicadas en sus portales entre el 11 de abril y el 24 de junio de 2019.

Los resultados obtenidos evidenciaron de qué forma los medios, motivo de análisis, publicaron los contenidos; se consideró: a) el estilo (¿qué dice?); y, b) la utilización del lenguaje (¿cómo lo dice?). Este caso, por la connotación periodístico-político fue incluido en la agenda de medios, como El País, que desde la detención ha publicado 32 contenidos incluyendo hipervínculos que direccionan hacia nueva información.

El manuscrito se fundamenta sobre la base de los aportes de expertos en comunicación, comunicación política, periodismo y periodismo digital, publicados en artículos científicos, libros, revistas, tesis doctorales y tesis de maestrías; entre los autores se encuentran: Bravo (2015), Buitrón (2005), Calduch (2012), Fernández (2007), Horkheimer (1937), Kottak (2011), Lopez (2013), Paoli (1977), Ramírez (2018), Sierra (2018).

* 025 - Iron Maiden: la música que gritó cine - Dr. David Fuentefría Rodríguez (Universidad de La Lagunadfuentef@ull.es

Quienes no han seguido la trayectoria musical del grupo británico Iron Maiden ignoran que, además de los grandes hitos de la literatura, las ficciones realistas o metafísicas y los sucesos históricos de alcance, el cine siempre fue una fuente capital de inspiración para sus letras. Encuadrada en la variante de la New Wave of British Heavy Metal (N.W.O.B.H.M.), surgida en el Reino Unido a finales de los 70, la banda cumplirá en 2020 cuarenta años incluyendo en sus discos lo que, por su elevado nivel de creatividad y producción, podrían calificarse como auténticas "bandas sonoras alternativas", que hasta nuestros días siguen contribuyendo a acercar el cine a las nuevas generaciones, mediante la traslación a sus notas, y la novelización/versificación breve, de clásicos y no tan clásicos de toda época, nacionalidad, condición y género, desde "El nombre de la rosa" a "Braveheart", desde "En busca del fuego" a 
"Planeta prohibido". Este trabajo trata de recopilar, y de poner en valor, todas las canciones del grupo inspiradas en películas, desde su primer disco en estudio, el homónimo "Iron Maiden" (1980), al último y más reciente, “The book of souls" (2015).

* 026 - Los medios digitales como herramienta de comercialización para las entidades deportivas náuticas - Dra. Paula González Redondo - Instituto Mediterráneo de Estudios de Protocolo - paula.gonzalez@protocoloimep.com

Las entidades deportivas náuticas del siglo XXI les es necesario profundizar en las nuevas herramientas de comunicación para ofrecer y comercializar sus servicios a su público objetivo. Cada vez más la comunicación convencional se está dejando de lado, no en su totalidad, para llegar a un público más amplio y especialista en este mundo online, en el que a golpe de click pueden adquirir todo tipo de productos y servicios. De este modo, este tipo de entidades sin ánimo de lucro deben de potenciar este tipo de herramientas digitales no sólo para fomentar y difundir el deporte, que es su razón de ser, sino también para que todos sus servicios relacionados con la práctica náutica deportiva lleguen a un mayor número de seguidores.

Los resultados de investigación, obtenidos en base a técnicas cualitativas y cuantitativas, constatan que el medio online es una herramienta de comunicación de mucho alcance para ofrecer los servicios del sector náutico. Este tipo de entidades son como cualquier empresa que tiene que actualizarse y estar a la vanguardia de las nuevas tecnologías, no sólo para comercializar sino para dar una buena imagen de marca frente a su competencia.

* 027 - Reconocimientos juveniles al mito Caicediano: Transposiciones Semióticas y Circulaciones Transmediáticas Víctor Hugo Valencia Giraldo - Pontificia Universidad Javeriana Cali - vhvalencia@javerianacali.edu.co

La figura pública del escritor Andrés Caicedo Estela (Cali, (*) 29/09/1951 - (†) 4/3/1977) ha ganado en los últimos años gran notoriedad entre los jóvenes de esta ciudad, gracias - entre otras 
cuestiones - a la circulación de sus textos a través de los medios digitales y las actuales redes sociales. Esta ponencia mostrará cómo se ha ido fraguando (primero en los medios convencionales analógicos y luego en las plataformas web) el "mito" que rodea a este precoz artista, al que su suicidio ayudó a eternizar entre sus más recientes fans. Usando la Teoría de la Discursividad Social (TDS), o sociosemiótica, y auscultando los pareceres de casi un centenar de jóvenes caleños(as), se pudo comprobar cómo los medios digitales y las nuevas producciones culturales que han adaptado y recirculado (en soportes artístico-mediáticos diversos, como el teatro, el cine, el video y los posteos en internet) mensajes perennes de un joven artista extemporáneo a jóvenes lectores contemporáneos, han ayudado a conservar vigentes epítetos, imágenes, posturas ideológicas o vitales; entre otras formas de perpetuidad discursiva que de no ser por la creciente transmediatización posiblemente habrían quedado confinadas al texto escrito y al libro impreso.

* 028 - Comunicación, patrones socioculturales y nuevas narrativas de series audiovisuales: caso de estudio Insaciable Gabriela Andrea Morocho Ocaña, gmorocho@utmachala.edu.ec; Lizette Ivonne Lazo Serrano, 1lazo@utmachala.edu.ec, y Karina del Rocío Benítez Luzuriaga, kbenitez@utmachala.edu.ec, Universidad Técnica de Machala, Ecuador

La comunicación audiovisual ha ido en auge durante los últimos tiempos, su producción se ha masificado y las plataformas de pago ayudan a que series, seriales, documentales y en general historias de todas partes del mundo se den a conocer, de ahí llega la pregunta ¿Qué y cómo se presenta el contenido? Ya que la deuda pendiente es mezclar lo educativo con el entretenimiento, siendo complicado, puesto los formatos educomunicativos son consumidos en menor cantidad por la audiencia; probablemente por su vaga atracción o no saber emplear de manera adecuada los recursos audiovisuales.

El caso propuesto para analizar es la serie estrenada en 2018 por la plataforma de pago Netflix, llamada Insaciable, en la cual retrata las necesidades que tienen las jóvenes por encajar en una sociedad con una 
gran cantidad de patrones o llamados estereotipos, asociando la belleza con la delgadez, o a las reinas de belleza como un ejemplo de la comunidad, las posiciones sociales de relevancia, la discriminación, estereotipando formas de ser y de vestir de los homosexuales, fomentando el odio, la ira e incluso satanizando las actitudes inadecuados como posesiones diabólicas. Todo ello presentado en una seria de apenas 12 capitulo, de género humor negro y drama, dibujando la realidad de una sociedad al borde del colapso.

La presente investigación busca definir la construcción de narrativa que es representada en cine y televisión en esta nueva era, a través de un estudio de caso tomando como ejemplo la serie Insacible, identificando los patrones que se refuerzan en este formato audiovisual mediante el uso de narrativas actuales que se han convertido en populares en plataformas de pago, el género de humor negro que se utiliza para satirizar lo que sucede en el día a día, haciendo que de una u otra forma se estandarice una manera de ver esa realidad social.

* 029 - La televisión pública francesa y el Mercado Único Digital: tecnología, acceso, innovación y participación ciudadana Gloria Rosique Cedillo - Universidad Carlos III de Madrid grosique@hum.uc3m.es y Dolores Rubio García-Universidad Complutense de Madrid - dorubio@ccinf.ucm.es

A fin de adecuarse a los nuevos mandatos del Mercado Único Digital y con base en las recomendaciones de la Unión Europea de Radiodifusión (EBU) sobre la necesidad de acelerar la innovación y el desarrollo de las empresas audiovisuales, aumentar su compromiso y diversidad, tener un mayor acercamiento y un mejor entendimiento de las necesidades de las audiencias, será cada vez más importante para el público joven, así como estar disponible y destacar en todas las plataformas relevantes. Por todo ello, la televisión pública francesa viene desarrollando un plan estratégico relacionado con la digitalización y la innovación.

Este estudio de tipo descriptivo tiene como objetivo conocer las claves de su estrategia empresarial a través de las últimas implementaciones tecnológicas y los mecanismos desarrollados en pro de la participación 
y el conocimiento de las audiencias. Para ello se ha aplicado la metodología de la observación indirecta vinculada a la documentación escrita y digital, a través de la búsqueda de información de fuentes que permitan obtener nuevas interpretaciones para contextualizar e interpretar el objeto de estudio.

Los resultados preliminares apuntan al desarrollo de estrategias basadas en la implementación de servicios digitales, servicios de accesibilidad a contenidos para diferentes pantallas y soportes, creación de plataformas digitales, uso de las redes sociales y la apuesta por producción de contenidos transmedia. Asimismo, se identifican las políticas sobre servicio público y digitalización que se caracterizan por la puesta en marcha de diversos mecanismos de participación de las audiencias como el Consejo Consultivo de Programas (CCT), los Encuentros con los Telespectadores, el Club de los Telespectadores, entre otros, y por una constante emergencia de reglamentación y regulación, que han llevado a France Télévision a establecer un auténtico proyecto digital global sobre todos los soportes, y ofrecer un número muy amplio de contenidos de calidad a un público cada vez más extenso.

* 030 - La percepción de competencia mediática y su relación con las variables sociodemográficas del profesorado de educación básica regular de dos instituciones educativas ubicadas en Lima Metropolitana - Milagros del Carmen Gonzales Miñán Universidad San Martin de Porres.mgonzalesm1@usmp.pe, Osbaldo Washington Turpo Gebera - Universidad San Martin de Porres. oturpog@usmp.pe y César Roberto Mejía Chiang Universidad San Martin de Porres. cmejiac@usmp.pe

En la actualidad, el ecosistema tecnológico demanda un cambio en el ambiente que ha de realizarse a nivel mundial y en los distintos niveles educativos (Maraver, Caldeiro y Pérez, 2017). Ante este desafío, se hace necesario contar con un profesorado con una sólida formación en competencias mediáticas para así poder orientar y ser un modelo sobre cómo acceder reflexiva y constructivamente a la información y el conocimiento a través de los medios (Gonzáles, Ramírez y Salcines, 2018) que permita resolver problemas y lograr un aprendizaje creativo. 
Por ello, el objetivo de este estudio fue conocer los niveles de percepción de competencia mediática y su relación con las variables sociodemográficas (sexo, edad, estado civil, tipo de gestión de la institución, nivel de enseñanza, años de experiencia docente, entre otras.) del profesorado de educación básica regular de dos instituciones educativas ubicadas en Lima Metropolitana. La metodología del estudio es cuantitativa, con nivel descriptivo correlacional y diseño no experimental. La muestra estuvo conformada por 60 profesores, en su mayoría mujeres, quienes respondieron el Cuestionario de Autopercepción sobre Competencia Mediática para Docentes en Formación (Mateus, Hernández-Breña y Figueras-Maz, 2019) conformado por 30 ítems distribuidos en las seis dimensiones que conforman el constructo. Los resultados refieren correlaciones estadísticamente significativas entre las variables $\mathrm{s}$

* 031 - Una experiencia ecuatoriana en la implementación del modelo de producción audiovisual de teleclase digital interactiva - Wellington Remigio, Villota Oyarvide - Universidad Católica de Santiago de Guayaquil - Wellington.villota@cu.ucsg.edu.ec Guillermo Segundo, Del Campo Saltos - Universidad Estatal de Milagro-gdelcampos@unemi.edu.ec Alberto Enrique, Franco Lalama - Universidad Católica de Santiago de Guayaquil aefrancol@gmail.com

Tanto en Europa como en América, la televisión educativa y cultural, pública o privada, ha tenido significativos cambios debido al uso de las tecnologías y los sistemas de transmisión digitales surgidos a fines del siglo pasado. Ello permitió una mayor interacción, socialización y participación de niños, jóvenes y adultos, alcanzando un mayor impacto y adaptándose a los nuevos tiempos, a través de métodos de producción acompañados de proyectos comunicacionales enfocados en la educación, la cultura, la ciencia y tecnología. En ese contexto, esta ponencia presenta los resultados de la evaluación del modelo de producción de teleclase en señal digital bajo procesos de interacción y en convergencia de medios, que permitió establecer criterios de producción para implementar el prototipo en estudios formales de tercer nivel, a través del canal televisivo de la Universidad Católica Santiago de Guayaquil (UCSG), en Ecuador. En el modelo se 
definieron los recursos técnicos, tecnológicos, metodológicos, pedagógicos y de producción requeridos para el desarrollo de la teleclase de una hora, dividido en dos fases, primero bajo un sistema de producción audiovisual de 30 minutos donde el docente imparte la clase en tiempo lineal, seguido de un acompañamiento pedagógico de 30 minutos a través de plataformas digitales y uso de recursos tecnológicos. El método empleado, bajo el esquema cualitativo, fue el análisis de grupo focal, compuesto por veinticinco estudiantes de la materia Estudios Contemporáneos que se imparte en la UCSG. La investigación permitió determinar la eficiencia del modelo de producción audiovisual de teleclase digital interactiva en convergencia de medios y su implementación en el proceso de estudios formales y regulares.

* 032 - La digitación de la televisión pública europea: la estrategia de la RAI - David Álvarez Rivas - Universidad Complutense de Madrid - dalvarez@ucm.es; María José Pérez del Pozo Universidad Complutense de Madrid - mjperezp@ucm.es y Sergio Príncipe Hermoso - Universidad Complutense de Madrid - sprincip@ucm.es

La Radiotelevisión pública italiana RAI ha representado históricamente, en el ámbito de la Europa comunitaria, un modelo público peculiar debido a su fuerte condicionamiento de una política nacional convulsa e inestable. Ese carácter sui géneris ha estado presente también en el proceso de digitalización de la cadena iniciada con la Ley 66/01 y la controvertida "Ley Gasparri" de 2004, que crearon mecanismos de protección para la RAI -y la privada Mediasetfrente a la prevista avalancha de nuevos operadores y plataformas; a la vez, nuevos marcos legales en 2015 y 2017 van concretando la función de servicio audiovisual público que debe regir las actividades de la cadena.

Todo el complejo -y, a veces, contradictorio- entramado legal en torno a la RAI ha afectado a su desarrollo y expansión digitales, al cierre de su etapa analógica y al inicio de la TDT. Sin embargo, y pese a las interferencias y peajes políticos que contaminan en ocasiones su mandato de servicio público, vive un proceso de adaptación y 
diversificación de contenidos, creación de nuevos formatos para nuevos públicos y desarrollo de proyectos de innovación, investigación para adaptarse al Mercado Único Europeo, y competir con un sector privado y de pago que siempre ha liderado los datos de audiencia.

A lo largo de este trabajo se analiza la estrategia digital seguida por la RAI en los últimos años, desde una perspectiva descriptiva, para poder evaluar si existe realmente un plan estratégico de transformación de los servicios digitales y de acceso y participación de los espectadores, así como nuevos mecanismos y recursos de transparencia propios de iniciativas política de servicio público.

* 033 - ¿Cómo influye la comunicación y la imagen que proyectan las universidades de la ciudad de Cali en los estudiantes que desean estudiar una carrera en la facultad de ciencias económicas y administrativas? - León Felipe Collazos- Profesor Universidad Autónoma de Occidente. Correo electrónico lfcollazos@uao.edu.co Natalia Polanco Aristizábal- Estudiante Universidad Autónoma de Occidente. Correo electrónico Natalia.polanco@uao.edu.co y María José Álvarez RestrepoEstudiante Universidad Autónoma de Occidente. Correo electrónico maria_jose.alvarez@uao.edu.co

La investigación aborda factores como la imagen y la comunicación de 7 universidades de la ciudad de Cali, observando su influencia en la decisión de elección de los estudiantes que están interesados en una carrera de la facultad de ciencias administrativas, también se tiene en cuenta la percepción y la opinión crítica por parte de los mismos con el fin que las instituciones de educación superior conozcan la importancia de construir su propia marca universitaria, pero ¿Cuáles son los factores que afectan o que construyen una buena marca universitaria?. Esta investigación se hace esta pregunta constantemente logrando comprender en qué punto las universidades se interesan hoy en día por construir una imagen que en este caso es la marca universitaria y el medio de comunicación más adecuado en estos tiempos, para comunicarse de una forma bidireccional con los estudiantes. Los objetivos específicos que se lograron alcanzar se dividieron de la siguiente manera: el primero hace referencia a la 
importancia de atributos de las instituciones, tratando de centrarse en cuales son aquellos que los estudiantes tienen en cuenta a la hora de tomar la decisión y los lleva a elegir una universidad y no la otra, el segundo se centra en la notoriedad de marca que tienen las universidades en la mente de los estudiantes para esto se enfatizó en el reconocimiento laboral y social. Y el tercero habla de la comunicación y de la evolución de los canales por donde los estudiantes desean ser contactados por las universidades para recibir la información.

* 034 - Victimización secundaria: tratamiento informativo en los familiares de los desaparecidos en Canarias - Sima González Grimón - sgonzalez@ufpcanarias.es- Docente en la Universidad Fernando Pessoa Canarias y Doctoranda en la Universidad Complutense de Madrid

Las noticias de desaparecidos generan mucho interés en la sociedad en general, y de manera muy significativa en el entorno del desaparecido, que se aferra a los medios de comunicación. De ahí, que los allegados experimenten lo que se conoce como victimización secundaria por parte de los medios de comunicación. Este trabajo presenta algunos de los factores que influyen en el tratamiento informativo, el seguimiento y la resolución de los casos más mediáticos, y al mismo tiempo, de los casos invisibles, que apenas lograron repercusión. Concretamente, se centra en los desaparecidos canarios. Canarias es una de las comunidades donde se registra más denuncias de alto riesgo, según datos del Ministerio del Interior.

El periodo estudiado comienza y acaba con dos casos históricos en el archipiélago: la desaparición, en 1998, de la menor Cathaysa Rosales, en Gran Canaria, Yéremi Vargas (2007), hasta Juana Ramos (2016).

Así, abordamos el tratamiento y los factores mediáticos, políticos, sociales o económicos, que hicieron más visibles unos casos sobre otros. Pretendemos reconocer las funciones y los efectos de la labor periodística, y discutir los aciertos y los errores éticos y deontológicos implicados en medios como dos periódicos canarios (Canarias 7, La Provincia) frente a dos periódicos de tirada nacional (ABC y El País) con un análisis cuantitativo y cualitativo de las noticias. A raíz de estos 
factores que afectan a la victimización secundaria investigamos un protocolo de actuación en el que trabajen en conjunto equipos de psicólogos y periodistas en el que se establezcan normas en el tratamiento de las desapariciones y en cómo actuar con los familiares para evitar la victimización secundaria.

* 035 - Estrategias transmedia de comunicación y creatividad audiovisual en proyectos de danza - Ana Sedeño-Valdellos Universidad de Málaga - valdellos@uma.es

La interrelación entre visuales y dispositivos electrónicos e interactivos y prácticas escénicas ha supuesto nuevas posibilidades en la construcción de experiencias intermediales, en lo que se puede agrupar como prácticas escénicas digitales, relacionadas con el teatro posdramático y la teatralidad expandida. Por su lado, el campo de la creatividad audiovisual digital aplicada a la danza transita entre los proyectos, más clásicos, de la cinedanza, la videodanza (screendance), o la danza social en red.

Menos conocidas son algunas experiencias transmedia que se aplican a ambos campos de las artes escénicas, y que tratan de poner al espectador en el centro de la experiencia, generando fórmulas de engagement e inmersivas. El trabajo tratará de revisar las premisas del transmedia adaptado a las artes escénicas, especialmente a la disciplina dancística. Proyectos como los del El Ball del Vetlator (2013) o The Cracked up (2011) son ejemplos que servirán en esta propuesta.

* 036 - Aprendizaje aplicado y creación con utilidad social en Comunicación Audiovisual: el caso de la Universidad de Barcelona - Jorge Franganillo - franganillo@ub.edu Universidad de Barcelona, Lydia Sánchez - 1sanchez@ub.edu Universidad de Barcelona, $M^{\mathrm{a}}$ Ángeles García Asensio garciaasensio@ub.edu - Universidad de Barcelona y Anna Marquès - anna.marques@ub.edu - Universidad de Barcelona

La universidad debe impulsar iniciativas de innovación docente con impacto social, orientadas a permitir un aprendizaje basado en competencias. En esa línea, el grupo de innovación docente In- 
COMAV del grado de Comunicación Audiovisual de la Universidad de Barcelona promueve el desarrollo de proyectos de aprendizaje servicio (ApS) que se organizan en torno a la creación de cortometrajes con una clara utilidad social y que inciden en el desarrollo de competencias profesionalizadoras.

Los estudiantes adquieren destrezas técnicas y creativas al tiempo que crecen en competencias cívicas y se capacitan para resolver problemas, tomar decisiones, e idear, planificar y ejecutar proyectos con una filosofía de calidad y excelencia. Igualmente, la necesidad de analizar el entorno, de investigar en las necesidades sociales y de generar y transferir conocimiento conduce a un trabajo interdisciplinario, en que los estudiantes colaboran con profesionales de diferentes áreas de conocimiento: historiadores, bibliotecarios, médicos, etc.

Desde 2016 se han desarrollado una decena de proyectos que han abordado objetivos tan heterogéneos como la recuperación de la memoria histórica de La Mina; la divulgación de un uso responsable de los antibióticos o el correcto tratamiento de la úlcera neuropática; la ruptura del estereotipo de la figura bibliotecaria; la difusión de la lengua de signos o de la cultura de los castellers; o la recuperación de las contribuciones sociales de una institución marítima bicentenaria.

Los proyectos nacen de necesidades que comunican agentes externos a la universidad, y pasan por un comité de selección porque no todas las propuestas son aceptables. Algunas carecen del compromiso social y del espíritu formativo del modelo ApS. Otras son peticiones disfrazadas de trabajo sin salario. Por ello, se ha elaborado un decálogo de buenas prácticas para identificar las propuestas con potencial y evitar la competencia desleal con productoras audiovisuales.

Los resultados indican un aumento de la motivación y entusiasmo de los estudiantes. Conscientes de la utilidad de sus proyectos, se implican en su (auto)aprendizaje, perciben el valor de esta práctica como sustitución de los trabajos académicos, y asumen que han de negociar con un «cliente», el promotor de la idea. Por todo ello desarrollan competencias sociales y profesionales, y construyen sus equipos de 
trabajo con los perfiles profesionales habituales. Además, obtienen mejores notas, y difunden su trabajo en festivales y congresos.

* 037 - Factores psicosociales que influyen en la percepción de marca al ser atendidos por personas con discapacidad cognitiva - León Felipe Collazos- Profesor Universidad Autónoma de Occidente. Correo electrónicolfcollazos@uao.edu.co Nyllireth Orjuela Rodríguez - Estudiante Universidad Autónoma de Occidente. Correo electrónico nyllireth.orjuela@uao.edu.coy Sebastián Beltrán - Estudiante Universidad Autónoma de Occidente. Correo electrónico sebastian.beltran@uao.edu.co

La investigación científica plantea un estudio cualitativo de las actitudes y los sentimientos que tienen los consumidores cuando son atendidos por personas en condición de discapacidad cognitiva y propone el análisis de la percepción que tienen los clientes respecto a las empresas que aplican esta práctica.

A partir de la revisión de estudios, se encuentra que para la ciudad de Cali en el año 2017 el porcentaje aproximado de personas con discapacidad cognitiva fue de un $2 \%$, equivalente a 5.082 personas. Además, los focos de investigación se centran únicamente en el impacto administrativo que tiene en las empresas la contratación de personas en condición de discapacidad cognitiva, enfocándose en temas referentes a la inclusión social, la sostenibilidad y la responsabilidad social empresarial.

Los resultados del proyecto, permiten identificar nuevas perspectivas. Primero, las actitudes y los sentimientos que tienen las personas ante este contexto, la percepción de los atributos de servicio que se ven afectados al momento de recibir el servicio y los factores psicosociales que influyen en el comportamiento del consumidor, como son la motivación y el aprendizaje. El análisis provee importantes datos para las empresas que contratan personas en esta condición, así como la incidencia en la imagen de la compañía y la alta probabilidad de recompra. 
Finalmente, los hallazgos también pueden resultar de interés para otros grupos académicos, estudiantes de sociología, psicología, mercadeo y demás ramas del estudio del comportamiento humano, ya que permite entender de qué manera incide realmente este contexto de servicio sobre las percepciones de los consumidores, permitiendo generar nuevos prospectos investigativos que vislumbren nuevos resultados.

* 038 - El diseño de branding como esencia para generar identidad: una propuesta desde la perspectiva del desing thinking para el grupo de investigación "Comunicación y migraciones" - Esmeralda López Alonso - Universidad Europea de Madrid-esmeralda.lopez@universidadeuropea.es y Begoña Moreno López - Universidad Europea begona.moreno@universidadeuropea.es

Con la nueva tendencia a la estetización en todos los sectores a la que apunta Lipovetsky (2015), las distancias entre el público general y la academia se hacen cada vez más patentes. Esto supone que esta última se ve forzada a buscar nuevas vías para impulsar la difusión de la actividad científica y dar a conocer los proyectos que se están llevando a cabo en cada universidad. Uno de los puntos débiles de la mayor parte de los grupos de investigación es la carencia de profesionales especializados en comunicación que ayuden a realizar planes de comunicación para cada trabajo y la gestión del branding y la identidad, con el fin de adecuarse a los nuevos parámetros de la sociedad. El objetivo de este proyecto es plantear una identidad corporativa para el grupo de investigación "Comunicación y migraciones", de la Universidad Europea de Madrid y plasmarla en los elementos fundamentales del branding: la identidad visual corporativa y la estrategia de comunicación. Para ello se ha seguido el modelo de gestión de la identidad impulsado por Paul Capriotti (2009) que toma como referencia los modelos de Villafañe (1999) y Sanz de la Tajada (1994), entre otros. La propuesta creativa se ha basado en las teorías de Justo Villafañe y Joan Costa sobre el diseño de marcas, logotipos y branding aplicado. 
* 039 - Mujer, edad e invisibilidad en los anuncios televisivos en Puerto Rico - Miriam Ramírez- Muñoz - Universidad de Puerto Rico-miriam.ramirez@upr.edu

Nuestro interés académico gira en torno a cómo interpretar los mensajes de los medios. Particularmente estudiamos las imágenes, las inferencias, los estereotipos y los prejuicios involucrados en los medios con especial atención a la publicidad televisiva. La investigación se centra en la representación de los mayores de 55 años en la publicidad televisiva durante el periodo Prime Time en Puerto Rico. Este estudio incluye todos los comerciales emitidos durante dos semanas, para un total de 280 horas, en cuatro canales de televisión. Descubrimos que solo sesenta y seis anuncios incluyeron imágenes de personas mayores de 55 años como talento dentro de los 524 comerciales (y de estos sesenta y seis anuncios, solo seis eran exclusivos con talentos mayores). Utilizamos metodología cuantitativa y cualitativa. La Compañía Nielsen y algunos productores de televisión proporcionaron datos. El análisis se realizó usando dos plantillas construidas para recopilar los datos. La primera plantilla se basa en una adaptación autorizada del Proyecto de Monitoreo de Medios Globales, y la segunda plantilla consiste en una tabla que contiene cuarenta y cuatro variables identificadas bajo el tema: estereotipos. A través de estos datos, pudimos analizar las referencias del contexto en el que estaban representados los mayores y los estereotipos en los anuncios de televisión en Puerto Rico. La subrepresentación de las mujeres mayores en comerciales de televisión fue patente. La presencia de personas mayores en las promociones de televisión no está relacionada con el porcentaje de la población de personas mayores de 55 años. Se consideran rasgos positivos, rasgos negativos, temas privilegiados por los anunciantes, la presencia de personas mayores solas o acompañadas, imágenes, frecuencia, anunciantes y contradicciones.

* 040 - Comparación de audiencias televisivas Vs. audiencias sociales de los contenidos deportivos de la televisión española Francisco-Javier Herrero-Gutiérrez - Universidad de Salamanca y Haokeqian Ye - Universidad de Salamanca idu005801@usal.es 
Esta investigación parte de un trabajo anterior en el que Ye y Herrero (2019, inédito) hablan de la importancia de los programas deportivos dentro de la televisión española. En él se realiza un análisis del periodo 2014-2018 de los acontecimientos televisivos más visto, a razón de 10 programas por mes durante el mencionado periodo de 5 años (muestra =600). En dicho trabajo se concluye la importancia del fútbol como principal contenido en la televisión en abierto de España.

A partir de ese punto inicial, ese trabajo se pretende completar con las audiencias sociales de los principales actores deportivos, a través de un exhaustivo análisis cuantitativo utilizando los programas Fanpage Karma y Twitonomy. Para ello, se analizarán las cuentas oficiales en redes sociales de los mencionados actores de la comunicación deportiva que forman parte de los programas deportivos más vistos en el periodo mencionado.

Finalmente, se pretende realizar un análisis comparativo entre las audiencias de la televisión en España con las audiencias sociales de los principales actores de la comunicación deportiva con el fin de aventurar posibles diferencias y semejanzas, así como analizar su comportamiento en redes sociales.

* 041 - Metodologías y modelos de información para el seguimiento de la acción de los responsables de los gobiernos locales y la rendición de cuentas - Nùria Simelio - Universitat Autònoma de Barcelona - Nuria.Simelio.Sola@uab.cat, Amparo Moreno Sardá - Universitat Autònoma de Barcelona Amparo.Moreno@uab.cat, Pedro Molina Rodríguez-Navas Universitat Autònoma de Barcelona - Pedro.Molina@uab.cat y Francisco-Javier Herrero-Gutiérrez - Universidad de Salamanca.

Esta comunicación presenta un resumen de la última oleada realizada dentro del proyecto "Metodologías y modelos de información para el seguimiento de la acción de los responsables de los gobiernos locales y la rendición de cuentas" (I+D+I 2016-2018 CSO2015-64568-R (MINECO/FEDER). 
A través de este proyecto, se ha analizado el nivel de transparencia a partir de una metodología probada, de corte eminentemente cuantitativo y que forma parte del Mapa InfoParticipa (http://mapainfoparticipa.com/index/home/). Dicha metodología se divide en varios indicadores para medir la transparencia de los gobiernos locales, así como su rendición de cuentas. Los indicadores (un total de 52) se dividen en 2 grandes bloques. El primero de ellos (transparencia de la Corporación) se centra en saber quiénes son los responsables políticos, saber cómo se gestionan los recursos colectivos y económicos (presupuestos, salarios, contrataciones, subvenciones...); el segundo bloque (información para la participación) mide los indicadores relaciones con la información sobre el municipio, la gestión de recursos colectivos, así como las herramientas disponibles para la participación ciudadana.

Especialmente, la comunicación se centrará en la última oleada realizada y haciendo especial hincapié en los 605 municipios españoles de más de 10.000 habitantes. Se presentarán los datos más relevantes en términos globales.

Este proyecto forma parte del proyecto "Metodologías y modelos de información para el seguimiento de la acción de los responsables de los gobiernos locales y la rendición de cuentas" (I+D+I 2016-2018 CSO2015-64568-R (MINECO/FEDER), cuyas IP son las profesoras Amparo Moreno y Nùria Simelio (UAB).

* 042 - La vejez como tema y el viejo como audiencia, construcción de contenidos para la web centrados en los adultos mayores - Sandra Leal Larrarte saleal@uniquindio.edu.co - Universidad del Quindío, Lilia Inés López - liliai@uniquindio.edu.co - Universidad del Quindío y Martha Estela Pérez -meperez@uacj.mx - Universidad Autónoma de Ciudad Juárez

Ocuparse de los contenidos audiovisuales de la televisión, la web o del streaming no es un tema banal, su importancia radica en hacer uso de la capacidad de comunicar que estos medios tienen: comunican más que ideas, emociones, a la vez que fagocitan la comunicación de quienes 
los consumen (Barbero, 1992). Tanto en México como en Colombia la población mayor está aumentando (DANE, 2018; INEGI, 2015), en cada uno de los países mencionados alcanzan a ser casi el 11\% del total, siendo el segmento poblacional que más crece y el que menos presencia tiene en los medios, pero además el que más estigmas sostiene (Leal, López y Rodríguez, 2018). Los medios, como educadores, deben apoyar el enriquecimiento personal y ayudar a las personas mayores, así como a los que se acercan a ella (que somos todos) a aprender a tener un envejecimiento activo sin caer en generalizaciones ni estereotipos (Guía de medios para la vejez, 2013). Esto no quiere decir que no se haya tratado el tema de la vejez, novelas como La abuela (1979) o Señora Isabel (1993) lo trabajaron muy bien. No obstante, aún falta decir mucho sobre cómo envejecen los colombianos y los mexicanos, especialmente las mujeres que son la población más vulnerada tanto en la vida real como en las tramas de las telenovelas. Por esta razón se propone exponer la importancia de crear contenidos para la Web en los que se reconozca al adulto mayor no sólo como audiencia potencial sino como sujetos que se reflejen en las historias de manera activa y protagónica para que el imaginario colectivo conforme nuevos esquemas de pensamiento.

* 043 - Análisis de la aportación de tráfico del blog a una web de turismo: generación de contenido - Ángel Quintana Gómez Universidad Atlántico Medio. España angel.quintana@pdi.atlanticomedio.es; Almudena Barrientos Báez Escuela Universitaria de Turismo Iriarte (ULL). España almudenabarrientos@iriarteuniversidad.es y David Caldevilla Domínguez - Universidad Complutense de Madrid. España davidcaldevilla@ccinf.ucm.es

En los últimos años, la generación de contenido en las páginas webs se ha incrementado por factores externos que han propiciado el fomento de los mismos. Cuando se habla de contenido, podemos distinguir diferentes tipos: por un lado el contenido informativo que da respuesta al objetivo por el que se crea la web; y por otro, el contenido divulgativo, que nace para aportar más información a los usuarios y suele profundizar en temas que se han mencionado en el contenido informativo. Este último tipo es conocido como blog y tiende a ser de 
mayor calidad ya que al contrario de lo que sucede con el informativo, la función del blog es la persuasión, la aportación de información extra de utilidad, que busca la fidelización del usuario en la web. Además, según el tipo de negocio que se gestione, el blog es la herramienta básica para comenzar el proceso de conversión en la web; por ejemplo, las empresas b2b que trabajan el Inbound Marketing. En las webs relacionadas con el turismo tienen la misma relevancia, ya que la conducta de los usuarios a la hora de planificar un viaje, no se reduce a buscar información objetiva como, "playas en Gran Canaria", sino contenido que enriquezca sus viajes como, "10 actividades imprescindible en Gran Canaria”. A partir de aquí, se analizará el tráfico de la web www.grancanaria.com y su blog. Para ello, se utilizará la herramienta de Google Analytics, teniendo acceso total a las visitas de los usuarios.

* 044 - El tratamiento mediático de la transición argentina en la prensa española de principios de 80 - Micaela Iturralde (UNMdP-CONICET) - micaelaiturralde@gmail.com y Ana Bartol Gutiérrez (Instituto de Iberoamérica, USAL) anabartolgutierrez@gmail.com / anita1113@usal.es

Durante los últimos años, es posible reconocer un creciente interés historiográfico en el estudio comparativo de las dictaduras que gobernaron América Latina y España durante la segunda mitad del siglo XX así como sus correspondientes transiciones a la democracia. En ese marco, es posible advertir la vacancia de análisis sistemáticos que reconstruyan, desde una perspectiva trasnacional y comparada, los procesos de producción y circulación de discursos en la prensa gráfica masiva en torno a las dictaduras del cono sur y sus transiciones a la democracia.

Teniendo en cuenta esto, el presente trabajo se propone analizar el tratamiento periodístico propuesto por los principales diarios españoles, ABC y El País, en torno al fin de la última dictadura militar y el retorno a la democracia en Argentina (entre octubre de 1983 y diciembre de 1985). El énfasis estará puesto no sólo en reconocer los posicionamientos editoriales de ambos medios gráficos sino en avanzar en la comprensión de las representaciones elaboradas en torno a los 
principales actores políticos implicados en la transición e indagar acerca de las condiciones de producción de esos discursos periodísticos en el marco de la también recientemente recuperada democracia española.

Se considera que, por sus características y el particular contexto de producción, los diarios españoles ofrecen un punto de mira privilegiado para el análisis de la realidad política argentina de principios de los ochenta. A modo de hipótesis, se considera que la referencia a la actualidad argentina configuró una modalidad indirecta y mediada de tratamiento de cuestiones vinculadas con la democracia, el rol político de las FFAA y las violencias política y represiva que inducía también a reflexionar sobre el pasado inmediato en España. Dicho de otra manera, el interés por fin de la dictadura militar y el retorno de la democracia en Argentina devino de la función de extrapolación/paralelismo/transposición de temas y personajes que permitió su abordaje.

* 045 - Implicación ciudadana de los jóvenes en el entorno digital. Uso de las redes sociales para la participación socio-política y la búsqueda de información - Beatriz Catalina-García Universidad Rey Juan Carlos - beatriz.catalina@urjc.es y Estefanía Jorge Domínguez - Universidad Rey Juan Carlos e.jorged@alumnos.urjc.es

En sistemas democráticos como el español, la desafección ciudadana, especialmente entre los jóvenes, ha sido motivo de interés para la literatura académica y empíricamente demostrada en los diversos procesos electorales y en la escasa participación en el tejido social. Las formas tradicionales para incentivar la implicación socio-política, en consecuencia, no están logrando la efectividad deseada; sin embargo, lejos de desaparecer, se complementan ahora con nuevas vías digitales. Herramientas como las redes sociales son empleadas, entre otros objetivos, para consultar y divulgar información y para la difusión de asuntos que preocupan al usuario relacionadas con su entorno. Los rasgos de horizontalidad, facilidad de acceso e inmediatez que caracterizan a las redes sociales favorecen la implicación ciudadana, aunque, como contrapunto, pueden inducir a una "pseudoparticipación" sin compromiso real. 
Este trabajo, vinculado al proyecto de investigación "Redes sociales, adolescentes y jóvenes: convergencia de medios y cultura digital" (CSO2016-74980-C2-2-R) financiado por el Ministerio de Economía, Industria y Competitividad de España (2017-2020), se aproxima al empleo de las redes sociales que realizan los jóvenes, en su calidad de ciudadanos, desde dos enfoques diferentes aunque vinculados entre sí: por un lado, el interés por la información de actualidad y la recurrencia a estas herramientas digitales para este cometido, y, en segundo término, el grado y su forma de participación en cuestiones políticosociales que se exponen en el entorno online.

* 046 - ¡Identifíquese! El catálogo de autoridades, la desambiguación de las firmas, y los sistemas de identificación de autor - Mandiá-Rubal, Sara - Universidade de Santiago de Compostela - sara.mandia.rubal@gmail.com

No pocos particulares se deciden a contar su historia de vida a través de la autoedición. Lo hacen demasiado a menudo sin contar con el asesoramiento de un experto en la clasificación de información que pueda guiarlos y asesorarlos a la hora de firmar estos trabajos, y ser reconocidos y reconocibles. Y aunque se tome el caso de la autoedición como ejemplo, no es para nada el único, esta problemática también se da en la literatura científica. Con Internet, el problema de identificar correctamente y sin ambigüedades al autor de un documento, se ha agravado aún más por la cantidad de información que se alberga y la carencia de un lenguaje controlado que evite homonimias y ruidos en las recuperaciones de la información. En la actualidad, conviven: sistemas de identificación de autor por codificación numérica o alfanumérica; sistemas de perfil personal-profesional; recursos híbridos o combinados; y, los catálogos de autoridades, la herramienta clásica de identificación y normalización en la ciencia de las bibliotecas. Además de un análisis descriptivo de los citados sistemas de identificación como recursos de búsqueda y obtención de información; y como modelo y herramienta para la autogestión del perfil profesional en la marea de información que aporta la Red-, se facilitan, a modo de cierre, algunas indicaciones para los escritores noveles, y no tan noveles, a la hora de distinguirse entre la masa de autores existente. 
* 047 - La revista digital como herramienta de sistematización de los procesos fotográficos en Norte Santander, Colombia - Sibia Daniela Guerrero García - Universidad de Pamplona programa de Comunicación Social Cúcuta- sibiaguerrero@gmail.com y Javier Enrique Suescun Duarte Universidad de Pamplona programa de Comunicación Social Cúcuta xavieren@gmail.com

La fotografía nace en un momento particular del desarrollo de la sociedad, es un producto de los adelantos científicos y tecnológicos que se ha propiciado a lo largo de casi doscientos años y que ha contribuido a casi todas las ramas del saber. "Esta es considerada una de las herramientas más efectivas en el campo de la comunicación, es la posibilidad de expresar visualmente sentimientos, ideas y conceptos" Roland Barthes

En el departamento Norte de Santander hay un gran interés por las artes audiovisuales; quienes construyen imágenes que se enmarcan en sentimientos, emociones, vivencias y representaciones de la realidad. Estas manifestaciones icónicas son el resultado de infinidad de técnicas, conceptos, e interpretaciones que se convierten en la esencia de la cultura del un territorio que se manifiesta en imágenes que resguardan el presente y se convierten en la memoria para futuras generaciones.

La revista Escotoma es un proyecto de publicación digital fotográfica que surge como un escenario de interacción, socialización y análisis de las artes audiovisuales, que permite sistematizar los procesos académicos de estudiantes de Comunicación Social de la Universidad de Pamplona, de otras instituciones de la región, egresados y profesionales del área audiovisual, para así consolidar la primera revista digital fotográfica de la región norte santandereana.

El concepto de E- Zine o revista Electrónica emerge como una oportunidad para que las publicaciones tenga impacto a nivel mundial, pues estar en la red y tener la facilidad de ser compartida por los medios sociales, hace que sea de fácil acceso para todos los cibernautas 
interesados en las artes audiovisuales. Estas publicaciones permiten que las manifestaciones artísticas y la cultura se unan en un archivo para la memoria audiovisual de Norte de Santander.

* 048 - Campo Semiótico del Vestuario Indígena; Fuente De Comunicación y Tradición Cultural En Contexto Mapuche Chileno - Ingrid Llamin Huenulaf-Universidad Austral de Chile-millarayll@gmail.com

La semiótica social concibe la cultura como un sistema de información (Halliday, M. 1978:235) dentro de este contexto vamos a asumir que la comunicación humana, se rige por una serie de normas y reglas que dan orden al intercambio de significaciones y sentidos, lo que claro requiere de un sistema que lo haga posible. En este caso, consideraremos al sistema de significaciones presentes en el vestuario indígena mapuche.

En el contexto social una de las prácticas de sentido de la sociedad mapuche que permanecen en el tiempo y que podemos reconocer como un signo visible de identificación cultural de sus miembros, es su vestuario, el que es concebido como un sistema expresivo, compuesto por un conjunto de piezas indumentarias y de adornos, que poseen una pauta de uso y es reconocido como tradicional e históricamente registrado en la cultura. Su existencia y uso posee una data de 1.350 años (Brugnoli y Hoces, 1995), y que a pesar la temática del vestuario mapuche ha sido abordada por estudios están más bien, se han abocado a la estética e iconografía de los artefactos textiles confeccionados para la indumentaria mapuche, invisibilizándose el contexto de dominio al que se ve enfrentada la sociedad mapuche en su acción de vestir, desconociéndose hoy el grado de vigencia de los códigos culturales relacionados con su vestimenta, así como la existencia de transformaciones de las prácticas de uso del vestuario y sus resignificaciones.

* 049 - Concentración, regulación y control: Una mirada a los medios de comunicación en Ecuador - Ketty Daniela Calva Cabrera - Universidad Nacional de Loja ketty.calva@unl.edu.ec; María Isabel Punín Larrea - 
Universidad Técnica Particular de Loja-mipunin@utpl.edu.ec, Diana Elizabeth Rivera Rogel - Universidad Técnica Particular deLoja-derivera@utpl.edu.ec

Esta comunicación analiza desde una perceptiva bibliográfica y cronológica las políticas de regulación y control de los medios por parte de los gobiernos de América Latina, centrándose de manera particular en Ecuador y las políticas implementadas entre 2007/2017, en la década presidencial de Rafael Correa. El mapa mediático ecuatoriano hasta el 2017 se caracterizó por una alta concentración monopólica, que pretendió ser diluida con la puesta en marcha de la Ley Orgánica de Comunicación (LOC-2013) y con la creación de más de una docena de medios públicos que compiten por una audiencia cuyas posibilidades de conexión a la Red van en aumento. Desde una perceptiva estadística se analizan los niveles de cercanía de los medios digitales privados: www.ecuadorinmediato.com, www.larepublica.ec, www.planv.com.ec, y de los digitales públicos www.mediospublicos.ec, www.andes.info.ec y www.elciudadano.gob.ec, tomando en consideración las visitas y seguidores de Facebook y Twitter, redes sociales más populares del país (Mintel, 2018). Se evidencia una disminución mínima en el número de medios activos, una escasa participación de los medios públicos y la activación del sector mediático empresarial como un actor más del escenario político en el país.

* 050 - Representaciones sociales sobre la mujer migrante venezolana en territorio de frontera - Nini Marcela Bonett Universidad Francisco de Paula Santander y Catalina Camargo Pardo - Universidad de Pamplona camargo.catalina269@gmailcom

La migración hoy es uno de los temas más importantes en las agendas políticas, sociales y económicas del mundo. Colombia y Venezuela son países históricamente reconocidos como hermanos, comparten un poco más de 2 mil 200 kilómetros de frontera, actualmente la crisis social humanitaria que atraviesan se entrecruza con el declive del desarrollo económico venezolano, situación que ha dejado como resultado la movilización de aproximadamente 45 mil venezolanos 
(Migración Colombia, 2018). Comprender las representaciones sociales que tienen en la frontera sobre la mujer migrante venezolana; es una prioridad para el territorio, por ello, a través de una entrevista se logró compilar las dinámicas en cuanto a la representación que se tiene. La mujer actualmente se concentra en el escenario de la migración, por ello es percibida como sujeto vulnerado, denigrada, afectada en su condición familiar como esposa e hija, con pocas oportunidades de empleo que le permitan ascender socialmente y mostrar sus conocimientos y capacidades. En este sentido, los medios de comunicación han permitido mostrar esa realidad de la migración venezolana, sin embargo, en el caso de la mujer migrante no se ha visibilizado su condición y transformación social en aras de mejorar su vida y la su familia. En conclusión desde la realidad del objeto de estudio se encontró un señalamiento y discriminación constante, en donde se vulneran los derechos desde su contexto laboral solo se piensa en una rol doméstico y sexual lo que indica un incremento de la xenofobia y desigualdad en la región. Esta inventigación permitirá propiciar espacios de discusión que permita la reflexión sobre la importancia del fenómeno de la mujer migrante venezolana, para así contribuir a la transformación de la realidad de los imaginarios de los habitantes de frontera a partir las dimensiones sociocultural, historicosocial, hermenéutica y personal donde sea posible analizar las realidades del contextos.

* 051 - La gestión de marca desde un enfoque cultural. Estudio de casos de marcas de gran consumo que operan en el mercado español - Paloma Sanz-Marcos —Universidad de Sevilla palomasanz@us.es

La relación entre las marcas y la cultura no es algo nuevo para los gestores de marca. Partiendo de una situación de tensión social caracterizada por las ansiedades y los deseos vitales de una sociedad, la gestión de marcas basadas en el modelo de branding cultural, permite construir marcas que consiguen absorber y reflejar la cultura que les rodea convirtiéndose en contenedoras de mitos identitarios que aprovechan los publicitarios para elaborar mensajes atractivos para sus audiencias. Este enfoque, ideado por Douglas B. Holt (2004), propone trabajar en la naturaleza colectiva de la marca a través de su interacción 
con las situaciones cotidianas y su relación con el entorno cultural que le rodea. Esta comunicación se propone analizar los casos de Campofrío, valorada como la compañía más elegida por los españoles en el ranking de marcas de Gran Consumo según Brand Footprint 2018 y el caso de IKEA, reconocida por el Foro de Marcas Renombradas como una de las marcas más reales y coherentes entre sus consumidores. A través de un análisis del discurso de todas las acciones publicitarias emitidas en televisión desde 2008 hasta 2018 de ambas firmas, los resultados indican que, en efecto, estas marcas consiguen publicitarse como marcas icónicas que han sabido aprovechar las tensiones y disrupciones sociales que viven los españoles tales como el feminismo, la fuga de cerebros o la polaridad política, para emitir un mensaje relevante y atractivo para los potenciales consumidores.

* 052 - Análisis de términos acuñados por políticos usados en titulares y tags de medios de comunicación peruanos Mercedes, Palomino Gonzales - Universidad de San Martín de Porres (Perú) - mpalominiog@usmp.pe y Carolina, Arrunátegui Matos - Pontificia Universidad Católica del Perú (Perú) carolina.arrunategui@pucp.pe

En un contexto de sobreabundancia informativa como el actual, se exige del periodismo político una marcada rigurosidad para construir una opinión pública informada. No obstante, debido al libre mercado en el que se desarrolla, su actuación está muchas veces enmarcada en la búsqueda del éxito económico, lo que empuja a las empresas de comunicación a la necesidad de presentar como parte del carril informativo aquello que sea espectacular y novedoso a la vista de las audiencias. Los actores políticos no solo han aprendido a ceñirse a esas reglas, sino que también han hecho suyos ya el lenguaje y los formatos de los medios para hacer más efectiva su presencia y sus intereses en esta. Esta ponencia se centra en analizar lexicológicamente algunos términos políticos acuñados por políticos que han sido utilizados irreflexivamente, precisamente por su espectacularidad, en medios de comunicación peruanos.

* 053 - Dime a quién sigues y te diré quién eres. Análisis de la construcción de redes en Twitter de tres movimientos indígenas 
colombianos - Eduardo César Augusto Muro Ampuero Universidad de Bonn-S5edmuro@uni-bonn.de

En los meses de marzo y abril del presente año (2019) miembros de las comunidades indígenas colombianas del Cauca, a través del Concejo Regional Indígena del Cauca, y con el apoyo de otras organizaciones sociales colombianas y de otras comunidades indígenas, se congregaron y bloquearon una parte de la carretera más grande de América Latina, la Panamericana. Estas movilizaciones no fueron simples paros o simples bloqueos, como fueron catalogadas por algunos medios de comunicación, sino que fueron denominadas por los propios indígenas como "Minga". Pero la Minga no es solo eso. Es el trabajo colectivo de la comunidad para la comunidad, es el reflejo de las cosmovisiones de las comunidades indígenas, las cuales sitúan al ser humano en una estrecha relación con el medio que les rodea.

En dicho contexto, esta investigación se sitúa en las relaciones y en la construcción de redes que algunas organizaciones del movimiento indígena colombiano construyen en Twitter. En ese sentido, se analiza la construcción de redes de tres organizaciones indígenas colombianas (el Concejo Regional Indígena del Cauca, el Concejo Regional Indígena de Caldas y la Organización Nacional Indígena de Colombia) a través de las cuentas que ellas siguen en Twitter. Así, se explora cómo estas organizaciones construyen sus redes en Twitter y se determina si es que estas redes online pueden equipararse a las redes offline de estas tres organizaciones.

Teniendo en cuenta la relación entre el espacio y el espacio público en el mundo online y en el mundo offline, se considera, por lo menos para estos casos, que hay una relación interindexical bastante presente en el caso de las cuentas de las tres organizaciones indígenas. Así, los resultados muestran una gran variedad de cuentas que pueden dividirse en: ecología mediática, sociedad civil, sociedad política, esfera económica y ciudadanía.

* 054 - Resistencias rurales en la ciudad: El aporte de la mujer en la transmisión oral del conflicto territorial en la comunidad 
ancestral la Toglla - Zaida Verónica Almeida Gordón-

Universidad Central del Ecuador-zvalmeida@uce.edu.ec

La ponencia relata los principales sucesos del proceso de resistencia territorial frente al tráfico institucionalizado de tierras en la comunidad ancestral la Toglla, ubicada en las faldas del volcán inactivo Ilaló, del Distrito Metropolitano de Quito-Ecuador. Para lo cual, partiendo de la historia de vida de Rosa Cabrera, una de las principales representantes del conflicto, se trazará una suerte de genealogía, en donde su vida cotidiana es parte del tejido social de un proceso histórico de organización. Es decir, se abordarán los principales actores sociales del conflicto, así como el sentido cultural de sus acciones, en tanto, prácticas políticas que buscan reconstruir y recapitular desde la memoria y la oralidad de una de las hijas de la montaña.

Por ende, primero se intenta comprender los elementos que contribuyeron a generar la tensión orientada al surgimiento de una causa considerada de bien común. Segundo, se aborda la violencia generada por parte de los traficantes de tierras y el Estado. En un tercer momento se esboza, la transformación de un orden hegemónico, por una relación política comunitaria, traducida en un proyecto de vida y de defensa del Ilaló. En consecuencia, la intención de entrever la voz femenina y su rol en la historia colectiva por la defensa de su patrimonio natural, va más allá del intento de hurgar una lucha popular, porque en el camino nos encontramos no sólo con un conflicto de carácter social, sino de identidad y de espiritualidad, desde ese sentido el espacio físico junto al imaginario de lo femenino y masculino cobra una dimensión sagrada.

* 055 - Cine, transformación urbana y reconstrucción del espacio público - José Ignacio Lorente - Universidad del País Vasco/Euskal Herriko Unibertsitatea - eneko.lorente@ehu.eus

El espacio urbano es el objeto de una doble producción en la que tanto su configuración como espacio construido y urbano, como su dimensión simbólica y ciudadana se hallan íntimamente relacionadas. A lo largo del pasado siglo, las ciudades industriales desarrollaron un 
programa urbano basado en la productividad y el crecimiento, hasta que se produjo la crisis estructural de los años setenta.

Las metrópolis modernas concebían la ciudad como un proyecto holístico bajo los imaginarios de una máquina productiva o de un organismo vivo, según la inspiración racionalista o humanista que respectivamente los sustentaba. Sin embargo, tras la crisis, las ciudades se vieron inmersas en profundos procesos de regeneración urbana con el fin de adaptarse a los retos surgidos del nuevo contexto postindustrial y a la progresiva globalización y deslocalización de los recursos financieros y productivos. A partir de este momento, las ciudades transforman el programa urbano y la comunicación estratégica hacia la identificación de oportunidades en el concurrente mercado global de ciudades donde compiten para atraer visibilidad, liderazgo e influencia, pero a costa de fragmentar y dispersar el tejido urbano y ciudadano.

El cine nace y desarrolla sus recursos narrativos coincidiendo con el auge de la ciudad moderna y a lo largo de este periodo ha puesto en escena las transformaciones urbanas generando nuevas formas de representación y de sensibilización de la experiencia ciudadana en el espacio público. El trabajo parte de la idea de que la mirada fílmica no representa un mero posicionamiento visual ante el espacio urbano, sino más precisamente una búsqueda de sentido que compromete tanto a la figura de la enunciación como al propio espectador. El análisis de las narrativas fílmicas que, como las denominadas sinfonías urbanas de entreguerras o las derivas postmodernas, han tomado las ciudades en proceso de transformación como objeto privilegiado de representación, trata de identificar el pensamiento y los imaginarios que sustentan la forma urbana contemporánea.

* 056 - Medios de comunicación en la Web: un análisis de los cibermedios de Ecuador y Colombia - Mayra Paola GonzalesCórdova - UTPL - mpgonzales@utpl.edu.ec y Ana Gabriela Rojas Bastidas- UTPL-agrojas1@utpl.edu.ec

Este trabajo de investigación tiene como objetivo analizar la morfología de los medios de comunicación en la Web, centrando la 
atención en el caso de los cibermedios de Ecuador y Colombia. Se realizará un análisis comparativo de la evolución de estos medios. Para ello se ha tomado como muestra de estudio a seis medios, entre los que cuentan medios tradicionales con su versión online (prensa, radio y televisión) y también los denominados medios digitales, que corresponden a cada uno de los países caso de estudio.

La investigación se realizará durante una semana compuesta utilizando una metodología mixta (cualitativa y cuantitativa) con el propósito de analizar las caracterísiticas de los cibermedios: arquitectura de la información de los sitios Web, accesibilidad, hipertextualidad, multimedialidad interactividad, entre otros. Los medios seleccionados para el estudio son: El Comercio, El Universo, La Hora, Ecuavisa, Radio Sonorama y La República; y de Colombia El Tiempo, El Colombiano, Caracol Tv, Caracol Radio, Las Dos Orillas y El Espectador.

Esta investigación permitirá analizar la influencia que, sin duda, Internet ha tenido en la evolución de la comunicación humana, así como la manera en la que los medios tradicionales se han adaptado a estos cambios, y que, por otra parte, han exigido que los periodistas cambien sus estrategias a la hora de informar. "El impacto de las tecnologías está alterando en profundidad las bases y entorno del periodismo en el contexto digital" (De Lara González y Arias Robles, 2016, p.23). Los cibermedios exigen una reinvención del periodismo en todos sus aspectos. Ahora tenemos cibermedios cada vez más veloces, multimedias, hipertextuales con acceso a una cantidad de información permitiendo al usuario nuevas dinámicas y contenido.

En términos generales, y en el marco de la investigación se puede concluir que los cibermedios cuentan con herramientas que permiten una mejor interacción con el usuario. Los medios que están en estas plataformas digitales y que son caso de estudio, utilizan contenidos distribuidos en diferentes formatos: archivos, fotografías, archivos de videos y de audios, entre otros. Una de las dinámicas más relevantes en los medios investigados, y que permiten encontrar información de forma fácil son las noticias destacadas y noticias de portadas, es decir todas estas prácticas conectan a los usuarios y los mantienen en los 
sitios web. Los cibermedios investigados cumplen con parámetros de accebilidad, cuentan con espacios de fácil acceso, es decir los usuarios pueden entrar a los sitios de forma sencilla y navegar. El usuario, que en un prinicipio era un simple consumidor de información, hoy lo observamos, sobre todo en las redes sociales, compartiendo, creando, comentando, es decir, es este ciudadano digital que se ha convertido gracias a la Web 2.0 en la persona que decide sobre la información que necesita consumir y puede producir.

* 057 - Realidad Aumentada como herramienta interactiva en medios impresos: estudio de tres diarios del continente americano - Wellington Remigio, Villota Oyarvide Universidad Católica de Santiago de Guayaquil Wellington.villota@cu.ucsg.edu.ec

La innovación tecnológica transmuta los procesos interactivos en las sociedades, con impacto en la comunicación. Con Internet y la telefonía móvil han surgido novedosas formas de buscar, procesar y difundir la información, una práctica que ha transformado el modelo comunicativo de los medios tradicionales, siendo la prensa impresa uno de los más afectados. En este contexto, la Realidad Aumentada -RA-, que complementa la percepción e interacción con el mundo real y permite al usuario aumentar su entorno con información adicional generada por la computadora, puede ser eficaz para acrecentar la interactividad de los usuarios con los medios de comunicación impresos. Con su apoyo, el consumo y venta de periódicos podría sostenerse por algunos años más, generando ganancia, o por lo menos un punto de equilibrio.

Esta ponencia expone el modo en que tres diarios del continente americano emplean la RA como herramienta interactiva en los medios de comunicación impresos. El estudio se fundamentó en Topeka Capital-Journal (noreste de Kansas, Estados Unidos), Burnaby NOW (Canadá) y el Kids News (Argentina), que incluyen RA en sus publicaciones. Se concluye que los rotativos objeto de análisis se suman a este proceso de renovación y reinvención del ecosistema mediático y su experiencia en la aplicación de la RA está motivada por las transformaciones tecnológicas -desde el punto de vista 
Las nuevas narrativas, en el entorno social

infraestructural- y culturales y sociales -desde la óptica superestructural-, lo cual no sólo trastoca los pilares de la profesión, sino también la estabilidad y supervivencia de las empresas periodísticas a las que pertenecen esos medios.

* 058 - La jerarquía protocolaria y el ceremonial en la corte española: la prelación existente en las damas de la corte de la Reina. Paralelismos con la actualidad de los festejos populares locales - Begoña Bueno Fernández- Universidad Pontificia de Salamanca-bueno.begona@gmail.com

El Protocolo y ceremonial están presentes en todas las etapas de la historia de la humanidad actuando como instrumentos de comunicación no verbal que transmiten mensajes de jerarquía y poder a sus destinatarios sociales. La vida en la corte española es referente de ceremoniales, símbolos y signos identitarios, que atesoran parte de nuestra historia, así como buena parte del patrimonio artístico y cultural. Del mismo modo, es ejemplo del protocolo solemne y de la etiqueta. El protocolo de la corte española fue introducido por el emperador Carlos V trasladando el que aplicaba la Casa de Borgoña. Todos los actos se desarrollaban al amparo de normas inquebrantables y escritas. De este modo, cada miembro de la corte sabía exactamente dónde y en qué orden se debía sentar, el tratamiento que debía recibir, así como se debía servir en la mesa. Del mismo modo, existía una corte de personalidades con funciones específicas reguladas por el protocolo que debían cumplir las normas con disciplina.

De entre los múltiples campos de estudio que se abren al respecto, en esta ocasión, nos detenemos en la investigación de unas determinadas figuras: las damas de la reina y las damas al servicio particular de la reina. ¿Quiénes eran? ¿Qué función tenían? ¿Qué requisitos debían cumplir? ¿Cuál era su papel en el ceremonial de palacio? Del mismo modo, se analiza como los patrones de conducta que se crearon con las prelaciones protocolarias que existían entre las anteriores figuras, se siguen recreando en la actualidad, por medio de las fiestas populares locales, patrimonio cultural de las distintas regiones de España. 
* 059 - Uso del celular en las relaciones interpersonales de los estudiantes universitarios y su incidencia económica, caso: Escuela Superior Politécnica de Chimborazo - María Belén Bravo Avalos; Santiago Patricio Bravo Avalos; José Luis López; María Fernanda Miranda y José Fernando López Aguirre Escuela Superior Politécnica de Chimborazo.

La investigación tiene como objetivo determinar las interrelaciones sociales de los estudiantes universitarios a través de los celulares y su impacto económico, las revisiones de contenidos científicos permitan encausar la investigación con conceptos claros sobre la tecnología y la importancia de las relaciones interpersonales, es una investigación descriptiva y de campo debido a la forma de recolección de información en donde se refleja el impacto económico. Los datos encontrados dan cuenta que las relaciones interpersonales no solo afectan a la persona, sino a la sociedad y la economía, pues pueden convertirse las futuras generaciones en ermitaños modernos, dependientes de tecnologías con un alto costo económico, escasos lazos familiares y como resultado del estudio realizado en una universidad también se ve reflejado el desinterés en el aprendizaje incrementando el bajo rendimiento académico.

* 060 - Gestión de comunidades de seguidores en canales de YouTube - Victoria Tur-Viñes - victoria.tur@ua.es; MaríaJosé González-Río - mj.gonzalez@ua.es y Carmen López Sánchez - Universidad de Alicante - España mc.lopez@ua.es

El objetivo planteado es identificar los indicadores que promueven la creación, el mantenimiento y el crecimiento de una comunidad de usuarios en torno a los canales de youtubers. Se plantea un análisis de contenido de carácter exploratorio sobre una muestra de 100 vídeos, 10 de cada uno de los 10 canales con más suscriptores del ranking Socialblade en el período comprendido entre el 14 de septiembre de 2018 al 22 de febrero de 2019. El estudio permite identificar cuatro estrategias de gestión de comunidades desplegadas por los youtubers: fidelización de la audiencia, ampliación de comunidad, generación de expectación sobre futuros contenidos y 
la gestión particular de la pestaña Comunidad del canal. Se revelan indicadores y prácticas válidas para comprender el fenómeno de las comunidades de youtubers, un fenómeno de masas con tan solo 15 años de existencia y un crecimiento imparable.

* 061 - “Las Mijas” Una estrategia de comunicación digital para la promoción y prevención de los derechos sexuales y reproductivos de los adolescentes y jóvenes en Norte de Santander, Colombia - Valeria Carolina Polo Robles Universidad de Pamplona programa de Comunicación Social Cúcuta- valeria99100109871@gmail.com y Luz Karime Poveda Monsalve - Universidad de Pamplona programa de Comunicación Social Cúcuta - karimepoveda9@gmail.com

Según el UNFPA en Colombia la edad promedio de acceso a información sobre sexualidad es de 16 años. Los adolescentes no reciben educación sobre salud sexual y reproductiva, esta desinformación los pone en una situación de vulnerabilidad y los hace más propensos a contraer enfermedades de transmisión sexual y a los embarazos no deseados.

De acuerdo a lo anterior surgió la necesidad de crear un proyecto con el objetivo de generar una estrategia de comunicación digital para la promoción y prevención de los derechos sexuales y reproductivos con los adolescentes en Norte de Santander. Se realizó un diagnóstico en relación con la temática, donde se evidenciaron la problemática y las necesidades. Con esa información se diseñó una estrategia educomunicativa para la sensibilización al respecto.

La estrategia se ha implementado a través de las plataformas digitales con contenidos audiovisuales y también se han propiciado espacios presenciales y virtuales de participación ciudadana y popular. Se está realizando una metodología de investigación acción participativa con énfasis en la fenomenología, donde se desarrollan grupos focales y entrevistas cualitativas. Esta metodología nos ha permitido identificar los imaginarios formados entre los 
adolescentes, temas de interés y las redes sociales que más consumen.

La estrategia ha logrado un impacto positivo en el departamento. En las redes sociales de "Las Mijas" el alcance de las publicaciones ha llegado a 8,600 vistas a tan solo un mes de la publicación. En instagram se ha tenido la respuesta esperada, los jóvenes interactúan por mensaje directo sobre las inquietudes que tienen sobre sexualidad y reproducción. La proyección es que "La Mijas" sea un referente de educomunicación en la región.

La alianza estratégica es con la fundación Oriéntame que realiza PyP en derechos sexuales y reproductivos, y Punto D enfatizada en la prevención del embarazo adolescente, quienes apoyan el desarrollo del proyecto.

* 062 - El emplazamiento de producto como transmisor de valores de marca: El caso de 3 marcas Premium del sector del automóvil (Lexus, Mercedes y BMW) - Alicia Martín García - Universidad de Málaga - alicia.martin@uma.es

Objetivo: El objetivo general de la presente investigación se resume en la descripción y valoración del emplazamiento de producto como vehículo transmisor y reforzador de los valores de las marcas emplazadas.

Metodología: Se recurre a fuentes documentales (análisis de material bibliográfico, hemerográfico y online), "entrevistas enfocadas" con diversos expertos que han trabajado en el ámbito del emplazamiento en los últimos treinta años y al análisis de contenido, con objeto de estudiar cómo las marcas seleccionadas (Lexus, Mercedes y BMW) transmiten sus valores y su filosofía empresarial a través de la técnica. Para ello, hemos realizado un análisis del principal proyecto cinematográfico en el que ha participado cada marca en los últimos años. La metodología de este análisis de contenido ha sido la propuesta por Méndiz (2001, 89-100), en el que establece una metodología aplicable genéricamente a los emplazamientos. 
Descripción: La técnica publicitaria emplazamiento de producto existe desde los orígenes del cine y alcanza su consolidación en 1991 tras la creación de ERMA, que regula la técnica y supone la máxima profesionalización. Actualmente, y debido a la saturación de la publicidad convencional, esta técnica alcanza su mayor esplendor al aparecer las marcas en un entorno sin competencia y como elemento natural de la trama, transmitiendo y reforzando los valores de marca de una manera no invasiva. Analizamos 3 marcas Premium del sector del automóvil (el más frecuentemente emplazado) y como transmiten su filosofía de marca en un contexto narrativo que ofrece credibilidad a su discurso.

* 063 - Comunicación y Salud 2.0: Cuidados informales en pacientes con marcapasos - Antonio López Villegas - Grupo de investigación CTS-609, Implicación Social de la Medicina Crítica y de Urgencias. Hospital de Poniente, Almería, España e Instituto de Medicina Clínica, Facultad de Ciencias de la Salud, Universidad de Tromsø, Tromsø. Noruega antoniolopezvillegas@andaluciajunta.es; y Daniel Catalán Matamoros - Departamento de Periodismo y Comunicación, Universidad Carlos III de Madrid, Madrid, España y Grupo de Investigación CTS-451, Ciencias de la Salud, Universidad de Almería, Almería, España

Introducción: La tele-comunicación o comunicación remota aplicada al seguimiento de pacientes con marcapasos cardíacos se ha incrementado en la última década. Sin embargo, no existen estudios a largo plazo basados en los cuidados informales donde se analicen las diferencias entre los sistemas de comunicación remota con los sistemas tradicionales de seguimiento en la consulta de los hospitales.

Objetivo: Evaluar la carga de trabajo y los costes asociados a los cuidados informales de pacientes monitorizados a través de los sistemas de comunicación remota.

Métodos: Se trata de un ensayo clínico controlado y no aleatorizado, con recogida de datos a los 5 años tras el implante del marcapasos y 
desde la perspectiva de los cuidadores informales. Se administró la Encuesta sobre Discapacidades, Autonomía personal y situaciones de Dependencia para obtener información sobre las características demográficas y sociales, tiempos y tipos de cuidados, dificultades en la prestación de servicios, estado de salud, económicos y familiares o de ocio que dichos cuidados tienen sobre las personas que realizan esta labor.

Resultados: Tras cinco años de seguimiento, 55 usuarios con marcapasos finalizaron el estudio. De los cuales, 50 informaron ser ayudados por un cuidador, 18 de ellos estaban incluidos en el grupo de comunicación remota y 32 en el grupo de comunicación convencional de seguimiento en el hospital. En general, las mujeres representaron el $96.0 \%$ de los cuidadores informales. La edad media fue de 63 años ( $p=0.83$ ). El 88.0\% de los cuidadores manifestaron prestar sus servicios entre 6 y 7 días por semana.

Conclusiones: Los resultados confirmaron que no hubo diferencias significativas entre los cuidadores informales incluidos en ambos grupos de seguimiento en relación a las características basales, carga de trabajo y el tiempo empleado en los cuidados.

* 064 - La evolución del estilo narrativo de los webdoc.

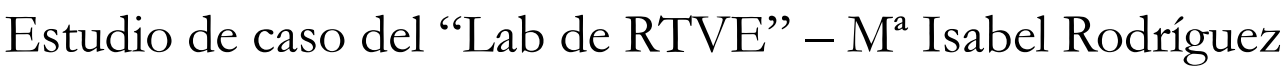
Fidalgo - mrfidalgo@usal.es y Adriana Paíno Ambrosio Universidad de Salamanca - adriana.paino@usal.es

La transformación digital ha propiciado diversos cambios dentro del contexto comunicacional que han dado lugar a novedosas formas de narrar; es el caso de los webdoc, también conocidos como documentales interactivos o i-docs. A medida que los avances tecnológicos se han ido sucediendo, éstos se han visto reflejados también a la hora de elaborar este nuevo tipo de documentales, y es por ello que surge la pregunta que propicia esta investigación: ¿cómo ha evolucionado el estilo narrativo de los webdoc?

Para dar respuesta a dicho interrogante se ha realizado un análisis bajo una perspectiva cualitativa con el fin de determinar los 
principales rasgos de innovación que se han ido introduciendo en los webdoc a la hora de narrar en los últimos años. La acotación del objeto de estudio se ha centrado en una muestra obtenida a raíz de los ejemplos de webdoc elaborados por el "Lab de RTVE", ya que este constituye una plataforma de referencia en la creación de contenidos interactivos a nivel nacional.

Los resultados ponen de manifiesto una evolución ciertamente muy ligada a los aspectos tecnológicos, y que se vinculan a los tres elementos narrativos por excelencia de este tipo de documentales interactivos, es decir, a la hipertextualidad, multimedialidad y la interactividad, que se manifiesta en las siguientes cuestiones: 1) Los contenidos presentan una mejor arquitectura, tanto desde el punto de vista audiovisual como de usabilidad, a la hora de acceder a los contenidos fragmentados. 2) Un mejor tratamiento de los elementos multimedia, en beneficio de hacer más atractiva la historia al usuarioespectador. 3) Y, sobre todo, una apuesta por la participación e interacción de los espectadores-usuarios, que ha ido aumentando considerablemente hasta el punto de que hoy en día es el principal atractivo de estos proyectos y que va unida al desarrollo y potencialidad de las redes sociales.

* 065 - La prensa en España: de la digitalización a los entornos de movilidad - Nereida Cea - Universidad de Málaga nereidacea@uma.es

En tiempos turbulentos como el actual, el sector de la comunicación evoluciona muy rápido y más concretamente la prensa -antiguo elemento definidor del sistema de medios en un país-, parece perder no solo lectores, sino también poder e influencia. La magnitud, intensidad y velocidad de los cambios amenazan a este sector, en constante y profunda transformación digital. El siguiente reto es incorporar estrategias de distribución en entornos de movilidad, dado que, en España, casi 7 de cada 10 usuarios de Internet usan el móvil para la lectura de diarios digitales. En el trabajo se revisa el proceso de migración digital de la prensa en España, a la luz de los últimos datos, y se sugieren vías de adaptación y propuestas sacadas de casos de éxito de otros países y mercados. Entre las iniciativas 
que están siguiendo los grupos editoriales líderes, se describen tres estrategias: proyectos editoriales para conectar con el público joven; medidas para incrementar la suscripción, que incluyen el medio digital; y fomento del periodismo más visual.

* 066 - Cien indicadores de transparencia para el análisis del buen gobierno en el servicio audiovisual público europeo Paulo Carlos López-López - paulocarloslopez@gmail.com, Francisco Campos-Freire -Universidade de Santiago de Compostela- francisco.campos@usc.es e Iván PuentesRivera -Universidade da Coruña- ivanpuentes@gmail.com

Los servicios públicos europeos de radio y televisión asumen, en la actualidad, varios retos en el ámbito de la gestión. Uno de ellos tiene que ver con su contribución al fortalecimiento democrático de los países, creando mecanismos efectivos que les permitan recuperar legitimidad y proyectar su vocación social a través de la difusión y ampliación de sus respectivos procesos de rendición de cuentas. El estudio de la transparencia en este tipo de corporaciones es relativamente reciente, y está caracterizado por el abordaje parcial e incompleto de la información generada por los entes, siendo necesaria la construcción de una metodología integrada que permita dos objetivos: a) analizar de forma holística la gestión de la información pública emitida; b) establecer comparaciones $y$ clasificaciones estatales y regionales.

Por ello, la presente investigación, que se realiza a través de una revisión bibliográfica y legal, desarrolla un modelo integrado de 100 indicadores de análisis de la información pública que generan las empresas informativas en sus respectivas páginas web. Estos se distribuyen en tres grandes bloques (Información Institucional, de Gobernanza y de Grupos de Interés; Información económica y de infraestructura; Producción de información, participación e inclusión) construidos sobre el estudio sistemático de las siguientes categorías: marco competencial, organismos y acuerdos; organigramas, estructuras y máximos responsables; relación de grupos de interés; tratamiento periodístico, mecanismos de independencia y calidad; accesibilidad de la información económica 
y laboral; igualdad e integración; empleo y plantilla de trabajadores y sostenibilidad.

* 067 - La repercusión de la modificación de la Directiva de servicios de comunicación audiovisual en las plataformas de vídeo bajo demanda (VOD) - Chicharro, Alicia - Profesora Contratada Doctora de la Universidad Pública de Navarra alicia.chicharro@unavarra.es

A finales de 2018, el Parlamento Europeo y el Consejo aprobaron la modificación de la Directiva de servicios de comunicación audiovisual de 2010, para adaptarla a los avances técnicos que hacen posible la convergencia entre televisión e Internet, dando lugar a nuevas experiencias de visionado.

Los actuales tipos de contenidos, como los vídeos cortos o las grabaciones de los usuarios han adquirido mayor importancia y los nuevos prestadores, incluidos los de servicios de vídeo a petición (VOD) y las plataformas de intercambio, están ya asentados. Esta convergencia de medios requiere un marco jurídico actualizado que refleje la evolución del mercado y que permita lograr un equilibrio entre el acceso a los servicios en línea, la protección del consumidor y la garantía de la competencia.

La Directiva pretende flexibilizar las reglas en aquellos casos en los que ya no están justificadas las restricciones aplicables únicamente a la televisión. A su vez, desde la UE se quiere fomentar las películas europeas, así como también apoyar la producción audiovisual por inversión directa en el contenido o contribuciones a los fondos nacionales.

Por otro lado, las normas nacionales que traspongan la Directiva deberán proteger a los menores y hacer frente al discurso del odio con más eficacia, siguiendo unas reglas comunes válidas para todos los proveedores de servicios de comunicación audiovisual, que se verán igualmente impelidos a adoptar mecanismos de auto y corregulación para evitar otros contenidos nocivos. 
* 068 - Intersecciones cine, danza y espacio ciudadano A propósito de Assemblage (Merce Cunninham, Richard Moore, 1968) - José Ignacio Lorente - Universidad del País Vasco/Euskal Herriko Unibertsitatea eneko.lorente@ehu.eus y Bárbara Díaz-Conservatorio de Danza de Castellón - diazbarbar@gmail.com

En el umbral del siglo XX, el cinematográfico surge como un dispositivo que comparte con la ciudad industrial el movimiento como imaginario fundacional de la modernidad. El movimiento de las máquinas, del tráfico y del propio acontecer urbano constituyen el objeto privilegiado de la representación fílmica, al mismo tiempo que alimenta la función y la forma de las metrópolis modernas. Pero la máquina urbana requería todavía una optimización del movimiento urbano y ciudadano, una coreografía precisa del movimiento que hace del reloj, de la estación ferroviaria y de la planificación misma de la expansión urbana, un metrónomo de la vida ciudadana.

El cine guarda memoria de este proceso de construcción coreográfica del movimiento urbano, del mismo modo que la danza, a partir de los años 50 sale del espacio teatral, hacia el espacio público, para confundirse con la vida ciudadana. La pieza fílmica Assemblage, dirigida por el coreógrafo Merce Cunninham y el realizador Richard Moore, en 1968, en la plaza Ghirardelli de San Francisco (EEUU), un espacio recientemente rehabilitado por el arquitecto y paisajista urbano Lawrence Halprin, fue filmada en el umbral indiscernible entre la danza contemporánea y el movimiento ciudadano.

El trabajo analiza el proyecto discursivo en el que se produce el encuentro entre la danza, el cine y el espacio urbano con el propósito de elaborar, a través de la forma del relato fílmico, una genealogía del imaginario del movimiento moderno.

* 069 - Indocumentas y sin miedo: prácticas feministas de DREAMers mexicanas en EUA - Carolina Aguilar Román - 
Las nuevas narrativas, en el entorno social

Colegio de la Frontera Norte (México) carolina.aguilar.dcser2018@colef.mx

En Estados Unidos viven aproximadamente dos millones de jóvenes indocumentados, que llegaron a ese país siendo menores. En 2001 se creó una propuesta de ley llamada DREAM Act (Ley de fomento para el progreso, alivio y educación para menores extranjeros) para regularizar la situación de las y los jóvenes indocumentados, sin embargo, no fue aprobada. A partir del DREAM Act a todas las personas que podría beneficiarse de esa propuesta de ley, se les conoce como DREAMers. Un aspecto relevante de estos jóvenes es que se han organizado en colectivos por todo Estados Unidos para exigir se aprueba la ley. A pesar de que las y los DREAMers son originarios de casi todo el mundo, la mayoría son de origen mexicano. Además, han sido las mujeres las que organizan las acciones colectivas como protestas, sit-in y actos de desobediencia civil.

La ponencia propone, responder ¿por qué existen más mujeres DREAMers que hombres? ¿por qué ellas son las líderes? y ¿cuáles son sus prácticas de lucha? Las preguntas serán abordadas desde la intersección del feminismo, movimientos sociales y las luchas migrantes. Lo cual significa un reto epistémico, puesto que las teorías de movimientos sociales no reconocen las luchas migrantes como movimientos sociales. Por otra parte, para abordar a las DREAMers desde el feminismo, me centraré en las prácticas cotidianas que realizan y que pueden entenderse como prácticas feministas de lucha.

* 070 - Análisis bibliométrico de las tesis doctorales defendidas en España sobre los nuevos servicios digitales y audiovisuales - Jesús Segarra-Saavedra - Universidad de Alicante - jesus.segarra@ua.es y Eduardo Villena-Alarcón Universidad de Málaga - eduardo.villena@uma.es

Se desarrolla un estudio bibliométrico de las tesis doctorales recogidas en Teseo -el repositorio institucional del Ministerio de Educación, Cultura y Deporte (España) - en torno a las plataformas 
audiovisuales mencionadas por el Informe económico sectorial de las telecomunicaciones y audiovisual de la Comisión Nacional de los Mercados y la Competencia (CNMC, 2019). Se ha de tener en cuenta que el mencionado informe diferencia entre: prestadores de contenidos audiovisuales online (Movistar+, Vodafone TV, Orange TV), plataformas (Netflix, Amazon Prime Video, HBO) y OT'T nacionales (Rakuten, Filmin, Flixolé y Cineclick). Además, se amplía el estudio con la búsqueda de LOVEStv (la plataforma común de RTVE, Atresmedia y Mediaset). Para ello se realiza un estudio longitudinal retrospectivo y un análisis de contenido de la información ofrecida por el portal institucional. Los resultados permiten detectar el escaso interés investigador suscitado entre la incipiente comunidad académica-investigadora, especialmente debido al breve período de tiempo desde la aparición de estos nuevos portales audiovisuales. También contrastan con la abundante literatura científica que se puede encontrar en otras bases de datos, así como el interés suscitado entre el alumnado de asignaturas como Trabajo Fin de Grado y Trabajo Fin de Máster en el área de Comunicación, entre otras.

* 071 - Los Premios a la Eficacia: un escaparate de la buena gestión de marca. - Irene Martín Soladana - Universidad Complutense de Madrid - Irenem14@ucm.es y Ana Sebastián Morillas-Universidad de Valladolid. Facultad de Ciencias Sociales Jurídicas y de la Comunicaciónana.sebastian@uva.es

La comunicación que se presenta tiene como objetivo mostrar por qué los Premios a la Eficacia en Comunicación Comercial pueden ser un buen escaparate de muchas marcas que han sabido gestionar con éxito su comunicación. Se pretende evidenciar por qué Los Premios a la Eficacia pueden ser relevantes en este aspecto con respecto a las piezas premiadas o presentadas en otro tipo de festivales de publicidad. En esta ponencia, se explicará en primer lugar qué son los festivales de publicidad y sus diferencias, para acercar el término a los miembros de la mesa. A continuación, se hará un breve repaso de los principales festivales de publicidad a nivel internacional como el Festival Cannes Lions, El Sol, Clio 
Awards, Festival Iberoamericano de Publicidad (FIAP) o El Ojo de Iberoamérica entre otros, con el fin de revisar cómo surgieron y por qué, para, posteriormente, entrar a conocer con más detalle los Premios a la Eficacia, en qué consisten y su trayectoria.

La metodología que se ha seguido para realizar este estudio es una metodología cualitativa. Se ha hecho una revisión bibliográfica general de los festivales de publicidad y se ha elaborado un listado de los más relevantes actualmente a nivel internacional, con el fin de analizar su contenido, trayectoria y objetivos, realizando a continuación una investigación más detallada de los Premios a la Eficacia.

El resultado que se busca obtener con esta reflexión es poner en valor los Premios a la Eficacia como un referente en el sector de la publicidad y presentarlo como una recopilación de casos que han tenido éxito en la gestión de la comunicación de sus marcas en algún punto de su ciclo de vida, lo que puede resultar de utilidad para otras empresas que se encuentren ante obstáculos similares. Estos premios dan a conocer cada año múltiples casos que muestran desde la problemática ante la que se encontraban los anunciantes, pasando por la estrategia que se utilizó para darle una solución, hasta los resultados que se obtuvieron. Además, mediante la previa revisión e investigación, se pretende ver si hay otros festivales que puedan ser igualmente válidos para este mismo fin.

* 072 - El tratamiento de las fake news en las redacciones de los medios de comunicación en Cataluña - Dra. Mònica Puntí Brun - Profesora Universidad de Girona monica.punti@udg.edu y Sr. Jordi Bes Lozano - Periodista freelance - jordibes@gmail.com

El objetivo de este artículo es el estudio del fenómeno fake news (o noticias falsas, en su denominación en español), un concepto que no es nuevo, pero que ha emergido con fuerza con la eclosión de las tecnologías de la información y la comunicación. En primer lugar, se hará una revisión de la literatura existente y se relacionará con 
conceptos como desinformación, deontología profesional, ética periodística y rendición de cuentas de los medios de comunicación.

En segundo lugar, se estudiará el fenómeno a través de una metodología cualitativa en la que se combinará la técnica de grupos de discusión (focus group) con periodistas y las entrevistas en profundidad con responsables de medios de comunicación de Cataluña. Con ambas técnicas se pretende indagar en cómo los periodistas, los responsables de los medios y los propios medios están actuando ante el fenómeno de las fake news: saber si se aplica el código deontológico en el quehacer diario del periodismo, si la ética profesional es suficiente para combatir la desinformación y si hay otras herramientas que se aplican o que se podrían aplicar que pueden ser útiles para los profesionales de los medios.

Finalmente, se expondrán los resultados y las conclusiones del estudio con las principales recomendaciones y prácticas que se están aplicando desde el ámbito periodístico tales como volver a los valores básicos del periodismo o la colaboración entre diferentes instituciones para conseguir una sociedad más informada.

* 073 - Competencias de emprendimiento a través de MOOCs: Un análisis a partir del Interaction Analysis Model/Computer-mediated Communication (IAM/CMC) Luis M. Romero-Rodríguez (luis.romero@urjc.es) Universidad Rey Juan Carlos y Bárbara Castillo-Abdul (barbaracastilloabdul@gmail.com)-Universidad de Huelva

Los MOOCs (Cursos Masivos Abiertos en Línea) han ido ganando popularidad como plataformas educativas no formales de aprendizaje permanente (life-long learning). Sin embargo, han sido criticados por su baja tasa de finalización (completion rates) y su escasa capacidad para crear redes y socialización entre sus participantes. El propósito de la presente investigación es analizar cómo la incorporación de competencias de emprendimiento en los MOOCs desarrolla atributos de innovación educativa y proyectos colaborativos. 
La investigación siguió un proceso de tres etapas: en primer lugar, se llevó a cabo una revisión exhaustiva de la literatura para identificar las dimensiones de las competencias de emprendimiento y los atributos de la innovación educativa en los MOOC. En la segunda etapa se realiza un estudio cuantitativo, basado en el análisis de encuestas basadas en pre y post-test a una muestra de 6517 participantes. En la última fase, se aplica el modelo de análisis IAM / CMC a través de un análisis cualitativo, utilizando la herramienta MAXQDA, para comprobar si se generan oportunidades de emprendimiento en las interacciones en los foros de discusión de los MOOCs.

Los resultados muestran, en primer lugar, que los MOOCs analizados obtienen una tasa general de finalización del 12,55\%, casi duplicando la media de las completion rates revisadas en la revisión de la literatura. Sin embargo, sólo el 14,29\% de los participantes expresaron al menos una oportunidad en los foros de discusión para generar emprendimientos relacionados con los temas de los MOOCs, por lo que se ratifica que en los MOOCs se dificulta la creación de redes y la socialización para el emprendimiento.

Esta investigación es uno de los pocos estudios sobre las competencias empresariales en los MOOCs que servirá para comprender cómo la inclusión de cuestiones relacionadas con el espíritu empresarial en los MOOC puede generar un impacto positivo en los participantes.

* 074 - Del espectro a Internet: evolución de la agenda tecnopolítica de las radios comunitarias latinoamericanas Santiago, García Gago - Universidad Complutense de Madrid - santia10@ucm.es

Desde sus inicios en 1947 las radios comunitarias de América Latina han liderado diversos procesos de democratización de los medios de comunicación en la región. Desde estas emisoras, agrupadas principalmente en las redes AMARC-ALC y ALER, se impulsaron campañas que culminaron con la aprobación de legislaciones en 
Uruguay, Argentina, Bolivia y Ecuador que garantizan el acceso de los medios comunitarios al espectro radioeléctrico.

Con la llegada de Internet y la reconfiguración convergente del ecosistema de medios, las demandas en torno al Derecho a la comunicación de este movimiento se han ido actualizando lentamente. Este nuevo espacio digital de reivindicaciones, surgido con la consolidación y masificación de Internet, y que incluye temas como la gobernanza, privacidad, software libre, acceso al conocimiento y la cultura, ha sido ocupado por otros actores más heterogéneos y multidisciplinares, algunos de ellos con profundas raíces en el mediactivismo comunitario.

¿Cómo plantean los medios comunitarios su agenda tecno-política en torno al Derecho a la comunicación en el contexto digital? ¿Qué rol juegan actualmente los medios comunitarios en la defensa de los Derechos Digitales? Esta investigación intenta responder a estas preguntas desde un abordaje multidisciplinar entre la sociología de la tecnología y la comunicación.

La ponencia presentará en su primera parte los resultados del análisis y sistematización de las reivindicaciones y marcos conceptuales históricos del movimiento de radios comunitarias latinoamericano (frame analysis). En una segunda, los avances de la investigación en curso que estudia los marcos discursivos de este movimiento en el contexto digital. Esto nos permitirá exponer la evolución de su agenda tecno-politica desde los años 70 hasta la primera década de este siglo. Por último, presentaremos unas conclusiones preliminares de esta investigación que tiene como objetivo identificar rupturas, continuidades y omisiones entre los discursos tradicionales del movimiento de radios comunitarias, sus nuevas propuestas y las de nuevos actores del mediactivismo digital.

* 075 - Entra la radio y la maloca, prácticas comunicativas y pedagógicas en comunidades indígenas de la Amazonía colombiana - Eliana Herrera Huérfanoeliana.herrera@uniminuto.edu, Diego Santamaría- 
Las nuevas narrativas, en el entorno social

diego.santamariac@uniminuto.edu y Juana Ochoa Almanza UNIMINUTO - juochoa@uniminuto.edu

Actualmente Colombia cuenta con 87 etnias indígenas, reconocidas como grupos minoritarios que están en riego de extinción cultural por factores externos a las mismas comunidades, como lo son la explotación de recursos naturales en sus territorios, el desarrollo de políticas educativas basadas en modelos occidentales estandarizados o propuestas etnoeducativas, en su mayoría, fallidas, así como la obligatoriedad del castellano y la escritura como única lengua y forma de intercambio/diálogo con la administración gubernamental y nacional, el turismo, la estigmatización de sus formas de lucha y movilización, entre otras.

Dentro de estas etnias indígenas se encuentran los tikunas, cocamas y yaguas, que cohabitan en el Resguardo Indígena Ticoya, ubicado en Municipio de Puerto Nariño, en la amazonía colombiana, con quienes tenemos una relación de investigación-interacción desde el año 2012. Durante los últimos años, el trabajo que se ha gestando con la comunidad está mediado por la necesidad de recuperar la radio comunitaria que tenía el resguardo, lo que ha permitido que se realicen capacitaciones en producción radial y la consolidación de la coordinación de comunicación del resguardo que ha buscado consolidar la radio como estrategia para el fortalecimiento de las culturas y la interculturalidad. Así mismo, se identificaron y caracterizaron las prácticas de comunicación propia o comunicación ancestral, y la forma como estas dialogan con la radio, internet e incluso apps como Whatsapp.

A través de una metodología dialógica y co-construida entre comunidad e investigadores se realizaron cartografías sociales, se realizó la historia de vida de una de las abuelas del resguardo y entrevistas a otros miembros significativos de la comunidad, con el objetivo de caracterizar las prácticas comunicativas y pedagógicas de la vida cotidiana que contribuyen al mantenimiento de los capitales simbólicos en los pueblos tikuna, cocama y yagua del resguardo Ticoya. 
La cotidianidad de la vida de estas comunidade transita por el río, la chagra, la maloca y la selva en donde se configuran diversas prácticas de comunicación y pedagógicas que a través del ejemplo, de la palabra de los abuelos o las abuelas, el conocimiento de las plantas, los animales y el río promueven la pervivencia cultural de estas comunidades. Así mismo, la articulación de estas prácticas propias entra en articulación y dialogan con la radio consolidando estrategias de comunicación para el fortalecimiento de las culturas y la interculturalidad en el resguardo Ticoya.

* 076 - La prensa española conservadora en el contexto multipartidista: ¿De la estrategia de bloques a la prensa de partido? - Carme Moreu Alfós - carme.moreu@gmail.com, Noemí de diego Peral - dediegoperalnoemi@gmail.com, Noemí Llopart Jimenez - noemi.lj.1997@gmail.com, Carlos Aguilar Paredes - carlos.aguilar@ub.edu y Gerard López Busquets- Universitat de Barcelona - gelobu97@gmail.com

Tras la recuperación de la democracia en España los medios de comunicación y en particular las cabeceras de prensa reinstauraron un sistema mediático claramente polarizado en bloques ideológicos. La ruptura del bipartidismo (PPPSOE) en las elecciones generales de 2015, y en especial la irrupción de Vox en las elecciones de 2019 nos llevan a preguntarnos por la evolución de la prensa conservadora al enfrentarse a esta diversidad de partidos ubicados en la derecha del espectro ideológico. El análisis es de especial importancia dado el elevado nivel de consumo selectivo de los medios en España que aboca al consumo de los diarios clásicos de derechas a un electorado cuyas referencias de voto se han diversificado.

Para estudiar el tratamiento de esta diversidad en la prensa de derechas hemos analizado el contenido de las noticas políticas de ABC y La Razón referentes a PP, Ciudadanos y Vox. durante el mes anterior a los comicios de abril de 2019. La muestra se realizó los lunes y viernes entre el 25 de marzo y el 26 de abril. Se cuantificó la relevancia otorgada a los tres partidos en número de noticias, y presencia espacial en la edición impresa, así como la temática y la orientación de las noticias 
respecto a los tres partidos mediante framing previo intercoder de los clasificadores.

Los resultados, si bien presentan matices para ambos medios, muestran una clara discrepancia en el tratamiento de estos partidos, siendo el tratamiento en ambos extenso y favorable al PP, neutro al referirse a Ciudadanos y escaso y en promedio negativo en de las noticias relacionadas con Vox. Esto nos lleva a concluir que debemos abandonar la visión de estos diarios como defensores de un espacio ideológico, y valorarlos más como voces del posicionamiento de un partido político.

* 077 - Los i-memes como medio de participación ciudadana en las relaciones diplomáticas a partir de un estudio de caso: \#PERDÓNESPAÑA - Laura Romero Vara - Universidad Complutense de Madrid - laurom05@ucm.es

Introducción: La presente investigación analiza la presencia de los memes en internet en las relaciones diplomáticas e internacionales a partir de un estudio de caso, específicamente, la controversia que surgió en marzo de 2019 entre México y España, a partir de las declaraciones, del actual presidente mexicano, en sus redes sociales, en las que instaba al rey de España a pedir perdón por los daños causados a México durante su conquista entre los años 1519 y 1521. El objetivo de la investigación es aportar una visión del uso de las figuras meméticas en el campo de las relaciones internacionales analizando cómo, en un conflicto internacional de menor escala, las partes, es este caso los propios ciudadanos, realizan críticas y dan su opinión, mediante el uso de memes. Además, se busca observar la tendencia de dicha participación, es decir, si forma parte de un proceso analítico, reflexivo y crítico o si más bien, es de carácter lúdico y de entretenimiento.

Metodología: La presente investigación descriptiva- interpretativa, utiliza una metodología híbrida, la cual combina el estudio de caso con el análisis multimodal del discurso, desde una perspectiva cualitativa. El análisis de los memes encontrados mediante el uso de diversas plataformas se basa en tres ejes principales: sistema referencial o de 
ideas, sistema contextual o interpersonal y sistema ideológico o visión del mundo (Knobel y Lankshear, 2007: 207).

Resultados y conclusión Los ciudadanos utilizan memes para expresar su opinión acerca de conflictos internacionales en redes sociales. El humor y la integración de elementos culturales en los memes son sus características principales. Se concluye que los “i-memes" forman parte de los procesos comunicativos de la sociedad en red del siglo XXI. Su estudio y utilización son vitales para comprender los procesos de socialización y convivencia modernos.

* 078 - Estudio de tendencias en el uso de herramientas de redes sociales y lenguaje digital - Susana Martínez Olazábal Universidad de Santiago de Compostela susana.martinez.olazabal97@gmail.com y José Miguel Tuñez López - Universidad de Santiago de Compostela miguel.tunez@usc.es

El trabajo consta de dos partes íntimamente relacionadas, las herramientas de redes sociales y las nuevas tecnologías de análisis de lenguaje digital. El estudio forma parte de un proceso que recorre un camino de lo general a lo concreto y que parte del análisis de las nuevas tecnologías y aplicaciones de la Inteligencia Artificial, especialmente el Procesamiento de Lenguaje Natual y la minería de opinión y argumentación, todos ellos incluidos en las herramientas existentes de análisis y gestión de redes.

Tras analizar las limitaciones y avances en este campo tecnológico a través de un proceso de documentación y entrevistas profundas a varios expertos, se procedió a realizar un estudio de tendencias en el uso de herramientas de redes sociales a través de una investigación cualitativa utilizando una muestra de conveniencia de expertos del departamento de digital de agencias de comunicación y marketing de Galicia.

Los resultados demuestran que, por una parte, los avances en materia de Inteligencia Artificial representan el resultado de una evolución natural del análisis de datos en la actual Sociedad Red, y por otra, que 
las características que se buscan en una herramienta de analítica de redes sociales son: que permita trabajar con varias plataformas de redes, elaborar informes de los datos analizados, programar publicaciones y aportar información sobre las mejores horas para publicar contenido. Además de esto, también se constató que los elementos de una buena gestión de redes no se pueden jerarquizar por pertenecer a un sistéma holístico en el que unos no funcionan sin los otros.

La utilidad de estos resultados es que ayudan a comprender los procedimientos de gestión y la cantidad de datos desestruturados que se generan en las redes sociales digitales. De la misma forma, deja claro que son los usuarios los que crean las redes sociales, las moldean e incorporan en sus rutinas diarias como una forma más de interacción vital. Las herramientas de gestión de redes sociales constituyen una ayuda de primera mano en el análisis de los procesos y comportamientos que se dan en las redes, así como un elemento indispensable en el tratamiento y gestión de la información que se genera constantemente.

* 079 - Avenida Río de los Remedios: Prácticas y estrategias sociales de protección cotidiana frente al delito en el Estado de México - Fabiola Olvera Aldana - Universidad Nacional Autónoma de México - f.olvera.aldana@gmail.com

Se presentarán los primeros resultados de la investigación que tiene como objetivo analizar las prácticas y estrategias sociales de protección cotidiana frente al delito en un contexto de violencia crónica en mujeres y hombres de 18 a 45 años en una zona de conflicto del Estado de México, el caso avenida Río de los Remedios, desde el concepto violencia crónica como la medición de la intensidad de la violencia desde la aplicación de contextos en que los actos de violencia se reproducen en el espacio y el tiempo. Incluyendo tiempo e intensidad; ahora bien, en la practicidad se entiende también como, lugares donde los índices de muertes violentas son al menos el doble del promedio para países de ingresos altos y bajos respectivamente, que se sostienen por cinco años o más y que se registran actos frecuentes de violencia que no necesariamente tienen como resultado la muerte a lo largo de 
varios espacios de socialización, incluyendo, el hogar, barrio, colegio, comunidades, espacio público (a nivel local y nacional) que contribuye con actos de violencia desmedidos, sancionados y no sancionados, donde la violencia ha permanecido enraizada en las interacciones sociales y en las relaciones entre el Estado y la ciudadanía.

* 080 - Nuevas arenas para la lucha libre mexicana: Estudio de procesos de transmediación en la Ciudad de México - Mtra. Patricia Celis Banegas - Universidad Nacional Autónoma de México - celisbanegas@gmail.com

La lucha libre arribó a México a comienzos del siglo pasado y en prácticamente 40 años fue transformada y resignificada hasta convertirse en una práctica local, que la llevó a ser nombrada patrimonio cultural de la Ciudad de México en 2018.

Dentro de este marco, la lucha libre mexicana fue mutado hacia una performance cultural que incluye la existencia de rituales, acciones, significados entrelazados que involucran la posibilidad de cambio, de repetición y que se reactualizan en cada nueva instancia. Dichas prácticas tienen una estética particular y están claramente separados y delimitados de otras prácticas sociales de la vida cotidiana. Tiene lugar en un tiempo y espacio definido y los espectadores siguen las reglas implícitas del evento e incluso pueden transformarlas.

En la actualidad, puede considerarse también como una industria creativa asociada al entretenimiento, que evoluciona y se diferencia en múltiples plataformas tradicionales y contemporáneas. Hoy la lucha libre también se disputa en las redes, las revistas especializadas prácticamente han desaparecido y dieron paso formatos digitales, que dialogan entre sí y con los espectadores. Por otra parte, los luchadores también se comunican y generan su propia imagen en las redes e incluso pueden vincularse directamente con sus fans. Las arenas se extendieron por encima de los dominios físicos hacia campos sociales que poseen reglas y estéticas diferentes a las tradicionales.

En la presente comunicación se analizará el lugar de la Lucha Libre Mexicana como industria creativa, conjuntamente con los procesos de 
mediación que la acompañaron, haciendo especial énfasis en la utilización de narrativas transmedia que influyeron definitivamente en el vínculo entre luchadores, espectadores y empresas luchísticas. Sobre las bases de las ideas expuestas, los luchadores, los críticos, y los mismos espectadores superaron la voz de las empresas de Lucha libre, generando una nueva forma de vivir y significar este deporte espectáculo.

* 081 - Mirada transmedia en el Estado de México: ¿cómo es la relación violencia crónica medios como Facebook, twitter y la televisión? - Fabiola Olvera Aldana - Universidad Nacional Autónoma de México - f.olvera.aldana@gmail.com

Se presentará el caso de la violencia crónica en el Estado de México desde la narrativa transmedia como un tipo de relato donde la historia se despliega a través de múltiples medios y plataformas de comunicación, en el cual, una parte de los consumidores asume un rol activo en ese proceso de expansión. Se analizarán los procedimientos productivos y la diversidad por el crecimiento exponencial de los canales de circulación informativa, las estrategias discursivas efectuadas que cuentan las experiencias subjetivas y vicarias de contextos con un cierto tipo de violencia que son puestas en juega para generar nuevas posibilidades de diálogo y conversación en la construcción del tejido social. A partir de este análisis, se plantea definir y conceptualizar a la violencia como un modelo narrativo que aborda la transmedia como parte de su proceso de consolidación, es decir, es una herramienta que termina siendo parte de la diversificación de la violencia en los ecosistemas mediáticos, así como las formas de expansión de la narrativa transmedia, la hibridación entre la industria cultura y participativa y el rol de experiencias en este contexto.

* 082 - Análisis de la agenda de género en los documentos finales la Cumbre Mundial de la Sociedad de la Información - María Inés Binder, Universidad Complutense de Madrid, mbinder@ucm.es

Si la Cumbre Mundial de la Sociedad de la Información (CMSI) celebrada en dos fases entre 2003 y 2005 es relevante aún hoy, es 
porque sentó los marcos conceptuales desde los cuales entendemos la llamada Sociedad de la Información. Dicho proceso contó, al menos formalmente, con la participación de organizaciones internacionales, Estados, sector privado y la sociedad civil en un formato novedoso llamado de múltiples partes interesadas.

La perspectiva de género, en tanto dimensión de análisis de las relaciones de poder, nunca ha sido una prioridad en las reuniones de alto nivel dedicadas a la comunicación, ni en MacBride ni en la CMSI. $\mathrm{Y}$, cuando la incorporan, predominan las visiones liberales del feminismo que no presentan una crítica a las bases mismas del sistema que produce y se sirve de dichas desigualdades estructurales.

Los documentos finales de la CMSI tienen, en mayor o menor medida, alusiones a la cuestión de género. ¿Desde qué perspectiva? ¿Cómo conciben a las mujeres y a las identidades diversas y sus necesidades? ¿Qué grado de incidencia tuvieron las organizaciones de la sociedad civil que impulsaban la agenda de género? ¿Incorporaron las recomendaciones sobre mujeres y TIC hechas en la Plataforma y Plan de Acción de Pekín?

El presente trabajo tiene como objetivo analizar el nivel de incidencia de la agenda de género de las organizaciones de la sociedad civil en los documentos finales de la CMSI: Declaración de Principios y el Plan de Acción de Ginebra; y el Compromiso de Túnez y la Agenda de Túnez para la Sociedad de la Información a través del análisis crítico del discurso y el análisis de marcos conceptuales.

* 083 - Mapeo sistemático de la producción científica de Alfabetización informacional en fuentes académicas de acceso abierto (2009-2019) - Maricela López Ornelas ornelas@uabc.edu.mx y Juan Alberto Díaz adiaz2@uabc.edu.mx - Instituto de Investigación y Desarrollo Educativo, Universidad Autónoma de Baja California, México

La literatura existente sobre el concepto alfabetización informacional (Alfin) ha llegado a un punto de infoxicación, por ello, es relevante depurar, discernir y seleccionar los aportes más referenciados en torno 
a dicho concepto. Bajo esta consideración, el objetivo del presente trabajo es identificar la evolución y posicionamiento de la Alfin. Como parte de la metodología se utilizó el Mapeo Sistemático de la Literatura (MSL) del término publicado en la década de 2009 a 2019. Para el procedimiento se consideraron los siguientes criterios de inclusión: documentos de acceso abierto en español comprendidos en las bases de datos de Scopus y Google Scholar; y como criterios de exclusión: se descartaron aquellos artículos que requerían pago para su acceso, información repetida o escrita en idiomas distintos al español. Se utilizaron palabras clave para la recopilación de los documentos que fueron puestos a revisión. La aplicación del MSL permitió clasificar los resultados dentro de cuatro indicadores: autores con mayor producción, tipología de los trabajos producidos en la última década, institución y país de adscripción de los autores. A partir de ello se identificó una tendencia, por parte de los autores analizados, por asociar, relacionar y/o definir, además de la Alfin, otros tipos de alfabetizaciones. De igual forma, se observó la ausencia de un consenso en la conceptualización del término y que la mayoría de los autores revisados están adscritos a instituciones de educación superior de España y Colombia. A manera de cierre, se reconoce que la cantidad progresiva de artículos y literatura gris publicados sobre alfabetización informacional puede percibirse como un indicativo del interés de la comunidad científica en la apropiación y posicionamiento del término.

* 084 - Propuesta de alfabetización transmedia en redes sociales: hacia la construcción de una pedagogía crítica dentro y fuera del aula en el sur de Chile - Luis Cárcamo-Ulloa - Instituto de Comunicación Social de la Universidad Austral de Chile lcarcamo@uach.cl, Camila Cárdenas-Neira - Instituto de Lingüística y Literatura de la Universidad Austral de Chile camila.cardenas@uach.cl,y Christopher Carrillo-Flores Unidad Técnico Pedagógica del Liceo Bicentenario de Valdivia c.carrillo@yahoo.com -

Internet tuvo una fuerte raigambre de instalación en los años 90s en las escuelas chilenas. La Red Enlaces conectó a la mayoría de los colegios públicos y concertados. A partir de esa década se han desarrollado iniciativas que incentivan el uso escolar de las tecnologías 
para ciencias, matemáticas, habilidades sociocomunicativas y entre otros. Los jóvenes chilenos dan pruebas del fuerte uso de redes sociales tanto con un sentido de consumo cultural genérico, como de su apropiación para fines de protesta y movilización social.

Una dificultad constante en la apropiación de herramientas web, como mediadores de aprendizaje, es la migración de hábitos de los jóvenes. Por ello, realizamos un estudio de caso en un colegio público de Valdivia. Elegimos el 2do año de secundaria $(N=74$ de niños y niñas de 15 ó 16 años de edad). Metodológicamente, recogimos información con el cuestionario propuesto por Scolari (2018), y también realizamos entrevistas a profesores y un grupo focal con estudiantes.

Entre los resultados confirmamos una radical migración hacia Youtube, Whatsapp e Instagram. Nueve de diez sujetos prefieren estas alternativas y sólo un 18\% mantiene un uso residual de Facebook y Twitter. También encontramos, mayoritariamente, hábitos de consumo medial sin diferencias de género significativas (uso de redes sociales, ver TV, hacer tareas en PC, mirar series y películas y usar el e-mail). Minoritariamente, existen diferencias significativas a la hora de usar videojuegos online (preferencia masculina) y leer libros digitales (preferencia femenina). Con estos y otros datos cuantificados, más la recogida de datos cualitativos con profesores y estudiantes, se elabora una propuesta de alfabetización transmedia para escolares de secundaria comprendiendo la cibercultura como un activo relevante de culturas juveniles y atendiendo a la necesidad de formar hábitos informativos de las audiencias nóveles.

* 085 - Acercamiento inicial a la Notoriedad y Reputación en el sector Retail de Cali (Colombia) - Laura Isabel Monroy Estudiante de Mercadeo y Negocios Internacionales Universidad Autónoma de Occidente laura.monroy@uao.edu.co. y Dr. Javier Andrés Mayorga Docente de Tiempo Completo - Universidad Autónoma de Occidente-jmayorga@uao.edu.co

Aunque en los últimos tiempos las grandes cadenas y sus grupos empresariales han llevado a cabo diversos movimientos que han 
generado una nueva conformación del mercado, el Retail en Colombia sigue siendo uno de los sectores con mayor aporte al crecimiento de la economía nacional ya que contribuye al desarrollo de un gran número de proveedores, de los cuales muchos son PYMES; asegurando una oferta adecuada y competitiva en precios, variedad y calidad para los consumidores, generando adicionalmente un gran número de empleos directos e indirectos. Según un estudio realizado por Amézquita y Patiño (2011) para la Superintendencia de Industria y Comercio, este sector se caracteriza por tener una composición muy interesante, debido principalmente a que en las últimas décadas han ingresado grandes cadenas de minoristas, se han llevado a cabo diversas integraciones de cadenas de supermercados y además porque existen las denominadas tiendas de barrio un detallista de gran importancia en la cultura del consumo nacional. Por lo tanto, esta investigación tiene como objetivo conocer el grado de notoriedad de marcas establecidas en el comercio minorista de la ciudad de Cali, y la relevancia comparativa que presentan los consumidores entre estas. Metodológicamente este estudio se realiza bajo una investigación cuantitativa, la cual, permite determinar la fuerza un análisis porcentual y estadístico de las variables determinantes para el análisis de notoriedad y reputación del sector retail de la ciudad de Cali. Este trabajo puede concluir que en el sector retail de esta región de Colombia, existen factores relevantes, como el regionalismo, la historia de la empresa, el contacto indirecto y directo con el consumidor final, entre otros, pueden afectar de forma positiva y negativa, la notoriedad y reputación de las empresas de esta categoría.

* 086 - Camino del infoentretenimiento: un estudio de los programas de debate y entrevistas de actualidad política en TVE (1980 - 1990) - Virginia, Martín Jiménez - Universidad de Valladolid - virginia.martin@uva.es, Itziar Reguero Sanz Universidad de Valladolid - Itziar.reguero@gmail.com y Pablo Berdón Prieto - Universidad de Valladolid pablo.berdon@uva.es

Los estudios sobre infoentretenimiento político sitúan la llegada de este acontecimiento a España a partir de la década de los noventa, con la liberalización del mercado audiovisual (Berrocal, 2016; Berrocal, 2017). 
Las noticias del guiñol, Caiga Quien Caiga o El Informal son tres ejemplos del aterrizaje que el politainment hizo en España (Martín Jiménez y Berrocal, 2017). Sin embargo, este género no aparece de un día para otro, sino que es el resultado de una evolución que merece ser estudiada.

El objetivo de esta investigación es estudiar los antecedentes del infoentretenimiento político, conocer de qué fuentes bebieron y comprobar si en esos programas anteriores se daban en menor medida ciertos estilemas que marcan lo que será ese nuevo género en los años noventa (Ortells, 2011; Berrocal, Redondo et al, 2014).

La metodología de estudio se enfoca en una triple vertiente. En primer lugar, se ha creado una base de datos en la que se ha incluido a todos los programas de debates y entrevistas de actualidad política emitidos en TVE durante la década de los 1980 (36). Más tarde, se ha realizado un examen de contenido - de corte cualitativo- de cada uno de los programas a través de obras de referencia, fuentes primarias en prensa y revistas especializadas para conocer quiénes estaban detrás de dichos espacios, así como sus invitados y su historia. Por último, se ha efectuado un visionado de los programas seleccionados previamente para, gracias a una ficha de análisis, examinar si tenían elementos propios del politainment.

Las principales conclusiones de este estudio revelan que, si bien es cierto que el infoentretenimiento nace en los noventa, algunas de sus características estaban presentes desde la irrupción de la democracia en España, cuando la televisión pública tenía el monopolio de la oferta de la pequeña pantalla.

* 087 - Pérdida de valores en México y trivialización de los hechos a través de los memes. Caso Huachicoleros - Dra. Silvia Inés Molina y Vedia del Castillo Universidad Nacional Autónoma de México molinass@hotmail.com y Dr. José Ángel Garfias Frías. Universidad Nacional Autónoma de México angelgarfias@politicas.unam.mx 
Esta investigación se sitúa en un horizonte que se transporta desde la sobremodernidad (Augé, 1992) hacia la cultura transmedia (Jenkins et al, 2015) y el espacio de la post verdad, donde los valores éticos están trastocados por la superabundancia de información y la relación social estrecha de los individuos con redes y tecnologías que facilitan la exacerbación del individualismo y la inmediatez.

El objeto investigado -mediante un análisis de contenido- son los memes que en ese periodo circularon en redes sociales sobre los "huachicoleros", a raíz de los sucesos del 18 de enero del 2019 en Tlahuelilpan estado de Hidalgo México. Se denomina aquí "huachicoleros" a organizaciones de los ladrones de combustible que, saboteando los ductos de Pemex, produjeron pérdidas al país por 35 mil millones de pesos mexicanos en 2018.

Estas personas habían sido descubiertas por el ejército y fueron advertidas del peligro que corrían, pues se encontraban festejando su desafío a las fuerzas de la ley. La explosión se produjo por la gran cantidad de gasolina, el movimiento y el descuido de los huachicoleros, que en su "festejo" se rociaban unos a otros con gasolina como si fuera agua en un carnaval. El resultado fue de 114 muertos según cifras oficiales.

Contrastando con este terrible hecho, los datos muestran a través de los memes e información recogida en los medios (prensa e internet y redes sociales), más que la existencia de una doble moral, la forma irreflexiva, vindicativa y burlona en que se trató el suceso en las redes se observó la ausencia de valores éticos como: justicia, libertad, responsabilidad o respeto (entre otros). En consecuencia, se concluye que la situación de violencia crónica que ha impuesto el crimen organizado (del cual los huachicoleros son sólo un sector) ha producido socialmente en México a través de los memes dos fenómenos que se complementan: la indiferencia y la agresión a través de la burla.

* 088 - Representación social de Nicolás Maduro entre migrantes venezolanos viviendo en México - Mtro. José Luis Flores Torres - Profesor de la Universidad Anáhuac México y 
estudiante del Doctorado en Investigación de la Comunicación (DEIC) del Centro de Investigación para la Comunicación Aplicada (CICA) de la Facultad de Comunicaciónjluisflorest@hotmail.com y Dr. Roberto Alejandro López Novelo - Profesor. Investigador del Centro de Investigación para la Comunicación Aplicada (CICA) - Universidad Anáhuac México-robertoa.lopez@anahuac.mx

$\mathrm{El}$ acercamiento a las representaciones sociales, constituye una forma de tener una idea clara, no solo de la manera en la que un grupo de personas percibe a un sujeto, a un fenómeno o algún lugar. La investigación sobre representaciones sociales muestra que el modo que tiene un colectivo de conceptualizar una parte de la realidad es apenas uno de los temas que aborda esta disciplina. Es decir, tan importante es conocer las representaciones sociales como las razones por las cuales se generan estos significados, el contexto desde donde se están generando, y las palabras que se están usando para manifestar estos conceptos.

En el caso de los migrantes venezolanos radicados en México la figura de Nicolás Maduro es de particular importancia. Si bien, la llamada revolución bolivariana, que ha marcado los destinos de la Venezuela contemporánea, fue emprendida a finales del siglo pasado por el carismático comandante Hugo Chávez Frías, a su muerte en 2013, los destinos del país quedaron en manos de Maduro, exsindicalista y mano derecha, hasta sus últimos momentos de Chávez.

Así figura (o causa) principal del éxodo venezolano, Maduro no es un personaje que pase desapercibido por sus paisanos (dentro y fuera del país caribeño). Señalado incluso por muchos como el principal causante de la crisis humanitaria 'por la que actualmente pasa esta nación, Maduro es apenas el personaje más visible de la crisis humanitaria por la que atraviesa Venezuela. Ante tal contexto la figura de Nicolás Maduro fue el sujeto central de este ejercicio de representación social.

* 089 - Estudio sobre ética y comunidades virtuales de migrantes latinoamericanos en México - Mtro. José Luis Flores Torres - 
Profesor de la Universidad Anáhuac México -

jluisflorest@hotmail.com y Dr. Roberto Alejandro López

Novelo - Profesor. Investigador del Centro de Investigación

para la Comunicación Aplicada (CICA) - Universidad Anáhuac

México-robertoa.lopez@anahuac.mx

El objetivo del presente documento tiene como fin constituir una reflexión que permita analizar la relación entre las comunidades virtuales que se agrupan en torno a la red social Facebook y la ética. En particular el presente estudio tiene como objetivo el análisis de las reglas de comportamiento que establecen las plataformas que agrupan a migrantes provenientes de algunos países latinoamericanos (en particular los que tienen como país de origen Venezuela) y que han elegido a México como nuevo lugar de residencia.

Como veremos a lo largo del estudio la relación entre las comunidades virtuales, la ética y la migración es apenas el telón de fondo en donde aparece reflejada la manera en la que el ser humano se relaciona hoy en día no solo con la tecnología, sino con su entorno, con sus semejantes y consigo mismo. Vista así dicha interfaz constituye parte importante de la paradoja del mundo postmoderno.

Más allá de esta contradicción, el hecho es que el mundo, hoy en día, gira en torno a Internet y la red constituye el tejido de nuestras vidas. En tal sentido el fenómeno migratorio hoy en día debe vincularse al nuevo entorno tecnosocial. Por ello resulta fundamental explorar la manera en la que las comunidades virtuales formadas por migrantes hacen uso de las ventajas proporcionadas por la cultura digital. En tal sentido resulta fundamental tener claro que este uso debe mirar más allá del sentido utilitario de la tecnología y centrarse en que lo ideal es que estas plataformas tecnológicas sirvan constituir espacios que satisfagan las necesidades de los grupos migrantes a partir del consenso y del respeto.

* 090 - El problema de la interdisciplina en la comunicación organizacional. Algunos avatares epistemológicos - Rafael Ávila González-UAM Cuajimalpa- ravila99@gmail.com y José Alfredo Andrade García-UAM Cuajimalpa-afredo@hotmail 
La cuestión de la usabilidad de la comunicación organizacional ha dominado históricamente este campo de estudios. Por lo mismo, consideramos que esa matriz pragmática tiene necesidad de sustento teórico y epistemológico que trascienda el determinismo tecnoeconómico y lo justifiquen como dominio de acción colectiva. Pensamos que una de las posibles vías de renovación de este ámbito radica en la posibilidad de explicitar cuestiones formales, técnicas y, de hecho, filosóficas, en cuanto a sus motivaciones y estándares de actuación. Para ello precisamos escrutar las representaciones que, en calidad de imperativos categóricos, modelan los ámbitos organizacionales en diferentes planos y distintas modalidades, originadas a su vez en diversas disciplinas epistémicas. Nos proponemos explorar algunos lugares de origen de tales representaciones y la función asignada a la comunicación, más allá del dispositivo sistémico, en tanto práctica social desontologizada. En tal virtud, la comunicación organizacional es cuestionada en su discurso monodisciplinar $y$ se hace necesaria una justificación inter $\mathrm{o}$ transdisciplinar para dotarla de credibilidad y validez. Poner de relieve esa estructura gnómica en esta materia es el objetivo del presente trabajo, que continúa además otros esfuerzos orientados en esa dirección.

* 091 - ¿Cómo funciona la ideología en Twitter? Análisis de un fragmento del procés: del \#1-O al \#21D - Andrea Pérez Ruiz Universidad Rey Juan Carlos (Madrid) a.perezrui@alumnos.urjc.es

En España la palabra 'posverdad' fue introducida por expertos, políticos y periodistas en su lectura de la crisis catalana a raíz de su irrupción en septiembre de 2017. De hecho, el Diccionario de la Lengua Española registró su definición en diciembre de ese mismo año. La red social Twitter es popular en la propagación viral de puntos de vista, y muchas personalidades del mundo de la política la utilizan para posicionarse públicamente sobre asuntos de interés general.

Este trabajo analiza el discurso político que el expresident catalán Carles Puigdemont hizo en Twitter del 1 de octubre al 21 de diciembre 
de 2017, como respuesta a una circunstancia político-social sin precedentes. Para ello, se plantea un sistema de variables y categorías que registra distintas características formales (recursos expresivos exclusivos de Twitter que no se dan en ningún otro canal de comunicación - como el retweet o los hilos de texto-) y de contenido (temática, fuentes, idioma, etc.) del objeto de estudio, siguiendo la técnica del análisis de contenido. Esta estructura metodológica pretende a su vez incorporar la dimensión ideológica de los tweets, conceptualizando detalladamente el contexto en que se produce su significado en un libro de códigos. Esta última parte de la metodología toma como referencia la propuesta teórica de John B. Thompson (2002), para la que el autor define cinco modos en que la ideología puede operar mediante una serie de estrategias típicamente asociadas a la construcción simbólica de significado en circunstancias particulares dadas.

La ponencia se centra en entender cómo opera la ideología a través del lenguaje con recursos expresivos propios del canal Twitter; explicar el uso que el político Carles Puigdemont hizo de la red social durante este periodo clave; y comprobar el papel del periodismo como elemento de credibilidad en el discurso.

* 092 - El concepto de Empresa Saludable: Los Programas de Salud en el ámbito empresarial en función de los criterios de Responsabilidad Social Corporativa - Milagros Ronco López milagros.ronco@ehu.eus y Carmen Peñafiel Sáiz - Universidad del País Vasco UPV/EHU - carmen.penafiel@ehu.eus, Lázaro Echegaray Eizaguirre - Camarabilbao University Business School - lazaro.echegaray@camarabilbaoubs.com, y Ana Mata Galíndez - Camarabilbao University Business School ana.mata@camarabilbaoubs.com

Introducción. Este trabajo se centra en el estudio de la promoción de hábitos saludables en el entorno empresarial, estudio paralelo y complementario a los criterios marcados por la ley sobre protección, seguridad y prevención en el seno de la empresa. Se trata de un análisis que recoge actividades que se sitúan más allá de lo que se considera de obligado cumplimiento y que entran de lleno en lo que actualmente se 
entiende como 'Empresa Saludable'. Estos aspectos tienen relación directa con el bienestar integral del trabajador, y no solamente con la prevención de riesgos, como es el caso, por ejemplo, de la conciliación de los horarios o de la implicación de la empresa en favorecer los hábitos de salud a través del deporte. El término 'empresa saludable' recibe influencias múltiples y persigue una mejor calidad de vida de los trabajadores, para lo que se llevan a cabo acciones y programas saludables de diversa índole. Objetivo. Este estudio se propone el análisis de las fuentes documentales imprescindibles para dar mayor soporte al Proyecto de investigación "Comunicación, Salud y Responsabilidad Social en el tejido empresarial vasco: análisis de los intangibles y del reporte no financiero en la empresa saludable". Método. Investigación cualitativa de tipo documental que supone la búsqueda, recopilación, valoración e información documental que permita una visión panorámica de las principales publicaciones en torno al objeto de estudio. Resultados. Se incorporan fuentes que contemplan tanto el enfoque legal como el enfoque evolucionado hacia programas integrales de empresa saludable, haciendo una comparativa de su evolución a nivel nacional e internacional.

* 093 - Identidad \& Community Management de Servicio Público: Estrategias online de representación social en la SBS australiana - Martín Vaz Álvarez - Universidade de Santiago de Compostela - martin.vaz.alvarez@usc.es, Marta Rodríguez Castro - Universidade de Santiago de Compostela m.rodriguez.castro@usc.es y José Miguel Túñez López Universidade de Santiago de Compostela - miguel.tunez@usc.es

Esta comunicación busca analizar y exponer las diferentes técnicas que utiliza el segundo medio de servicio público australiano, el Special Broadcasting Service, para cumplir con su cometido de universalidad en el ámbito online. El Special Broadcasting Service (SBS) es el canal multicultural de servicio público australiano encargado de representar las diferentes identidades que conviven en el territorio australiano, y posee contenidos en al menos 68 idiomas diferentes. La metodología empleada será documental y cualitativa, a través del diseño de una herramienta para analizar y categorizar las diferentes acciones online 
de la SBS con la audiencia; según su plataforma, forma de interacción, contexto y lenguaje.

* 094 - La interactividad en Instagram de los principales influencers en el sector periodístico de Ecuador - Andrea Victoria Velásquez Benavides - Universidad Técnica Particular de Loja - avvelasquez@utpl.edu.ec, Fanny Yolanda Paladines Galarza - fypaladines@utpl.edu.ec y Sarai Paola Gutiérrez Valle -sarpaolagutierrez@gmail.com

En un mundo globalizado, en donde las empresas buscan otras formas de dar a conocer su marca, y donde la publicidad ha llegado a saturar a las audiencias, la figura de los influencers se ha convertido en una de las principales estrategias favorables que busca conseguir prescriptores. Este poder de influencia permite incidir en las percepciones, decisiones o en el punto de vista del público. Los influencers han estado presentes en la sociedad desde hace años atrás, solo que ahora las organizaciones han cambiado su comportamiento comunicacional a un entorno más digital.

La presente investigación tiene como objetivo identificar los principales influencers del ámbito periodístico en Ecuador, conocer el tipo de contenido que utiliza y si las organizaciones los consideran verdaderos influencers. Para ello se focalizó la atención en Instagram, por ser la red más popular de estos tiempos. La herramienta que se utilizó fue Fanpage Karma que analiza las actividades de las redes sociales. La investigación se llevó a cabo en dos etapas: en la primera, se realizó un estudio exploratorio, en donde la recoleccion de datos permitió plantear un estudio descriptivo y correccional. En la siguiente etapa se planteó un estudio descriptivo que ayudó a identificar el tipo de contenido que generan los influencers, llegando a concluir que los 10 influencers seleccionados son del medio televisivo, y que el género femenino es quién ha tenido mayor éxito en generar contenidos e interactividad con sus usuarios.

* 095 - Nuevas expectativas, nuevas narrativas: La

Transmedialidad y el Storytelling en la Publicidad - Bárbara

Castillo-Abdul (barbaracastilloabdul@gmail.com) Universidad 
de Huelva y Luis M. Romero-Rodríguez (luis.romero@urjc.es) Universidad Rey Juan Carlos

Desde la llegada de internet se han producido muchos cambios antropológicos que han afectado las forma de relacionarse e interactuar de los individuos. Es así, como la publicidad y los encargados de la comunicación de las marcas se ve en la necesidad de utilizar internet como herramienta para llegar al público estratégico, seleccionando aquellos canales y recursos que con mayor efectividad permitan alcanzar el objetivo de la promoción y ventas de productos.

La presente investigación analizada la transmedialidad y el storytelling en la publicidad y la promoción de marcas de moda a través de la revisión del estado de la cuestión acerca de las nuevas narrativas en entornos social media, especialmente la publicada en aquellas revistas que pertenecen a bases de datos de referencia internacional (Journal Citation Reports y Scopus).

Los resultados de la investigación evidencian como el mundo del marketing se ha transformado vertiginosamente con la narrativa transmedia, provocando que los consumidores se involucren en lo procesos de co - creación de la marca a través de los contenidos que ella misma genera. El público pasó a tener un rol protagonista en la perdurabilidad de una marca, al tener la posibilidad de manifestar sus puntos de vista a través de diferentes canales, generando nuevas comunidades y vínculos entre la marca y sus consumidores y hasta generar un código de valores para este grupo.

* 096 - Comunicación corporativa y móvil. Un binomio necesario - Carmen Costa-Sánchez - Universidad da Coruña carmen.costa@udc.es y José-Miguel Túñez López Universidade de Santiago de Compostela miguel.tunez@usc.es

El trabajo aborda la relación entre la gestión de la comunicación en las organizaciones y su necesaria adaptación a un contexto móvil, permanentemente conectado y cambiante. A aquellos dispositivos que ya nos acompañan desde hace algunos años (teléfonos móviles, 
teléfonos inteligentes, ordenadores portátiles o tabletas), se añaden nuevos soportes móviles como los smartwatches, los asistentes virtuales, las gafas de realidad virtual o los wereables. El contexto de la comunicación móvil continúa, además en crecimiento, lo que se ve reforzado por el deseo y necesidad de adquisición de smartphones por usuarios cada vez más jóvenes.

El presente trabajo se estructura en tres grandes partes. En primer lugar, se realiza una reflexión sobre la situación de la comunicación móvil en España a la luz de los principales análisis y estudios sobre el sector. En segundo lugar, se exploran las relaciones entre la comunicación corporativa y móvil, su situación actual y las tendencias de futuro más próximas. Finalmente, se recoge el proceso que debe seguir una organización en el desarrollo de una aplicación móvil y se ilustra con ejemplos las diversas funcionalidades. Los resultados son de tipo analítico-descriptivo. La reflexión sobre la situación actual y las tendencias de futuro resulta necesaria para una correcta gestión de la comunicación por parte de empresas e instituciones en el contexto actual. Los ejemplos, recientes, en una temática hasta el momento subexplorada aproximan la investigación a la práctica profesional y alumbran nuevos caminos de adaptación y evolución. La temática se considera novedosa y necesaria en la investigación sobre gestión comunicativa organizacional en España.

* 097 - El rol de la prensa escrita en la consolidación del Estadonación moderno colombiano: mujeres, cuerpos y subjetividades - Juana Ochoa Almanza - Uniminuto juochoa@uniminuto.edu

La necesidad de consolidar un Estado-nación moderno colombiano durante el siglo XX, implicó la producción de sujetos dóciles y cuerpos aptos para el desarrollo y el capitalismo, este ejercicio se dio a través de campañas higienistas y la consolidación de la salud como tema de interés público, entre otros. Esta forma de gubernamentalidad tuvo particular interés en los sujetos reproductores de la vida biológica y cultural, haciendo de las mujeres su principal foco de impacto, convirtiéndolas en centro de la salud pública. 
La prensa escrita tuvo un lugar preponderante en este proceso de modernización, fue el paladín del discurso de las élites y, a través de la producción y reproducción de discursos médicos e higienistas en artículos y publicidad, emprendieron la tarea de moldear unas subjetividades y cuerpos modernos, especialmente el de las mujeres. La selección de lo noticioso y el tratamiento discursivo que tenía la prensa escrita no eran neutro, por el contrario, había una decisión en lo que se escribía y lo que se omitía, generando unas dinámicas discursivas particulares de las representaciones del mundo social. En esta lógica, uno de los órdenes sociales que produjo y reprodujo, dándole un lugar hegemónico y legítimo, fue la idea de mujer reproductora, presentándola como lo deseable, lo normal y natural.

A través de 1800 piezas, entre artículos periodísticos y publicidad de los periódicos El Tiempo y El Espectador, publicadas entre 1920 y 1925, se analizaron los discursos que la prensa escrita producía y reproducía en torno al deber ser de las mujeres, en medio del contexto de modernización y consolidación de un Estado-nación moderno.

Los discursos que presentó la prensa escrita en la producción y reproducción de nuevas subjetividades y corporalidades se cimentaron sobre lo que Monique Wittig denomina el régimen heterosexual, consolidando la idea de las mujeres-madres-maestras como medio para lograr el desarrollo y progreso de todo un país, negando cualquier otra forma de construir relaciones que no sean heterosexuales. Incluso, en este proceso de consolidar esta idea como parte del discurso médico e higienistas, se les despoja a las mujeres de su capacidad de articulación a partir de la experiencia, para hacerlas subalternas del consejo médico. La responsabilidad vital, moral y cultural que se les delega a las mujeres en la reproducción de los cuerpos del otro y para otros, da cuenta de la continuidad y adaptabilidad del régimen heterosexual como pilar del deseo modernizador en la consolidación del Estado-nación.

* 098 - La programación original de ficción distribuida por Netflix (2013-2018) - Tatiana Hidalgo-Marí - Universidad de Alicante - tatiana.hidalgo@ua.es 
Desde que en 2007 Neflix iniciara su servicio de VOD en Estados Unidos, la forma de entender el consumo televisivo cambió, dando lugar a un nuevo escenario en el que el consumo a la carta y la personalización de la programación condicionan la producción y distribución de los productos televisivos, en especial, a partir de 2016, año en el que la plataforma se extendió a, prácticamente, todos los lugares del mundo. En este contexto, la ficción televisiva se reformula y adapta a las nuevas lógicas de consumo y los perfiles de las nuevas audiencias, cada vez más exigentes y selectas.

Esta comunicación pretende presentar un estudio sobre géneros, formatos y contenidos alrededor de la ficción televisiva emitidas en Netflix desde su consolidación como plataforma de VOD, con el fin de ofrecer una radiografía alrededor de la ficción y poder detectar tendencias, estilos y líneas emergentes que caracterizan la producción y distribución actual de series de televisión producidas para VOD, detectando, además, líneas comunicativas, productivas y de difusión que puedan servir como pretexto para las producciones actuales y futuras.

* 099 - La ficción que "vende": estudio comparativo de las principales distribuidoras de VOD en España - Tatiana Hidalgo-Marí - Universidad de Alicante tatiana.hidalgo@ua.es

El fenómeno del video bajo demanda (VOD) ha revolucionado la forma de hacer, crear, distribuir y consumir producto audiovisual televisivo. En el caso concreto de la ficción televisiva, la gran aceptación de las plataformas VOD ha supuesto un reto importante para las cadenas de televisión y productoras, que han tenido que apostar por estos nuevos escenarios, para ser competitivos en el mercado televisivo general.

En este sentido, la presente comunicación pretende aportar un estado de la cuestión sobre series de televisión producidas por las plataformas VOD en España, en concreto: Netflix, HBO, Amazon Prime Video, Sky y Movistar+Lite, con el fin de conocer y detectar tendencias, estilos, géneros más prolíficos y audiencias a las que se dirige cada 
plataforma. El objetivo es comparar la oferta de cada una y detectar estrategias de posicionamiento en las plataformas VOD desde su producción y distribución de ficción.

* 100 - Análisis operacional sobre diez medios digitales del entorno Slow Journalism - Carmen Peñafiel, catedrática, departamento de Periodismo de la Universidad del País Vasco/Euskal Herriko Unibertsitatea, carmen.penafiel@ehu.eus, Udane Goikoetxea,profesora del departamento de Periodismo de la Universidad del País Vasco, udane.goikoetxea@ehu.eus e Itsaso Manias-Muñoz,profesora del Departamento de Lengua Vasca y Comunicación. Facultad de Ciencia y Tecnología de la Universidad del País Vasco, itsasomanias@hotmail.com

Introducción. - La investigación en comunicación social es importante para comprender los cambios que experimentamos en la sociedad contemporánea y para analizar los medios de comunicación digitales en tiempos postinternet. Actualmente se habla de nuevos periodismos o corrientes innovadoras como el periodismo de inmersión, de investigación, periodismo literario y periodismo reposado (slow journalism). Objetivos. - Esta ponencia se centra en el proceso metodológico aplicado al estudio de diez medios digitales del entorno slow journalism de habla hispana: cinco editados en España, dos en México, otros dos en Colombia y el último en Argentina. Teniendo en cuenta que lo más importante en el arte de la investigación en comunicación es el desarrollo de la capacidad metodológica, la capacidad de relacionar conceptos con datos y los datos con referentes, con hechos, con el fin de describir, explicar y evaluar la diversidad y la pluralidad de estos medios periodísticos digitales de países diferentes. Metodología. - Explicamos el desarrollo de una investigación mixta utilizando la triangulación, para desarrollar técnicas exploratorias, descriptivas y cuantitativas: estudios de caso, entrevistas en profundidad, estudio Delphi y encuestas. Resultados. - Las entrevistas cualitativas y el Delphi nos darán a conocer las opiniones de los profesionales que escriben sobre creatividad, innovación, cultura, pensamiento, tendencias y proyectos positivos. Los periodistas manifiestan su deseo de informar, inspirar, empoderar a la ciudadanía. 
En la revisión documental y los estudios de caso analizados, se observa que son medios que marcan tendencias, que apuestan resueltamente por el slow journalism -demostrando que los contenidos de largo formato tienen su hueco en el mercado-, con estilo y diseño cuidados, centrados en el peso y la fuerza comunicativa de las imágenes. Generalmente, son medios sin fecha de caducidad, que invitan al pensamiento crítico y a la lectura reposada. Son medios que se diferencian entre sí por el modelo de empresa. Las encuestas nos permiten conocer las fortalezas y debilidades del periodismo narrativo, así como los motivos específicos que llevan al lector a escoger este tipo de periodismo. Discusión. - En conjunto, todo ello ofrece un valor teórico de interés para el sector profesional del periodismo con destacadas implicaciones en el ámbito de la comunicación social.

* 101 - Inviolabilidad del domicilio en la frontera de la revolución tecnológica - Cristina Zoco Zabala - Profesora Titular de Derecho Constitucional. Universidad Pública de Navarra cristina.zoco@unavarra.es

La inviolabilidad del domicilio constituye el objeto de un derecho fundamental (art. 18.2 CE) cuyo enunciado delimita de modo restrictivo su contenido a la posibilidad de intervenir tal espacio domiciliar; bien sea mediante resolución judicial, por consentimiento de su titular, o tras la evidencia policial -visual o acústica- de la perpetración de hechos presuntamente delictivos (delito flagrante). El art. 18.2 CE protege la invulnerabilidad del espacio domiciliar frente a la intervención de terceros; garantiza la impenetrabilidad de tal espacio, con independencia de que en él desarrolle o no vida íntima, o al margen de que existan objetos que permitan presuponer que allí se desarrolla vida íntima por parte del propietario o titular del uso y disfrute del mismo. Tradicionalmente, la jurisprudencia ha vedado toda intromisión física en el espacio domiciliar por parte de terceros poderes públicos o particulares- que no cumpliera las citadas garantías enumeradas en la norma de derecho fundamental. Sin embargo, la evolución de las tecnologías de la información y de la comunicación ha redundado en la existencia de dispositivos tecnológicos -aeronaves no tripuladas- que interfieren en el espacio domiciliar sin necesidad de intervención física por parte de los manipuladores de tales artefactos 
teledirigidos. También ha repercutido en la existencia de instrumentos tecnológicos (prismáticos, micrófonos espía) capaces de interceptar imágenes o conversaciones directas que se desarrollan en el espacio domiciliar sin la necesaria presencia física del titular de tales dispositivos; o en la existencia de programas informáticos capaces acceder al espacio domiciliar mediante la interceptación de equipos remotos -ordenador en red, o spyware- sin que tal espacio domiciliar sea invadido de forma física en el sentido del precepto constitucional. La ponencia verifica en qué medida los cambios tecnológicos han transformado el derecho a la inviolabilidad (ya en su objeto, ya en la necesidad de reforzar el contenido).

* 102 - La Transición en La Palma: un viaje a través de la documentación hemerográfica - Nazaret Martín Pérez Universidad de La Laguna - mmartinp@ull.edu.es

Esta comunicación surge como resultado de una parte del proyecto "Inventario del patrimonio documental de la Transición en la Isla de La Palma" que intentaba poner luz sobre cómo se articuló este complejo proceso en la isla palmera y qué legado en cuanto a documentación y fuentes nos dejó a los investigadores de la historia en particular y de otras ciencias sociales en general.

En este caso concreto, se abordará la cuestión de la prensa histórica. Qué periódicos nos quedan, de cuánta información disponen y, sobre todo, qué diferencias internas y comunicativas se pueden encontrar en los diferentes títulos de prensa existentes en aquel momento. En cierta medida, es la prensa canaria resultante la que aún nos otorga la mayor cantidad de información sobre ese tiempo de la historia palmera, canaria y española. Por último, pero no por ello menos importante, esta comunicación buscará ampliar, de manera modesta, el saber histórico sobre la transición palmera, puesto que, intentará clarificar, de forma tangencial, algunos aspectos no investigados, relacionándose de manera necesaria con la, hasta ahora, escasa bibliografía existente.

* 103 - El fenómeno de la posverdad: La manipulación de la opinión pública en la era del relativismo y las ciberdemocracias - Berenguela Peleteiro Abeal - Universidade de Vigo - 
Las nuevas narrativas, en el entorno social

bpeleteiro07@gmail.com y Aurora García González Universidade de Vigo - auroragg@uvigo.es

La mentira en política no es ninguna novedad. Desde que se forjaron las primeras sociedades los líderes políticos se han servido del engaño y la manipulación para convencer a la ciudadanía de la validez de sus discursos. Sin embargo, en los últimos años se ha llevado a un nuevo nivel lo que Arendt consideraba «el conflicto entre la verdad y la política» (2017, p.19) porque actualmente los políticos no solamente mienten, sino que muestran una total indiferencia hacia los hechos objetivos.

Esta devaluación del concepto de 'verdad' en el discurso público se ha producido en un contexto marcado por la lógica mediática impuesta por Internet. La dependencia económica de las inversiones publicitarias -dado el carácter fundamentalmente gratuito de la redobliga a las empresas de comunicación a ofrecer contenido espectacularizado para poder captar la atención de la audiencia en un mercado altamente competitivo. Esto, sumado a la ampliación y personalización de la oferta de entretenimiento, la posibilidad de emitir mensajes libremente, la rápida viralización de contenidos engañosos, etc. sitúa al poder frente a una opinión pública debilitada que, ante la incapacidad de distinguir la información relevante y verídica que fluye por los medios, abandona la búsqueda de la verdad y basa sus decisiones políticas en criterios regidos por los valores de relativismo y hedonismo surgidos en la Posmodernidad.

Esta ponencia se centra en explicar en qué consiste el fenómeno de la 'posverdad', cuáles son los factores que han derivado en su desarrollo y qué riesgos entraña para el futuro de la democracia si continúa siendo utilizada como la principal herramienta de manipulación de la ciudadanía. Partiendo de una investigación cualitativa, se pretende comprender por qué las iniciativas desarrolladas hasta el momento para luchar contra la desinformación resultan insuficientes y proponer nuevas medidas basadas en el fomento del pensamiento crítico.

* 104 - Precarización de narrativas de la mujer migrante venezolana en un medio glocal (La Opinión 2015-2019) - 
Gladys Adriana Espinel Rubio. Universidad Francisco de Paula Santander - gladysespinel@ufps.edu.co y Eliana Caterine Mojica Acevedo. Universidad de Pamplonaelianamojica@unipamplona.edu.co

Este ponencia es el resultado del proyecto de investigación 'Nuevos roles, liderazgos y transformaciones de la mujeres de frontera' identificó, a través del análisis de contenido, las narrativas que de las mujeres migrantes venezolanas difunde el periódico virtual de Norte de Santander, LaOpinión.com Tras analizar 80 notas publicadas entre el 2015 y el 2019 en el medio digital, se pudo encontrar que las narrativas sobre las migrantes venezolanas fueron construidas desde la noción de la violencia. Las publicaciones hacen referencia a estas mujeres como víctimas de asesinato o como asesinas; también como las autoras de delitos relacionados con la extorsión y el hurto o víctimas de la trata de personas. El 90 por ciento de las notas publicadas corresponden a hechos sucedidos en Cúcuta o Norte de Santander, lo que contribuyen a la construcción de narrativas de la frontera también desde la violencia, lo peligroso o inseguro. Otras publicaciones las relacionan con la prostitución y el trabajo informal o ilegal.

Los hallazgos en el medio de comunicación permiten confirmar primero que "la feminización de las corrientes migratorias responde asimismo a estrategias de resistencia de las mujeres ante las situaciones de pobreza y exclusión impuestas a gran parte de la población de estos países" (Sassen, 2003. P. 21); pero también que se usa el cuerpo de la migrante como recurso discursivo para vincular su identidad "con los temas de la maternidad, la reproducción y el cuidado de la vida, así como con la prostitución" (Ramírez, 2018. P.56). Contribuyen así a la reproducción de condiciones de desigualdad e injusticia perpetuando las relaciones de subordinación, estigmatización y segregación que enfrentan no solo en Colombia, sino en otros países de Latinoamérica. El medio glocal construye una narrativa de la precariedad sobre la mujer migrante venezolana que afecta la forma como esta se relaciona y asume su condición.

* 105 - Audiojuegos, nueva herramienta para el periodismo y medios de comunicación digital - Alex Rene Jaramillo 
Campoverde - Universidad Técnica Particular de Loja arjaramillo6@utpl.edu.ec, Hernán Antonio Yaguana Romero hayaguana@utpl.edu.ec y Graciela Martínez Matías Universidad Nacional Autónoma de México chelamar19@hotmail.com

This research shows the production of journalistic audio games, within the framework of a study on gamification, new narratives, journalism and sound. The main objective was to analyze the relevance of audio games as new journalistic elements and the construction of social communicative processes in Ecuador. As part of the methodological process of this research, four audio games were developed, two of journalistic type and two of historical type that were later validated through surveys by journalists from Ecuador and by experts from Latin America. As a result, four audio games were certified, built from the adaptation of a video game production model.

Concluding that, when new narratives are investigated in journalism, a series of elements are disaggregated which make it possible to foresee that being able to tell a story is important, since the audience learns more effectively, even more so when this process is accompanied by ludic elements. This can be called user experience.

* 106 - Vídeo musical y consumo actual: análisis de la viralidad del vídeoclip en YouTube - Mario Rajas - Universidad Rey Juan Carlos-mario.rajas@urjc.es

El coste de producir un videoclip provoca que las discográficas busquen obtener su máxima difusión consiguiendo que tengan un "carácter viral". Metodología: Con el objetivo de conocer las bases esenciales que expliquen la capacidad viral de un video musical, se ha realizado una investigación utilizando como técnica metodológica el análisis de contenido aplicado a una muestra de 400 videoclips, 200 en 2015 y 200 en 2018 siguiendo criterios de difusión. Resultados: los videoclips han evolucionado, en los 3 años que separan los dos análisis, en aspectos como el idioma de las canciones, su estilo o la temática. Discusión y conclusiones: A partir del análisis se percibe un cambio en los gustos musicales de los públicos que acceden a este tipo de 
contenidos y, como consecuencia, la evolución hacia un nuevo modelo de videoclip que los usuarios estén dispuestos a compartir a través de sus redes sociales.

* 107 - Influencia de las flagship store de fast fashion en los estímulos emocionales del consumidor a través de experiencias - Elisa Regadera González - UIC Barcelona - eregadera@uic.es, Zahaira González Romo - UIC Barcelona - zfgonzalez@uic.es y Rejina Mary Selvam - UIC Barcelona - rmselvam@uic.es

La venta on line de fast fashion se ha incrementado durante los últimos años y ha contribuido a que las marcas busquen reforzar sus tiendas físicas generando nuevas experiencias en los consumidores. Investigaciones anteriores nos han ayudado a comprender el entorno de las tiendas insignia y cómo sus elementos pueden afectar la toma de decisiones del consumidor. Los estudios de marketing e investigación del consumidor sugieren además que las respuestas emocionales en las tiendas pueden verse afectadas por las características que configuran el entorno de las mismas. El presente estudio trata de identificar y evaluar la relevancia de dichos elementos, abordando cómo afectan el estado de ánimo y la experiencia de los consumidores, centrándose en el caso específico de las tiendas insignia de fast fashion. Además, también examina los estados emocionales del cliente generados en dicho punto de venta y su influencia en la satisfacción e intención de compra posteriores. Los resultados del presente estudio confirman la naturaleza de la atmósfera dominante en el gasto y otros comportamientos de acercamiento al entorno de la tienda para el caso de las flagship stores, a diferencia de los hallazgos anteriores que no muestran suficientemente estas relaciones con otro tipo de tiendas. Este estudio tiene implicaciones importantes para discutir el proceso y las estrategias de implicación comercial de las tiendas insignia de la moda rápida.

* 108 - Audiencias y debates electorales: De la televisión a las redes sociales - José Rúas-Araújo - Universidad de Vigo joseruas@uvigo.es, Julia Fontenla-Pedreira-Universidad de Vigo.julia.fontenla.pedreira@uvigo.es y Erika Conde-Vazquez. Universidad de Vigo. erikaconde@uvigo.es 
Los debates electorales televisados constituyen uno de los acontecimientos más importantes, en términos de audiencia, en todo proceso electoral.

El interés en los debates electorales queda reflejado en las históricas cuotas de pantalla que alcanzan, uno de los indicadores unánimemente aceptados en el estudio de las audiencias (Webster, Phalen y Lichty, 2014; Huertas, 2002; Berrocal, 2005). Los efectos que el visionado de los debates puede tener sobre la audiencia han sido ampliamente investigados en el ámbito internacional (Blais y Perrella, 2008; Benoit, Hansen y Verser, 2003; Yawn, Ellsworth, Beatty y Kahnet, 1998; Chaffee, 1978), pero no tanto en el entorno español.

La irrupción de las redes sociales propició una convergencia (Jenkins, 2008) e hibridación mediática (Chadwik, 2013), en la que los nuevos medios conviven con los medios tradicionales, generando un consumo y formato multipantalla -que algunos autores denominan "segundas pantallas" (Horning, 2017; Gil de Zúñiga et al., 2015)- y permite a los usuarios compartir su experiencia televisiva (Esteinou, 2017), a través de la formación de comunidades virtuales (Marzal y Zallo, 2016).

Esta comunicación analiza el impacto en las redes sociales de los dos debates electorales televisados celebrados con motivo de las elecciones generales de España de abril de 2019, en TVE y Atresmedia, a partir de una encuesta telefónica realizada a un total de 734 entrevistados, en las ciudades de Madrid, Barcelona, A Coruña y Vigo.

Los resultados muestran que un porcentaje estimable de los usuarios consultados $(43,2 \%)$, ha realizado comentarios o compartido información en las redes sociales, en relación con ambos debates televisados.

* 109 - Comunicación Interna en el área turística: Departamento de Lingüística Aplicada en la Universidad de Leuven (Bélgica) Dr. Kris Buyse - KU Leuven, Lovaina, Bélgica kris.buyse@kuleuven.be, Dra. Almudena Barrientos Báez Escuela Universitaria de Turismo Iriarte (ULL), España - 
almudenabarrientos@irairteuniversidad.es y Dr. José Alberto Martínez González - jmartine@ull.edu.es - Universidad de La Laguna, España

Los objetivos del curso de maestría en Comunicación Interna (CI) en el departamento de Lingüística Aplicada (LA) de la Universidad KU Leuven de Bélgica son que los estudiantes puedan producir o reescribir textos y discursos en los idiomas elegidos en registros especializados en el campo de la CI en las empresas, y que logren tener un dominio del idioma extranjero elegido a nivel avanzado, especialmente para los registros especializados relacionados con la CI en la industria turística.

El curso CI potencia la manera de trabajar informes orales y escritos dentro de la empresa y los estudiantes se enfrentan a documentos españoles siempre que es posible (confidencialidad de datos). Sin embargo, en una encuesta realizada al final del curso, los estudiantes calificaron la autenticidad y el impacto motivador de los contenidos y el enfoque del curso como muy bajos, y las calificaciones no alcanzaron los estándares generales de los cursos de maestría en el departamento de LA.

Por tanto, en las últimas dos ediciones del curso, se adoptó un enfoque de enseñanza de lenguas mediante tareas (ELMT), con un fuerte énfasis en las tareas de la vida real, la creación de significado y la motivación bajo el paraguas del concepto del yo futuro (Future Self) (Oyserman, Destin y Novin, 2015). En lugar de copiar textos y presentaciones de varias empresas españolas existentes, se pide a los estudiantes que inventen una nueva empresa con sede en España, cuyos departamentos estarán representados por pequeños grupos de estudiantes. Todas las tareas están destinadas a ser actividades significativas con tareas previas y posteriores, y su resultado debe publicarse en el blog público de la empresa. Se utilizan varias herramientas web 2.0 como Google Docs con el objetivo de fomentar el trabajo en equipo, la interacción y el pensamiento crítico dentro de la empresa turística. 
Para medir el impacto del enfoque ELMT en la motivación de los estudiantes y el profesor, así como la calidad de su producción, se realizó un análisis cuantitativo y cualitativo.

* 110 - Tratamiento de la violencia de género en los medios sociales de los diarios digitales de la Región Andina - Vanessa Rojas - Fernández - Universidad Técnica Particular de Loja vlrojas1@utpl.edu.ec, Verónica Altamirano - Benítez vpaltamirano@utpl.edu.ec y Gabriela Moreira - Aguirre Cátedra Unesco de Cultura y Educación para la Paz dgmoreira@utpl.edu.ec

La violencia de género según la Organización de las Naciones Unidas define a esta como cualquier acto de violencia como cualquier acto basado en la pertenencia al sexo femenino que pueda tener como resultado un daño o sufrimiento físico, sexual o psicológico para la mujer, inclusive las amenazas de tales actos, la coacción o la privación arbitraria de la libertad, tanto si se producen en la vida pública o privada. Durante las últimas décadas la violencia de género contra las mujeres ha marcado la agenda política, legislativa y social de los países del mundo, América Latina de manera especial es uno de los más afectados por este fenómeno, que es considerado un problema de salud pública para los estados. Sin lugar a duda el feminicidio es la manifestación más atroz de esta violencia. A través del presente trabajo de investigación se investiga el tratamiento informativo que los medios de comunicación dan a la problemática de la violencia de género de manera específica el cometimiento de delitos de feminicidio a través de la revisión de noticias publicadas en medios sociales de los principales diarios digitales de los países de la Región Andina: Bolivia, Perú, Ecuador y Colombia. La investigación parte de un análisis de las legislaciones y códigos deontológicos de los países analizados para establecer las principales características del tratamiento informativo, y elaborar la ficha de investigación para el análisis de contenido en los medios de comunicación, que permite determinar que a pesar que se avanzado en la normativa para regular las publicaciones referentes al tema, aún existe sensacionalismo en los medios de comunicación. 
* 111 - Las radios comunitarias, otra comunicación socialmente rentable. El caso de cuatro emisoras de Bogotá - J. Ignacio "Iñaki” Chaves G. jose.chaves@uniminuto.edu Uniminuto (Bogotá, Colombia)

Las radios comunitarias trabajan por otra comunicación. Sus propuestas permiten escuchar a aquellas personas y colectivos que, teniendo vOz propia son ignorados y excluidos, no son tenidos en cuenta ni por los poderes ni por los medios masivos de difusión de noticias. Si hablamos del ejercicio comunicativo de las radios comunitarias estamos haciéndolo de una comunicación participativa, dialógica y horizontal. De un espacio de libertad en el que se reconoce el derecho a la comunicación y se democratiza la palabra.

La tarea de las radios comunitarias es una labor social que busca la metamorfosis de una realidad social las más de las veces ocultada. Su finalidad no es el lucro sino la escucha y el diálogo abierto a la comunidad para que ésta cuente (narre) y sea tenida en cuenta, que se hagan visibles frente a la sociedad a partir de la comunicación que practican y del papel que juegan en la construcción de tejido social.

En esta ponencia se presentan los resultados de la investigación llevada a cabo con cuatro emisoras comunitarias de Bogotá para establecer qué comunicación practican a partir de determinar su rentabilidad social con la aplicación de una versión adaptada del Índice de Rentabilidad Social de la Comunicación (Irscom) creado por el grupo de investigación "Laboratorio de Comunicación y Cultura" de la Universidad de Málaga. El método aplicado nos permite tener un panorama de las potencialidades de esas emisoras comunitarias, así como de sus carencias, a la hora de contribuir a la construcción de ciudadanías críticas y participativas desde la comunicación que realizan.

* 112 - La virtualización de los vínculos socioafectivos - Olivia Velarde Hermida- Profesora Titular de Universidad. Universidad Complutense de Madrid - ovelarde@ucm.es

Las aplicaciones informáticas posibilitan a los usuarios el establecer, mantener, y en su caso reforzar, los vínculos con personas de su 
entorno mediato e inmediato. Esos contactos on line, adoptan las pautas derivadas del factor de "distancia social" que opera en las relaciones mantenidas en los espacios físicamente presenciales. De las personas desconocidas a la pareja, pasando por los conocidos, los amigos y los miembros de la familia, los internautas van virtualizando cada vez más sus interacciones. En ocasiones, el contacto on line se lleva a cabo en un escenario de privacidad en el que el usuario se encuentra solo. Pero cada vez es más frecuente que estando presentes otras personas con las que incluso el internauta puede estar hablando, se simultaneen y yuxtapongan ambas modalidades de interacción. Como se sabe, la coexistencia de esas prácticas comunicativas incide en las nuevas formas de relación social mediadas por las tecnologías. Y su manifestación está asociada a un repertorio muy amplio de variables sociodemográficas. Hemos averiguado como intervienen dichas variables y presentamos los resultados en esta ponencia. Ofrecemos datos provenientes de una investigación $\mathrm{I}+\mathrm{D}$ en la que se ha indagado, entre otros temas, la virtualización de las relaciones sociales. Hemos identificado cuántos usuarios mantuvieron contactos on line en un día determinado y cuál es el vínculo que les ligaba a esos contactos. Analizamos las circunstancias y características de quienes se comunicaron estando solos o acompañados. Y hemos indagado la percepción que dichos comunicantes virtuales manifestaron sobre el desarrollo y resultado de esas interacciones comunicativas. Los resultados que ofrecemos están basados en una muestra representativa de usuarios de internet en España.

* 113 - Estrategia intercultural de atención primaria en salud para el empoderamiento femenino, social y cultural, aplicada a la prevención de cáncer de cuello uterino, en 5 etnias de la Amazonía - María Inés, Sarmiento Medina misarmiento@fucsalud.edu.co, Adriana, Ardila-Sierra amardila@fucsalud.edu.co, Myriam Beatriz, Puerto de Amaya Fundación Universitaria de Ciencias de la Salud mbpuerto@fucsalud.edu.co, Claudia Marcela, Velásquez Jiménez y Ambientales, U.D.C.A. - mvelasquez@udca.edu.co, Esteban, Quintana - U.D.C.A. - esteban.quintana@gmail.com, Sandra, Vargas - Universidad El Bosque - 
vargassandra@unbosque.edu.co y Vilma Cenit, Fandiño Osorio - U.D.C.A. - vfandino@udca.edu.co

Introducción. Nuestro equipo desarrolla una investigación-acciónparticipativa que busca construir una estrategia intercultural de atención primaria en salud, la cual aporte al empoderamiento social y cultural para la autogestión y sostenibilidad de los programas de cuidado y conservación de la salud, aplicada a la prevención del cáncer de cuello uterino, en 5 etnias de la Amazonía colombiana. La iniciativa surgió de mujeres indígenas preocupadas por mejorar el cuidado ginecológico en su resguardo. Método. Docentes de tres universidades apoyamos la formación como investigadoras de 5 mujeres de 5 grupos étnicos, en un territorio de liderazgo tradicionalmente masculino. Previo consentimiento informado, cada una de ellas entrevista personas de su comunidad, en lengua propia (Curripaco, Puinave, Cubeo, Sikuani y Piapoco), para comprender aspectos relacionados con las costumbres, significados y recursos en salud, sexualidad y salud sexual. Las entrevistas son semiestructuradas, individuales y grupales. Los audios se transcriben al español, para hacer el análisis entre todas. Resultados. Las mujeres están dispuestas a hablar de sus asuntos personales y de salud con otras mujeres, prefieren hablar en lengua propia y se sienten intimidadas con el personal de salud no indígena. Para la educación, las mayores prefieren la comunicación personal, las adultas y jóvenes prefieren el video; aunque hay pocos televisores, les gusta mirar telenovelas y allí conocen costumbres occidentales, que a veces imitan. Los jóvenes están viviendo una incursión acelerada en costumbres occidentales, especialmente a través del celular. Las lideresas, cada vez más empoderadas, han concluido que el formato de video multilingüe debe ser la estrategia comunicativa para sus acciones comunitarias y para motivar la toma de citología cervicouterina. Los videos se difundirán en sus respectivos grupos étnicos $\mathrm{y}$, posteriormente, se hará una brigada donde se invitará a las mujeres del resguardo a realizarse una citología. Al final, se espera que las comunidades analicen si la experiencia fue culturalmente segura, si les parece conveniente sostener el programa de tamizaje o cómo podría ajustarse a sus expectativas. 
* 114 - Extractivismo y acción colectiva: reconocimiento de la pesca artesanal como práctica comunicativa - Laura Melina Martínez Páez - Uniminuto - melymartinezp@gmail.com y Paola Porras Camacho - Uniminuto-paoporras03@gmail.com

En el Magdalena Medio colombiano, desde hace más de 50 años habita una comunidad de pescadores artesanales en el corregimiento de El Llanito. Su vocación productiva y representación simbólica y comunicativa de saberes ancestrales está construida desde la relación con los cuerpos de agua que rodean su espacio geográfico. Sin embargo, desde su devenir histórico han enfrentado diversos tensionantes, entre ellos, la presencia de empresas extractivas que han generado una visión hegemónica frente a la relación que los sujetos deben tener con la naturaleza.

Estos conflictos representan una amenaza para la pervivencia de sus dinámicas sociales y anclajes espirituales. Ante este panorama, se presentará un estudio etnográfico de la Asociación de Pescadores y Acuicultores del Llanito (APALL), una acción colectiva líder en la cuenca baja del Río Sogamoso que ha gestado mecanismos de control comunitarios para los métodos de pesca ilícitos, procesos que han fortalecido el tejido asociativo de toda la región y han visibilizado al pescador artesanal como un gestor territorial.

APALL se ha valido de mecanismos visibles de protesta y mecanismos simbólicos que se consolidan en medio de sus faenas en el río. Es allí cuando la cotidianidad se convierte en resistencia y configura nuevos significados alrededor de la práctica comunicativa. La existencia de esta acción colectiva no sólo les permite a los pescadores formalizar una plataforma de exigibilidad de derechos, sino el propósito invisible pero contundente de mantener la esperanza en un proceso para su comunidad en general.

* 115 - Nuevas plataformas de televisión: el HbbTV e impactos en la industria televisiva - Joan-Francesc Fondevila-Gascón joanfrancescfg@blanquerna.url.edu, Eduard Vidal, Marc PoloLópez, Joan Cuenca-Fontbona 
El medio televisivo está cambiando aceleradamente en los últimos años a raíz del advenimiento de nuevas plataformas de televisión, que implicarán cambios en las formas de producir, distribuir y recibir contenidos. El desarrollo de la televisión híbrida, liderada por el HbbTV (Hybrid broadcast broadband Television), aporta unas oportunidades de interactividad y de personalización de mensajes que no pasan desapercibidas para los diversos agentes del sector, incluidos los publicitarios. En esta investigación se intentan detectar los factores de motivación principales y las tendencias de futuro en la relación entre televisión y publicidad interactiva. Metodológicamente, se utiliza la técnica cualitativa del Delphi, la más recomendable en aproximaciones prospectivas a objetos de estudio incipientes como el HbbTV. A manera de conclusión, se observa que se consolida la televisión inteligente a la carta, que existe menor relevancia televisiva como medio básico para la publicidad, pero mayor importancia si se añade la interactividad, que evoluciona el branded content y que, gracias a las posibilidades de diálogo con los anunciantes, el mensaje se adecua mejor al medio.

* 116 - El rol de la ficción audiovisual en la detección inteligente de situaciones de peligro en las víctimas de violencia de género - Marian Blanco-Ruiz - Instituto Universitario de Estudios de Género (UC3M) y Departamento de Ciencias de la Comunicación y Sociología (URJC) - marblanc@inst.uc3m.es, Clara Sainz de Baranda - Instituto Universitario de Estudios de Género. Departamento de Periodismo y Comunicación Audiovisual (UC3M) - cbaranda@hum.uc3m.es y Rosa San Segundo - Instituto Universitario de Estudios de Género. Departamento de Biblioteconomía y Documentación (UC3M) -rsan@bib.uc3m.es

En un mundo donde la imagen sirve como estímulo, las bases de datos científicas más utilizadas para el estudio de los sentimientos (como MAHNOB o DEAP) utilizan recursos audiovisuales partiendo de la premisa del efecto realidad acuñado por Barthes (1968) en el que a través del audiovisual se invocan muchas de las emociones que experimentamos durante los encuentros directos en nuestros espacios 
vividos. Es decir, un clip audiovisual es capaz de inducir a un estado emocional.

El objetivo de la comunicación es presentar cómo la ficción audiovisual es empleada para la construcción de una base de datos (BBDD) que permite entrenar a los dispositivos inteligentes para detectar la violencia de género. La elaboración de una base de datos audiovisual que contemple los diferentes tipos y etapas de la violencia permite mejorar la gama de estímulos medidos por los sensores actuales con el objetivo de identificar con mayor precisión las emociones "negativas" como el miedo, el dolor o pánico.

Para la selección de las escenas que forman parte de la base de datos se ha empleado la técnica de entrevistas en profundidad a profesionales que atienden a víctimas de violencia de género. En total 138 títulos fueron nombrados, pero en el experimento se han incluido en el experimento 76. El resto han sido desestimados. Tras su visualización y minutado, se han seleccionado las escenas pertinentes para el estudio y, tras su edición, se han mostrado a paneles de jueces expertos para la composición de la BBDD.

El empleo de la ficción audiovisual para inducir emociones vinculadas con la violencia de género busca la empatía e identificación con las escenas audiovisuales y sus personajes. La medición de estas reacciones permite el desarrollo de tecnología de sensores inteligente que sea capaz de prevenir una agresión.

* 117 - Feminicidios de inmigrantes venezolanas en Colombia y México - Neida Albornoz-Arias. Universidad Simón Bolívar, Colombia. Universidad Católica del Táchira, Venezuela. Correo: n.albornoz@unisimonbolivar.edu.co, Myriam-Teresa CarreñoParedes. Universidad Simón Bolívar, Colombia. Correo: m.carreno@unisimonbolivar.edu.co, Izabel Solyszko Gómez. Universidad Externado, Colombia. Universidade Federal de Mato Grosso, Brasil. Correo: izabel.solyszko@uexternado.edu.co y Magali Alba Niño. Universidad Simón Bolívar, Colombia. Correo: m.carreno@unisimonbolivar.edu.co 
El presente artículo tiene como objetivo analizar la apropiación del concepto de feminicidio por parte de la prensa colombiana y mexicana con relación a casos de muertes de mujeres inmigrantes venezolanas durante el período 2017-2019. Las fuentes de información indagadas correspondieron a periódicos virtuales nacionales y regionales de ambos países. Se realizó la revisión y sistematización de las noticias y el posterior análisis de los relatos contenidos en las mismas. Se consideró en este proceso la condición de inmigrante de cada víctima y el contexto donde ocurrieron los hechos. El proceso investigativo de este fenómeno social se realizó desde el paradigma interpretativo, enfoque cualitativo y análisis del discurso como método. Los hallazgos revelan semejanzas en el tratamiento del delito, dentro de cada país, pero también diferencias al comparar a ambos países; mientras en Colombia son feminicidios íntimos en México son feminicidios no íntimos.

* 118 - El papel del fandom televisivo en la estrategia de comunicación digital de Netflix. Análisis de la interacción y engagement online en Twitter - Alba-María, Martínez-Sala Universidad de Alicante - albamaria.martinez@ua.es y CarlosEduardo, Prado-Jiménez - Universidad de Bogotá Jorge Tadeo Lozano - carlose.jimenezp@utadeo.edu.co

El desarrollo de las tecnologías de las relaciones, la información y la comunicación ha provocado nuevos hábitos de consumo audiovisual propiciando la aparición de nuevos modelos de negocio como las plataformas de distribución de contenidos audiovisuales, entre las que cabe destacar a Netflix. En este contexto va adquiriendo protagonismo el fandom televisivo por el potencial comunicacional y relacional que ofrece a este tipo de organizaciones, fundamentalmente bajo el modelo web 2.0. Esta investigación se plantea como objetivo principal analizar el impacto del fandom televisivo en la interacción y el engagement online de Netflix en Twitter. Para ello se realiza un análisis de contenido cuantitativo de las publicaciones de Netflix y de la interacción generada en dicha red social desde el enfoque de una metodología de carácter exploratorio y descriptivo y aplicando el algoritmo Twitter Decahose. Previo al análisis de la interacción y del engagement online las publicaciones se clasifican en función de su carácter y contenido. En lo 
que respecta al contenido, la distribución de tweets está bastante equilibrada y aquellos que se centran en series generan menor interacción y engagement online revelando una escasa incidencia del fandom televisivo. Con relación al carácter se observa una presencia considerable de publicaciones comerciales pese a que las colaborativas generan mayores niveles de interacción y engagement online. Además, cabe señalar que siendo el carácter colaborativo el factor que determina en mayor medida la interacción y el engagement online, ninguno de los tweets sobre series es de este tipo. Se concluye en este sentido acerca de la necesidad de reorientar la estrategia de comunicación de Netflix en Twitter de tal forma que se propicie y se incentive el carácter multidireccional de la comunicación en las publicaciones sobre series con el fin de aprovechar el potencial del fandom televisivo.

* 119 - Los parlamentos, medios tradicionales y redes sociales y ONGs en los conflictos armados: Recomendaciones prácticas para los profesionales de la comunicación - María Rosa Berganza Conde - URJC.) - rosa.berganza@urjc.es, Roberto de Miguel Pascual - URJC. Madrid - roberto.demiguel@urjc.es, Fátima Gómez Buil URJC. Madrid - fatima.gomez@urjc.es y Marcos Mayo Cubero - Universidad Nebrija. Madrid mmayo@nebrija.es

En el presente trabajo parte de una investigación sobre el desarrollo de distintos conflictos armados de la última década en lugares como Congo, Burundi y la guerra civil de Siria -considerado el conflicto bélico más mediatizado de la historia- y la forma en la que transmiten la información sobre ellos a la opinión pública nacional e internacional los periodistas, los medios sociales, las ONGs y los políticos. Estos actores desempeñan un importante papel en la construcción de las agendas públicas y políticas (que en este trabajo observamos a través de los debates en cinco parlamentos europeos) y en la elaboración de discursos y políticas, encaminados y orientados a fomentar la paz y la prevención de la violencia o, en caso contrario, a su instigamiento. Por esta razón, en este estudio se abordan una serie de implicaciones prácticas para los profesionales de la comunicación, provengan de los medios de comunicación, redes sociales, ONGs o de instituciones políticas. 
El propósito es contribuir a la mejora de la información que rodea el desarrollo de los conflictos armados y el período posterior que les sucede buscando como objetivo la prevención y la paz. En esta línea, incluimos también una revisión de los trabajos realizados previamente sobre la materia. En este trabajo, entre otras recomendaciones, abogamos por la difusión informativa que se hace de los conflictos bélicos contemple una visión holística del problema y tenga a su vez la capacidad de transmitir mecanismos de resolución de los problemas que ayuden a fomentar la paz y la resolución de dichos conflictos.

* 120 - Alimentación, nutrición y nuevas maneras de comunicar: el caso de Carlos Ríos en Instagram - Iñigo Marauri Castillo Inigo.marauri@ehu.eus, María del Mar Rodríguez González Mariadelmar.rodriguez@ehu.eus, Flora Marín Murillo Flora.marin@ehu.eus e Ignacio Armentia Vizuete Ignacio.armentia@,ehu.eus - Universidad del País Vasco/Euskal Herriko Unibertsitatea (UPV/EHU)

La consolidación de las redes sociales como plataforma de información es un hecho. Dentro de las principales opciones que tiene a su disposición la comunidad de usuarios, Instagram ha experimentado un notable crecimiento en todo el mundo. Y España no es una excepción. Tal y como constatan diferentes estudios, este aumento de su uso es mayor entre los grupos de edad más jóvenes. En una red en la que, como es el caso, prima la imagen, las cuestiones relacionadas con la apariencia y el cuidado del aspecto personal tienen especial protagonismo. Entre ellas se incluye la alimentación y la nutrición. En el caso español, hay un especialista en nutrición, Carlos Ríos, que ha logrado sobresalir gracias al éxito en Instagram de su cuenta y del movimiento que ha bautizado como Realfooding. El objetivo del estudio preliminar que se presenta en esta investigación es identificar las claves de creación de contenido y de gestión de la red que ayuden a explicar los resultados obtenidos por este influencer.

* 121 - Caricatura política y agenda mediática en Ecuador Villalva, Tania - Universidad Politécnica Salesiana, Ecuador tvillalva@ups.edu.ec, Romero, Pablo-Universidad Politécnica 
Las nuevas narrativas, en el entorno social

Salesiana, Ecuador - promerrog@ups.edu.ec y Villagómez, Patricia - Universidad Politécnica Salesiana, Ecuador pvillagomez@ups.edu.ec

El presente artículo es parte del trabajo del Observatorio de Medios de la Carrera de Comunicación de la Universidad Politécnica Salesiana Sede - Quito; pretende analizar la cobertura noticiosa de las secciones de actualidad, política y seguridad, para determinar la agenda mediática de los medios impresos El Comercio y El Universo, en el marco del gobierno de Lenín Moreno; Gobierno de transición entre el populismo de izquierda a un escenario político marcado por el retorno de un gobierno de corte neoliberal; y su relación con la caricatura política publicadas en los mismos medios.

La construcción conceptual se caracteriza por interrelacionar las categorías de Medios y Política en función de la cosntrucción de la Agenda Setting y la Caricatura Política; para ello se espera lograr trabajar desde la triangulación metodológica, que especifica el levantamiento de información partiendo de una matriz de análisis que permita identificar las temáticas recurrentes en los medios y contrastarlo con la representación gráfica de la caricatura.

* 122 - Las prácticas en empresas periodísticas en España y

Noruega: resultados preliminares de un estudio comparativo García-Borrego, Manuel - Universidad de Málaga manoletus@uma.es, Córdoba-Cabús, Alba - Universidad de Málaga - albacordoba@uma.es y Gómez-Calderón, Bernardo Universidad de Málaga - bjgomez@uma.es

Esta comunicación presenta los resultados preliminares de un proyecto de estudio comparativo entre las prácticas en empresas periodísticas en España y Noruega. El método elegido para recabar los datos fue la encuesta, que se distribuyó en la Universidad de Málaga ( $n=55)$ y en las de Bergen y Stavanger ( $\mathrm{n}=7$ ) a lo largo del curso académico 2018-2019. Las prácticas desarrolladas en España fueron extracurriculares —es decir, voluntarias y paralelas a los planes de estudios-, mientras que en Noruega se optó por las curriculares — de carácter obligatorio y las únicas disponibles durante su etapa de formación-. En términos 
económicos, las prácticas curriculares en Noruega, sin remuneración en España, llevaban aparejadas una ayuda que triplicaba la de las extracurriculares de Málaga (una media de 1.209,43 euros mensuales1, con mínimos de 986,88 y 1.408,78 euros, frente a los 375,71 de Málaga). Este tipo de prácticas en Noruega tenían lugar durante los meses lectivos y solían derivar en un contrato laboral para el período estival —así ocurrió en cinco de los siete casos estudiados- que oscilaba entre los $2.664,59$ y los 3.521,89 euros (media=3.213,53).

La jornada habitual de los alumnos noruegos se movía entre las 7 y las 9,5 horas (media =8,07), por encima de las 6,11 de promedio de Málaga y equiparables a las de un redactor sénior, aunque en ellas no sobrepasaban las dos piezas realizadas (media $=1,17$ ) frente a las 4,11 de los estudiantes de la UMA. Las condiciones y rutinas señaladas por los estudiantes apuntan a diferencias de calado entre ambos modelos de prácticas, cuyo estudio en profundidad puede resultar de utilidad para mejorar el funcionamiento de las estancias en empresas españolas. 1 Los encuestados respondieron por su salario en coronas noruegas (NOK). Las equivalencias en euros se han extraído del conversor de Google a partir de los datos de Morningstar el 16 de octubre de 2019 a las 11.32 horas.

* 123 - El Periodismo de datos y el uso de cifras. Acceso, tipos y representación de la información - Alba Córdoba-Cabús Universidad de Málaga - albacordoba@uma.es y Manuel García Borrego - Universidad de Málaga - manoletus@uma.es

El Periodismo de Datos es una herramienta empleada por el periodista en cualquier área temática con el propósito de extraer información de grandes conjuntos numéricos y presentarlo a la audiencia de una manera atrayente implicándola en el proceso comunicativo. Se trata de un instrumento en constante evolución, debido al surgimiento incesante de nuevos programas y técnicas, que requiere ser sometido a evaluación continua para seguir desarrollándose como práctica periodística.

A través de un análisis de los proyectos nominados a los Data Journalism Awards 2019 -otorgados por la Global Editors Networks 
y considerados como el mayor reconocimiento-, se pretende examinar el sustento principal de estos trabajos: los datos, con la finalidad de conocer su naturaleza, su tipología, el modo de acceso y la forma de presentación.

Del análisis de contenido $(\mathrm{n}=42)$ se desprende el amplio uso de cifras emitidas por fuentes gubernamentales u oficinas públicas (59,5\%), siendo en su mayoría datos demográficos $(35,3 \%)$ y de localización (33,3\%). La gran parte de los proyectos tratan la información a escala nacional $(54,7 \%)$, recabando menor visibilidad aquellos que cubren temas locales, regionales o hiperlocales. Los resultados evidencian el amplio uso numérico para mostrar conexiones y flujos $(57,1 \%)$, así como para trazar cambios en el tiempo (52,3\%). La infografía es, junto con el análisis textual (59,5\%), el modo de representación más usual $(45,2 \%)$. Asimismo, se detecta que la entidad tiende a premiar a aquellos proyectos que apuestan por datos recopilados por la propia organización (en el 37,5\% de los premiados se emplea este tipo).

La identificación de patrones en lo relacionado a las cifras permitirá plantear acciones que repercutan en una mejor práctica del Periodismo de Datos, permitiendo, a aquellos que pretendan concurrir a este galardón, descubrir qué uso se hace de ellas y cuál es la valoración otorgada por el comité evaluador.

* 124 - Aprendizaje Social entre jóvenes mexicanos consumidores de Cereales Ultraprocesados y su papel en la Sociedad Civil Organizada - Mtro. Ricardo Ignacio Prado Hurtado - Director de Servicios Creativos de MostroTown Publicidad, Profesor de la Universidad Anáhuac México - rprado@mostrotown.com.mx - Mtro. José Luis Flores Torres - Profesor de la Universidad Anáhuac México - jluisflorest@hotmail.com

El objetivo del presente trabajo tiene como fin señalar un posible cambio de actitud en jóvenes consumidores de publicidad de Cereales Ultraprocesados (CUP) en redes sociales digitales y el papel de las campañas de contrargumentación que se gestan desde la sociedad civil organizada, especialmente desde las ONG protectoras de los derechos del consumidor. En particular la presente investigación tiene como 
objetivo analizar el nivel de influencia de las ONG en las reacciones que los jóvenes desarrollan actualmente frente a la publicidad de CUP que identifican como engañosa.

Como se observará durante el presente estudio la publicidad de CUP frente a las campañas de las ONG protectoras de los derechos del consumidor es solo el escenario para el despertar de un grupo de jóvenes que están, por un lado, en un modelo de aprendizaje social sobre los estilos de vida propuestos por la publicidad y por otro reaccionando de diferentes maneras frente a los mensajes que identifican como engañosos reconociendo que su salud se está viendo afectada.

Esto parece presentar una contradicción, sin embargo, es en el mundo de las redes sociales digitales es donde el fenómeno empieza a gestarse y este grupo de jóvenes empiezan a contagiar a sus pares sobre un problema social que hoy en México ha rebasado al sistema de salud pero que puede, a través de la prevención desde la comunicación ser la punta del iceberg de un fenómeno mucho más potente en contra de las prácticas publicitarias que fomentan el consumo de ingredientes que pueden resultar nocivos, aun en pequeñas cantidades.

* 125 - La integración en la lógica de trabajo conjunta propia de los medios de comunicación a través de los proyectos colaborativos en las asignaturas prácticas - Silvia Magro-Vela Universidad Rey Juan Carlos, URJC, España silvia.magro@urjc.es, Roberto Gelado Marcos - Universidad San Pablo CEU, España - roberto.geladomarcos@ceu.es y Nuria Navarro Sierra - Universidad Rey Juan Carlos, URJC, España - nuria.navarro.sierra@urj.ces

El presente trabajo destaca la relevancia en la articulación de módulos de trabajo cooperativo a través de la creación de proyectos en las asignaturas prácticas para la adquisición y fortalecimiento de las competencias sociales propias de los diferentes perfiles profesionales dentro de los medios de comunicación. 
Mediante la utilización de una metodología clásica, como es el aprendizaje a través de la realización de ejercicios prácticos que permitan la consolidación de conceptos teóricos, se busca introducir un componente propio de la lógica empresarial. De esta manera, se motiva la capacidad creativa del alumno en el proceso de producción de sus ideas, se fomenta la función dialógica entre los distintos roles en el desarrollo del trabajo en situaciones similares a la realidad profesional. Por otro lado, los grupos de deberán integrarse en un sistema de trabajo de nivel superior, donde el desempeño de sus funciones es imprescindible para el buen funcionamiento y éxito del proyecto colectivo, creando un marco en el que priman valores como la responsabilidad y el compromiso. En resumen, una práctica mejorada para la vehiculación de destrezas necesarias en el ejercicio de los diversos perfiles de los profesionales comunicativos.

* 126 - El Branding OnLine: La creación de un espacio para las marcas en Internet - Juan Francisco Álvarez Sigüenza Universidad de Cádiz - E-mail: juan.alvarezsi@alum.uca.es

El branding online o marca digital se ha convertido en parte fundamental de la comunicación de las marcas actuales para darse a conocer y ampliar mercado en el entorno digital, esta publicidad más evolucionada que la tradicional está compuesta por el conjunto de factores que la forman, es decir, Internet - marca - emisor - usuario, por tanto se podría definir como "el proceso de transformar un sitio web en una experiencia [...] única por la calidad de su diseño, por la utilidad y usabilidad de sus contenidos y por la simple y eficaz lógica funcional en la navegación e interacción" (Ros, 2008). Encuentran en los procesos de comunicación 2.0 la posibilidad de construir, captar y fidelizar a sus públicos, parte imprescindible para el crecimiento de las marcas en el mundo de Internet "representado por la tendencia creciente a construir un vínculo personalizado, significativo e influyente con los usuarios, a través de la e-brand" (Pol, 2015); la 2.0 permite conocer de primera mano la opinión del usuario y el valor del símbolo empleado o en palabras de Vicente Ros haciendo que sea una "experiencia real de todos los públicos objetivos cuando entran en contacto con la marca". El e-branding llega a los públicos a través de las emociones por su color, diseño o contenido, por tanto produce así 
el efecto deseado por los anunciantes "como una forma de diferenciarse con respecto a la competencia, ofreciendo al usuario la posibilidad de acceder a experiencias visuales llamativas. (Morales y Andrés, 2012) Se pueden encontrar los E - branding ejemplarizados en diferentes marcas con carácter netamente digital, es decir, que su funcionamiento y contenido son de naturaleza digital, como es la Red Social Facebook, las páginas web como Badoo y Booking o compañías como Yahoo, Google.

* 127 - Talleres tipográficos: aplicación de un aprendizaje práctico en torno a uno de los elementos básicos del diseño gráfico Nuria Navarro Sierra - Universidad Rey Juan Carlos, URJC, España - nuria.navarro.sierra@urjc.es, Laura González Diéz Universidad San Pablo CEU, España - design@ceu.es y Belén Puebla Martínez - Universidad Rey Juan Carlos, URJC, España - belen.puebla@urjc.es

La propuesta que presentamos busca concienciar a los alumnos, que cursan grados relacionados con la comunicación, de la importancia de la tipografía como atributo básico del diseño gráfico y su potencial como instrumento eficaz de comunicación, con independencia del soporte utilizado. Para ello se proponen talleres y actividades a través de los cuales los alumnos puedan comprender que se trata de un atributo esencial en la construcción de cualquier diseño gráfico, ya que forma parte de una disciplina transversal a todas las áreas.

Con este punto de partida se aplica una metodología que busca, mediante un aprendizaje práctico activo, la mejora de la docencia: fomentar que el alumno llegué a comprender el significado del proceso tipográfico y conceda a la elección de la tipografía el valor que se merece, prestándole atención y dedicando tiempo para saber cuál es la más adecuada según el tipo de trabajo gráfico que se vaya a realizar y el público objetivo al que se dirija, no dejándose llevar por gustos personales.

Como punto de partida, se ha tomado la idea de James Victore, un diseñador gráfico cuya obra se expone el MoMA, y que organiza safaris tipográficos en NY. Estos safaris adaptados a las aulas favorecen que 
el alumno participe de primera mano y entienda lo que significa una tipografía, las características de las diferentes familias, y las difer

* 128 - Las brechas digitales: la reproducción de las seculares desigualdades sociales - Vicente Baca Lagos. Profesor Titular de Universidad, Universidad Complutense de Madrid. Email: vicbaca@ucm.es

El cambio social al que ha contribuido el desarrollo de Internet en los últimos 25 años, según algunos autores, tiene un alcance tan profundo y general como el que se produjo con el surgimiento de la Sociedad Industrial. Sin embargo, esta nueva Sociedad digital o Sociedad red no parece que apunte a terminar con las desigualdades sociales que impuso aquel orden social que surgió tras la liquidación del antiguo régimen en Europa Occidental, en el tránsito del siglo XVIII al XIX. Las brechas digitales actuales (de género, edad, nivel de estudio, renta y lugar de residencia) continúan reproduciendo las seculares desigualdades sociales. Más aún, por la complejidad de la transformación social en curso y la naturaleza de los principales actores globales que la promueven, cabría pensar que tales brechas sociales se vean incrementadas, si no se adoptan las políticas públicas adecuadas. Los problemas iniciales son el acceso a Internet y la velocidad de conexión, desde luego; pero, luego están la disponibilidad de los distintos servicios que ofrece la red, el grado de aptitud de los actores para aprovecharlos y los usos sociales concretos de dichas tecnologías de la información y la comunicación, que hacen posible la orientación de los cambios sociales, económicos y culturales en el sentido que más interese a la mayoría de los ciudadanos.

En esta ponencia se ofrecen datos sobre la situación en España y su contexto internacional, provenientes de una investigación $\mathrm{I}+\mathrm{D}$ en la que se ha indagado sobre este y otros temas, basados en una muestra representativa de usuarios de internet españoles, así como de fuentes secundarias.

* 129 - Aplicación de estrategias de storytelling para la docencia universitaria en el campo de la Comunicación - Roberto Gelado-Marcos - Universidad San Pablo CEU, España - 
roberto.geladomarcos@ceu.es y Silvia Magro-Vela Universidad Rey Juan Carlos, URJC, España silvia.magro@urjc.es

El campo de la comunicación de masas ha experimentado un viraje en los últimos años hacia el empoderamiento del consumidor y su reposicionamiento hacia un rol más activo. En palabras del antiguo director de la BBC Mark Thompson, las audiencias ya no quieren recibir pasivamente contenidos, sino debatir, crear, comunicar y compartir (en Rosen, 2012, p. 16). Todo ello se ha traducido en un incremento de las posibilidades de interacción que ha cambiado el perfil no solo de los consumidores de contenidos mediáticos, sino también en el ámbito académico, cuya audiencia también procesa información (e interacciona con ella) de un modo distinto a generaciones anteriores.

La presente comunicación explora el potencial del storytelling como respuesta a este perfil renovado del alumnado de los estudios universitarios, con especial énfasis en las asignaturas relacionadas con la comunicación. Para ello, se aborda, en un principio, el estudio de las características de este nuevo perfil de universitario y, a continuación, se exponen elementos retóricos y estructurales del storytelling que pueden encontrar su acomodo en este nuevo contexto pedagógico. Finalmente, y como resultado de todo este planteamiento teórico, se exploran posibles aplicaciones prácticas de todos estos recursos en el aula.

* 130 - Radio Loma: una experiencia de comunicación para el cambio social por medio de voces y sonidos - Diana Carolina Velasco - Universidad Autónoma de Occidente dianisvelasco4@gmail.com y Diana Lorena Granja Universidad Autónoma de Occidente diana.granja@uao.edu.co

En esta ponencia presentamos la historia de Radio Loma de la Cruz, una experiencia de capacitación en producción radiofónica que desarrollamos con artesanos y poetas del Parque Artesanal Loma de la Cruz, lugar catalogado como hito histórico y cultural de la ciudad de 
Las nuevas narrativas, en el entorno social

Cali, Colombia. Durante un año, impartimos una serie de talleres que dieron lugar al colectivo Radio Loma de la Cruz, iniciativa de los participantes para seguir haciendo radio en el Parque Artesanal.

A partir de allí, realizamos una sistematización y análisis de la experiencia, que nos da como resultado un claro ejemplo de lo que Alfonso Gumucio describe como comunicación para el cambio social, pues con Radio Loma logramos demostrar que fue un proceso ideado por la comunidad, de manera que nos solo respondió a sus necesidades, sino que también generó aprendizajes para nosotras y para el campo de investigación en comunicación.

Así, en nuestra ponencia primero haremos una reconstrucción de la experiencia, destacando los aprendizajes adquiridos por ambas partes. Luego presentaremos el ya mencionado análisis a la luz de los planteamientos de Gumucio, donde se demuestra que la teoría puede llevarse a la práctica con experiencias sencillas de gran impacto y se destaca la apropiación de la comunidad al seguir haciendo radio por su cuenta, aplicando lo aprendido y proponiendo cosas nuevas según su entorno y sin presencia permanente de las investigadoras.

Y finalizamos contando cómo Radio Loma, más que un proyecto nuestro, fue en realidad un trabajo colectivo en el que ambas partes aportaron y recibieron. Además, a lo largo de nuestra exposición presentamos las voces de la comunidad y algunos productos radiales resultado de esta experiencia.

* 131 - Desafíos del sector audiovisual independiente y comunitario de Bogotá en el contexto definido por la Ley Naranja - Leidy Julieth Gómez Uribe - Universidad Autónoma de Barcelona, Doctorado Medios, Comunicación y Cultura leidy.gomez.u@gmail.com

La economía naranja es un término creado por Buitrago y Duque (2013), con el apoyo del Banco Interamericano de Desarrollo (BID), para promover el desarrollo de las industrias creativas en América Latina y el Caribe. En consonancia con lo plateado por estos autores, en 2017 Colombia aprobó la denominada Ley Naranja la cual ha 
despertado una serie de inquietudes por parte del sector cultural referidas a las consecuencias que puede traer este enfoque, donde la producción cultural está determinada principalmente por las lógicas del mercado. El gobierno de la ciudad de Bogotá ha creado una serie de proyectos culturales y urbanísticos que recogen la iniciativa de la Economía Naranja. Según la Cuenta Satélite de la Cultura y Economía Naranja de Bogotá 2014-2018, "el segmento audiovisual aporta el 62,6\%" (DANE, 2019) del valor agregado del área de las industrias creativas, por ello este estudio se enfoca en él y, en particular, se interesa por aquellas organizaciones de carácter independiente y comunitarias de la ciudad de Bogotá que plantean su quehacer desde la promoción de la participación social, la autonomía, la creatividad, la diversidad cultural, la democratización y búsqueda de la reducción de las desigualdades. De acuerdo con lo anterior, este trabajo tiene por objetivo proponer acciones y políticas públicas encaminadas a mejorar las condiciones del sector audiovisual independiente y comunitario de Bogotá frente al desafío de la economía naranja. Para ello se ha construido una propuesta metodológica en tres fases: primero, un análisis de las políticas públicas nacionales y locales con este enfoque; segundo, un diagnóstico de carácter participativo con las organizaciones de este subsector $\mathrm{y}$; tercero, entrevistas semiestructuradas con líderes de opinión y funcionarios públicos a cargo de la implementación de las políticas públicas.

* 132 - TIC y accesibilidad cognitiva de personas con discapacidad en los principales museos españoles - Juan Enrique Gonzálvez Vallés -Universidad Complutense de Madrid- jegonzalvez@ucm.es, Mónica Viñarás Abad Universidad CEU San Pablo- monica.vinarasabad@ceu.es y Sofía del Pozo Ramos -Universidad CEU San Pablos.pozo2@ceu.es

El acceso a la cultura y las tecnologías de la información y la comunicación (TIC) es un derecho universal de todas las personas, independientemente de sus características o habilidades. El objetivo de este trabajo es analizar la accesibilidad cognitiva de las páginas web de los museos españoles, mediante una metodología descriptiva y deductiva, que busca comprender todos los requisitos que deben 
cumplir los entornos para poder ser accesibles para personas con discapacidad intelectual, identificando las mejores prácticas, y finalmente, analizar cada caso para definir las prácticas que mejor facilitan su acceso. Los museos españoles cumplen una parte de las recomendaciones establecidas para facilitar un acceso cognitivo, sin embargo, aún son muchas las mejoras que deben aplicarse a dichas páginas para poder considerarse plenamente accesibles. Ninguna de las páginas cumple los requisitos de las pautas WCAG y bastantes son las mejoras que pueden aplicarse para facilitar la comprensión del contenido, ya que ni si quiera es utilizada la lectura fácil como recurso.

* 133 - El estatus de la comunicación como función directiva de la gestión estratégica de las organizaciones: ¿lugar merecido u otorgado? - Dr. Mariana Sueldo - Universidad de Vilnius, facultad de Comunicación (Lituania) - ISM University of Management and Economics (Lituania) marianasueldoluque@gmail.com

Un genio del management hace más de 50 años declaró que "el 60 \% de los problemas empresariales son consecuencia de una mala comunicación" (Drucker, 1967). Aún hoy seguimos citándolo por su indiscutible actualidad y aplicabilidad a todas las organizaciones, sin cuestionar demasiado la fórmula que arrojó éste cálculo porcentual. Lo cierto es que las organizaciones surgen de una interacción, por tanto su raíz es comunicacional (Formanchuk, 2010). Cabe preguntarse por qué en pleno siglo 21 todavía existen tantas organizaciones donde la comunicación opera a nivel meramente táctico, o incluso otras instituciones con escasos indicios de una comunicación gestionada, y menos aún integrada en la estrategia global de la organización.

Mediante el presente trabajo se comparten los resultados empíricos obtenidos a través de entrevistas en profundidad (semiestructuradas y no estructuradas) con expertos en gestión de la comunicación, consultores, académicos, ejecutivos superiores y mandos intermedios de Argentina, España y Lituania. Algunos informantes justifican la frecuente opción por la comunicación externa cortoplacista orientada a resultados más tangibles y medibles. Otros, aunque conscientes del potencial oculto en la comunicación integral bien gestionada, la tienen 
en su lista de pendientes para tiempos mejores. Gestores y expertos en comunicación reflejan el recorrido que han de hacer para alcanzar y mantener el rol estratégico de un trabajo comunicacional más integral, con un valor que se revelará a largo plazo aportando sustentabilidad a toda la organización.

Considerar la comunicación como una función directiva esencial y merecedora de voz y voto en la gestión estratégica de la organización debería ser un corolario que inspire la apuesta efectiva y favorable de la alta gerencia. La comunicación funciona para aquellos que la trabajan (Powell, J. en Rey, A. 2006) siempre que se den las condiciones para una labor visiblemente integrada en la estructura organizacional junto a las demás funciones estratégicas.

* 134 - Comunidades virtuales: Nuevos espacios de convivencia ciudadana - Juan Francisco Álvarez Sigüenza - Universidad de Cádiz - E-mail: juan.alvarezsi@alum.uca.es

Las Comunidades Virtuales generadas entorno a las Redes Sociales, se mueven en un espacio creado por los ciudadanos, dejaron de ser lugares físicos de reunión o de convivencia a ser ocupados por el espacio virtual dentro del universo Internet. La creación de espacios ha acompañado al ser humano desde sus principios, en palabras de Lefebvre "Platón ha descrito maravillosamente el espacio cósmico y el espacio de la ciudad, imagen del Cosmos" esta cita como si de una premonición se tratase por parte de del autor, trasladada a día de hoy, existen similitudes entre "Ciudad como espacio físico" y "Espacio cósmico como Universo Internet", diferenciados por miles de años existen paralelismos en cuanto a las transformaciones sufridas en las ciudades actuales por parte de Internet del mismo modo que la similitud descrita por Plantón en que las ciudades son transformadas como reflejo del cosmos, por lo que se podría decir que ambos fenómenos "ciudad e Internet" se han convertido en lugares de coexistencia y convivencia "se trata de resaltar la relativa autonomía y capacidad de agencia que adquieren esos objetos sumados al mundo por los seres humanos, en el sentido de cosas y acciones nuevas con las que hemos coproducido el entorno construido que es la ciudad" (Salazar, 2013). Se podría decir que "desde la perspectiva del 
conocimiento, el espacio social [...] como instrumento de análisis de la sociedad" (Lefevre, 2013) la construcción de estos nuevos espacios a lo largo de la historia y actualmente con las comunidades virtuales son claro reflejo del funcionamiento de la social actual e incluso estos espacios virtuales se encuentran insertos en las estructuras gubernamentales, familiares, culturales, etc.

* 135 - Los desafíos del comercio electrónico para las personas mayores: Percepciones, usos, motivaciones y frenos - Carmen Llorente Barroso - Universidad Complutense de Madrid carmenllorente@ucm.es, María Sánchez Valle - Universidad CEU San Pablo - mvalle.fhum@ceu.es y Marilé Pretel Jiménez Universidad CEU San Pablo - marilepretel@gmail.com

El progresivo envejecimiento de la población obligará a los estados a la implementación de planes que garanticen la inclusión de los mayores. En Europa, el porcentaje de personas de 65 o más años se incrementará del 18\% en 2019 al 29,3\% en 2100 (United Nations, 2019). Aunque el INE (2018) indica una significativa reducción de la brecha digital generacional en España, se perciben notables diferencias en el tipo de consumo tecnológico que excluyen a los mayores de determinadas esferas digitales. Así, solamente el $12 \%$ de las personas de entre 65 y 74 años compraron online en los últimos tres meses, frente al $60,9 \%$ de las personas entre 25 y 34 años (INE, 2018). Entre los frenos que limitan el uso del e-commerce destacan la desconfianza en la plataforma y el riesgo percibido en el tratamiento de sus datos (Palvia, 2009; Chen \& Dhillon, 2003), mientras que las motivaciones aparecen vinculadas a la comodidad de esta forma de compra (Curran et al., 2008; Llorente-Barroso et al., 2018).

El objetivo de esta propuesta es explorar las percepciones que los españoles mayores de 60 años tienen sobre el e-commerce, con el fin de conocer sus experiencias y expectativas respecto a su uso. Para ello, se ha planteado una metodología explicativa, fundamentada en cuatro focus group constituidos por individuos de 60 y más años, internautas y con interés por llevar una vida autónoma y activa. El análisis de sus discursos experienciales demuestra una considerable desconfianza en el comercio electrónico, indicando como freno más destacado el miedo 
a ofrecer sus datos bancarios. Los mayores que declaran un uso del ecommerce, reconocen que comenzaron a utilizarlo con ayuda, y que sus experiencias se focalizan en compras sencillas. En general, manifiestan una percepción positiva sobre el e-commerce, si bien, sus miedos les limitan en su aprovechamiento.

* 136 - Estrategias digitales para ganar elecciones presidenciales. Caso de los candidatos Iván Duque y Gustavo Petro en las elecciones Colombia 2018. - Marcela López Ponce Universidad de la Costa - mlopez38@cuc.edu.co, Hada M. Sánchez Gonzales - Universidad de Sevilla - misago@us.es, Daniel Barredo Ibáñez - Universidad del Rosario daniel.barredo@urosario.edu.co y Javier Martos Moreno Universidad de Sevilla -javiermm94@gmail.com

Las redes sociales se han constituido en una de las principales herramientas de comunicación política. Las plataformas digitales son el escenario donde los aspirantes a altos cargos gubernamentales crean y desarrollan estrategias para posicionar sus candidaturas, y así, conseguir adeptos con el fin de ganar las elecciones democráticas. Por ello, con el objetivo de identificar y comparar las estrategias digitales que los candidatos Iván Duque y Gustavo Petro utilizaron durante la campaña electoral a la presidencia de Colombia en el 2018, para obtener la mayor votación en la primera vuelta presidencial. A través de entrevistas hechas a profundidad a los asesores digitales de las campañas de estos candidatos, comparamos las acciones aplicadas y su relación con los usuarios. Los resultados arrojaron conceptos y categorías entre las que se destacan el acompañamiento a la agenda del candidato, la divulgación de los planes de gobierno en formatos adecuados según el público al que van dirigidos, así como, acciones específicas para el manejo de crisis. También, se encontraron argumentos opuestos sobre la red social que permite obtener más adeptos, mientras que para una campaña lo es Facebook y YouTube, para la otra, lo es Twitter. Las conclusiones muestran la pertinencia de la gestión de un plan de acción estratégico para posicionar la imagen de los candidatos, así como, la necesidad de la creación de contenidos acordes al público objetivo y a la dinámica de cada una de las redes sociales. 
* 137 - La mejora del diseño interactivo de Apps para niños con Necesidades de Aprendizaje Diversas - Mariona Grané Ph.D. Associate Professor, Universitat de Barcelona Mundet Campus - mgrane@ub.edu, Lucrezia Crescenzi-Lanna Ph.D. Associate Professor Universitat de Vic - Universitat Central de Catalunyalucrezia.crescenzi@uvic.cat tel y Rafael Suárez - Ph. D. Associate Professor Tecnocampus Mataró Lluch rsuarezg@tecnocampus.cat

Esta investigación se centra en el diseño interactivo de aplicaciones para su uso en dispositivos móviles y dirigidas a niños pequeños con necesidades educativas especiales. Los resultados de este análisis detallado del contenido y del diseño interactivo se han llevado a cabo con una muestra de 55 aplicaciones diseñadas para atender diferentes necesidades especiales que han sido calificadas como buenas o muy buenas por bases de datos y clasificaciones internacionales independientes. Las Apps se han estudiado en términos de sus características de diseño audiovisual e interactivo, con especial énfasis en sus características de accesibilidad y analizando cuán adaptables son al usuario segun su desarrollo. Los resultados del estudio exponen una falta de conciencia de los desarrolladores en relación con el diseño de aplicaciones para niños con necesidades de aprendizaje diversas, sus condicionantes y sus capacidades específicas. El estudio también examina las implicaciones de estos hallazgos con referencia al diseño audiovisual y de interacción de las aplicaciones, además de su contenido, y cualquier posible efecto sobre cómo los niños podrían usarlas. La tecnología no debería ser un problema para los niños, de hecho, debería ser una oportunidad para la autoexpresión, la comunicación, el juego, la creatividad y el desarrollo de su conocimiento. Garantizar la calidad y la accesibilidad de los recursos móviles para todos los niños les permitirá aprender desde sus fortalezas utilizando sus mejores habilidades.

* 138 - Deporte, ética y publicidad: el caso de Carrusel Deportivo y los anuncios de apuestas deportivas - Javier de Sola Universidad de Zaragoza - jdesola@unizar.es 
Con el debate de si es necesario prohibir la apertura de más locales de casas de apuestas como telón de fondo, las cifras de negocio de las empresas de juego en línea, y especialmente las centradas en las apuestas deportivas, se multiplica. Tanto, que en los últimos años sus inversiones en márquetin rondan los 150 millones de euros. En este contexto, esta investigación analiza, en concreto, el protagonismo que los anuncios de las diferentes casas de apuestas tienen en uno de los programas de referencia de la radio española, el Carrusel Deportivo de la Cadena SER. El estudio, muy reciente y actual, puesto que está centrado en la primera jornada de Liga de Primera División de la presente temporada 2019/2020, atiende a cuestiones que van más allá de lo cuantitativo para profundizar en aspectos formales como los elementos del lenguaje radiofónico que componen esos anuncios, los protagonistas de los mismos, la (no) diferenciación en muchas ocasiones de los anuncios y la propia retransmisión deportiva o los estados de ánimo y acciones que invitan a adoptar con dichos anuncios. Los resultados revelan que, efectivamente, el protagonismo de los anuncios de casas de apuestas está a la altura de otros sectores que, tradicionalmente, han gozado de una posición privilegiada en el mercado de anunciantes radiofónicos.

* 139 - Cultura, sanidad, gobierno y participación ciudadana: El caso de "FICAE [nómada]: Las voces de los pacientes" - Dr. Ricard Mamblona Agüera y Dra. Ángeles Durán Mañes CESAG - Centro de Enseñanza Superior Alberta Giménez (Universidad Pontificia Comillas) Emails: rmamblona@cesag.orgy aduran@cesag.org

La presente comunicación pretende analizar la intervención e interrelación que se establece entre el sector público y aquellos proyectos culturales cuyo principal objetivo es el valor social obtenido, en gran medida, a través de la participación de la propia ciudadanía. Para evaluar los detalles de esta confluencia entre sectores, organismos y ciudadanía, nos centraremos en el proyecto "FICAE[nómada]: Las voces de los pacientes", realizado en Mallorca en varias fases, de octubre de 2018 a junio de 2019, y cuyo máximo objetivo era el de vincular asociaciones de pacientes y agentes sanitarios a través del cine. La gran peculariedad de este proyecto fue que los ejes temáticos, los 
cortometrajes a proyectar y la confección de las mesas de debate fueron seleccionados y establecidos de forma colaborativa por miembros de asociaciones de pacientes a través de un proceso de dinamización de grupos.

"FICAE[nómada]: Las voces de los pacientes" contó con la financiación del Ajuntament de Palma en una primera instancia y, posteriormente, con la del Govern de les Illes Balears. Además, se llevaron a cabo sesiones temáticas y proyecciones en los 4 hospitales públicos de la isla, así como en centros culturales de carácter público. Por otro lado, y como parte importante de análisis para esta investigación, la ayuda pública no fue exclusivamente económica, sino que fue también participativa, en cuestiones logísticas y organizativas a través de diferentes programas e instituciones internos, y en términos de comunicación, a través de sus propias herramientas de difusión e interacción con los medios de comunicación y usuarios.

* 140 - La radio universitaria como escenario de investigación: una mirada desde Nuestro rollo - Jenny Marcela Rodríguez Rojas-Universidad Santo Tomás, Instituto de estudios sociohistóricos fray Alonso de Zamora jennyrodriguezr@usantotomas.edu.co jennymarcelarodriguez@gmail.com

Para las personas que pertenecemos a escenarios educativos formales es común escuchar que los estudiantes no leen y que esa situación desencadena problemas en la argumentación y claro, en la investigación. Sin embargo, las actividades llevadas a cabo por el semillero Mareiwa dan cuenta que estos jóvenes ya no son de la tecnología del libro o de las narrativas escritas, sino de la era de los medios, mediaciones y narrativas audiovisuales; este equipo de investigación formativa rompió el estereotipo inicialmente planteado llevando un proceso de aprendizaje en investigación en el que además del texto escrito se tenían en cuenta otras narrativas como el cine, la fotografía, la ilustración y la radio.

Como resultado del ejercicio investigativo en temas relacionados con las humanidades los estudiantes y docentes crean en 2016 el programa 
radial Nuestro Rollo, un magazín donde se discuten temas relacionados con la investigación de Mareiwa además otros temas cercanos a su cotidianidad dejando ver que la manera en que la viven y expresan ya no puede ser comprendida desde una mirada unilateral, en ello consiste la ruptura, intereses y comprensiones nuevas de la realidad. Entonces, el espacio radial se volvió un escenario donde pueden conversar libremente de esas temáticas e inquietudes propias bajo tres ejes; cine, literatura y música contando con la participación de invitados conocedores del tema central, con lo cual se extiende la discusión a personas fuera de su entorno de formación profesional.

Este espacio radial continúa hasta la fecha y los estudiantes siguen considerándolo el medio más efectivo para dar a conocer sus ideas. En ese sentido, para el semillero Mareiwa su participación en la radio universitaria se establece como el medio cercano y efectivo para construir una VOz auténtica, incluso se puede afirmar que se resignifican las transformaciones y narrativas técnicas, tecnológicas y audiovisuales ya no solo consumiendo contenidos a través de apps sino creándolos a través de este espacio que permite otras narraciones. Si bien se han presentado desafíos desde el aprender el "idioma de la radio" hasta constar con el apoyo institucional, pasando por el crear una audiencia sólida, después de 100 programas creemos que es importante dar a conocer esta experiencia.

* 141 - Diseño de un programa de radio alternativa como herramienta educomunicativa y participativa para desmovilizados en proceso de reintegración en Cali - Richard Stiven Romero Tróchez - Universidad Autónoma de Occidente - richard.romero.10b@gmail.com y Juan Sebastián Cerón Lora - Universidad Autónoma de Occidente - jsc1722@gmail.com

Tras la firma del Acuerdo Final para la terminación del conflicto y la construcción de una paz estable y duradera, entre el Estado colombiano y la antigua guerrilla de las Fuerzas Armadas Revolucionarias de Colombia - Ejército del Pueblo, en septiembre de 2016, se acogieron más de 12 mil excombatientes a la ruta de la reincorporación tanto colectiva como individual en el país. Se estima que poco más de 200 de ellos se encuentran hoy día en la ciudad de 
Cali, siendo uno de los municipios urbanos con más recepción de exguerrilleros.

La presente investigación reunió tres excombatientes de la otrora guerrilla FARC-EP, ahora partido político denominado Fuerza Alternativa Revolucionaria del Común, FARC, pertenecientes al Consejo Nacional de Reincorporación, CNR, en la ciudad de Cali, para la elaboración en conjunto de una serie radial en formato podcast con el fin de mejorar sus procesos comunicativos y participativos, bajo la metodología de Investigación-Acción Participativa (IAP) y desde una radio democratizada.

El podcast Voces del Común es el resultado de cuatro capacitaciones teórico-prácticas sobre producción y realización radiofónica, elaboradas e impartidas por los investigadores durante un mes; su contenido, análisis y resultados se detallan en la ponencia. Pretende también, acercar a la academia hacia la implementación del Acuerdo Final en el marco de la reconciliación para lograr una convivencia pacífica que respete la diferencia, la inclusión y la participación.

* 142 - El activismo digital en Twitter y Facebook frente a los medios tradicionales. Estudio de caso del sismo del 19 de septiembre de 2017 en Ciudad de México - MC. Perla Janeth Charles Gómez - Facultad de Derecho y Ciencias Sociales, Universidad Autónoma De Tamaulipas perlacharles82@gmail.com

El activismo digital como lo define el Ministerio Tecnológico de la información y las telecomunicaciones es el ejercicio de la ciudadanía y del compromiso social mediante la participación activa en redes sociales de personas naturales o jurídicas, creando dinámicas de información, sensibilización, educación y movilización social usando la web. En esta participación entran las redes sociales Facebook y Twitter que si bien son dos interfaces en las cuales el activismo digital se desarrolla en ciertos ámbitos, como los desastres naturales y algún otro tipo de emergencia en la cual los usuarios de estas plataformas puedan emitir algún mensaje para obtener información o dar algún mensaje de apoyo. 
$\mathrm{El}$ presente trabajo se deriva de la tesis doctoral "El activismo digital en Twitter y Facebook frente a los medios tradicionales. Estudio de caso del sismo del 19 de septiembre de 2017 en ciudad de México"; de este se desprende un análisis comparativo entre el uso de las redes sociales en el 2017 y los medios tradicionales radio y televisión en el temblor del 1985. Esto parte de un análisis de las cualidades que fueron un parteaguas para que la cultura del activismo digital se desarrolle y se implemente en desastres naturales y situaciones de emergencia a futuro en México, tomando como base de estudio dos grupos: nuevos activistas y activistas consolidados.

* 143 - Feminismo en los Medios de Comunicación y Jóvenes Masculinos: un Estudio de Recepción Cinematográfica de "No Soy un Hombre Fácil” - Juan Pablo Osman - Universidad del Norte, Barranquilla, Colombia - osmanj@uninorte.edu.co y Nancy Gómez - Universidad del Norte, Barranquilla, Colombia -ngomez@uninorte.edu.co

Uno de los principales desafíos que enfrenta el feminismo contemporáneo es involucrar a los hombres jóvenes en la lucha por la igualdad de género. En este sentido, se ha debatido en torno a las posibilidades de los medios de comunicación como herramienta para crear en los jóvenes masculinos una mayor consciencia en torno a la presencia de actitudes sexistas en su cotidianidad. Esta investigación se centra en "No soy un hombre fácil" (2018), película francesa producida por Netflix y dirigida por la cineasta Éléonore Pourriat. El largometraje pertenece al tipo de narrativa de transformación corporal de los personajes y narra la historia de un hombre que es transportado a un mundo paralelo donde enfrenta la opresión diaria de las mujeres.

La crítica cinematográfica ha destacado que la película consigue expresarle a los hombres cómo sería vivir en una realidad donde se intercambia la jerarquía de género. En esta investigación, observamos el efecto de la película en un grupo de doce jóvenes hombres y cómo esta historia los motiva a reconocer la importancia y vigencia de la desigualdad de género. Basados en los resultados del estudio, nuestro argumento afirma que la película no logra crear una empatía entre los 
hombres jóvenes frente al sexismo cotidiano por dos razones fundamentalmente: primero, la narrativa construye un escenario situacional exageradamente fantasioso, lo que hace difícil para los participantes involucrarse con la transformación corporal de los personajes y sus puntos de vista. Segundo, en aquellos casos donde los jóvenes participantes aceptaron la fantasía de la transformación corporal, expresaron resistencia frente al relato afirmando que refuerza la dicotomía mujer / hombre. Concluimos la investigación discutiendo las posibilidades y limitaciones del recurso cinematográfico de la transformación corporal de los personajes como una herramienta narrativa que permita sensibilizar a los jóvenes frente a la desigualdad de género.

* 144 - La Comunicación de la crisis de la Policía de Seguridad Pública: Una contribución a la actividad operativa de la policía en Portugal - Nuno Ferreira - Instituto Superior de Ciências Policiais e Segurança Interna (njferreira@psp.pt) y José Gabriel Andrade - Universidade do Minho (jgandrade@ics.uminho.pt)

Esta investigación propone acercarse a la gestión de comunicación de crisis y hacer su encuadre con las ciencias policiales. Dos áreas distintas se entrecruzan en la actividad operativa de la policía, con énfasis en eventos multitudinarios, donde a veces ocurren incidentes con consecuencias en el nivel de la imagen, lo que provoca una situación de crisis. En esta investigación exploratoria, con un carácter cualitativo e interpretativo, se pretende comprender que las metodologías de gestión de la comunicación de crisis pueden aplicarse a la acción policial para que la legitimidad de la policía pueda reforzarse. El estudio se divide en dos partes, la revisión de la literatura y la investigación empírica. Los datos se recopilaron por meio de la encuesta con la participación de cuatro oficiales de la policía de seguridad pública y cuatro investigadores. Las entrevistas fueron transcritas y se analizó su contenido. Los resultados muestran que la Sociedad está cambiando constantemente, lo que crea desafíos para la ciudadanía y la actividad policial donde la sociedad en red es una realidad. Los resultados expresan que ninguna institución es inmune a una crisis y que su gestión es un proceso de contingencia y situación que requiere capacitación previa. En una situación de emergencia, la mayoría de las 
acciones que se toman son actividades de comunicación, por lo que su administración es un factor crítico para el éxito de la policía, como una institución bajo un escrutinio cercano (que funciona con medios sociales) y cuyas acciones dependen de la cooperación ciudadana.

* 145 - Parque huertero "La Gotera". Una mirada al tejido de siembra y encuentros de arte en Manizales, Colombia - Mora Sánchez, Andrés Mauricio - Universidad Nacional de Colombia - amoras@unal.edu.co

Entre la praxis de la gestión cultural es, usualmente, sistematizada una porción de la experiencia de la gestación de proyectos comunitarios: la interconexión de los actores, el impacto inmediato, las influencias globales, las mediaciones locales y la expectativa de las intervenciones realizadas, sensibilidades colectivas, entre otros aspectos. Con lo anterior, provocando reflexiones y vacíos respecto a la ejecución de una huerta urbana en inmediaciones de las universidades públicas en Manizales, Colombia, el parque huertero "La Gotera"; el contexto actual del abandono de la tierra urbana en Colombia, la desprotección de los líderes sociales ambientalistas y la digitalización humana al borde del transhumanismo de las expresiones y las cotidianidades son críticas surgidas en el proceso de construcción de esta memoria.

* 146 - Ausencia de políticas públicas en la televisión hondureña - Amelia Argentina Espinoza Hulse - Universidad Complutense de Madrid -ameespin@ucm.es

Honduras es de los pocos países Latinoamericanos que aún no ha aprobado una Ley General de Comunicación Audiovisual, por otra parte, los canales de televisión hondureños no han podido formar una asociación de medios sólida e inclusiva y tampoco existe un ente que regule la emisión de contenidos audiovisuales, solo se cuenta con la Comisión Nacional de Telecomunicaciones (CONATEL), quien regula y administra el bien público del espectro radioeléctrico. A través de un diseño de estudio bajo un enfoque mixto, se conoció la opinión de los directores de los medios televisivos que operan en Tegucigalpa, con relación a la necesidad de elaborar y aprobar una política pública para la industria audiovisual, quienes abogan que cada medio televisivo debe 
de autorregularse según su línea editorial y ética periodística, el gobierno no debe de tener ninguna inherencia o participación en la regulación de sus contenidos ya que esto podría coartar su derecho a la libertad de expresión y emisión de pensamiento. Los resultados de la investigación indicaron que la principal ventaja de poseer una Ley General de Comunicación Audiovisual es que se mejorarían los contenidos televisivos que se emiten y se dejaría de fomentar una cultura de muerte en la población hondureña. A su vez, al poder aprobar una política pública audiovisual, el medio televisivo se vería afectado en el área financiera ya que deberá de invertir en la producción de programas de calidad y contratar personal capacitado. En cuanto a los dos principales géneros televisivos que se emiten en los dos canales con mayor rating del país, estos son entretenimiento y noticieros. Por lo que se recomienda que los medios de comunicación se asocien para lograr un mejor funcionamiento y que la formulación y aprobación de una política pública para la industria audiovisual en Honduras es necesaria para ordenar el crecimiento del sector y fomentar así el desarrollo sociocultural en la nación.

* 147 - Interacciones en Twitter y nuevas plataformas de difusión de los debates electorales en las elecciones legislativas del 2019 en España - Patricia Zamora Martínez - Universidad de Valladolid - patricia.zamora@uva.es, Salomé Berrocal Gonzalo Universidad de Valladolid - salomeb@hmca.uva.es y Ana González Neira Universidade da Coruña ana.gneira@udc.es

Los debates electorales han traspasado en los últimos años las fronteras de la televisión para acomodarse al nuevo escenario mediático que brinda Internet. Con una audiencia cada vez más fragmentada y una elevada competencia audiovisual por mantener el liderato entre los telespectadores, las cadenas televisivas amplían la difusión de estos debates en el espacio digital, para alcanzar a una audiencia con un perfil activo, multimedia y multiplataforma, acostumbrada al contacto directo con la red y al visionado en línea (García-García; Viander-Segura; Abuín-Vences, 2012).

Esta investigación profundiza en las nuevas fórmulas de consumo de los debates electorales a través de diferentes plataformas online 
(Twitter, Facebook, Periscope, You'Tube, webs y apps) y examina de manera concreta la participación de los usuarios de Twitter por ser la plataforma que tradicionalmente produce mayor intercambio de opiniones sobre contenidos televisados (Gómez-Domínguez, 2019).

Los resultados del estudio indican que algunos canales televisivos se han adaptado al nuevo ecosistema mediático y han aprovechado las nuevas plataformas de difusión para emitir en directo los debates electorales logrando una audiencia más amplia. En cuanto al examen particular del prosumo en Twitter, se aprecia una escasa interacción entre los usuarios de esta red social.

* 148 - El novísimo cine chileno: el sujeto contemporáneo a través de la ficción y la soledad - Tayri Paz García Medina Universidad Carlos III de Madrid - tayripazgm@gmail.com

Ante la mercantilización de la individualidad, una sociedad de la fatiga, y el imperativo del emprendimiento de la modernidad tardía, pareciera imposible crear lugares y modos de resistencia en los que también atenderse a uno mismo. A través del estudio de la soledad como parte crucial de la subjetividad y noción necesaria para la vida en comunidad, veremos cómo los cines de autor contemporáneos han estado trabajando alrededor de esta idea -Canadá, Francia, España, Argentina..... Concretamente, se partirá del análisis de lo que se ha llamado "novísimo cine chileno" y se dará cuenta de este sujeto tardomoderno desasosegado atravesado por la contradicción y la ambivalencia tan estudiado desde esta novísima generación de cineastas. Contaremos con el siguiente corpus fílmico y estudiaremos su porosidad para con su contexto y otros filmes: Bonsái (2011), Gloria (2014), De jueves a domingo (2012) y Tarde para morir joven (2019).

Para esta investigación hemos empleado un enfoque cualitativo, un acercamiento desde la filosofía-sociología de lo cotidiano. Proponemos la combinación de una revisión bibliográfica y un análisis de discurso fílmico con los que pretenderemos dar cuenta de un momento reseñable en el sujeto actual a través de la producción cinematográfica chilena. Partimos del principio de inmanencia, tanto por el estudio de la sí mismidad y la soledad como por la defensa del texto fílmico como 
ser único en sí mismo, que contiene tanto lo visible como lo invisible, un indicador social y espacio que recoge imaginarios colectivos. El cine será nuestra herramienta para acceder a la cultura del otro, entendiéndolo como texto que recoge imaginarios colectivos: una transcripción. Refleja un estado de la cuestión que intenta definir lo imperceptible. En lugar de una ventana, podríamos decir que el cine de autor más reciente ha estado funcionando como un tubo de ensayo en el que los directores han ido explorando y traduciendo malestares.

* 149 - Enseñar a comunicar en redes sociales: la integración del social media marketing en la universidad - Mariché NavíoNavarro - Universidad San Pablo CEU - CEU Universities mariajose.navionavarro@ceu.es, Belén Puebla-Martínez Universidad Rey Juan Carlos - belen.puebla@urjc.es y Laura González-Díez Universidad San Pablo CEU - CEU Universities - design@ceu.es

La penetración del uso de las redes sociales entre los usuarios de todo el mundo provocó en la primera década del siglo XXI importantes cambios en la comunicación de marketing. En todo tipo de organizaciones, los profesionales encargados de la promoción o la difusión de información se vieron obligados a transformarse digitalmente para adecuar sus habilidades y conocimientos a los requerimientos de la comunicación digital. Estas demandas afectaban a la propia concepción de las dinámicas de los mercados, a la planificación estratégica de la comunicación publicitaria y a la gestión técnica de nuevas herramientas, métricas y contenidos que acercaban las instituciones a las comunidades virtuales de usuarios. El nuevo ecosistema exigía a los profesionales de la comunicación nuevas competencias, para las que una formación actualizada y adecuada a las demandas del mercado laboral era inexorable. Las universidades se vieron entonces llamadas a satisfacer estas necesidades formativas.

Una de las misiones principales de la educación superior es posibilitar que los futuros egresados adquieran las competencias necesarias para incorporarse al mercado de trabajo. Sin embargo, estas instituciones cuentan con procesos de actualización de los planes de estudio que en la mayoría de las ocasiones les impiden alinearse con los ritmos y 
requisitos de las industrias a las que sirven. En materia de comunicación y marketing, donde cada año se producen importantes cambios, este desfase es aún más acusado. Por ello, la presente investigación tiene como objetivo proveer a las universidades españolas que ofertan Grados del sector de la Comunicación, de una solución, en formato de currículo modulable, que les facilite la tarea de incorporar una formación adecuada a las actuales demandas de las organizaciones en materia de comunicación en redes sociales.

Para ello, hemos implementado una metodología que busca una triangulación que asegure la validez de los resultados. De un lado, se ha analizado la oferta universitaria disponible al respecto, a través de un análisis de contenido pormenorizado de las guías docentes de todas las asignaturas que, en todos los Grados sobre Comunicación de las universidades de España, incluyen algún contenido teórico o práctico relacionado con las redes sociales. Este detallado estudio de más de 400 asignaturas ha puesto el foco en las competencias que desarrollan los alumnos que las cursan. Por otra parte, hemos estudiado, a través de entrevistas en profundidad a profesionales en activo del social media marketing, para diferentes tipologías de institución, cuáles son las demandas de competencias que requieren en los actuales y futuros trabajadores encargados de la comunicación en redes sociales. Los resultados, que muestran una falta de adecuación entre la oferta universitaria y las demandas del mercado laboral actual, nos han permitido determinar cuáles son las habilidades y conocimientos sobre la materia a los que han de dirigirse los planes de estudio.

A partir de ello, esta investigación ha desarrollado un currículo modulable, esto es, adaptable a las características propias de cada tipo de Grado en Comunicación y los ECTS disponibles, que sirva de propuesta práctica real para la incorporación efectiva y eficiente de asignaturas actualizadas sobre redes sociales en las universidades españolas. Para comprobar su validez, se han realizado grupos de discusión y entrevistas en profundidad a estudiantes que, habiendo estados matriculados en una asignatura que implementaba esta propuesta, han trabajado profesionalmente en la comunicación en redes sociales de distintas empresas y organizaciones. Esto nos ha permitido perfeccionar la propuesta, implantarla en otros formatos y 
conseguir un modelo adaptable y completamente actualizado que ponemos, aquí, a disposición de cualquier institución educativa.

* 150 - Communitools: innovación docente para las competencias mediáticas de la Generación Z - Mariché Navío-Navarro Universidad San Pablo CEU - CEU Universities mariajose.navionavarro@ceu.es

La Generación Z ha accedido a la Educación Superior con un dominio pleno de los canales digitales de comunicación interpersonal. En lo que respecta al consumo de contenido, este grupo de nativos digitales tiene como principales fuentes de información los medios, instituciones y marcas que utilizan las redes sociales, aplicaciones móviles y otras herramientas en línea para generar conversaciones con sus públicos objetivo. En este ecosistema, la necesidad de formación de estos estudiantes para con la comunicación digital vas más allá una capacitación técnica para centrarse el desarrollo de competencias mediáticas que les permita consumir y crear, difundir, analizar y optimizar mensajes con plena atención a la consecución de sus objetivos comunicacionales. En esta dirección, la Universidad española, a nivel de grado, se encuentra rezagada.

La innovación docente para el desarrollo de competencias mediáticas entre los alumnos universitarios de la Generación $Z$ pasa necesariamente por el desarrollo de plataformas plenamente adaptadas a las tendencias del mercado digital. Esto conlleva posibilitar una formación constante, personalizada y actualizada en un sector en constante cambio. Como respuesta a esta problemática, el proyecto de innovación docente Communitools propone una solución que parte de la adaptación individualizada del proceso formativo a las necesidades e intereses de cada estudiante. Esto, a través de mecanismos como la gamificación o el aprendizaje basado en proyectos y problemas (ABP) como base de la formación.

Communitools es una plataforma formativa sobre comunicación online y marketing digital dirigida íntegramente a los estudiantes universitarios de cualquier rama de la comunicación que, formando parte de la Generación Z, tienen especial interés por desarrollar su 
carrera profesional en el ámbito digital. Para ello, propone a diversos grupos de alumnos un portal web (acompañado de canales sociales, email marketing, eventos, etc.) en los que estos actúan como autores de contenido formativo especializado y como estrategas y gestores de su comunicación. Los alumnos adquieren roles profesionales rotativos y trabajan, en equipos, en áreas profesionales como el community management, diseño gráfico, la edición de vídeo, la planificación estratégica, la organización de eventos, el SEO, la publicidad digital, etc. Se proponen retos periódicos, con objetivos reales de mercado, al que los equipos de estudiantes tienen que hacer frente para conseguir insignias que, después, se convierten en beneficios dentro del ecosistema del portal.

Esta comunicación pretende acercar Communitools a otros docentes e investigadores del sector y desarrollar las metodologías educativas implementadas y los resultados formativos obtenidos a lo largo del desarrollo del proyecto.

* 151 - Formación preuniversitaria en expresión oral: una propuesta de acercamiento - Flávia Gomes-Franco e Silva Universidad Rey Juan Carlos - flavia.gomes@urjc.es

Con base en el desarrollo de la competencia comunicativa, aspecto que se contempla en la legislación educativa vigente en España, se propone un acercamiento al panorama de la formación preuniversitaria en cuanto a una de las facetas más importantes de la comunicación: la expresión oral. Para ello, se aplica un cuestionario a una muestra de 44 estudiantes del Grado en Filosofía de la Universidad Rey Juan Carlos (Madrid, España), en el marco de la asignatura Expresión Oral y Escrita y Búsqueda de Información, que se imparte en el primer curso de dicha titulación. La investigación tiene como objetivo principal averiguar si los alumnos dispusieron de algún tipo de formación reglada en expresión oral en períodos anteriores a la educación superior, teniendo en cuenta las etapas de educación primaria, secundaria y bachillerato. Se observa una escasa preparación del alumnado en lo que se refiere a la construcción y la práctica de discursos orales en clase, lo que supone, en muchos casos, afrontar por primera vez el reto de hablar en público una vez que empiezan sus estudios universitarios. 
* 152 - La mafia en el cine coreano pre Hallyu: la saga The General's Son de Im Kwon-taek (1990-1992) - Luis Miguel Machín Martín - Universidad de La Laguna luismachinm@gmail.com

La explosión del cine coreano a finales de los años 90 del siglo XX se produjo bajo el amparo del fenómeno conocido como ola coreana o Hallyu, fenómeno en el que la cultura y el arte coreanos han alcanzado gran difusión e importancia a nivel nacional y global. Dentro del cine coreano contemporáneo desarrollado a partir del Hallyu uno de los géneros más importantes ha sido el criminal, con películas como Memories of Murder (Bong Joon-ho, 2003) o A Bittersweet Life (Kim Jee-woon, 2005), entre muchas otras, alcanzando un gran éxito de público y crítica tratando temas relacionados con asesinatos y con la mafia. No obstante, antes de que estos temas se popularizaran en el cine de la ola coreana, ya existían precedentes en el cine nacional que anticipaban la diseminación del género en el cine coreano contemporáneo. Uno de esos precedentes más próximos temporalmente es la saga The General's Son (Janggunui adeul), también conocida como Son of a General, del director Im Kwon-taek, compuesta por tres películas realizadas en 1990, 1991 y 1992, y que narran la incorporación y ascenso de un joven vagabundo en una organización criminal en el contexto de la Corea ocupada por Japón antes de la Segunda Guerra Mundial. Este estudio establece una comparativa entre los rasgos del cine criminal presentes en esta saga y otros existentes en el género criminal coreano contemporáneo, de forma que puedan apreciarse diferencias y semejanzas entre uno y otro.

* 153 - El comercio electrónico como instrumento para la inclusión y autonomía de los mayores - Mónica Viñarás AbadUniversidad CEU San Pablo-monica.vinarasabad@ceu,es y Leopoldo Abad Alcalá-Universidad CEU San Pabloabad.fhm@ceu.es

El rápido envejecimiento de las sociedades europeas requiere de investigaciones que arrojen luz para afrontarlo desde su interpretación como una oportunidad. Según la proyección del INE (2018-2068), en 
2068, en España habrá más 14 millones de personas mayores, un 29,4\% del total de la población (Abellán-García et al., 2019). El uso del comercio electrónico podría contribuir al desarrollo de un envejecimiento autónomo y progresivo que, por otro lado, apunta a ser necesario según las estimaciones mencionadas. Respecto al ecommerce, la ONTSI (2019) confirma un incremento en la compra de productos y/o la contratación de servicios, situándolo en un 43\% durante el tercer trimestre de 2018. Si bien, los datos del (INE, 2018) indican que solamente $12 \%$ de las personas de entre 65 y 74 años han comprado en Internet en los últimos tres meses.

El objetivo de esta comunicación es profundizar en el conocimiento de las relaciones de los internautas mayores con el comercio electrónico. Para ello, se propone un riguroso estudio documental de la literatura científica y técnica (procedente de fuentes públicas o privadas) que han abordado desde diferentes perspectivas el objeto de estudio. En esta exploración, se diferenciarán fundamentalmente dos tipos de trabajos de investigación; por un lado, estudios desarrollados según metodologías cuantitativas que ofrecen datos muy técnicos; y, por otro lado, investigaciones apoyadas en triangulaciones metodológicas que combinan técnicas cuantitativas y cualitativas para abarcar de forma más holística el uso del comercio electrónico por parte de las personas mayores. Los resultados obtenidos indican un escaso uso del ecommerce entre las personas mayores (de 65 o más años) atendiendo a su percepción de riesgo en ofrecer sus datos bancarios, centrado en la contratación de servicios, y motivado por la agilidad, comodidad y el precio.

* 154 - Los medios en línea y la enseñanza de idiomas: un estudio comparado de China Daily (China), El País (España) y El Tiempo (Colombia) - Daniel Barredo Ibáñez - Universidad del Rosario (Colombia) - daniel.barredo@urosario.edu.co, y Karen Tatiana Pinto Garzón - Universidad del Rosario (Colombia) karen.pinto@outlook.es

Los medios de comunicación son unos poderosos aliados para la enseñanza de idiomas, particularmente las plataformas en línea, dado que pueden incorporar numerosas opciones para facilitar el consumo 
de sus contenidos en una u otra lengua o, incluso, habilitar versiones globales. Esto es relevante para tres países como China, España y Colombia, los cuales se caracterizan tanto por la acogida de comunidades procedentes de otros contextos, como sobre todo por la emigración de sus nacionales a otros países. Por ello, el rol de los medios puede resultar determinante no solo para la integración o acogida, sino también para la formación de sus usuarios en las dinámicas laborales de carácter internacional. Para abordar el estudio de las posibilidades de enseñanza de otras lenguas, en la siguiente ponencia se presentan los resultados comparados de tres medios digitales de referencia, como son China Daily, El País y El Tiempo.

* 155 - Contenidos transmedia de proximidad en la televisión pública; innovación en programas divulgativos para audiencias jóvenes - Nadia Alonso López - Universitat Politècnica de València - naallo1@har.upv.es y Raúl Terol Bolinches Universitat Politècnica de València - rautebo@upv.es

En los últimos años ha descendido de manera progresiva el consumo de televisión lineal, particularmente en los jóvenes entre 13 y 24 años, entre los que observamos que, desde 2017, consumen 8 minutos menos de contenido televisivo. Paralelamente, el consumo audiovisual online y bajo demanda caracteriza cada vez más el actual ecosistema mediático, así como el acceso a contenido a través de diferentes dispositivos. En este contexto, a los medios de comunicación se les plantea el reto de la innovación en cuanto a contenidos que se adapten a la demanda de una sociedad cada vez más digital. Al respecto, juegan un papel fundamental los formatos transmedia con la presencia de los contenidos en diferentes plataformas, medios y redes sociales. En el caso de la televisión de proximidad, además, ha de buscar diferenciarse del resto de cadenas generalistas con elementos propios de su ámbito de referencia.

En la presente investigación analizamos formatos innovadores en las televisiones públicas de proximidad basados en contenidos transmedia y con una finalidad divulgativa. En concreto nos centramos en el programa 69 raons emitido en À Punt, la radio y televisión pública de la Comunidad Valenciana, que, desde sus inicios, aboga por un 
marcado carácter transmedia en sus contenidos. El formato estudiado es un espacio divulgativo sobre educación sexual y afectiva dirigido a adolescentes. Junto con el análisis del programa y su estrategia transmedia, contextualizándolo en la programación de la cadena, así como en referencia al resto de televisiones autonómicas de titularidad pública, se estudian los referentes de proximidad y la respuesta de la audiencia, tanto en las emisiones lineales como en los diferentes canales de difusión online.

Con todo lo anterior, se constata la necesidad de formatos transmedia dirigidos a jóvenes que reflejen y naturalicen sus circunstancias y problemáticas, desde la innovación y la divulgación.

* 156 - El discurso de género en los políticos/as españoles e italiano en tweeter en la campaña electoral a las elecciones europeas. Un análisis comparativo - Juan Carlos Suárez Villegas - Universidad de Sevilla - Email: jcsuarez@us.es y Paola

Panarese - Univesidad Sapienza - Email:

Paola.panarese@uniroma1.it

En este trabajo se analizan las declaraciones de los políticos/as españoles e italianos en tweeter los temas relacionados con la igualdad de género, en el periodo de las diez semanas previas a las elecciones europeas de 2019, en concreto entre los días día 6 de marzo y el 22 de mayo de 2019. Las cuestiones relacionadas con el género se pueden englobar en las siguientes categorías: familia, conciliación familiar, aborto, violencia de género, el día internacional de la mujer, violencia contra las mujeres, alusiones a otras identidades sexuales. Estos temas se conectan a su vez con otros argumentos políticos, como la inmigración y natalidad, o condiciones de trabajo y educación.

Los políticos seleccionados fueron los de las principales fuerzas políticas en cada país. En España: Pedro Sánchez (PSOE); Pablo Casado (PP); Pablo Iglesia (Podemos); Albert Rivera (Ciudadanos) y Santiago Abascal (Vox). Mientras que en Italia se siguieron los tweets de: Di Maio (5 stelle); Matteo Salvini (Lega); Forza Italia (Berlusconi); Partito Democratico (Zingaretti); y Fratelli d'Italia (Giorgia Meloni). 
Los datos fueron recogidos a través de Netlytic. En total 6038 tweets publicados por estos políticos, 2737 por los italianos, y 3301 por los españoles. De esos tweets, en el caso de los políticos italianos, sólo 42 se refieren a contenidos relacionados con temáticas de género, mientras que en el caso de España fueron 133 (tres veces más en proporción). Hemos de aclarar que se una vez seleccionados los tweets que incluría las palabras claves de mujer, hombre, igualdad, violencia, familia, derechos, se procedió a una selección manual para descartar aquellos que introducían dichos términos en otros contextos informativos que nada tenían nada que ver con temas de género.

El reparto entre los políticos italianos, queda del siguiente modo: Silvio Berlusconi (3); Luigi di Maio (1); Nicola Zingharetti (2); Giorgia Meloni (17) y Matteo Salvini (19), Mientras que el reparto en España queda del siguiente modo: Pedro Sánchez (53); Pablo Casado (34); Pablo Iglesias (6): Albert Rivero (10); Abascal (26).

A su vez, estas declaraciones fueron calificadas en cuatro temas para ver el peso que cada uno de ellos les concedía en su discurso político: 1) La igualdad de género; 2) cuestiones relativas a la familia; 3) La violencia de género; 4) sobre los derechos de la mujer.

* 157 - Twitter y TCA: una revisión sistemática en Scopus - Lydia Steinbrüggen Toledo - Universidad Autónoma de Barcelona (InCom UAB) - lydia.steinbruggen@gmail.com -y José Luis Terrón Blanco - Departament de Comunicació Audiovisual i Publicitat de la UAB e InCom-UAB - joseluis.terron@uab.cat

Según el informe de Vigilancia Epidemiológica de los Trastornos del Comportamiento Alimentario y Conductas Relacionadas de la Comunidad de Madrid (2011), en 2010 se produjeron 367 ingresos hospitalarios por TCA que suponen el 12,1\% de los ingresos producidos por trastornos mentales entre los 15 y 24 años, el 1,8\% en hombres y el $23,1 \%$ en mujeres. A pesar de la prevalencia y gravedad de estos trastornos, como argumentan Areseniev-Koehler et. al. (2016), es muy difícil acceder a las personas que los padecen, ya que suelen ocultar los síntomas y muchos no llegan a tratar el problema con profesionales. Por esta razón es posible que acaben buscando el apoyo 
de sus pares en Internet. Los mismos autores afirman que las comunidades pro-TCA aparecieron en plataformas on-line a principios de los 2000, con el objetivo de apoyar los Trastornos de la Conducta Alimentaria como estilo de vida.

El objetivo de este estudio es revisar los originales que contiene la base de datos Scopus para saber, a grandes rasgos, cuánto se publica, de qué se habla cuando se escribe sobre TCA, quiénes lo hacen, desde qué área del conocimiento y en qué revistas. Para analizar la muestra hemos utilizado el análisis de contenido cuantitativo y cualitativo.

La muestra está compuesta por todos los originales de Scopus publicados entre el año 2006 (momento de nacimiento de Twitter) y 2019-. Para su búsqueda hemos utilizado las palabras clave Twitter y anorexia, bulimia o eating disorder en el título, keywords o abstract. Tras la búsqueda se registraron un total de 32 resultados de los cuales 5 fueron descartados por no corresponder con el objeto de estudio. Por lo tanto, la muestra final la conforman 27 publicaciones.

El primer resultado a destacar es el bajo número de publicaciones obtenidas, 27. De ellas, $14(51,8 \%)$ se enmarcan en el sector salud, 8 $(29,6 \%)$ en ingeniería y ciencias de la computación y $3(11 \%)$ en ciencias de la naturaleza. Las 2 publicaciones restantes, que representan el 7,4\%, pertenecen a ciencias sociales. De igual forma, de los 27 autores principales $13(48 \%)$ son del sector salud, $8(29,6 \%)$ provienen de ingenierías y ciencias de la computación, 3 (11\%) de ciencias de la naturaleza, $2(7,4 \%)$ de ciencias sociales y sólo 1 (3,7\%) del ámbito de comunicación, arte y humanidades. En cuanto a las revistas en las que se han publicado, 13 (48\%) están especializadas en el ámbito salud, 4 $(14,8 \%)$ en ingeniería y ciencias de la computación, 3 (11\%) en ciencias de la naturaleza, $2(7,4 \%)$ en ciencias sociales y las 5 fuentes restantes no se corresponden con revistas. En lo que al idioma se refiere, 26 publicaciones han sido redactadas en inglés y 1 en español. Este dato también se apoya en el hecho que 21 originales se han publicado en países anglosajones.

En definitiva, pese a la relevancia del tema, está poco tratado y mayoritariamente investigado por autores del ámbito de la salud o de 
centros especializados. A su vez, se observa cómo la mayoría de los estudios se han realizado en países de habla inglesa (Estados Unidos, Reino Unido y Australia principalmente) y se publican principalmente en revistas de salud por investigadores del campo de la salud, por lo que prevalece un enfoque biomédico. Dado el objeto de estudio también destacan los autores del ámbito de las ingenierías y las ciencias de la computación. Finalmente, en lo que a contenido se refiere, gran parte de los originales centran su investigación en analizar las comunidades pro-TCA en diferentes redes sociales o en la socialización que hacen los usuarios alrededor de estos trastornos.

* 158 - Evaluación analítica de la presencia del motivo del paisaje solitario dentro de la obra de Abbas Kiarostami - Juan José Caballero Molina - Universidad de Barcelona juanjo.caballero@ub.edu

Reivindicada de forma entusiasta por algunos de los más reconocidos teóricos, críticos y cineastas (J. Rosenbaum, Y. Ishaghpour, J.-L. Nancy, W. Wenders, J.-L. Godard, ...), la obra del creador iraní Abbas Kiarostami se significó por la persistente matriz poética que animara tanto su producción cinematográfica, cuanto fotográfica, pictórica o poética. El conjunto de su obra se halla presidido por una mirada severa y desafectada, desprovista de pretensiones, que se interesa por abundar en motivos recurrentes que la surcan. Y uno especialmente privilegiado es el del paisaje solitario.

Aquí se propone una aproximación analítica a la presencia que esa imagen estilemática del camino serpenteante, observado de manera imperturbable desde una voluntad despojada de toda pulsión narrativa alcanza, dentro del periplo creativo del propio Kiarostami como plataforma privilegiada para la instauración -como ya nos advirtiera A. Bergala- de un verdadero programa de reeducación de la mirada. En el interior del mismo, se promueve el goce de una cierta experiencia epifánica, donde lo que se nos muestra parece sernos desvelado por vez primera. Nuestro objetivo pasa por determinar las implicaciones que en términos culturales, estéticos y espectatoriales pueden ser desplegadas en torno a este motivo, verificando el modo en que su relevancia se va modulando en el curso del tiempo. 
Por el camino, la mirada kiarostamiana se nos revela sumida en un ejercicio riguroso y disciplinado de la espera en pos de aquella regalía que la realidad pueda eventualmente brindarle en su obstinada incursión por el camino hacia lo invisible. Así, partiendo del gusto por aquello banalmente concreto que conforma la herencia de la tradición cultural persa, esta mirada se destaca por su pasmosa neutralidad y distanciamiento, pareciendo deslizarse desde una "presencia ausente" hasta quedar plasmada, como si de un espejismo se tratase, sobre la pantalla, el lienzo o el papel.

* 159 - Comunicando a través de la música. Un acercamiento al western en la primera temporada de "The Walking Dead" Lucas Morales Domínguez - Universidad de La Laguna lucasmoralesdominguez@gmail.com

La música es un elemento definitorio de la personalidad de un producto audiovisual, ayudando a confeccionar el universo de una película o darle forma a su mitología de una serie. Si bien en el cómic este elemento no tiene un peso fundamental a la hora de construir historias, en el caso de las adaptaciones del papel al celuloide juega un papel fundamental, generando sensaciones y evocando ideas que condicionan la experiencia de la audiencia o, al menos, de una parte de ella. Esta comunicación parte de un trabajo anterior donde se demuestra que un conjunto de patrones visuales y narrativos del western están presentes en la primera temporada de "The Walking Dead", que van desde el papel que desarrollan los muertos vivientes hasta la forma de presentar a los héroes. Con este texto, se amplía el espectro hasta la selección musical y la composición de la banda sonora, un elemento determinante en la aproximación al género del Lejano Oriente que se hace en los 6 capítulos inaugurales de esta saga de terror.

* 160 - Publicidad y medio ambiente Caso de estudio el sector petrolero - María Margarita Gutiérrez Gutiérrez - Corporación Universitaria Asturias /Universidad Autónoma de Barcelona margaritaggutierrez@gmail.com 
La civilización se ha construido sobre la base del aprovechamiento de los combustibles fósiles, del carbón y en general del acceso insostenible de los recursos naturales, generando un proceso de colisión con el mundo natural, ante lo cual parece demasiado tarde seguir pensando en la vía del desarrollo sostenible. Un desafío para el que la tradición humanista no la ha preparado, evidenciándose en la aceleración del cambio climático acabará con el confortable entorno al que ha estado adaptada. De lo anterior se desprende la pertinencia de esta investigación que a través de casos de estudio de la actividad petrolera, y metodológicamente enmarcada en la investigación-acción de corte cualitativo, conlleva a determinar que el contenido de los discursos publicitarios que emiten no es siempre coherente con la normatividad ni con los códigos de auto-regulación que orientan sus actividades comunicativas, induciendo a error por cuanto crea en el consumidor y usuario expectativas que no se corresponden con la protección medio ambiental y la responsabilidad social empresarial. Utilizando para ello, información falsa, mensajes sugestivos, abuso del naciente «greenwashing», persuasión engañosa y publicidad subliminal. En respuesta a esta situación, día a día se acentúan a nivel global posturas en contra del ejercicio de una publicidad no responsable en lo que respecta a temas socio-ambientales, en particular por parte de la sociedad civil. Las críticas que arrecian desde diferentes sectores de la sociedad provienen en parte de los consumidores, en parte de las personas del común, pero las más inquietantes están siendo generadas desde los análisis de las ciencias sociales y en especial en el núcleo de grupos anti-corporativos, movimientos organizaciones medioambientales y grupos anti-publicitarios propiamente dichos.

* 161 - ¡Sonría! La comunicación y la marca de la Cadena SER a través de las promos de Ortega - Javier de Sola - Universidad de Zaragoza - jdesola@unizar.es, Ana Segura-Universidad de Zaragoza-asegura@unizar.es y Antonia Isabel Nogales Universidad de Zaragoza - anogales@unizar.es

"Estás escuchando la Cadena SER, la emisora de radio que escuchan los Bee Gees", anuncia una voz mientras suena de fondo Stayin' alive. “CCómo que la emisora que escuchan los Bee Gees?, le responde otra. 
"Es una forma de vender un producto... ¿Qué pasa? ¿Que los Bee Gees no pueden escuchar la Cadena SER? ¿Que la SER decide quién les puede oír y quién no? ¿No presume esta radio de ser una radio abierta a todos?", zanja la primera. De esta manera, con el humor llevado al absurdo y la ironía, comienza uno de los recursos con los que la Cadena SER ha decidido promocionarse en los últimos meses entre sus oyentes a través de la voz, y el ingenio, de Juan Carlos Ortega. La presente investigación analiza, en ese sentido, la apuesta de la SER, la emisora más escuchada de España, de introducir nuevas formas de comunicación con su audiencia. La investigación se lleva a cabo a través del estudio de caso de las promos de Ortega, todas distintas, pero con una serie de características comunes con las que se transmiten ideas concretas (relativas a programas, informativos o especiales), pero también más generales vinculadas y para potenciar la marca de la SER. Los resultados del estudio de caso apuntan a que, entre esas características, destacan la originalidad, el humor, el hecho de apelar a la propia audiencia y plantear cuestiones comúnmente conocidas o con las que se puede asociar al oyente tradicional de la emisora.

* 162 - El discurso de derrota electoral: claves de un género Joan G. Burguera Serra - Universidad de Barcelona burguera@ub.edu

La derrota se inserta, de forma tan consubstancial como despreferida, en todos aquellos ámbitos de la vida social estructurados en torno a dinámicas competitivas. Los encuentros deportivos, los juicios o incluso los procesos de oposición para el acceso a empleos públicos son algunos de estos entornos, de entre los que sobresale la contienda política. $\mathrm{Y}$ en este último marco, las campañas electorales $\mathrm{y}$, en concreto, la confirmación y comunicación del escrutinio durante la noche electoral suponen la piedra de toque a partir de la cual puede hablarse de vencedores y vencidos.

Las liturgias comunicativas en el ámbito político exigen, en este punto, una comparecencia pública del líder, independientemente del resultado. Esta suerte de epílogo se convierte, pues, en un género prototípico, central e ineludible en cualquier campaña electoral, de la misma manera 
Las nuevas narrativas, en el entorno social

que lo son el spot, el debate o el propio programa político, entre tantos otros.

En la presente comunicación queremos abordar las características del discurso de derrota (concession speech, en terminología anglosajona) de las noches electorales españolas. Para ello, seguiremos la propuesta de Malkmus (2013) y abordaremos el tema desde una perspectiva macro y micro atendiendo a los actos de habla que configuran el género; la macroestructura del mismo; el uso de deícticos y expresiones metafóricas; las expresiones evaluativas y la interrelación entre las fórmulas retóricas y la incentivación del aplauso. Se ha elaborado, en este sentido, un corpus con 10 discursos que permiten una primera aproximación (culturalmente diferenciada de la norteamericana) y un posterior análisis de cara a ratificar la sistematicidad de este género y su cada vez mayor planificación por parte de asesores de comunicación y/o speechwriters.

* 163 - El Grado de Comunicación e Industrias Culturales de la Universidad de Barcelona: una apuesta formativa estratégica frente a los nuevos perfiles profesionales y sus competencias asociadas - Joan G. Burguera Serra - Universidad de Barcelona - burguera@ub.edu; Juan José Caballero Molina - Universidad de Barcelona - juanjo.caballero@ub.edu y Anna Tarragó Mussons - Universidad de Barcelona - annatarrago@ub.edu

En el curso 2011-2012, la Universidad de Barcelona, a partir de la autonomía derivada de las directrices académicas del EEES, implantó una nueva titulación oficial en el ámbito de los estudios de comunicación: el Grado de Comunicación e Industrias Culturales. Desde una perspectiva innovadora e integradora, se pretendía dar respuesta a las nuevas necesidades surgidas dentro de un sector especialmente poliédrico, cambiante y dinámico, como es el de la comunicación, en cuyo seno proliferan incesantemente nuevos productos, servicios y técnicas de gestión, entre ellos, los relacionados con el producto cultural.

Para encarar este reto, el diseño curricular del grado desplegó una formación diferenciada de las precedentes titulaciones de periodismo, 
comunicación audiovisual u otras conectadas con la gestión cultural o empresarial. Se forjó un core competencial idóneo para los nuevos perfiles profesionales. En este sentido, se optó por enfatizar, entre otros aspectos, las habilidades comunicativas y expresivas; el manejo de las TIC, a través del tratamiento de todo lo relativo al fenómeno de las redes y del multimedia; el dominio del entorno digital en su conjunto; la caracterización de los sectores de las industrias culturales o, ya desde una perspectiva más competencial, el desarrollo del trabajo autónomo tutorizado, por lo general en régimen colaborativo, buscando estimular así la responsabilidad en el trabajo y la toma de decisiones.

La experiencia de estos nueve cursos, la superación de los procesos de acreditación por parte de las agencias de calidad y la aproximación analítica a los resultados del TFG y de las Prácticas Curriculares Obligatorias (con 12 y 24 créditos ECTS, respectivamente), nos permitirán validar el grado de funcionalidad formativa alcanzado.

* 164 - Emprendimiento periodístico: estudio de caso de innovación docente en la enseñanza-aprendizaje en gestión empresarial y organización de proyectos del alumnado de Periodismo - Gema Alcolea-Díaz - Universidad Rey Juan Carlos - gema.alcolea@urjc.es

El sector periodístico se encuentra inmerso en una profunda transformación, en un entorno de periodismo postindustrial, en el que los propios periodistas, en muchos casos, gestionan los proyectos, bien porque han optado por el emprendimiento como salida laboral, bien porque se han visto empujados ante los recortes en las plantillas de los medios.

En este escenario, resulta fundamental que el alumnado de Periodismo, como futuros profesionales, se sitúe, a través de un proceso formativo riguroso y práctico, en un lugar aventajado del mundo laboral, preparado para dar el salto a la gestión y organización de empresas informativas. El presente trabajo tiene como principal objetivo transferir la experiencia de innovación docente en la enseñanzaaprendizaje en gestión empresarial y organización de proyectos periodísticos, llevada a cabo en la asignatura Empresa Periodística, del 
Grado en Periodismo, de la Universidad Rey Juan Carlos (URJC). Recogemos la evolución innovadora, durante tres cursos académicos, en el planteamiento, utilización y evaluación del Plan de Empresa Periodística, herramienta formativa de aprendizaje basado en proyectos. Esta herramienta se ha demostrado como fundamental para alcanzar de forma práctica y cooperativa las competencias de esta asignatura, especialmente la de "conocer el funcionamiento de las empresas periodísticas". Y, asimismo, la consecución del "espíritu de empresa", una de las ocho competencias básicas con las que el Parlamento Europeo considera que el sistema de enseñanza debe dotar a los ciudadanos y ciudadanas.

* 165 - Energy drinks en los medios españoles: ¿bebida de riesgo o placer inocuo? - Jose-Luis Argiñano - Universidad del País Vasco/Euskal Herriko Unibertsitatea (UPV/EHU) Joseluisarguinano@ehu.eus

La presencia de las bebidas energéticas en la prensa española esta mediatizada por el patrocinio que algunas marcas ejercen, especialmente en eventos deportivos o lúdicos, y por la relación de conflicto entre este producto y las bebidas azucaradas. Esta investigación trata de dilucidar el tratamiento periodístico ante un producto que resulta exótico y que se relaciona con la resistencia física y el placer, y por otro, con las consecuencias perjudiciales que para la salud puede causar su ingesta debido tanto al exceso de azúcar como a la presencia de sustancias como la taurina. El campo de análisis abarca los diarios elpais.com, elmundo.es y lavanguardia.com. El objetivo del análisis preliminar que se presenta en esta investigación es inducir los encuadres que más destacan a la hora de enmarcar el objeto de estudio y diferenciar las valoraciones positivas y negativas en las informaciones para establecer si la prensa digital presenta este tipo de bebidas como un peligro real para el consumidor o si por el contrario su ingesta se puede ver con matices hedonistas.

* 166 - El perfil de los públicos bancarios de la publicidad tradicional en una era digital - Adriana Margarita Hernández López - Estudiante de doctorado - Universidad Autónoma de Barcelona, UAB, España - adrianamargarita.hernandez@e- 
campus.uab.cat, Carlos David Badajoz Dávila - Profesor Universidad Autónoma de Barcelona, UAB, España David.Badajoz@uab.cat, Luis Edgardo Romero Sepulveda Estudiante de doctorado - Universidad Autónoma de Barcelona, UAB, España - luisedgardo.romero@ecampus.uab.cat, Pauline Paredes Bedoya - Estudiante de doctorado - Universidad Autónoma de Barcelona, UAB, España - yulypauline.paredes@e-campus.uab.cat, Silvia Andrea Cristian Ladaga - Profesora en Comunicación Visual Universidad de La Plata, UNLP, Argentina crisladaga@geardesign.com.ar

En una era digital, las empresas de banca españolas están enfocadas a la atención de diversos públicos, que, para ser captados, deben generar esfuerzos de comunicación con la finalidad de atraer la mayor cantidad de usuarios posibles y conseguir la rentabilidad. El presente artículo se deriva de una investigación realizada por el Laboratorio de Análisis Instrumental en la Comunicación (LAICOM) de la Universidad Autónoma de Barcelona en el que se muestra el perfil de los públicos a los cuales fueron dirigidas las campañas promocionales de Banco Santander, BBVA, CaixaBank y Sabadell; con base en los elementos de su comunicación impresa durante el primer semestre de 2018. Esta investigación de corte cualitativo analiza el contenido de 16 diferentes carteles que fueron exhibidos en las cristaleras de los principales bancos de España. Con públicos que muestran una preferencia por la tecnología; la estrategia promocional de la banca por medios tradicionales busca la persuasión de sus públicos para migrar su interacción hacia las plataformas digitales.

* 167 - La comunicación periodística y la lengua española en la enseñanza secundaria: usos didácticos e innovadores de la crónica deportiva - Próspero Manuel Morán López Universidad de Oviedo - moranprospero@uniovi.es

La enseñanza de la lengua española en las etapas tanto obligatorias como postobligatorias necesita en la sociedad de la información apoyarse en una comunicación constante con la realidad social y cultural, amén de tecnológica. 
Y preocupada por esa evidencia, la Federación de Asociaciones de Periodismo de España (FAPE) considera desde 2016 que se hace imprescindible la creación de una asignatura de periodismo para los cursos de Enseñanza Secundaria Obligatoria (ESO) ante el creciente fenómeno de las denominadas "fake news" o noticias falsas. Desde hace ya tres años los periodistas españoles buscan apoyos parlamentarios para convertir en realidad una idea que platean como asignatura transversal independiente de la de Lengua Española donde ahora se enmarcan los contenidos referidos a los géneros periodísticos y los procesos de comunicación. Pero en tanto cristaliza esa posibilidad, parece necesario incorporar las posibilidades que el conocimiento del periodismo y la comunicación en todas sus manifestaciones ofrece en la programación didáctica donde actualmente se encuadra.

La vitalidad de la crónica y su primacía como género periodístico en el contexto de un periodismo deportivo cada vez más universalizado y el hecho de que el contenido periodístico global por excelencia sea en este momento la información deportiva en general y la futbolística en particular son el punto de partida de un proyecto de herramienta informática con formato de blog que plantea la enseñanza de la lengua española en secundaria, tanto desde la perspectiva de la lecto-escritura como en el plano morfológico y sintáctico.

Nuestra propuesta ha sido diseñada y acotada a lo largo de los dos últimos cursos escolares con herramientas de la Web 2.0 y está siendo ensayada en el ámbito de la asignatura de Lengua Española en cursos de la ESO y Bachillerato de centros del Principado de Asturias.

* 168 - La reforma necesaria de los órganos de regulación de la comunicación - Alejandro Gesto Louro - Universidade de Santiago de Compostela - alejandrogesto@gmail.com, Francisco Campos-Freire - Universidade de Santiago de Compostela - francisco.campos@usc.es y José-Miguel Túñez López - Universidade de Santiago de Compostela miguel.tunez@usc.es 
La Directiva europea 1808/2018 de servicios de medios de comunicación audiovisual, aprobada en noviembre del año pasado, tiene que ser trasladada a las legislaciones de los estados de la UE antes de finales de $2020 \mathrm{y}$, entre los temas a abordar, propone reforzar la independencia de los órganos reguladores de la comunicación, una asignatura pendiente en el panorama autonómico y estatal de España. Esa recomendación de la Unión Europea afecta a los tres órganos reguladores actualmente vigentes en España: la Comisión Nacional de los Mercados y la Competencia del Estado, así como a los Consejos Audiovisuales de Cataluña y Andalucía respectivamente. En esta comunicación se contextualiza la recomendación de la nueva Directiva europea con la legislación, trayectoria, competencias, composición y funcionamiento de los citados tres órganos de regulación de la comunicación de España.

* 169 - Los modelos de comunicación estratégica de la banca española en el marco de la digitalización: Banco Santander, BBVA, Caixabank y Banco de Sabadell. - Paulina Guajardo Figueroa - paulina.guajardo@e-campus.uab.cat, Erika Marisol Ruiz Castillo - Erikamarisol.ruiz@e-campus.uab.cat, Norminanda Montoya Vilar - Norminanda.Montoya@uab.cat y Ángel Rodríguez Bravo - Universidad Autónoma de Barcelona (España)-Angel.Rodriguez@uab.cat

Dentro de un análisis teórico y contextual sobre la revolución digital en la banca española se puede afirmar que la tecnología ha determinado cambios radicales en los flujos de distribución y de acceso a la información. La sobreabundancia en la circulación desenfrenada de mensajes ha conducido a una expansión de la hipercomunicación como realidad dominante.

El objetivo de la presente investigación ha sido estudiar cómo están gestionando los cuatro bancos más grandes de España sus flujos comunicativos, en un momento de transición a la digitalización generalizada, y localizar de qué modo desarrollan actualmente sus estrategias comunicativas. Implementando una metodología de carácter cualitativo, con enfoque descriptivo y exploratorio, centrada en: a) Entrevistas en profundidad semiestructuradas a los máximos 
responsables de la Comunicación del Banco de Santander, BBVA, Caixabank y Banco de Sabadell y b) en la confrontación del análisis de estas entrevistas con los documentos oficiales de los bancos publicados en sus respectivos sitios-web corporativos.

Dentro de los resultados del análisis se demuestra que la banca española en combinación con las agencias ejecutoras de estrategias de comunicación y marketing se han visto en la obligación de crear nuevos flujos que optimicen su comunicación financiera. Estos flujos se dispersan en el entorno analógico y digital intentando construir una relación estrecha con sus clientes, pero terminan creando una comunicación unidireccional y descendente que solo se retroalimenta del "big data". Además, la sobresaturación de mensajes publicitarios provoca que la identidad de marca se pierda en el camino, y en consecuencia los valores corporativos mencionados en sus documentos oficiales son imperceptibles en su comunicación.

* 170 - Propuesta metodológica para el estudio de las nuevas competencias y perfiles de los periodistas digitales vascos Jesús, Pérez Dasilva - jesusangel.perez@ehu.eus; Koldobika, Meso Ayerdi - koldo.meso@ehu.eus; Terese, Mendiguren Galdospín - terese.mendiguren@ehu.eus; Simón, Peña Fernández - simon.pena@ehu.eus; Ainara, Larrondo Ureta ainara.larrondo@ehu.eus; María, Ganzabal Learreta maria.ganzabal@ehu.eus Iñaki y Lazkano Arrillaga UPV/EHU - inaki.lazkano@ehu.eus

El último estudio sobre la situación profesional de los periodistas en el País Vasco se realizó hace casi 20 años (Cantalapiedra, Coca, Bezunartea, 2000) cuando la penetración de Internet era muy limitada y conocida solamente entre la comunidad científica española. Desde entonces, el uso de internet se ha multiplicado hasta tal punto que casi la mitad de los españoles asegura estar conectado constantemente $\left(21^{\mathrm{a}}\right.$ encuesta de AIMC, 2018) y ha generado importantes cambios en la manera de producir y consumir los contenidos informativos. Debido a todo esto, la Euskal Kazetarien Elkartea (EKE)-Asociación Vasca de Periodistas (AVP) se puso en contacto con la Universidad del País Vasco para solicitar la realización de un nuevo estudio que recogiese el 
impacto que ha tenido Internet en la labor periodística. La iniciativa se ha concretado en el proyecto US18/06 financiado por la por la propia $\mathrm{UPV} / \mathrm{EHU}$ y de cuya producción forma parte este texto.

El trabajo presenta la propuesta metodológica elaborada para estudiar las nuevas competencias y perfiles de los periodistas digitales vascos y su relación con la audiencia y, además, da cuenta de otras investigaciones similares que analizan la profesión (Mompart, Lozano y Palau, 2015; Llanos, 2018; Túñez y Toural, 2018 o Weaver, Willnat y Wilhoit, 2019). La técnica de recolección de datos para obtener información sobre la realidad o escenario en el que se desenvuelven los periodistas se basa en un cuestionario de 26 preguntas que abordan cuestiones como la relación con la audiencia o los cambios en la profesión y organización del trabajo, entre otros.

* 171 - El estilema de Clint Eastwood al servicio del discurso musical: Jersey Boys - Juan Enrique Gonzálvez Vallés Universidad Complutense de Madrid- jegonzalvez@ucm.es

El estilema autorial en la cinematografía de Clint Eastwood le ha llevado a encumbrarse dentro del Olimpo del cine comercial estadounidense. Su obra sobre el origen y posterior éxito del grupo musical 'Jersey Boys', así como su foco sobre el personaje de Frankie Vallie, construyen un biopic atípico en el trabajo del director californiano. En este punto surgen varias preguntas que serán objeto de nuestra investigación, como saber si esta película responde a las huellas insertadas por el director californiano en el resto de su obra cinematográfica. Igualmente, cabe cuestionarse, desde el punto de vista de la metodología propuesta por Seymour Chatman en su Historia y Discurso (1990), si el modo de narración utilizado encaja en la huella de Eastwood. Esta pregunta adquiere especial relevancia si se tiene en cuenta que el resto de películas biográficas sobre personajes reales de este autor han sido construidas desde el punto de vista formal de la narración de un manera bien distinta, con saltos narrativos hacia delante y hacia atrás para conformar un caleidoscopio que otorgue una visión holística sobre la personalidad del personaje principal de la película. Por último, y siguiendo a Roland Barthes en su libro Elementos de semiología, siempre enfocado claramente al análisis 
narrativo audiovisual, tendremos por objeto de nuestro trabajo el análisis de todos los sistemas de signos, especialmente en el plano formal, y adquiriendo una relevancia superior los que provienen del ámbito musical. No pretendemos adentrarnos en el proceloso mundo del género musical, ni del género en su conjunto, sino que adoptamos un enfoque analítico práctico donde la música, casi omnipresente en todas las escenas, posee un peso específico tanto en historia como en el discurso narrativos.

* 172 - Comunicación política y redes sociales: Análisis de la campaña para las elecciones de alcaldes de 2019 en Loja (Ecuador) - Mónica Hinojosa Becerra - Universidad Nacional de Loja (UNL) (es profesor) - monica.hinojosa@unl.edu.ec

A través de esta investigación se determina el uso de Facebook y Twitter en las campañas electorales. Se visibilizaron los resultados de cinco potenciales candidatos a la alcaldía de Loja (Ecuador) en los comicios electorales de marzo de 2019. Para este efecto, se realizó un análisis mixto, se cuantificó los indicadores de desempeño de los candidatos en sus redes sociales y a nivel cualitativo se analizó las estrategias utilizadas, la interacción con los seguidores durante tres cohortes y cómo esto se evidencia directamente con su crecimiento en las plataformas digitales. Como consecuencia, se determinó que las características de las redes sociales no son explotadas en su totalidad por los candidatos y que estos medios son simplemente un complemento de las campañas tradicionales, que todavía son predominantes en Ecuador.

* 173 - Ir escuchando: Comunicar desde el cuerpo-territorio para el cambio social - Stephania, Rincón Malagón - Corporación Universitaria Minuto de Dios - srinconmala@uniminuto.edu stephaniarmalagon@gmail.com

A manera de reflexión se hace una relación entre la comunicación, la cartografía social y el cuerpo como territorio, en el marco de la exposición fotográfica "El testigo" de Jesus Abad Colorado una muestra de las huellas que ha dejado al guerra en Colombia; se escribe este texto para hacer la relación entre las tres al reconocer la necesidad 
y la importancia que tiene para la transformación social y la humanidad: el cuerpo como un lugar de narración y encuentro para una comunicación para el cambio social.

Superar el paradigma reduccionista de la comunicación implica entender que no son los medios sino el tejido colectivo de un compartir y co-construir significados, de tener voz y dar voz. Fundamentalmente una oportunidad de retornar a nuestra humanidad y reconocer la diversidad que somos, comunicar es ir escuchando; como lo entiende el pueblo indígena arhuaco de Colombia.

Es por ello que las múltiples manifestaciones de comunicación como una foto o un mapa en la cartografía social, son oportunidades para ir escuchando las voces de quienes no han contado su historia y merecen ser escuchados, para tejer entre las interacciones, las configuraciones y los territorios.

Con el propósito de acercarse a lugares y experiencias que guardan memoria como lo es el cuerpo territorio, lugar de narración y encuentro para una comunicación que permita el cambio social y supere el paradigma reduccionista de la comunicación.

* 174 - Formas de empoderamiento digital: el escándalo Cambridge Analytica en Twitter - Camila Pérez Lagos Universidad Sorbonne Nouvelle Paris 3 (Francia) camila.perez-lagos@sorbonne-nouvelle.fr

El escándalo Cambridge Analytica (CA) sale a la luz pública el 17 de marzo 2018 cuando periódicos como The Guardian, The New York Times, y The Observer, gracias a las informaciones otorgadas por el denunciante Christopher Wylie (ex empleado de la empresa), acusan a CA de haber utilizado datos privados (provenientes de cuentas de Facebook) para influir en la campaña de Donald Trump. Lo anterior, fue posible gracias a una aplicación (this is your digital life) del Global Science Research de la Universidad de Cambridge, concebida por el investigador Aleksandr Kogan que "absorbió" los datos de quienes la usaron y también de sus amistades. En abril y mayo del 2018 Marc Zuckerberg, fundador y director ejecutivo de Facebook, es audicionado 
Las nuevas narrativas, en el entorno social

frente al senado estadounidense y al parlamento europeo donde admite haber "recolectado" los datos de al menos 87 millones de cuentas sin consentimiento de los usuarios.

Desde un punto de vista pragmatista del estudio de los acontecimientos (Quéré, 2006; Neveu et Quéré, 1996) nos preguntamos si el caso CA contribuyó a hacer visibles los mecanismos y las consecuencias de la captación de datos personales cuyo propósito es manipular la participación política de los ciudadanos. Para ello, se analizó un corpus de tweets emitidos durante el desarrollo del escándalo con el fin de identificar las marcas de empoderamiento (Bacqué y Biewener, 2015; Freire, 2012). El análisis de los datos muestra que los usuarios negocian los significados de las diferentes maneras de nombrar el hecho (la polémica, el escándalo, el asunto) y crean una narrativa que permite extender las consecuencias del escándalo (el Brexit, la Ley Europea de Datos Personales, el hackeo ruso). Asimismo, en un contexto digital interrumpido por escándalos digitales vinculados a la falta de protección de la privacidad de los ciudadanos, los mismos usuarios comparten mecanismos de empoderamiento en la red social.

* 175 - Realidad social y literatura en "La Hija de la Española” de Karina Sainz Borgo - José Bernardo San Juan - Departamento de Ciencias de la Educación, Lenguaje, Cultura y Artes, Ciencias Histórica-Jurídicas y Humanísticas y Lenguas Modernas. Universidad Rey Juan Carlos - jose.bernardo@urjc.es

El éxito del lanzamiento de La Hija de la Española (Lumen, 2019) de la escritora venezolana Karina Sainz Borgo responde a los cánones de escritura que van más allá de los tradicionales best seller. La obra refleja una realidad social de manera que puede entenderse que la sociedad venezolana es un personaje colectivo de la obra. En esta comunicación e realiza un análisis de contenido de esa obra y se muestran los rasgos más señalados de ese particular "personaje colectivo".

* 176 - "Cada canción es un anuncio: medios, discográficas y (des)equilibrios de poder - Juan Carlos Regueira Rey I 
doctorando Universidad de Santiago de Compostela carlos.regueira@gmail.com

Cuando un artista interpreta su repertorio en televisión o cuando sus canciones suenan en la radio, el disco se publicita a sí mismo. No es de extrañar, por tanto, que los medios broadcast (radio y televisión) hayan tenido un alto valor promocional para la industria discográfica desde los primeros tiempos de las emisiones analógicas en abierto. En el área de los popular music studies se echa de menos un enfoque que profundice en los factores profesionales y económicos que se hallan en la raíz de las relaciones institucionales entre mediadores discográficos y mediáticos. Si consideramos que la prensa escrita es también parte de esta alianza entre mediadores, no es difícil ver una continuidad temporal de la que emerge un relato ausente del énfasis textual de la mayoría de textos académicos. Con los contenidos musicales de nuestros medios bajo sospecha, se hace necesario profundizar en el conocimiento de los pormenores de este entramado de intereses cruzados. La aportación de la academia en este campo puede servir para que nuestra ciudadanía tenga las claves que le permitan identificar este pacto oculto entre mediadores y las consecuencias del mismo para medios, discográficas, músicos y audiencia.

* 177 - Análisis del segmento "La Comunidad” del noticiario 24 Horas de Teleamazonas de Ecuador - Karina Elizabeth Amaguaya Vela, Narcisa Medranda Morales y Victoria Palacios Mielles - Ecuador

El presente artículo "Análisis del segmento "La Comunidad" del noticiario 24 Horas de Teleamazonas de Ecuador" presenta un seguimiento realizado a cada una de las notas presentadas en el segmento la comunidad, durante una semana, con el fin de poder determinar el rol de este medio de comunicación al momento de presentar la nota, es decir, si el medio cumple como mediador para otorgar soluciones a los ciudadanos o simplemente se dedica a la espectacularización de los temas tratados. La metodología usada en esta investigación fue la observación descriptiva, la cual contó con el desarrollo de una matriz en la que se recoge las variantes del tiempo designado a cada nota y el seguimiento de la noticia, así se pudo 
concluir que el segmento la comunidad, del noticiero 24 horas, realiza el seguimiento a las notas presentadas y cumple con el papel de mediador para otorgar soluciones a los pedidos de los ciudadanos, actos que reflejan la existencia de participación ciudadana en el medio.

* 178 - Proyectos y metodologías de detección de noticias falsas en español utilizando el aprendizaje automático - Arsenii Tretiakov - Universidad Carlos III de Madrid ars.tretyakov@gmail.com y Susana Herrera Damas Universidad Carlos III de Madrid - dherrera@hum.uc3m.es

La investigación analiza los mecanismos de publicación y distribución de noticias falsas en español y posibilidades de identificación de las mismas. A continuación, se extraen conclusiones sobre los métodos para la identificación de este tipo de noticias en los medios de comunicación masiva utilizando sistemas con elementos de aprendizaje automático. Este problema se ha resuelto bastante bien inglés al contrario que en español, ya que hay falta de artículos científicos sobre el análisis de las falsificaciones españolas. La poca investigación sobre el análisis de las noticias falsas españolas y la desinformación generalizada durante la campaña elecciones generales de España (28A) hicieron posible la realización de este estudio.

El estudio hace un breve repaso de los proyectos existentes sobre detección de noticias falsas. Se presenta la investigación realizada por los autores, cuyo objetivo es desarrollar el concepto del método de definición automatizada de noticias falsas para textos en español con aprendizaje profundo para el análisis del contenido del texto. Para una capacitación exitosa, está recopilado un corpus de diferentes tipos de información falsa de medias de comunicaciónes, Facebook, Twitter y WhatsApp. Los principales objetivos del estudio son probar la hipótesis de la posibilidad de identificación de noticias falsas de aprendizaje automático con una precisión más que 95\% con un único corpus de noticias falsas. Se hace la conclusión sobre el gran potencial que se obtiene de la aplicación de la inteligencia artificial en relación con el juego de herramientas sobre el procesamiento de bases de datos. 
* 179 - Propuesta de análisis de los instrumentos de rendición de cuentas en los medios de comunicación españoles: aplicación de herramienta de evaluación - Juan Carlos, Suárez - Universidad de Sevilla - jcsuarez@us.es, Ruth, Rodríguez-Martinez Universitat Pompeu Fabra- ruth.rodriguez@upf.edu y Marcel. Mauri de los Ríos - Universitat Pompeu Fabramarcel.mauri@upf.edu

La necesidad de rendir cuentas ante la ciudadanía se presenta como uno de los retos más importantes a los que se enfrentan los medios de comunicación. Con el fin de conocer hasta qué punto los medios han incorporado y hacen uso de los instrumentos de rendición de cuentas, el grupo de investigación MediaACES (Accountability y Culturas Periodísticas en España. Impacto y propuesta de buenas prácticas en los medios de comunicación MINECO/FEDER, UE, ref: CSO201566404-P) ha desarrollado una herramienta que permite determinar la presencia de este tipo de instrumentos creados por los medios de comunicación. Los instrumentos recogidos en esta propuesta están vinculados a aspectos fundamentales como la transparencia, la autorregulación y la participación de la audiencia. Los resultados derivados del empleo de la herramienta, que emplea un sistema de puntuación cuantitativa, identifican el tipo de instrumentos de rendición de cuentas que los medios ponen a disposición de los usuarios; determinan en qué medida un contexto mediático es responsable o no; y detectan aquellos aspectos que los medios deben optimizar para garantizar un ejercicio periodístico ético y responsable.

* 180 - Propuesta educomunicativa en Ruanda: una radio escolar como medio para el desarrollo - Lis Gaibar García Universidad Miguel Hernández de Elche - lisgaibar@gmail.com y José Luis González-Esteban - Universidad Miguel Hernández de Elche-jose.gonzalez@umh.es

Durante los meses de julio a septiembre de 2019 se desarrolló en el instituto público ESSA Ruhengeri, ubicado en la localidad ruandesa de Musanze (Provincia Norte), un proyecto de radio escolar con contenidos fundamentalmente divulgativos y de entretenimiento. La formación se ideó en base a una investigación previa del ecosistema 
mediático ruandés y las prácticas educomunicativas de iniciativas nacionales, y se tuvo en consideración para el desarrollo de la iniciativa el modelo de la radio de la universidad pública ruandesa, que configura un espacio de aprendizaje para el estudiantado y goza de un sentimiento de pertenencia muy elevado por parte de la comunidad a la que se dirige.

El contexto histórico, económico y sociopolítico de Ruanda, así como las necesidades y preferencias del instituto público partícipe del proyecto (ESSA Ruhengeri), ha condicionado el desarrollo de la formación. La dinámica de las clases, la elaboración de la programación y la actual continuidad del proyecto se han basado en procesos horizontales y participativos, coordinados desde sus inicios con la ayuda de un profesional local.

El presente estudio pretende contextualizar la realidad del medio radiofónico en el país y presentar algunas iniciativas exitosas vinculadas a contenidos divulgativos — Radio Salus y Energy Radio-, para posteriormente desmenuzar los aciertos y las dificultades encontradas durante el proceso formativo y técnico de la radio escolar, compartir los resultados de la observación participante y los métodos cuantitativos (encuestas) y cualitativos (entrevistas) y exponer una serie de conclusiones que, aplicadas a los contextos particulares, puedan configurar una aportación válida para las investigaciones y desarrollos de proyectos vinculados con la educomunicación.

* 181 - Frente a la vía fast digital, el movimiento slow como brújula y la lectura como mapa de navegación: hacia el puerto de las ideas - Udane Goikoetxea -UPV/EHUudane.goikoetxea@ehu.eus

El presente trabajo es la carta de presentación de la Tesis sobre la importancia de la lectura que se enmarca dentro del movimiento slow en la sociedad actual. "Nadamos en un mar de información," afirma Susan Greenberg. No hay día que no se hable sobre el riesgo del dominio de internet, el dominio de la imagen, el riesgo del aislamiento o la superficialidad. Pertenecemos a una sociedad de la información en la que la imagen está por encima del texto y sin duda, en un modo de 
vida en la que interesa lo inmediato. Parece que en el siglo XXI la lectura ha pasado a un segundo plano ante la fuerza de la televisión, el ordenador y los móviles. La atracción de las tecnologías puede nublar esa atención que requiere la lectura, la concentración, la capacidad de reflexión. Ante esta realidad fast hacemos un acercamiento al movimiento slow, que surge como respuesta a la sobrecarga informativa y que nos sirve como brújula para poder navegar teniendo como base el mapa que ofrece la lectura y así poder partir hacia el puerto de las ideas.

* 182 - Frente a la vía fast digital, el movimiento slow como brújula y la lectura como mapa de navegación: hacia el puerto de las ideas - Abel Suing- Grupo Comunicación y Cultura Audiovisual, Universidad Técnica Particular de Loja arsuing@utpl.edu.ec

Las empresas de comunicación, al igual que en otras iniciativas de mercado, buscan beneficios en sus actividades, sin embargo, responden a condicionamientos particulares en razón del doble público al que sirven, consumidores y anunciantes, pero también por el valor cultural e ideológico de la información. En los últimos años, a consecuencia de la Ley Orgánica de Comunicación, las empresas informativas del Ecuador debieron comprometer recursos para cumplir con cuotas de contenidos y otras regulaciones que les significaron incrementos en los costos de operación, esto junto a la transición digital implican cambios en los modelos tradicionales de operación. Estás variables probablemente inciden en la "salud" económica y financiera de las empresas mediáticas. El propósito de la investigación es evaluar la viabilidad económica de las empresas de comunicación más grandes del Ecuador a partir de los resultados de los ejercicios económicos de 2014 a 2018. El método de investigación es cuantitativo, se estudian los estados financieros declarados ante el Servicios de Rentas Internas (SRI). El ranking de las empresas de Ecuador muestra cifras decrecientes que evidencian la urgencia de diversificar servicios, y de asumir nuevas alternativas tecnológicas y de operación comercial, para alcanzar los fines tanto empresariales como de responsabilidad hacia sus audiencias en la edificación de la opinión pública. 
* 183 - Microsegmentación electoral y entrevistas blandas en España. Candidatos que posan para Vogue y chutan para Marca - Raquel Quevedo Redondo - raquel.quevedo.redondo@uva.es - Universidad de Valladolid y Salomé Berrocal Gonzalo Universidad de Valladolid

La investigación que se presenta al XI Congreso Internacional Latina de Comunicación Social aborda el auge de las llamadas "soft interviews" en año de celebración de elecciones a Cortes Generales en España. En lo tocante a medios impresos, el desarrollo del patrón comunicativo que caracteriza a las entrevistas blandas protagonizadas por políticos españoles resulta especialmente notorio en revistas femeninas de alta gama (RFAG) como Glamour, Telva, Woman, Elle o Vogue, pero en el último lustro también se ha observado una progresiva implantación del enfoque 'soft' tanto en suplementos de periódico como en diarios de información deportiva. Así, no sorprende comprobar que en abril de 2019 cinco de los candidatos a la presidencia del Gobierno posaron para el diario Marca, respondiendo a interrogantes que, en la mayoría de ocasiones, apuntaban a aspectos alejados del cuestionario político tradicional. Para averiguar cuáles son los rasgos distintivos de este nuevo tipo de entrevista en el medio impreso, la presente investigación se apoya en la metodología del análisis de contenido. Igualmente, la popularidad del tipo de prensa a analizar y las características más o menos concretas de su público instan a cotejar datos de encuestas a cientos de lectores, a fin de extraer los rasgos sociodemográficos, socioeconómicos y psicográficos de un target group particular. Con ello se ofrece una información útil para entender y aplicar los beneficios que brinda la microsegmentación electoral.

* 184 - Engagement de redes sociales para el ecosistema chileno de medios de información en Facebook, Twitter, Instagram y Youtube - Luis Cárcamo-Ulloa - Instituto de Comunicación Social de la Universidad Austral de Chile - lcarcamo@uach.cl

El ecosistema de medios de prensa chilenos resulta muy activo en redes sociales. El proyecto Fondecyt 1150545 logró detectar y seguir a más de 500 medios digitales nacionales, regionales e hiperlocales vierten 
contenidos a redes sociales e intentan conseguir interacciones con los usuarios. Tradicionalmente, Twitter y Facebook fueron las plataformas más cómodas para la amplificación de informaciones noticiosas, pero los cambios generacionales hacen pensar en la integración de rutinas periodísticas de community manager también en Instagram y Youtube.

El engagement, al ser una métrica que valora interacciones como valoraciones comentarios y compartidos, parece ser un indicador de eficacia comunicativa obviamente mejor que la cantidad de seguidores o la cantidad de impresiones de un contenido o post. Mitchelstein, Leiva, Giuliano \& Boczkowski (2018) diagnosticaron que las noticias de asuntos públicos tales como política o la enonomía lograban mejores niveles de compromiso que las noticias de asuntos no públicos como deportes y entretención.

El presente artículo diagnostica y compara el factor de engagement de los 30 medios de prensa que más producen información en Chile -sin importar si son televisiones, prensa escrita o radiodifución- y rankea dicho factor para las cuatro plataformas de redes sociales abiertas más comunes: Facebook, Twitter, Instagram y Youtube. Metodológicamente, a) se seleccionaron los 30 medios más productivos de información en base a un dataset de 2,5 millones de noticias vertidas en redes sociales, b) se realizaron seguimientos de las cuentas en redes sociales de los medios de prensa chilenos con la aplicación Karma FanPage en el mes de marzo del presente año y c) se configuraron perfiles informativos (orientados hacia asuntos públicos, no públicos y mixtos) de los medios con mayor engagement. Los resultados sugieren que los medios de mayor engagement en Facebook responden más bien a medios que atienden a fuertemente noticias de asuntos públicos (Cambio 21, El Desconsierto) o con algún grado de mixtura deportiva (Ahora Noticias, Radio Cooperativa y Radio Biobio).

Por otra parte, en Twitter e Intragram alternan medios que se orientan hacia asuntos públicos (El desconcierto, Cambio 21), pero también logran buen engagement medios témáticos de asuntos no públicos (AS Chile, Página 7). Finalmente, las observaciones sobre Youtube hacen pensar que prevalece el peso de los canales de televisión tradicionales (Chilevisión, Tele 13 y Mega) y se incorpora con fuerza el trabajo de 
Las nuevas narrativas, en el entorno social

las transnacional informativa sueca publimetro (Publimetro-Chile y su herramienta publimetro TV).

* 185 - La recuperación del montaje vertical en el cine digital: comparación de "Un perro andaluz" y "Requiem for a dream" - José Luis Valhondo Crego - Universidad de Extremadura jlvalcre@unex.es-Grupo ARDOPA

En su acepción clásica, el montaje fílmico consiste en un proceso de descomposición de la acción y su recomposición en un flujo de imágenes que terminan montándose en la mente del espectador con un objetivo retórico. Como ha señalado Karen Pearlman, los editores suelen guiarse por cinco operaciones: mirar, clasificar, recordar, seleccionar y componer. Son etapas que coinciden con las descritas en los manuales clásicos de retórica. El modo en que se combinan esas operaciones se traduce en el estilo de montaje. Nuestra concepción clásica y popular del montaje se identifica con lo que los teóricos denominan montaje horizontal, secuencial o narrativo. Nogueiras nos recuerda que el montaje clásico trata de un conjunto de procedimientos cuyo principal propósito es la caracterización de personajes y la construcción del espacio, tiempo y la causalidad siempre bajo la premisa de crear la ilusión de realidad, es decir, en cuanto es posible, hacer desaparecer el dispositivo de representación. Por decirlo en palabras de Bürch, este estilo se ha destacado como el Modo de Representación Institucional cinematográfico. Sin embargo, dentro de la retórica fílmica también existió un tipo de montaje distinto basado en la composición del plano más que en su yuxtaposición. Nos referimos al montaje vertical, que trabaja con la profundidad de campo, la pantalla dividida, las inserciones, las sobreposiciones o el movimiento de cámara. Este texto aborda cómo este tipo de montaje que era propio del surrealismo de Buñuel ha sido recuperado en el cine digital sin dejar de ser popular. Para ello realizamos un análisis comparativo de Un perro andaluz y "Requiem for a dream". Concluimos con una reflexión sobre cómo la tecnología del cine digital puede haber cambiado nuestra concepción del relato clásico.

* 186 - Populismo mediático y sátira política: una perspectiva histórica de la apelación al "pueblo" - Agustín Vivas Moreno - 
Universidad de Extremadura - aguvivas@unes.es - Grupo

ARDOPA y José Luis Valhondo Crego - Universidad de Extremadura-jlvalcre@unex.es-Grupo ARDOPA

Si repasamos el debate académico actual en torno al populismo, se pueden distinguir dos relatos antitéticos que, comparados, pueden dar la impresión al lector de que no se está hablando del mismo término. Por un lado, encontramos a aquellos que entienden el populismo en función de una idea de "pueblo" reencarnado en la necesidad política de dar sentido a las promesas de la modernidad. El populismo se significa aquí la energía pura y auténtica de los pueblos en aras de empoderarse y tomar las riendas de sus destinos plantando cara al poder. Por otro lado, en otros contextos político-mediáticos, especialmente nos referiremos a Europa y Estados Unidos, el populismo tiene la connotación negativa de un término ya acuñado por los griegos: demagogia. La demagogia siempre ha sido parte de la política. El agente de esa demagogia es la élite y su víctima el pueblo, a quien instrumentaliza bajo la excusa de empoderarlo. Este texto se ocupa de tratar la cuestión del populismo a través de la comunicación social de la sátira en diferentes épocas de la Historia española, desde el siglo XVII hasta el XX, entendiendo el populismo en su acepción negativa, como un relato que se reinventa a cada paso en la Historia y se transforma en función de un mínimo común denominador: el deseo. El populismo extrae su energía política de esa identificación más primaria que nos conecta como humanos. A partir de la Colección de Papeles Varios del Archivo Histórico de la Universidad de Salamanca (A.U.S.A.) y la prensa satírica del siglo XX, realizamos una comparación de lo que se ha denominado la razón populista. Nuestro análisis confirma una serie de características presentes en la prensa satírica reciente que ya figuraban en el Barroco, una época que, como recuerda Maravall, presenta rasgos de una cultura de masas.

* 187 - M. N. Shyamalan y la deconstrucción de héroes y villanos en el cine fantástico: Análisis e interpretación del tratamiento de personajes en la trilogía cinematográfica de El Protegido (2000), Múltiple (2017) y Glass (2019). - Anna Tarragó Mussons Universidad de Barcelona - annatarrago@ub.edu 
Cuando en el año 2000 M. Night Shyamalan -tras su exitoso debut en Hollywood con El sexto Sentido (1999)- estrenó El protegido, todavía no tenía en mente el universo que construiría posteriormente alrededor de su protagonista fetiche, David Dunn (Bruce Willis). Un antihéroe inicial que derivó en superhéroe gracias a su némesis, Mr. Glass, acabaría aceptando su condición y desarrollándola posteriormente en Glass (2019), al enfrentarse a la asociación de villanos encabezada por Mr. Glass y La Bestia, a la que el público conoció en Múltiple (2017), para finalmente unir fuerzas contra unos detractores mucho más peligrosos dispuestos a acabar con héroes y villanos indiscriminadamente. Shyamalan construyó una trilogía nada típica, ya fuera por su estructura (que puede ser vista por separado y de forma independiente); por su recepción (fueron los fans de Shyamalan los que pidieron durante años una secuela para El protegido); o incluso por el tratamiento de sus personajes, muy alejados de los habituales superhéroes y supervillanos de franquicias como Marvel o DC. Shyamalan quiso crear personajes verosímiles jugando con los recursos narrativos habituales en su filmografía, esencialmente centrada en mundos ordinarios que se ven alterados por un hecho fantástico trascendental que cambiará o mejorará a sus personajes de forma definitiva.

A partir de la tesis realizada sobre la trayectoria de este cineasta y su pertenencia a la segunda generación de Storytellers fantásticos, esta comunicación trabaja el análisis de protagonistas, coadyuvantes y antagonistas de esta trilogía, estudiando la creación de dichos personajes (tramas, referentes y arquetipos, así como sus relaciones afectivas y conflictos principales) para demostrar que Shyamalan, a través de la reformulación de narrativas clásicas, no habla simplemente de superhéroes, sino de personas convencionales, adaptadas o inadaptadas de la sociedad actual, que en un momento dado se pueden comportar como verdaderos héroes cotidianos.

* 188 - Propuesta de un cuestionario breve de adicción al Smartphone - Ubaldo Cuesta Cambra - Catedrático UCM ucuestac@ucm.es, Victoria Cuesta Díaz - Enfermera Hospital Quirón de Madrid - victoria.cuesta.diaz@gmail.com, Luz 
Martínez Martínez - Profesora UCM - luzmar03@ucm.es y Jose Ignacio Niño González - jnino@ucm.es

Diferentes trabajos han analizado la adicción al Smartphone (Young, 2009; Beard, 2005). Sin embargo, todavía no existe una base teórica sólida que permita interpretar desde la psicología social este trastorno adictivo, ni una herramienta de diagnóstico precoz breve derivada de este fundamento (Cuesta, Cuesta y Martinez, 2019). Se hace indispensable la creación de herramientas que permitan estudiar los mecanismos psicosociales que subyacen al uso problemático del Smartphone, y que aporte conocimientos que permitan analizar sus fundamentos psicosociales.

Objetivo: El objetivo de esta investigación ha sido la creación, desde un planteamiento psicosocial, de un cuestionario breve de adicción/uso problemático al Smartphone.

Método: Un meta análisis de la bibliografía permitió detectar los factores psicosociales intervinientes validados empíricamente sobre los que existe mayor consenso. Posteriormente se realizaron tres grupos de discusión y cinco entrevistas en profundidad entre expertos y profesionales. Con estos datos se elaboró un cuestionario abreviado de nueve ítems el cual fue cumplimentado por una muestra de 66 sujetos jóvenes universitarios.

Resultados: El cuestionario obtuvo adecuados valores de Cronbach y test-retest en todos los ítems. Se han obtenido también resultados de validez concurrente analizando las correlaciones con los resultados académicos y se han analizado valores descriptivos de la muestra, así como diferencias de género. El análisis factorial realizado permitió encontrar una estructural factorial de 4 factores de consumo. Fueron denominados, en función de las varianzas explicadas por cada, de la manera siguiente: envolventes, socializados, virtualizados y estresados. Estas denominaciones, que remiten a los factores psicosociales presentes con mayor peso en cada factor, parecen indicar la existencia de diferentes patrones de consumo problemático del móvil. En un futuro se deberá explorar la existencia de estos (u otros) factores, lo 
que supone replantearse la adicción al Smartphone dentro de un único concepto o patrón unitario.

* 189 - Índice de Transparencia de Marca: una propuesta metodológica para la medición de la transparencia de marca como aspecto central de la comunicación estratégica - Andrés López Martínez - Técnico investigador en la Cátedra de la Marca Corporativa de la Universidad de Alicante y estudiante de Doctorado en Empresa, Economía y Sociedad en la Universidad de Alicante - andres.lm@ua.es

En el año 2013 se produjo el derrumbe de un edificio comercial en Bangladesh que costó la vida a más de mil personas. Entre las dependencias del inmueble denominado 'Rana Plaza' se encontraban varias fábricas textiles, que confeccionaban prendas de ropa para marcas de reconocido prestigio como El Corte Inglés o Mango, entre otras. Este accidente despertó a diferentes movimientos sociales alrededor de la industria de la moda textil exigiendo transparencia a marcas para que declarasen dónde estaba fabricada la ropa. Por su parte, las marcas de la moda textil, y de otros sectores, son cada día más receptivas a adoptar medidas de rendición de cuentas, a compartir más información sobre sus acciones, e incluso a asumir la transparencia en el centro de sus estrategias comunicativas. El presente trabajo tiene como objetivo aportar un mecanismo objetivo y empírico de medición de la transparencia de marca, definida por Olivares (2018) como "el flujo de información de marca relevante, exacta y clara hacia los grupos de interés a partir de indicadores objetivables". Se realiza una propuesta metodológica del Índice de Transparencia de Marca (ITM). Este índice ofrece la posibilidad de evaluar cuánto de clara, exacta y relevante es la información que comparten las compañías y organizaciones sobre sus marcas. La medición de la transparencia de marca se realiza a partir de una metodología estadística concreta basada en diferentes bloques y variables de cálculo, a partir del trabajo previo de Bonsón y Escobar (2006), Olivares (2018) y Sanz y Bernal (2008), entre otros. Los resultados apuntan que indicadores o índices como el ITM se plantean como fundamentales en el presente y en el futuro para medir el desempeño en materia de transparencia en las estrategias comunicativas de las organizaciones. 
* 190 - La internacionalización de la Universidad Autónoma de Barcelona y la comunicación estratégica - Erika Marisol Ruiz Castillo - Universidad Autónoma de Barcelona (España) erikamarisol.ruiz@e-campus.uab.cat y Norminanda Montoya Vilar - Universidad Autónoma de Barcelona (España) Norminanda.Montoya@uab.cat

La internacionalización de la educación superior es un proceso que se debe realizar desde la raíz de la institución para que pueda aplicarse de una manera eficaz y arroje resultados que le permitan competir en el sistema globalizado. Actividades como la difusión de la investigación, atracción de estudiantes internacionales y la ampliación curricular de sus académicos están implicadas en el proceso de internacionalización y demandan para su ejecución una estrategia organizacional junto con una comunicativa.

El objetivo de la presente investigación ha sido estudiar cómo está gestionando la Universidad Autónoma de Barcelona su estrategia de internacionalización, abordándola desde una perspectiva comunicológica, además de identificar las áreas de la organización involucradas en los procesos y acciones. La metodología utilizada es de carácter cualitativo, con enfoque descriptivo y exploratorio, centrada en entrevistas en profundidad semiestructuradas a los máximos responsables de la Internacionalización y de Comunicación de la Universidad Autónoma de Barcelona. Además, se confronta con un análisis de su sitio web oficial y documentos de la propia institución.

Dentro de las conclusiones del estudio se menciona la importancia de las relaciones públicas internacionales y la comunicación directa entre grupos de investigación como detonantes principales de los convenios universitarios. Además, destaca la figura del Vicerrector de Relaciones Internacionales como un agente articulador en el proceso de internacionalización, el cual facilita la comunicación entre los cuerpos académicos y las distintas instituciones educativas.

* 191 - Las metodologías proppiana y lógico estructural: usos en la virtualización y capacidad prospectiva - C. Rosa Borrás 
Las nuevas narrativas, en el entorno social

Machado-Universidad Complutense de Madridrossboma@gmail.com

La presente ponencia ofrece una visión de la evolución de la comunicación en el ser humano. Las nuevas tecnologías, arraigadas en la vida de gran número de ciudadanos, se han convertido en una herramienta comunicacional. Las TIC no solo resultan útiles para la transmisión de la palabra (oral y escrita) y su perdurabilidad, sino que esbozan una aldea global mediática y mediada con participación activa en algunos aspectos del cambio social.

El mundo virtual se torna más que interesante para evidenciar la aplicabilidad de la metodología proppiana combinada con la lógica para el análisis comunicacional acaecido en estos medios. Caso del estudio de la actividad en Facebook y Twitter de los candidatos a presidente del Gobierno de España en la campaña electoral del año 2016. Estos líderes políticos, o los gestores de dichas redes sociales en los partidos estudiados, interactuaban con los ciudadanos interesados en seguirlos por estos medios. El análisis plasmó una aproximación a la realidad, pero no por el número de seguidores o comentarios y likes recibidos, sino por el estudio de esas comunicaciones, lo que estos candidatos transmitían y lo que los adeptos y no adeptos expresaban.

Todo ello permite ir más allá y comprender la capacidad prospectiva de los métodos lógicos en la virtualización; aquellos escenarios posibles y no posibles, atendiendo a la consistencia de los componentes, a las constricciones presentes en dichos escenarios.

* 192 - De niñas campesinas a mujeres de ciudad - el discurso educativo en la construcción identitarias de las mujeres en Duitama-Colombia (1920 a 1970) - Mónica Patricia, Perassi Corporación Universitaria Minuto de Dios monica.perassi@uniminuto.edu

Colombia durante las primeras cuatro décadas tuvo un incremento poblacional que se dividía entre el campo y la consolidación de cabeceras municipales por las migraciones internas. A partir de la década del cincuenta el proceso de urbanización se consolida 
convirtiendo a Duitama en zona de una rápida agro-industrialización. Las condiciones para los migrantes del campo a la ciudad, fueron diversas, pero en particular las mujeres campesinas sufrieron un panorama de doble discriminación.

Mientras la educación las había formado para ser mujeres a cargo del cuidado hogar y ejercer ayuda en las labores del campo, la crisis agraria, los desequilibrios regionales, el auge del comercio y los servicios, la presión demográfica en el campo y la violencia política las llevaron a movilizarse a las ciudades, encontrando un campo laboral cerrado en las industrias hacia los hombres y relegándolas a actividades de mercados informales.

Así, los discursos educativos de la época condicionaron los campos de acción que poco a poco se abren camino cumpliendo con los deberes asignados por estos, pero modificando poco a poco.

Lo que aquí se presenta es el acceso real de las mujeres de la época a la escuela y a los espacios de desempeño laboral que se abrieron para ellas. Para ello se trabajó con una muestra poblacional de tres mujeres nacidas en las décadas de los veinte y los treinta, encontrándose así para 1940 en su etapa productiva y reproductiva. De ellas se recolectó el relato de la vida de la época, pudiendo identificar cuáles fueron las formas de habitar el mundo desarrollado por estas mujeres, no siempre acordes a las formas del "deber ser" propuestas por la educación, incluso siendo discriminadas y juzgadas por sus modelos económicos y sociales.

* 193 - Propuesta metodológica para el estudio de la presencia del sexo en los cibermedios - Jose-Luis Argiñano - Universidad del País Vasco/Euskal Herriko Unibertsitatea (UPV/EHU) Joseluisarguinano@ehu.eus, Rubén Olveira Araujo Universidad del País Vasco/Euskal Herriko Unibertsitatea (UPV/EHU) - ruben.olveira@sexmediaresearch.com

Es irrefutable la presencia del sexo en los medios de comunicación. Sin embargo, su representación mediática parece estar limitada por una visión sesgada que encajona el sexo como agente opresor. Del mismo 
modo, las escasas investigaciones académicas que se han centrado en esta dimensión lo han hecho desde una perspectiva de género, que entiende el sexo como fuente de desigualdades. Teniendo en cuenta que la teoría de la agenda-setting ha demostrado que los medios de comunicación son capaces de moldear el imaginario colectivo mediante la preeminencia de unos temas y encuadres sobre otros, es indudable la influencia de los news media en la manera en la que la sociedad piensa y afronta la cuestión sexual. Con el objetivo de abordar la representación de esta dimensión de una forma holística y no únicamente desde una perspectiva de poder, este trabajo presenta una metodología para análisis de la representación mediática del sexo y, más concretamente, del «sexo que se hace» en los cibermedios. Para ello, se han identificado una serie de nociones o unidades cognitivas de significado epistemológico que tienden a asociarse a esta dimensión. La clasificación de las informaciones en función de su carácter positivo o negativo, junto a la tipología de los titulares y las temáticas, son otras variables que también se tienen en cuenta y que, paralelamente, contribuyen a identificar características del periodismo de servicio.

* 194 - Los conflictos sociales (2016-2018) y la marca Barcelona como destino turístico - Diego Brito Lorenzo- Universidad de La Laguna - diegobritolorenzo@gmail.com

Barcelona tiene una marca como destino turístico que está intrínsecamente relacionada con la región de Cataluña y con su marca ciudad. La situación política, el atentado terrorista de las Ramblas, la paradoja de los pisos turísticos y las reticencias de los residentes hacia la actividad turística y el turismo en sí (turismofobia es el término empleado por los medios de comunicación) han provocado un resentimiento de esta marca, sobre todo en aspectos de reputación y percepción de los diferentes públicos.

El punto de partida de este análisis han sido los conflictos sociales que se han producido en la ciudad de Barcelona desde el año 2016, evaluando cómo afectan los mismos a tres públicos principales: turista residente en España, turista extranjero y residente en la ciudad condal. Se ha realizado una revisión conceptual, contextualización y definición de los diferentes conflictos para aplicar una metodología que permita 
valorar la afección de los mismos a las diferentes tipologías de público y turistas.

A través de entrevistas en profundidad, one to one, análisis cualitativo y encuestas se ha determinado que la marca Barcelona como destino turístico se ha visto afectada por los diferentes conflictos sociales estudiados. En términos de reputación sufre una caída, con indicadores de pérdida de visitantes, $\mathrm{y}$ ha perdido el reconocimiento de dos de sus públicos principales: turista residente en España y residentes en la ciudad condal.

* 195 - La promoción de valores relacionados con los Objetivos de Desarrollo Sostenible (ODS) en la programación de Playz Isaac Maroto González - Universidad de Santiago de Compostela - isaac.maroto@rai.usc.es y Talía Rodríguez Martelo - Universidad Complutense de Madrid talrodri@ucm.es

Desde el año 2016 los Objetivos de Desarrollo Sostenible han marcado la ruta política y social de los países que adquirieron el compromiso de la agenda 2030. Dichos objetivos promueven valores de protección hacia las personas, la sociedad y el medio ambiente y forman parte de la estrategia de responsabilidad social de la corporación de RTVE. A través de su canal Playz, cuyo público principal son los jóvenes, RTVE articula una serie de contenidos audiovisuales que atienden a múltiples temáticas. En calidad de canal perteneciente a la televisión pública, este trabajo analiza la función de servicio público en la difusión concreta de la información y los valores expuestos en su estrategia de comunicación y responsabilidad social corporativa. La investigación planteada propone una aproximación analítica y descriptiva del canal Playz y cómo integra la divulgación y promoción de los valores de los ODS a través de sus contenidos audiovisuales y nuevos formatos interactivos.

* 196 - Prensa comunicación y transiciones políticas a ambos lados del Atlántico - Joaquín Baeza Belda - Universidad de Salamanca-baeza@usal.es 
1983 es una fecha clave para la historia reciente argentina, ya que marca el retorno a la democracia y el fin de un ciclo de inestabilidad política e intervencionismo militar rastreable desde 1930. Por supuesto, eso no quiere decir que no existieran hilos que comunicaran con la etapa anterior y que esta no fuera motivo de debate. Precisamente, esta propuesta se centra en un actor, el diario La Voz del Mundo, que nació en 1982, todavía en dictadura, y tuvo su última edición tres años después, recorriendo, por tanto, los años centrales de la última transición a la democracia en Argentina.

A medio camino entre los problemas planteados por la comunicación social y la historiografía, nuestro objetivo es rastrear cómo se interpretaba el pasado reciente del país en las páginas claves de La Voz: qué fechas jalonaban ese relato, qué se recordaba y qué interpretación, en general, se daba a este proceso. A pesar de que La Voz, editado en Buenos Aires, no fue un diario con gran tirada, su caso es interesante por diversas razones. En primer lugar, porque tras su dirección se encontraban miembros de la organización armada Montoneros: aunque el periódico se caracterizó por la pluralidad de voces dentro del espectro progresista, es una manera de adentrarnos al pensamiento de esa izquierda peronista tras el fracaso de su proyecto revolucionario.

El peronismo, además, cayó por primera vez derrotado en unas elecciones presidenciales en 1983, lo que abrió una fuerte crisis de identidad. Este recorrido por la interpretación historiográfica de La Voz también nos ayuda a comprender cómo se pensaba en sus páginas el peronismo, movimiento político caracterizado por sus líquidas fronteras ideológicas. Asimismo, este repaso nos sirve para conocer la visión de la democracia que tenían estos sectores en un momento clave para su regreso y consolidación.

* 197 - Nuevas narrativas en RTVE ante el cambio de siglo. Las series Mar de dudas y La pecera de Eva como casos de estudio de interactividad y fronteras narrativas - Elena de la Cuadra de Colmenares - Universidad Complutense de Madrid ecuadra@ucm.es 
Conceptos como "nuevas narrativas" o "hibridación de formatos" se están extendiendo en los estudios sobre la televisión en el mundo, impulsados por las tendencias emergentes que Internet y las plataformas han propiciado en las narrativas de ficción. Sin embargo, los nuevos modos en televisión, concretamente en ficción, no son exclusivos del siglo XXI. En este análisis veremos cómo dos ficciones en a caballo del cambio de siglo experimentaron desdibujando las fronteras de los géneros y las narrativas. Mar de dudas (TVE, 1995) y La pecera de Eva (Telecinco, 2010) fueron dos series pioneras en diferentes aspectos: la primera dejaba en manos del espectador la resolución de los conflictos de la trama; la segunda experimentaba desafiando los modos en que tradicionalmente los actores se aprenden un guion y se desenvuelven en escena, además de ser uno de los pocos casos de ficciones en España con cross over entre series.

Esta comunicación se enmarca en el Proyecto I+D+I "Historia de la programación y programas de ficción televisiva en España (cadenas de ámbito estatal): de la desregulación al apagón analógico, 1990-2010 (CSO215-66260-C4-C-P), dirigido por Charo Lacalle Zalduendo, financiado por el Ministerio de Economía y Competitividad en el marco del Plan Estatal de Investigación Científica y Técnica y de Innovación 2013-2016, como proyecto del Programa Estatal de Fomento de la Investigación Científica y Técnica De Excelencia.

* 198 - Medios audiovisuales de servicio público y desinformación. Principales políticas y estrategias contra las noticias falsas - Ana María López Cepeda - Universidad de Castilla-La Mancha-Ana.lopezcepeda@uclm.es, María José Ufarte Ruiz - Universidad de Castilla-La Mancha Mariajose.ufarte@uclm.es y Francisco José Murcia Verdú Universidad de Castilla-La Mancha-Francisco.murcia@uclm.es

El incremento de noticias falsas, que tienen como objetivo distorsionar la realidad y generar confusión entre la verdad y la mentira, se ha convertido en una problemática social a nivel global. La verificación de la información ha surgido como elemento fundamental para la profesión periodística y ya se han lanzado algunas experiencias desde diversos medios de comunicación, plataformas y organizaciones. La 
Unión Europea ha presentado un Plan de Acción - en vigor desde 2019- para contrarrestar cualquier campaña de posverdad, basado en un incremento de los recursos, la coordinación, la elaboración de un código de buenas prácticas y la creación de grupos de verificación y contraste de datos. En este contexto, el papel de los medios audiovisuales de titularidad pública no tiene que ser secundario y debe liderar un proceso de alfabetización mediática coordinado en cada Estado miembro para recortar el incremento de la desinformación. El objetivo de esta investigación es analizar las políticas y estrategias que las principales radiotelevisiones públicas europeas están aplicando para potenciar la lucha contra las fake news. El diseño metodológico para alcanzar este propósito parte de la revisión sistemática de la literatura científica, que ha permitido conocer las principales aportaciones al estado de la cuestión y generar un relato sobre este tema, que es de interés creciente en el área de Comunicación, pero aún no exhaustivamente abordado. Además, se analiza la literatura gris (memorias, informes y otros documentos) y acciones desarrolladas por las televisiones públicas objeto de estudio. Los resultados revelan que se perfilan nuevas políticas y estrategias en los medios audiovisuales de servicio público asociadas a la lucha contra la desinformación y las noticias falsas.

* 199 - Rafael Nadal, la marca personal más reconocida internacionalmente dentro del deporte profesional español Santiago Mayorga Escalada - Universidad Europea Miguel de Cervantes-smayorga@uemc.es

El marketing deportivo despega en Estados Unidos en la década de los 70 del siglo pasado junto al desarrollo profesional del deporte entendido como una parte fundamental dentro de la industria del espectáculo. Se construyen grandes competiciones, aparecen deportistas elevados a la categoría de ídolos, se profesionalizan todas las actividades que rodean al negocio y los medios de comunicación de masas generan audiencias millonarias lo que implica una inversión muy fuerte del sector publicitario aupada en gran medida también por el inicio de la infatigable disputa entre Nike y Adidas. 
Dentro de los cambios disruptivos experimentados a lo largo de la llegada del siglo XXI se encuentran los nuevos paradigmas de la comunicación, el poder de los usuarios y el protagonismo que han alcanzado las marcas hasta convertirse en los activos estratégicos más valiosos de las organizaciones. Las sociedades líquidas construyen un nuevo imaginario colectivo donde las marcas pasan a ostentar una posición de icono cultural, comercial y simbólico de naturaleza eminentemente global.

La nueva coyuntura ha permitido que, en la medida de las circunstancias de cada mercado, el deporte profesional haya tenido que adaptarse. El marketing deportivo, la comunicación estratégica y todo lo relativo a nuevas tendencias en publicidad han entrado dentro del sector. Especialmente relevante es todo lo que tiene que ver con el branding y la gestión de marcas dentro del ámbito del deporte profesional. En este sentido se hace necesario analizar y conocer cómo se está construyendo y cuál es la situación de la marca del deportista español más laureado de la historia, Rafael Nadal.

* 200 - La reputación corporativa online del sector terciario en México: una propuesta metodológica - Ma del Carmen Gómez de la Fuente - Universidad Autónoma de Tamaulipas mcgomez@docentes.uat.edu.mx

Actualmente, las empresas se enfrentan a un entorno globalizado de cambios constantes derivados por el uso de las TIC, ofrecen servicios que están susceptibles a la evaluación de la calidad mediante el uso del internet, de ahí radica la importancia de contar con una reputación sólida que le ayude a mantener los estándares competitividad en el mercado, tal y como lo define Galvis \& Silva (2016, p. 206), la reputación en línea puede ayudar a crecer una empresa o destruir en minutos su tradición, su historia y su permanencia en el mercado; tomando en cuenta que el cincuenta por ciento de la población mundial tiene acceso a Internet, se observa una gran interacción de los usuarios, ya sea como simples espectadores, o bien, como prosumer generando contenidos que marcan tendencia en la información, para vender un producto, o un servicio, emitir juicios de valor derivados de la 
experiencia de consumo, generando credibilidad y confianza en los diversos públicos internos y externos es, un reto.

La reputación corporativa tradicional se ha estudiado a lo largo del tiempo tanto en Europa como en Estados Unidos principalmente desde diversas perspectivas teóricas del campo de la administración, la comunicación, el marketing, la publicidad y la antropología, entre otras disciplinas. En México, la reputación corporativa ha evolucionado en su forma de operar y entrar a este nuevo entorno digital.

La presente investigación tiene como principal objetivo presentar una propuesta metodológica con base en la revisión teórica que aborda el estudio del comportamiento organizacional, las teorías comunicativas, de imagen y de gestión en un entorno digital, tomando en cuenta que, la reputación corporativa se construyó con las percepciones de acciones pasadas y futuras en la mente de los consumidores y a diferencia de la competencia para incidir en una respuesta favorable a las empresas e instituciones.

* 201 - El entorno 'blockchain' y su potencial innovador en el área del periodismo y los medios de comunicación - Marçal Sintes - Olivella Facultad de Comunicación y Relaciones Internacionales Blanquerna (Universidad Ramon Llull) marcalso@blanquerna.url.edu, Elena Yeste-Piquer Facultad de Comunicación y Relaciones Internacionales Blanquerna (Universidad Ramon Llull) - elenayp@blanquerna.url.edu Joaquín Marqués-Pascual EAE Business School joaquin.marques@campus.eae.es

El periodismo se enfrenta a una grave crisis causada por un brusco cambio de contexto que se inició con los procesos de digitalización. La extensión de Internet y, en especial, de las redes sociales, así como los consiguientes cambios en las formas de consumo mediático explican en gran parte lo que ocurre. Los medios de comunicación convencionales se enfrentan desde hace años a la necesidad de rediseñar su modelo de negocio, pues sus cuentas de resultados se han visto fuertemente erosionadas. En paralelo, la confianza del público en el periodismo ha ido menguando hasta un punto alarmante. Tal 
quebranto de la confianza - que tienen su correlato en la pérdida de influencia - tiene mucho que ver con la multiplicación exponencial de la oferta comunicativa - favorecida por la posibilidad de que todos puedan hablar con todos, la llamada por Manuel Castells "autocomunicación de masas"—, el descenso general de la calidad periodística y la incidencia sobre la opinión pública de la desinformación, categoría en la que cabe incluir a las llamadas fake news.

La tecnología de la cadena de bloques, blockchain, nació como base tecnológica de la criptomoneda bitcoin. Sin embargo, dicha tecnología está encontrando otras aplicaciones en una extensa variedad de sectores, principalmente en el financiero. El entorno blockchain, una tecnología relativamente nueva, ofrece algunas posibilidades que pueden ser relevantes y útiles para el periodismo y los medios a la hora de afrontar los citados desafíos. Blockchain —un archivo digital, encriptado, descentralizado e inalterable retroactivamente- no va a convertirse en la solución mágica a todos los problemas que acucian al periodismo, pero sí que ofrece funciones que pueden resultar de utilidad, entre otras cosas, para: a) certificar el origen de los contenidos y detectar su manipulación ilícita, b) preservar los derechos de propiedad intelectual, c) favorecer la transparencia y la accountability mediática, d) limitar, a través de sistemas de incentivos y de micropagos, las posibilidades de presión externa, e) esquivar la censura en regímenes autoritarios o totalitarios, y f) construir comunidades y obtener financiación mediante el uso de una criptomoneda propia.

Aún son pocas las experiencias de medios de comunicación basadas o que hayan incorporado la tecnología de bloques, pero algunos casos pioneros a nivel internacional pueden servir para reflexionar sobre sus potencialidades y arrojar luz entorno a la discusión en curso sobre el potencial innovador de la cadena de bloques en el área de la comunicación periodística.

* 202 - Virtualización y aportaciones de las TIC en la conservación de la Memoria Histórica - Ana Fuertes Zapatero Universidad de Coruña (fuertesdoc@gmail.com) 
En el actual contexto en el que vivimos de innovaciones tecnológicas continuas, existe una enorme capacidad de producir información gracias a los muchos dispositivos que para ello hay. Transmitir toda esta información que se genera en cualquier momento y lugar a todo el mundo, hace de los procesos de virtualización un fenómeno que hay que tener muy en cuenta y estudiarlo. Como objetivo de la ponencia se ofrecerá una reflexión sobre la aportación de los procesos de virtualización de la información, al mantenimiento y consolidación de la Memoria Histórica. Para ello, nos basaremos en una investigación que a lo largo del año 2012 se realizó desde la Universidad Complutense de Madrid y se denominó: “Tratamiento documental avanzado del archivo audiovisual de los testimonios orales de los Brigadistas Internacionales depositado en el Archivo Histórico Provincial de Albacete".

Esta investigación viene a dar un paso más en la recogida de testimonios y en el depósito de materiales audiovisuales en archivos. Todo ello, desde una perspectiva multidisciplinar de las diferentes ramas de las Ciencias Sociales y dentro de las subvenciones del Ministerio de la Presidencia del Gobierno de España enmarcadas en la Memoria Histórica. Partiendo de los resultados obtenidos y transcurrido este tiempo en el que, a parte de la reflexión, confluyen otros factores como la mediación social. Habremos de preguntarnos sobre si verdaderamente la virtualización es ya real o, en caso contrario, cómo podemos utilizarla para crear definitivamente repositorios en los cuales conservar los trabajos de Memoria Histórica y que ésta llegue a todo aquel público interesado en el tema. En esta ponencia se hará una reflexión sobre este proyecto, su pertinencia y continuidad en el tiempo, ya que sirve como modelo sistematizado para trabajos similares

* 203 - Nociones del concepto de Internet durante la infancia y su implicación en la confianza - Rebeca Martín Nieto Universidad Rey Juan Carlos - rebeca.martin@urjc.es Silvia Guerrero - Universidad Castilla-La Mancha Silvia.Guerrero@uclm.es Elena Varela - Universidad Complutense de Madrid - evarea01@ucm.es 
En los últimos años han proliferado las investigaciones sobre el uso de Internet durante la infancia, la adolescencia y la juventud (Livingstone et al., 2011). La mayoría de los estudios giran alrededor de hábitos de consumo, tiempos de exposición a las pantallas y posibles riesgos (Pastor, Martín, Montes, 2019). Se observan menos acercamientos al concepto de Internet que se tiene en esas edades, así como sus implicaciones básicas: qué es, quiénes son los autores de sus contenidos, cuál es su utilidad o su fiabilidad, entre otros.

En esta comunicación se muestran los resultados obtenidos en la primera fase del proyecto $\mathrm{I}+\mathrm{D}$ "Aprender a través del testimonio durante la niñez. El papel del maestro e Internet como fuentes de información (PSI2016-76399-P)" financiado por el MINECO. En esta fase se desarrollaron 38 entrevistas semiestructuradas, realizadas por psicólogos a niños y niñas entre 5 y 8 años. Se parte de este conocimiento para profundizar, en los siguientes bloques del proyecto, en la confianza que despierta el medio respecto a la que despierta la figura del docente y sus posibles transformaciones.

Las entrevistas se dividieron en varios aspectos: conocimientos generales sobre el medio, la autoría y fiabilidad de los contenidos, preferencia de consulta a una persona o a Internet y un último bloque de conocimiento específico sobre elementos concretos de la red. De los primeros resultados se desprende que la red está integrada en la vida cotidiana durante la infancia, que se observa como una herramienta útil y eficaz en la búsqueda de contenidos específicos, de procedimientos y en cuestiones sobre localización geográfica. En cuanto a la confianza, en los resultados de análisis de las entrevistas se percibe que la credibilidad es similar entre una persona o Internet, aunque se observan algunas diferencias en función de los ámbitos de análisis.

* 204 - Guía didáctica para la secuenciación formativa de las asignaturas Lenguaje Audiovisual y Técnicas de Creación Audiovisual del primer curso de los Grados de Comunicación de la UPV/EHU - Estibaliz Alonso - estibaliz.alonso@ehu.eus y Aintzane Pagadigorria =aintzane.pagadigorria@ehu.eus $\mathrm{UPV} / \mathrm{EHU}$ 
El objetivo del presente trabajo es presentar el Proyecto de Innovación Educativa "Preparación de una guía didáctica para la secuenciación formativa de las asignaturas Lenguaje Audiovisual y Técnicas de Creación Audiovisual del primer curso de los Grados de Comunicación de la UPV/EHU". Este proyecto recoge la experiencia de un proyecto de innovación anterior basado en el modelo IKD (Aprendizaje Cooperativo y Dinámico. Modelo educativo de la UPV/EHU) que buscaba reforzar la secuencia formativa entre las materias anteriormente nombradas, revisando y rediseñando los programas teórico y práctico de ambas, dos asignaturas básicas de rama y complementarias entre sí que se imparten de manera secuencial en el primer curso de los grados de Periodismo, Comunicación Audiovisual, y Publicidad y Relaciones Públicas: Lenguaje Audiovisual (primer cuatrimestre) y Técnicas de Creación Audiovisual (segundo cuatrimestre).

Se trata, principalmente, de sistematizar las prácticas modulares de ambas asignaturas en una guía que incorpore el material necesario para que el profesorado pueda implementar en sus grupos el proyecto audiovisual práctico, secuenciado y común a ambas asignaturas que vertebra la propuesta testada en la precedente experiencia de innovación: fichas de las actividades prácticas y su programación semanal, detalle de las tareas del alumnado, los plazos de entrega y su presentación en el aula; y rúbricas y propuestas de evaluación.

Asimismo, en este nuevo proyecto se buscará introducir nuevas técnicas y mecanismos multimedia que faciliten al alumnado destrezas que se adecúen a los actuales retos del campo de la comunicación; se rediseñará y optimizará el sistema de evaluación, integrando nuevas herramientas; y se impulsará la relación del alumnado con agentes externos del mundo profesional favoreciendo la participación de los proyectos prácticos en distintos certámenes audiovisuales.

* 205 - Percepción del alumnado del primer curso de los grados de Comunicación de la UPV/EHU sobre el Aprendizaje Cooperativo en el marco de la asignatura Técnicas de Comunicación Audiovisual - Aintzane Pagadigorria - 


\section{aintzane.pagadigorria@ehu.eus y Estibaliz Alonso estibaliz.alonso@,ehu.eus UPV/EHU}

Este estudio ha explorado las percepciones del alumnado del primer curso de los grados de Periodismo, Comunicación Audiovisual, y Publicidad y Relaciones Públicas de la UPV/EHU sobre el trabajo cooperativo. La muestra ha estado formada por 164 sujetos matriculados en los grados de Comunicación de la UPV/EHU y que han trabajado de forma cooperativa en grupos de trabajo en la materia "Técnicas de Creación Audiovisual" que se imparte durante el segundo cuatrimestre.

El objetivo principal de esta materia es formar al alumnado para que pueda desarrollar la capacidad de crear y realizar proyectos audiovisuales innovadores; y los contenidos teóricos y prácticos de esta asignatura se centran mayoritariamente en la creación de dichos productos audiovisuales siguiendo las dinámicas del entorno profesional, para lo que es imprescindible potenciar el trabajo cooperativo y en equipo.

Para la recogida de datos se ha utilizado un cuestionario de preguntas que ha sido cumplimentado por cada alumna y alumno individualmente. A través de dicho cuestionario se han obtenido respuestas correspondientes a cuatro categorías: 1) Identificación de los aprendizajes realizados en la materia; 2) Identificación de los aprendizajes realizados sobre el trabajo cooperativo; 3) Valoración de la experiencia con la metodología de aprendizaje cooperativo y 4) Valoración del diseño de la materia. Los resultados nos servirán para realizar propuestas de mejora y ajustes tanto en el diseño de la asignatura como en el planteamiento y formulación del trabajo cooperativo en el aula.

* 206 - Comunicación política y lobbies. Perfiles de los lobbistas en España - Antonio Castillo Esparcia - Universidad de Málaga - acastilloe@uma.es y Elizabet Castillero Ostio - Universidad de Málaga - ecastillero@uma.es 
En el ámbito de la comunicación política, el papel de los lobbies cada vez han adquirido mayor importancia y significación en los procesos de construcción del temario público y en los objetos de discusión pública de las temáticas más relevantes socialmente. Para ello, los lobbies se han dotado de profesionales de la comunicación, cuyas funciones principales son la gestión estratégica de sus campañas de comunicación y la elaboración de actividades específicas para conseguir participar en el proceso de elaboración, discusión y resolución de políticas públicas.

Este texto analiza los perfiles profesionales (denominaciones de los cargos y organizaciones en las que trabajan), los perfiles académicos y los perfiles sociodemográficos de 321 lobbistas españoles. Los resultados nos muestran que, terminológicamente, al lobbista se le define de muchas maneras diferentes, como pueden ser "responsable de relaciones internacionales o gestor de incidencia pública", pero sin utilizar la expresión lobbista. Desde el punto de vista académico, una parte significativa de los lobbistas provienen en primer lugar del Derecho y en segundo lugar de la Comunicación. Por último, son en su mayoría hombres y sobrepasan la edad de 40 años.

Esta propuesta ha permitido comprender con mayor profundidad cómo son los lobbistas en España, avanzando en el conocimiento de la actividad lobbística en nuestro país.

* 207 - Gestión Dialógica de la Comunicación en Facebook: Un Estudio aplicado a las Empresas en América Latina - Paul Capriotti - Universitat Rovira i Virgili (URV), España paul.capriotti@urv.cat e Ileana Zeler - Universitat Rovira i Virgili (URV), España - ileana.zeler@urv.cat

Las redes sociales se han convertido en un instrumento importante de la comunicación de las organizaciones, ya que permiten un modelo de comunicación más participativo basado en la interacción y el diálogo. Los planteamientos conceptuales sostienen que la gestión de la comunicación en las redes sociales se sustenta en los principios de comunicación dialógica: la voluntad de los sujetos (organizaciones y públicos) de establecer un intercambio comunicativo, y la realización 
efectiva del diálogo mediante diversos tipos posibles de intercambio comunicativo entre una organización y sus públicos. El objetivo de este estudio es analizar si las principales empresas de América Latina están impulsando la comunicación dialógica en Facebook. Para ello, se estudió el nivel de predisposición a la interacción y el tipo de interacción alcanzado por las empresas en Facebook. La muestra incluyó el análisis de 30.000 publicaciones en 157 fanpages de empresas que operan en América Latina. Los resultados indicaron que las empresas no desarrollan una comunicación dialógica en esta red social, puesto que falta una mayor predisposición a la interacción, y también porque la interacción generada es muy baja. Esta tendencia se ha manifestado en otros estudios, demostrando la falta de una estrategia de comunicación que se adapte a la naturaleza dialógica de Facebook. Por lo tanto, se observa la necesidad de revisar la estrategia de comunicación en redes sociales y definir una estrategia alineada a la naturaleza dialógica de la red social.

* 208 - La Comunicación En Las Instituciones Europeas. El Caso Del Registro De Transparencia - Andrea, Moreno Cabanillas Universidad de Málaga andrea.morenocabanillas.15@gmail.com

El proceso de construcción europea cuenta con numerosos pasos de profundización en los sistemas y modelos comunicativos que ayuden a que las instituciones de la Unión Europea establezcan, desarrollen y gestionen relaciones satisfactorias con los ciudadanos. Para ello, se han establecido mecanismos de participación ciudadana en los procesos normativos que se gestionan tanto en el Parlamento Europeo como en la Comisión Europea. Uno de los aspectos más relevantes es cómo los ciudadanos comunitarios participan en esos procesos y qué protocolo de actuación se establece. Así, este texto quiere analizar qué es el Registro de Transparencia como mecanismo que permite conocer las organizaciones que tratan de influir en el proceso legislativo y de aplicación de políticas de las instituciones de la UE. La metodología consistirá en analizar cómo se gestiona el registro, qué directrices se siguen para que los representantes europeos (Comisarios, Direcciones Generales) se relacionen con los grupos de interés y qué tipo de organizaciones están inscritas en el Registro. 
* 209 - Esclerosis Múltiple: sobre qué se investiga y de qué hablan los medios - $\mathrm{M}^{\mathrm{a}}$. Angélica Real Serrano - Departamento de Periodismo y Comunicación Audiovisual, Universidad Carlos III de Madrid - mariaangelica.real@uc3m.es

Introducción: La Esclerosis Múltiple (EM), descrita así por el neurólogo Jean-Martin Charcot (1868) al descubrir las placas características que se forman en el cerebro de los afectados por esta patología, se evidencia en posibles casos ya en el s.XIV (Moreira et al., 2002). La trayectoria investigadora va in crescendo debido al desconocimiento de su etiología y la necesidad de encontrar terapias adecuadas a los diferentes tipos de EM que existen.

Objetivo: Se establece un estudio comparativo entre el tratamiento informativo de la EM en los medios y la investigación llevada a cabo de dicha enfermedad.

Metodología: Se realiza un muestreo de conveniencia, acudiendo a dos bases de datos: Web of Science (WOS), revisando etiología, diagnóstico, tratamiento, investigación y síntomas de la enfermedad; MyNews, para recuperar publicaciones de ámbito nacional El País y El Mundo entre 2012 y 2017, determinando a través de un análisis de contenido el tratamiento que la EM recibe en prensa y qué temas generan mayor interés en este campo.

Resultados: El aspecto social (seguido del económico) despunta en El País (55\%) y El Mundo (53,3\%) frente a WOS (16,6); Por otro lado, en WOS destaca la investigación con un 70\% frente al 23,3\% en El País y un 41,6\% en el Mundo. En cuanto a su etiología, en la prensa analizada aparecen las cifras más bajas del estudio (5\% en ambas) a diferencia de WOS $(30 \%)$.

Conclusión: La investigación aparece como factor clave para profundizar en su origen. El carácter incierto de su etiología parece influir en el bajo porcentaje con el que se trata este aspecto en prensa. No obstante, el auge del aspecto social se evidencia gracias a la visibilidad por parte de instituciones, asociaciones y fundaciones. 
* 210 - Evolución de la situación del sector de la gestión de marcas en España (2012-2018) - Santiago Mayorga Escalada Universidad Europea Miguel de Cervantes smayorga@uemc.es

Tener notoriedad, una buena reputación y ser reconocido frente a la competencia gracias a un posicionamiento determinado genera un alto valor añadido en cualquier marca, especialmente cuando es capaz de ofrecer una experiencia única que conecta de forma relevante con sus usuarios potenciales. Para ello es necesario establecer un proceso que, siendo conscientes de su naturaleza eminentemente multidisciplinar, sea capaz de integrar estratégicamente todos los elementos de management, marketing y comunicación bajo una dirección de largo plazo que resulte coherente, constante y consistente.

A esta actividad tan compleja y fundamental se le denomina gestión de marcas. Paradójicamente se trata de una disciplina relativamente joven que, hasta hace no mucho tiempo era ninguneada, desconocida o directamente descartada para muchas organizaciones. Los cambios disruptivos acaecidos con la llegada del siglo XXI han convertido a la marca en el principal activo estratégico de las compañías lo que ha generado un crecimiento exponencial en el sector profesional del branding, alumbrando grandes consultoras estratégicas, especialización de agencias y profesionales, y la aparición de departamentos internos dedicados a la gestión de marca.

De acuerdo con las variables expuestas se hace necesario conocer cuál es la situación profesional de la gestión de marca en España. Para ello vamos a realizar una síntesis metodológica de recolección y análisis de datos de los tres barómetros publicados por la Asociación Española de Empresas de Branding (AEBrand) entre los años 2012 y 2018 con el objeto de acumular la información más relevante relativa a las variables identificadas en la investigación lo que nos permite esbozar una prospectiva sobre el escenario que conforma actualmente el sector.

* 211 - Entrenamiento de la creatividad y la cooperación en el aula a través de la improvisación teatral - Elena González 
Leonardo - Universidad de Valladolid elena.gonzalez.leonardo@uva.es y Saúl García González

La improvisación teatral es una forma de teatro espontáneo que surge al principio del siglo XX. En España, en los últimos años, se han consolidado numerosas compañías profesionales que realizan espectáculos, encuentros y formaciones a empresas y a público amateur de forma regular. Su trabajo se fundamenta en dos pilares: el trabajo de ideación, donde se entrena el pensamiento divergente, la originalidad, la flexibilidad y la fluidez, y el trabajo de la cooperación, ya que las dinámicas implican escucha, asertividad, ausencia de juicio y sincronía grupal.

Llevamos la disciplina al aula con el objetivo de entrenar a los alumnos en las competencias de creatividad y cooperación, fundamentales para el ejercicio creativo en un equipo profesional. La experimentación tuvo lugar en el entorno docente y comprendió un espectáculo en directo y 4 talleres. La muestra abarcó 60 estudiantes de $4^{\circ}$ de grado en Publicidad y RRPP de la Universidad de Valladolid. Los improvisadores profesionales diseñaron los talleres "ad hoc" con el fin de que los contenidos resultaran extrapolables al proceso creativo en publicidad. El programa formativo se dividió en 3 bloques: el primero, comprendió ejercicios de "calentamiento" orientados a generar un clima de confianza; el segundo, estuvo enfocado al entrenamiento específico en competencias a través de ejercicios de improvisación teatral; en el tercer bloque estudiantes y formadores pusieron en común la utilizad de lo aprendido.

La actividad superó las expectativas docentes. Por un lado, logró que los participantes ofrecieran soluciones altamente creativas a los ejercicios, y por otro, sentó un referente en cooperación, ausencia de juicio y autoconfianza. El desarrollo de tipo lúdico y el empleo del lenguaje corporal, supusieron una experiencia emocional que contribuyó a liberar la actitud creadora en los estudiantes, influyendo positivamente en su participación en la asignatura y generando un clima de trabajo cooperativo que se extrapoló al resto de sesiones prácticas. 
* 212 - De los medios tradicionales a los nativos digitales: la construcción del rol profesional en las nuevas redes sociales Miguel Álvarez-Peralta — miguel.alvarez@uclm.es y Raúl Rojas Andrés - joseraulrojas1989@gmail.com Universidad de Castilla-La Mancha

Más allá de ser una moda inducida por el paradigma liberal de la emprendiduría, la construcción narrativa de una marca personal profesional está adquiriendo una importancia clave en el sector periodístico contemporáneo. Una de las tendencias confirmadas de la esfera pública digital es el desplazamiento de la confianza de los ciudadanos desde las instituciones (partidos, gobiernos, periódicos) hacia los individuos que dan visibilidad a las mismas, tales como políticos o periodistas (cfr. Pew Research Global Trust and Media Report 2018).

En esta comunicación, se analizan las estrategias de construcción del perfil profesional entre los periodistas de opinión de referencia en España, contrastando las diferencias y similitudes entre los que pertenecen al sistema tradicional de prensa, los nativos digitales, y los perfiles mixtos que han emprendido una transición en uno u otro sentido. Para ello se aplicará una combinación metodológica que recurre tanto al análisis del discurso como a las técnicas lexicométricas cuantitativas, aplicadas a más de cincuenta periodistas de los medios de mayor impacto en el ecosistema informativo nacional. El estudio recoge las estrategias semióticas de construcción del self profesional, tanto en el plano verbal como visual y narrativo.

A partir de ellas, se postula un sistema de agrupamientos y polarizaciones de dichas estrategias, dando cuenta de sus reiteraciones, regularidades, y principales rasgos contrastivos. De ello se desprenden diferentes tendencias en función de la ideología y soporte de cada medio, que influirán en cómo el profesional se relaciona con algunos valores simbólicos del oficio, tales como la objetividad, neutralidad, implicación, etc.

* 213 - Redes sociales y diversidad informativa: el previsible cierre de la ventana de oportunidad para el pluralismo en el ecosistema 
digital - Miguel Álvarez-Peralta - miguel.alvarez@uclm.es y Roberto Mendès Barbudo - romeba2@gmail.com Universidad de Castilla-La Mancha

La aparición de tecnologías broadcast a mediados del siglo XX supuso inicialmente una concentración de la palabra en la esfera pública, posteriormente diversificada tras su liberalización y sin embargo nuevamente sujeta a dinámicas de concentración horizontal, vertical y multimedia a raíz de los procesos de globalización neoliberal a finales del siglo pasado. La transición digital ha seguido un esquema evolutivo similar: concentración inicial en pocos operadores nacionales y globales, posterior explosión de empresas prestadoras de servicios digitales a través de la red, incluyendo servicios informativos, y finalmente consolidación de una dinámica de creciente concentración de muchos de estos servicios en manos de pocas empresas transnacionales, como ocurre en el caso de las redes sociales digitales, agencias informativas o plataformas de vídeo bajo demanda.

Esta comunicación evalúa la evolución reciente del pluralismo en el ecosistema periodístico español, focalizando en las audiencias usuarias de redes sociales digitales, y tomando como hipótesis de partida la estabilización y polarización de las mismas en torno a un conjunto de referencias dominantes con escasa movilidad y posibilidades de disrupción, de manera similar a lo que terminó ocurriendo en el universo broadcast.

Las perspectivas más tecnooptimistas postularon que las redes sociales y los dispositivos móviles democratizarían el alcance de la palabra en la esfera digital, fomentando una mayor movilidad y la irrupción de perspectivas editoriales antes excluidas, gracias a la reducción de los costes de entrada al mercado. Sin embargo, esta investigación aporta evidencias cuantitativas que apuntan en sentido inverso: las audiencias digitales se estarían estabilizando en un mercado de tipo "long-tail" establemente concentrado en torno a referentes procedentes del mundo analógico, lo que parece indicar el final de aquella ventana de oportunidad inicial que permitió la irrupción de nuevos medios nativos digitales de bajo presupuesto durante la última década. 
* 214 - Mujeres Migrantes y No Migrantes de la Comunidad Indígena Triqui de México: Un Estudio Cualitativo de sus Creencias acerca del Matrimonio y de la Comunicación y Organización Familiares - Palmira Flores García - Colegio de San Luis (COLSAN), México - palmira.flores@colsan.edu.mx y Santiago Roger Acuña - Universidad Autónoma de San Luis Potosí (UASLP), México - santiagoacu1@gmail.com

En el campo de la investigación social, y en particular en las ciencias de la comunicación, existe un creciente interés por realizar estudios que documenten y analicen las condiciones de vida de las mujeres indígenas y que posibiliten avanzar en el conocimiento de aspectos importantes referidos a las brechas de género, a partir de la recuperación de las voces de las propias mujeres en dichas comunidades indígenas. Por ejemplo, en las comunidades indígenas triquis del sudoeste mexicano, la cultura patriarcal determina la forma en que se conciertan los matrimonios y se organiza la vida familiar, los patrones comunicativos en la familia y los roles de género (Lewin, 1999). Sin embargo, la investigación científica no ha profundizado en las creencias y concepciones que sustentan las propias mujeres indígenas sobre estas prácticas culturales y su relación con los procesos de migración que dichas mujeres suelen emprender en el interior del país mexicano. El objetivo del presente trabajo es describir y comparar las creencias y concepciones que sostienen diferentes mujeres triquis, migrantes y no migrantes, sobre los procesos comunicativos dados en el matrimonio y la organización familiar indígena. En este estudio se siguió un enfoque metodológico cualitativo, con un alcance descriptivo-comparativo. Se utilizaron historias de vida y entrevistas semiestructuradas para la recolección de datos. Participaron 8 mujeres pertenecientes a la Comunidad Triqui de San Juan Cópala, en el estado de Oaxaca (México); cuatro de ellas migraron de su comunidad y radican actualmente en la ciudad capital de otro estado (San Luis Potosî), ubicado en la región industrializada de México. Los resultados muestran tanto diferencias como similitudes en las creencias que sostienen las mujeres triquis migrantes y no migrantes. Principalmente, las mujeres triquis migrantes, a diferencia de las mujeres no migrantes, asumen su derecho a decidir y opinar ante la realización del matrimonio triqui. Sin embargo, son similares sus concepciones sobre el rol de la 
mujer en el matrimonio, en el tipo de patrones comunicativos que establecen con sus maridos y en los modelos educativos familiares. En la conclusión se señalan implicaciones del estudio respecto a la vigencia plena de los derechos de la mujer indígena y su entramado con las prácticas culturales y las brechas de género en el interior de las comunidades indígenas y en el contexto social mexicano.

* 215 - Visibilidad y representación de la mujer afrodescendiente en las prácticas culturales patrimonializadas en el Caribe colombiano: Caso bullerengue. - Dayana Jiménez Caraballo Universidad Complutense de Madrid - Dayana01@ucm.es

Desde el siglo XVII en el Caribe colombiano, mujeres afrodescendientes y con un pasado esclavista, usaron sus cuerpos y sus voces como otra manera de narrar historias y arrastrar con ellas sus cosmovisiones y percepciones del mundo. Así se representa el bullerengue, como memoria, baile, corporalidad y movimiento donde la mujer es percibida y puede percibir a los otros. El bullerengue nació como un baile-cantado femenino en contra de las represiones a los negros cimarrones y afrodescendientes esclavizados durante la colonia, por lo tanto, fue en su génesis un género que se desarrolló en las periferias y desde la marginación.

Esta investigación se centra en dar a conocer la perspectiva que las mujeres bullerengueras tienen de sí mismas, cómo se visibilizan y se representan en los medios de comunicación y desde la institucionalidad. Gracias al empleo fundamental de una metodología cualitativa, con técnicas como la observación participante, las entrevistas individuales en profundidad, el análisis de noticias y las comunicaciones de fuentes institucionales en las que se relacione el bullerengue y a sus intérpretes.

En la actualidad es una práctica en la que muchas personas encuentran un ejercicio liberador, de configuración de su subjetividad y consolidación en comunidad. Con esta investigación también se pretende hacer un acercamiento a las cantadoras de bullerengue como sujetos activos en una población donde han sido discriminadas por su condición afro, de pobreza, y de mujer. Enfrentadas también al 
encierro doméstico al que la mujer se ha visto sometida históricamente, al conflicto armado en Colombia y muchas otras formas de violencias desde un sistema estructural que las oprime e interpela en su subjetividad.

* 216 - Diseño de un instrumento para la evaluación de la creatividad publicitaria en el entorno docente - Elena González Leonardo - elena.gonzalez.leonardo@uva.es Universidad de Valladolid -

Evaluar la creatividad de los proyectos publicitarios no es tarea fácil. A pesar de que la creatividad es un aspecto de especial relevancia en el sector, la subjetividad juega un papel determinante a la hora de valorar el potencial creativo de una campaña. En el entorno profesional, los creativos establecen valoraciones subjetivas basadas en su experiencia para filtrar las distintas alternativas generadas. Sin embargo, en las asignaturas de creatividad publicitaria enmarcadas en los grados en publicidad y RRPP integrados en el EEES, nos encontramos ante un doble reto, por un lado, los estudiantes no poseen experiencia previa, y por otro, es necesario traducir dicha evaluación cualitativa, propia del entorno profesional, a una calificación numérica que la represente. Dado que, en España, por lo general, estas asignaturas tratan de emular en el aula, de forma práctica, la actividad de las agencias de publicidad, el objetivo de esta investigación es proporcionar un instrumento formativo que actúe como guía durante las etapas conceptuales del proceso creativo en el aula y sistematice la evaluación, reduciendo la subjetividad y haciendo comprensible la valoración docente.

El diseño de la herramienta constituye la primera etapa de esta investigación, que parte de la elección y sistematización de las dimensiones que determinarán la calidad creativa de la campaña. El método comprende entrevistas a profesionales en creatividad publicitaria y una extensa revisión teórica en torno a la evaluación del producto creativo en publicidad. En la segunda etapa, se llevó a cabo una experimentación empírica de tipo cuantitativo, que utilizó una muestra formada por 76 estudiantes de $4^{\circ}$ curso en Publicidad y RRPP de la Universidad de Valladolid y 9 directores creativos que participaron en calidad de jueces expertos. Se aplicó la herramienta a 17 campañas 
creativas elaboradas por los estudiantes. Empleamos los estadísticos Tau-b de Kendall y Pearson en el análisis cuantitativo para validar la herramienta y estudiar la correlación entre las evaluaciones subjetivas y sistemáticas de los jueces expertos.

El resultado obtenido pone de manifiesto que, pese a que lo que es y no es creativo en publicidad siempre estará determinado subjetivamente, la herramienta propuesta representa un recurso útil en el ámbito docente, tanto en la cuantificación de la evaluación como en la vertiente formativa.

* 217 - Innovación educativa y mejora de la competencia comunicativa a través del uso del podcast - Rebeca Martín Nieto - Universidad Rey Juan Carlos - rebeca.martin@urjc.es y Desiré García Lázaro - Universidad Rey Juan Carlos desire.garcia@urjc.es

La competencia comunicativa está contemplada en la legislación educativa española en etapas obligatorias (BOE, Real Decreto 1630/2006, de 29 de diciembre y Real Decreto 1513/2006, de 7 de diciembre), lo que confluye con la vivencia que los alumnos de los grados de Educación Infantil y Primaria tienen del consumo de recursos multimedia (Roblizo Colmenero, Cózar Gutiérrez, 2015). La cotidianeidad en su uso presupone un dominio que no siempre se alcanza sin formación complementaria. En el proceso de enseñanzaaprendizaje son necesarias destrezas específicas para un uso provechoso en las aulas por parte de docentes y discentes.

Ser competentes en el uso de la comunicación supone conocer, no solo la comunicación verbal y no verbal, sino también las tecnologías que son mediadoras de los mensajes: redes sociales, vídeos, podcast o aplicaciones, participan en procesos de enseñanza-aprendizaje, fomentando además la competencia digital de profesorado y alumnado (INTEF, 2017). Aquí se muestran los primeros resultados del proyecto Corre la voz, que pretende dar a conocer el podcast como recurso con elevado potencial en el aula, entre el alumnado de los Grados de Educación Infantil y Primaria de la Universidad Rey Juan Carlos y, por tanto, futuros docentes. 
El punto de partida es determinar el grado de consumo de podcast que hacen los futuros docentes, así como el acercamiento que han tenido a él durante su formación universitaria para observar, posteriormente, si reconocen sus potencialidades en el aula. La primera fase se ha puesto en práctica empleando técnicas cuantitativas de recogida de información, a través de un cuestionario con 22 items agrupados en cuatro bloques. Los resultados obtenidos, pertenecientes a la cohorte de nuevo ingreso del curso 2018-2019, evidencian el desconocimiento del recurso y, por tanto, la necesidad de trabajarlo en las aulas para continuar con la formación mediática actualizada que requiere el devenir actual.

* 218 - La guionización inclusiva como estrategia para atraer la atención del espectador en el entorno multipantalla - Esteban Galán - Universitat Jaume I de Castelló - egalan@uji.es, Lindsey Drylie Carey - Glasgow Caledonian University-

L.Carey@gcu.ac.uk y Emilio Sáez-Soro - Universitat Jaume I de Castelló - soro@uji.es

Los servicios de traducción y de accesibilidad audiovisual como el subtitulado y la audiodescripción han crecido de manera exponencial en los últimos años. La calidad de los mismos no siempre es la idónea ya que solamente se destina menos de un 1\% del presupuesto a este tipo de trabajos (Romero-Fresco, 2013). Por tanto, pese a que cada vez más producciones audiovisuales son accesibles desde el punto de vista teórico (cuentan con subtitulado y/o audiodescripción), son pocas las producciones que garantizan una experiencia de consumo lo suficientemente rica.

No obstante, la falta de calidad que se detecta no depende solamente del apartado económico, hay un aspecto clave que también tiene que ver con la propia gestión del proyecto audiovisual. Si en el esquema clásico de la producción audiovisual, todas las tareas (en mayor o menor medida) se planifican en las diferentes fases de la producción ¿por qué no hacer lo mismo con la accesibilidad audiovisual? La guionización inclusiva es un concepto que nos permite introducir los 
requerimientos de accesibilidad audiovisual desde el nacimiento del proyecto.

La guionización inclusiva se ha identificado durante los análisis realizados en formatos de no ficción emitidos en horario de máxima audiencia como un aspecto clave para adaptar el producto a un consumo audiovisual con atención dividida. La recepción multipantalla de los contenidos, ha motivado que cada vez sea más habitual ver televisión mientras se consulta el servicio de mensajería instantánea y se tuitea. Es habitual por ejemplo que el uso de grafismos sustituya y complemente la información que proporciona la narración de tal manera que el relato puede ser comprendido sin necesidad de escucharlo.

En este contexto, parece imprescindible que el concepto de guionización inclusiva devenga en uno de los ejes sobre los que pivote la producción audiovisual. Los trabajos de accesibilidad, que estaban centrados fundamentalmente en los colectivos con necesidades deben ser tomados además como un requerimiento narrativo en el contexto multiplataforma.

Esta investigación se enmarca en el proyecto de investigación ITACA. Inclusión social, Traducción Audiovisual y Comunicación Audiovisual, ref. FFI2016-76054-P, financiado por el Ministerio de Economía y Competitividad de España (Programa Estatal de Fomento de la Investigación Científica y Técnica de Excelencia) durante el periodo 2016-2019.

* 219 - "From Ideas Conference": investigación que innova para mejorar la accesibilidad audiovisual - Esteban Galán Universitat Jaume I de Castelló - egalan@uji.es, Emilio SáezSoro - Universitat Jaume I de Castelló - soro@uji.es y Lindsey Drylie Carey - Glasgow Caledonian UniversityL.Carey@gcu.ac.uk

"From Ideas Conference" es un formato de Congreso innovador que se ha diseñado para presentar los resultados del proyecto de investigación ITACA desarrollado desde 2017 y cuyo principal objetivo 
ha sido proponer soluciones para mejorar el nivel de accesibilidad de las obras audiovisuales para personas con limitaciones sensoriales (sordera y ceguera).

En esta conferencia han participado profesionales y expertos de diferentes áreas para resolver un reto común en un entorno internacional, interdisciplinar e intergeneracional. Durante el evento se ha proporcionado formación práctica a los participantes en metodologías de co-creación para generar un ambiente creativo: narrativas transmedia, gamificación y storytelling con la finalidad de que los resultados tuvieran un impacto real en la sociedad.

La primera experiencia en Glasgow en enero de 2019 contó con 21 participantes de 4 universidades (Francia, Reino Unido y España) pertenecientes a todos los niveles académicos. En julio de 2019 se desarrolló la segunda experiencia para diseñar una estrategia del bien común para la Universidad Jaume I con la colaboración de la Glasgow Caledonian University.

"Audiovisual Filmmaking for the Common Good: From Ideas Conference" ha significado la tercera experiencia de aplicación de esta innovadora metodología con el bien común como finalidad. Este modelo de Congreso celebrado en noviembre de 2019, ha supuesto una extraordinaria oportunidad para aplicar técnicas de co-creación y creatividad para la redacción de una guía de buenas prácticas para facilitar a los creadores la realización de productos inclusivos que sean accesibles desde el inicio.

Esta investigación se enmarca en el proyecto de investigación ITACA. Inclusión social, Traducción Audiovisual y Comunicación Audiovisual, ref. FFI2016-76054-P, financiado por el Ministerio de Economía y Competitividad de España (Programa Estatal de Fomento de la Investigación Científica y Técnica de Excelencia) durante el periodo 2016-2019.

* 220 - Las producciones accesibles como herramienta de inclusión social - Ana Tamayo Masero - Universidad del País Vasco (UPV/EHU) - ana.tamayo@ehu.eus, Laura Mejías 
Las nuevas narrativas, en el entorno social

Climent-lmejias@uji.es e Irene de Higes Andino - Universitat Jaume I - dehiges@uji.es

Desde el proyecto ITACA*, nos hemos planteado buscar soluciones para mejorar el nivel de accesibilidad de las obras audiovisuales para personas con limitaciones sensoriales (sordera y ceguera) a partir del concepto de producción audiovisual accesible. Este enfoque tiene por objetivo integrar la accesibilidad como parte del proceso de producción audiovisual con la intención de promover que se elaboren los productos audiovisuales ya desde el principio teniendo en cuenta que deben ser accesibles para personas sordas y ciegas, entre otras.

En camino de finalizar esta investigación y con miras al futuro, es momento de discutir en esta comunicación acerca del paradigma del proyecto y su contribución a la sociedad en un sentido más amplio. Teniendo en cuenta el elevado volumen de información audiovisual que se consume en la actualidad, el concepto de producción accesible puede convertirse en una herramienta importante de inclusión social si las buenas prácticas resultantes de nuestra investigación, centrada en los informativos de televisión, se aplican a otros géneros audiovisuales y, más aún, a otros ámbitos de la sociedad, como, por ejemplo, la cultura, la educación, el entretenimiento, el turismo, la salud, el comercio, los negocios, etc.

Asimismo, es conveniente reflexionar si las mejoras que se proponen para incrementar el disfrute de obras audiovisuales por parte de receptores con limitaciones sensoriales (sordera y ceguera) no son también útiles para receptores normoyentes y normovidentes dada la situación de "atención dividida" vigente. En la actualidad es habitual que se consuman los materiales audiovisuales al tiempo que se visionan otras pantallas y otros dispositivos o en un contexto sin concentración absoluta, es decir, con "ruidos" (por ejemplo, en un bar mientras se come con amigos).

Esta investigación se enmarca en el proyecto de investigación ITACA. Inclusión social, Traducción Audiovisual y Comunicación Audiovisual, ref. FFI2016-76054-P, financiado por el Ministerio de Economía y Competitividad de España (Programa Estatal de Fomento de la 
Investigación Científica y Técnica de Excelencia) durante el periodo 2016-2019.

* 221 - Recepción de la subtitulación para personas sordas en los programas en directo: el caso de los informativos - Ana Tamayo Masero - Universidad del País Vasco (UPV/EHU)ana.tamayo@ehu.eus, Julio de los Reyes Lozano delosrey@uji.es y José Luis Martí Ferriol - Universitat Jaume I martij@uji.es

Las personas con hipoacusia acceden a los productos audiovisuales principalmente a través de la subtitulación para personas sordas (SPS), una modalidad de traducción audiovisual que se caracteriza por emplear colores para identificar a los personajes y añadir información sonora y paralingüística. Sin embargo, existen diversos formatos audiovisuales que, debido a su emisión en directo, no admiten la posibilidad de incorporar estas informaciones extralingüísticas, como por ejemplo los informativos. Asimismo, el directo, o el semi-directo, suele implicar un retraso en la aparición de los subtítulos y un aumento en la velocidad de lectura, lo que puede suponer un problema para la recepción por parte de los espectadores.

Desde el proyecto ITACA*, nos proponemos buscar soluciones para mejorar el nivel de accesibilidad de las obras audiovisuales para personas con limitaciones sensoriales (sordera y ceguera). Para ello, se ha llevado a cabo una investigación de carácter exploratorio, basada en un modelo de análisis con parámetros traductológicos y fílmicos, sobre la SPS emitida en las piezas de los informativos para objetivo evaluar el retraso y la velocidad de lectura. Se ha observado una mayor diferencia entre el inicio de las intervenciones y los subtítulos que las reproducen en los subtítulos en directo que en los emitidos en semidirecto, así como una mayor velocidad de lectura en los subtítulos emitidos en semi-directo.

A partir de la información obtenida de un análisis estadístico descriptivo general, se ha diseñado un estudio de recepción con la intención de evaluar la comprensión y la opinión de los destinatarios (personas con discapacidad auditiva). Para ello, se han seleccionado 
siete piezas breves de los informativos pertenecientes al corpus analizado y se han planteado diferentes cuestiones de comprensión y valoración para cada pieza. En esta comunicación se presentan los resultados preliminares de este estudio, basadas en las aportaciones de 18 sujetos.

Esta investigación se enmarca en el proyecto de investigación ITACA. Inclusión social, Traducción Audiovisual y Comunicación Audiovisual, ref. FFI2016-76054-P, financiado por el Ministerio de Economía y Competitividad de España (Programa Estatal de Fomento de la Investigación Científica y Técnica de Excelencia) durante el periodo 2016-2019.

* 222 - Los fake comments como segundo estadio de la posverdad: destrozos éticos y democráticos - Dr. Óscar Sánchez Alonso - Universidad Pontificia de Salamanca osanchezal@upsa.es, Dr. Pedro Rivas Nieto - Universidad Loyola Andalucía, privas@uloyola.es y Dr. Pablo Rey García Universidad Pontificia de Salamanca, preyga@upsa.es

La peligrosidad de ciertos fenómenos surge no tanto por lo nocivos que sean, que también, sino por lo inadvertidos que resulten. En su invisibilidad reside lo más corrosivo. Así ocurre con las traídas y llevadas fake news. Al margen de que el término merezca revisión (dejemos ahora aparcados esos pormenores), su florecimiento es en sí mismo pernicioso. Pero además de las propias amenazas cívicas e institucionales que siempre acarrea la desinformación, las fake news resultan aún más dañinas cuando se vuelven imperceptibles. Y en esta comunicación abordaremos un disfraz que les brinda en bandeja la impunidad. Por eso focalizaremos la atención sobre los fake comments. La propia tradición periodística, a través de tópicos y falaces mensajes ("Facts are sacred, comments are free"), ha propiciado esa impunidad. Ante las fake news aún existe el dato veraz como referencia, como alternativa, como estándar de calidad ante el que puede calibrarse el engaño. Sin embargo, ante los fake comments no existe ni siquiera esa referencia a lo veraz: que la opinión haya pasado a tener la consideración de "libre" (engañoso eufemismo y triste banalización del 
valor "libertad") ahuyenta el contraste con los hechos, disipa el requisito de la verificación.

Dado que la posverdad no es un sinónimo de la mentira, contemplaremos como hipótesis que los fake comments (más que las fake news) están en mayor sintonía y correspondencia con ese perverso clima que caracteriza a la posverdad. Mediante el estudio de caso trataremos de corroborar esas vertientes, reparando propiamente sobre una comunicación política contemporánea que se ve envuelta en esas coordenadas. El desatino político-comunicativo acarrea innegablemente coste. Un alto precio que, en términos éticos y democráticos, siempre se acaba pagando.

* 223 - La territorialidad virtual en la creación participativa: el mapa interactivo y sus paisajes como forma de comunicación Juanjo Balaguer - Universidad de Granada balaguerjuanjo@gmail.com

De entre la multitud de herramientas, procesos y tecnologías que estructuran nuevas narrativas en el entorno virtual, los mapas interactivos han ocupado un espacio significativo. Esta técnica consiste en una interfaz que permite tanto la navegabilidad en el mapa como, en ocasiones, la contribución por parte de cualquier usuario, a veces con geolocalización. Aunque estos mapas se han creado a menudo con una función periodística, también han conformado otro tipo de iniciativas. Con indicación previa sobre la temática o la finalidad del mapa, los usuarios están habilitados en esos últimos casos para subir contenidos que, dependiendo del proyecto, pueden ser sonoros, gráficos, textuales o audiovisuales.

El presente trabajo analizará una serie de creaciones cuya narración polifónica y dispersa se organiza en torno a la representación gráfica de un territorio. Se considerarán casos tempranos (One Day on Earth, 2012) y otros más recientes (Queering the Map, 2017; Radio Right Left, 2017). Los archivos que se diseminan por esta interfaz cartográfica constituyen una suerte de paisajes de los lugares que habitan los usuarios. En su representación virtual, estos espacios son apropiados para convertirse en un territorio diverso y abierto, en consonancia con 
la lógica de la cultura participativa y de la sociedad red. Por ello, esta modalidad de participación tiene un condicionante a priori que permitiría expresar una pluralidad no siempre presente en otras formas de creación colectiva. En consecuencia, la territorialidad simbólica del mapa interactivo podría tener implicaciones en relación con la visibilidad de experiencias locales, representaciones sociales, identidades colectivas, así como con expresiones de pertenencia o desarraigo.

* 224 - La aproximación del film Gernika al imaginario común Ander Goikoetxea Perez - Universidad Del País Vasco / Euskal Herriko Unibertsitatea (UPV/EHU) ander.goikoetxea@ehu.eus

A principios del milenio la memoria histórica ha adquirido una relevancia importante en el Estado Español. Nuestro pasado más reciente es un tema de sumo interés en la sociedad, y por eso, se han multiplicado los reportajes periodísticos y documentales que abordan el asunto. El aumento de producción no se ha limitado a esos géneros, sino que se ha expandido a tales cómo la literatura y el cine. Pero una cosa es lo sucedido, y otra su representación. He ahí la cuestión del llamado cine histórico: cómo representar y comunicar lo sucedido en el pasado al público del siglo XXI. El cine, tiene sus propias estructuras y sus propios códigos.

En este artículo se estudia la relación entre la memoria histórica y cine. Para ello, se ha escogido uno de los episodios más trágicas de la Guerra Civil en el País Vasco: El bombardeo de Gernika. A través del film Gernika, dirigido por Koldo Serra, se analizan sus claves históricas y fílmicas para ver cómo se aproxima al imaginario común de hoy en día. Se ofrecen algunas reflexiones de ese acercamiento; un acercamiento que difiere notablemente del imaginario común.

* 225 - Interrupción Legal del Embarazo en México. Entre el control patriarcal y la libertad del cuerpo femenino - Luis Alfonso Guadarrama Rico- aguadarrama.famecom@gmail.com y Jannet Valero Vilchis-Universidad Autónoma del Estado de México-javavi3@gmail.com 
Introducción. El primer país que promulgó una ley que permitía el aborto fue la Unión de Repúblicas Socialistas Soviéticas (URSS) en el año 1920. Cuba lo despenalizó en 1965. Actualmente, apenas 70 países aprueban la Interrupción Legal del Embarazo (ILE); aunque varían los lapsos, pues van desde las primeras ocho semanas hasta la 24. Los periodos más amplios los aceptan Canadá, Países Bajos, Reino Unido y Singapur. En el año 2007, la Ciudad de México despenalizó el aborto dentro de las primeras 12 semanas de gravidez. A pesar de agudas oposiciones de grupos conservadores, las mujeres que así lo decidan, pueden optar por la ILE, sin costo económico para ellas. El Código Penal de la capital del país mantiene la penalización, pasados tres meses de preñez. En septiembre de 2019, el Estado de Oaxaca fue noticia al aprobar la ILE, también hasta la doceava semana; convirtiéndose en la segunda entidad mexicana. Desde aquel año 2007 hasta la fecha, gradualmente, miles de mujeres procedentes del resto del territorio nacional, al vivir en entidades donde está penalizado el aborto por decisión de la mujer, acuden a una de las clínicas con que cuenta la Ciudad de México para acceder a la ILE. Objetivos. Presentamos un panorama internacional sobre la ILE; poniendo de relieve los principales argumentos que nutren la visión patriarcal y machista, misma que parcialmente ha logrado imponer el control sobre la salud sexual y reproductiva de las mujeres. En contraste, exponemos los planteamientos progresistas que, apegados a Derechos Humanos, han servido para que sean las propias mujeres quienes decidan continuar o no con su embarazo. Método. Con base en el procesamiento de once macrovariables nominales contenidas en la base de datos proporcionada por la Secretaría de Salud de la Ciudad de México, generamos el perfil sociodemográfico de las mujeres que en México optaron por la ILE, durante el periodo enero de 2018 a mayo de 2019. Resultados. Durante el periodo analizado, un total de 7,211 mujeres, procedentes de todas las entidades del país, optaron por la ILE en la Ciudad de México; por el número de casos atendidos, según la entidad de procedencia, el primer lugar lo ocupó la propia Ciudad de México, el segundo, el Estado de México y, el tercero, el estado de Hidalgo; la edad promedio de las mujeres fue de 25.7 años; $68 \%$ declararon ser de religión católica; la escolaridad alcanzada fue con estudios de secundaria en $28.5 \%$ y de nivel medio superior (bachillerato) $46.6 \%$ 
de los casos; casi 90\% de los casos, la ILE fue aplicada entre la cuarta y la novena semana de gestación, utilizando solamente medicamentos. Discusión y Conclusiones. La ILE, aunque está circunscrita geopolíticamente a la Ciudad de México y, de manera reciente en el estado de Oaxaca, está atendiendo y protegiendo la vida, así como la dignidad, de un sector femenil vulnerable, que si bien cuenta con empleo, en su mayoría carece de seguridad social y, casi la cuarta parte de ellas no tiene empleo. Es indispensable que el Estado Mexicano, haga uso de su postura laica para hacer posible que la ILE sea una realidad en todo el país, para beneficio y protección de la salud sexual y reproductiva de las mujeres que, por distintas condiciones y motivos, necesiten optar por la ILE.

* 226 - Las competencias comunicativas como insumo de permanente innovación en la educación superior - Jessica Villamar Muñoz - Grupo de Investigación GIFE Universidad Politécnica Salesiana Ecuador - jvillamar@ups.edu.ec

En el momento presente la sociedad a través de la educación necesita desarrollar y robustecer competencias y aptitudes comunicativas, que son y serán de actualidad, ya que la persona es y está en constante comunicación. La educación superior se constituye en el espacio privilegiado para desarrollar y fortalecer dichas capacidades y habilidades desde la constante interacción de docentes y estudiantes, así como de la profundización y concienciación de las experiencias de enseñanza -aprendizaje cuya finalidad es orientar a la persona hacia la reflexión, el diálogo y el compromiso desde una postura crítica y propositiva que suscitan el respeto, la escucha, la inclusión, la aceptación y valoración de lo diverso. La Actualización, reconstrucción y reflexión de esta temática permitirá revalorizar las competencias comunicativas como insumo formativo que rescata prácticas valiosas que construyen saberes y seres humanos que forjan sociedades sensibles, justas y solidarias.

* 227 - Periodismo Transmedia: Estrategias Comunicativas Colaborativas para la Producción y Difusión de Contenido de una Plataforma Digital Mexicana - Iván Cárdenas Martínez Universidad Autónoma de San Luis Potosí- 
ivncdns@gmail.com, Santiago Roger Acuña - Universidad Autónoma de San Luis Potosí - santiagoacu1@gmail.com y Luis Amador Iranzo Montés - Universitat Jaume I iranzo@uji.es

En los tiempos digitales actuales, las organizaciones mediáticas no solo deben adaptarse a la innovación tecnológica, sino también se ven impelidas a transformar sus dinámicas de trabajo y los modos de producción de contenidos. En este estudio se abordan diferentes aspectos del proceso de cambio que ha seguido un medio digital informativo mexicano en referencia a la producción de contenidos informativos transmedia. Concretamente, se describen cómo son las estrategias comunicativas, que, desde la perspectiva del trabajo colaborativo, despliegan los equipos de una organización informativa para producir y difundir contenidos periodísticos transmedia en el entorno digital. Para conceptualizar a las organizaciones de este sector se contempla la visión latinoamericana organizacional (Rebeil, Hidalgo y Moreno, 2011). Sobre el periodismo digital, el concepto de transmedia es el punto de partida para estudiar la narrativa del contenido periodístico en los nuevos medios (Scolari, 2008). Los conceptos teóricos de discurso y poder permiten comprender la realidad compleja que rodea a los medios y a los integrantes que la componen (Van Dijk, 2009); y para dar cuenta del entorno de la sociedad en red, se emplea como aproximación teórica la noción de cultura de pantalla (Castells, 2012). Metodológicamente, en este estudio se siguió un enfoque cualitativo, mediante la técnica de entrevista grupal, que fue aplicada a cinco trabajadores del área de comunicación y producción de una organización mediática informativa de la región central de México. Los resultados permiten correlacionar la idea de lo colaborativo con el concepto de transmedia, así como un aspecto determinante en las estrategias comunicativas y el desarrollo de contenidos periodísticos. En las implicaciones se hace referencia a los factores sociales que se ven involucrados en una organización mediática para producir y comunicar la información periodística siguiendo una narrativa transmediática- a su público consumidor y prosumidor a través de una plataforma digital. 
Las nuevas narrativas, en el entorno social

* 228 - Transmediación y transferencia: explorando el potencial de las narrativas expandidas para la divulgación del conocimiento científico - Carolina Campalans - Universitat Oberta de Catalunya - ccampalans@uoc.edu

A partir de dos estudios de casos, este trabajo analiza el potencial -a la vez que las dificultades- de la aplicación de una estructura narrativa transmedia para la divulgación del conocimiento científico. El análisis recurre a un marco teórico transdisciplinario, que se sustenta, por un lado, en las ciencias de la comunicación y los estudios de medios y en particular en la teoría y los hallazgos empíricos acerca de la narrativa transmedia de no ficción y, por otro, el campo de la gestión y transferencia del conocimiento. El puente entre estos dos campos del saber lo conforma un marco conceptual inspirado en el modelo de ISpace (Boisot, 1995) sobre el fenómeno de estructuración (Giddens, 1984; Webster, 2006) de la información en el contexto de un proceso de aprendizaje social. El análisis de los dos casos seleccionados sigue un diseño metodológico mixto, mediante técnicas combinadas de análisis de contenidos del inventario de activos del conocimiento (Boisot, 1999) y análisis narrativo (Spink, 2010). Adicionalmente, con base en los resultados de este doble estudio de caso, junto con la fundamentación conceptual que nos proporciona la investigación sobre narrativas transmedia (Campalans et al., 2014; Scolari, 2013) y gestión del conocimiento (Canals, 2003; Davenport \& Prusak, 1998), hemos desarrollado un prototipo de documental transmedia para la divulgación de los resultados de una investigación en el ámbito de estudios urbanos e innovación digital, cuyos avances incluimos en este trabajo.

* 229 - Apropiación y uso de las apps al servicio de la enseñanza y aprendizaje en instituciones educativas urbanas y rurales de la región de Urabá (Colombia) -Beatriz Elena Marín Ochoa beatrize.marin@upb.edu.co, Mg. Gabriel Lotero-Echeverri gabrielj.lotero@upb.edu.co, Mg. Oscar Eduardo Sánchez García - Profesor de la Universidad Pontificia Bolivariana, Medellín, Colombia - oscar.sanchez@upb.edu.co y Mg. Juan Zambrano Acosta Comunicador Social - Periodista - Universidad Pontificia Bolivariana - juan.zambrano@upb.edu.co 
Se presenta la experiencia de investigación "Ecosistema de contenidos digitales para Apps al servicio de procesos de enseñanza y aprendizaje en la región de Urabá", actualmente en ejecución por parte de tres grupos de investigación de diferentes áreas: comunicación, TIC y educación virtual, pertenecientes a la Universidad Pontificia Bolivariana (Colombia). En el proyecto participa también Camaleón Multimedia, una empresa de base tecnológica. Y es financiado por el gobierno colombiano, a través de Colciencias, con recursos de regalías del Departamento de Antioquia.

La investigación se desarrolla en la subregión de Urabá (Antioquia), un territorio tropical, de vocación agrícola, con costas sobre el Caribe y de gran biodiversidad, que cuenta también con una importante población afrodescendiente e indígena y con una dispersión rural significativa. La región tiene un gran potencial portuario y turístico, por los proyectos de infraestructura que se proyectan a mediano plazo. Sin embargo, presenta índices de pobreza por encima del promedio de Antioquia, con un índice de personas con Necesidades Básicas Insatisfechas del $53 \%$, en el año 2012. El proyecto parte de la pregunta problematizadora: ¿Qué estrategias didácticas se articulan a los nuevos escenarios de conectividad y acceso a las TIC en las instituciones educativas rurales y urbanas de Antioquia? Como primer paso, se priorizaron tres municipios: Apartadó, Carepa y Necoclí. Se visitaron doce instituciones educativas de la zona urbana y rural, lo cual permite diagnosticar el uso y apropiación de aplicaciones en procesos de enseñanza y aprendizaje e identificar necesidades, expectativas y oportunidades presentes de las comunidades educativas del territorio.

En un segundo momento, se realizaron talleres de ideaci\{́n y cocreación con los docentes de la región, que permitieron reconocer iniciativas de aprendizaje móvil creadas por ellos mismos. Además, se formaron en curaduría de contenidos digitales y prototipado para se identificar propósitos de formación para el trabajo con apps.

* 230 - La función social de la radio universitaria - Francisco Gerardo Valdez Rincón - Universidad Autónoma de Nuevo León - francisco.valdezr@uanl.mx / Verónica Guajardo del 
Las nuevas narrativas, en el entorno social

Bosque - Universidad Autónoma de Nuevo León verónica.guajardob@uanl.mx / Sergio Manuel de la Fuente Valdez-Universidad Autónoma de Nuevo León sermanfuen@yahoo.com

La radio universitaria nace en México en los tiempos del Presidente Lázaro Cárdenas (1934-1940), de tal forma que la primera estación de radio inicia sus operaciones el 14 de julio de 1937 y fue radio UNAM, bajo las siglas XEXX en el 1170 de amplitud modulada (AM), con 5000 watts de potencia y con 4 horas de programación con contenidos de interés universitario. Es importante señalar que las primeras experiencias de radio cultural en nuestro país, son de 1923 con estaciones gubernamentales de los estados de Chihuahua y Yucatán y en 1924 con la emisora de la Secretaría de Educación Pública, Radio Educación. Cuando hablamos de Radio Universitaria, nos referimos concretamente al medio de comunicación que pertenece a una Universidad o Institución educativa, ya sea pública o privada.

La radio universitaria posee características específicas, que la diferencian de la radio comercial, entre ellas podemos mencionar las siguientes: su propósito primordial es difundir el conocimiento, la cultura y la investigación, la promoción y difusión de tareas institucionales por encima de los intereses comerciales y la audiencia es limitada. Las Universidades son un ente catalizador de fenómenos sociales, ya sean públicas o privadas, deben procurar estar cerca de la población, la radio, entre múltiples formas de comunicación que hoy día tienen las Instituciones educativas, ofrece la posibilidad de estrechar estos lazos, pero para ello deberá reinventarse día con día y ofrecer alternativas útiles y prácticas para mantener la atención de su audiencia. La radio es única, la radio universitaria no está obsoleta, ni pasada de moda y tampoco está muriendo. Hoy en día las Universidades utilizan la radio, entre otros medios, para dar a conocer lo que están haciendo en el campo de la investigación, la cultura y la ciencia.

La función de la radio universitaria, en el contexto de una sociedad mediatizada y consumista, se vincula con las funciones propias de la universidad como un generador de conocimiento y juicio crítico. En esta investigación se abordan los antecedentes de la radio universitaria 
en México y se pretende establecer un marco referencial sobre la función social de la radio universitaria y el deber institucional de ser un puente que conecte con amplios sectores de la sociedad.

* 231 - Guionización Inclusiva: la producción audiovisual al servicio de la accesibilidad - Ximo Granell - Universitat Jaume I - granell@uji.es, Irene de Higes Andino - Universitat Jaume I dehiges@uji.es y Julio de los Reyes Lozano - Universitat Jaume I - delosrey@uji.es

En la actualidad, los productos audiovisuales se hacen principalmente accesibles a las personas ciegas o con discapacidad visual mediante la técnica de la audiodescripción (AD), que aprovecha los silencios y espacios sin diálogos de las obras audiovisuales para incorporar una narración en off que describa las acciones de los personajes, la ambientación, el lugar en el que transcurre la acción o los sonidos que no son fácilmente distinguibles. Sin embargo, existen diversos formatos audiovisuales que no admiten la posibilidad de audiodescribirlos, por ejemplo, los informativos.

Desde el proyecto ITACA*, nos proponemos buscar soluciones para mejorar el nivel de accesibilidad de las obras audiovisuales para personas con limitaciones sensoriales (sordera y ceguera) a partir del concepto de producción audiovisual accesible (Romero-Fresco, 2019). Este enfoque integra la accesibilidad como parte del proceso de producción audiovisual teniendo en cuenta una serie de factores (semióticos y lingüísticos) desde el principio para que sea más fácil hacerlos accesibles y traducirlos. Tras llevar a cabo una investigación de carácter exploratorio acerca de las necesidades de las personas con problemas visuales en el consumo de diversos géneros audiovisuales, se ha observado que los informativos, pese a ser bastante accesibles por su propio formato, admiten un margen de mejora que no puede cubrirse mediante la audiodescripción.

Nos basamos en criterios traductológicos y fílmicos para identificar y describir en detalle qué tipo de información deberían incorporar los informativos en sus guiones para que no afecte a la comprensión de las personas con discapacidad visual y tampoco resulte redundante a 
normovidentes, un enfoque similar al realizado por Fryer (2018) en el teatro mediante el concepto de "integrated audio description". Denominamos a esta mejora "guionización inclusiva" y los resultados de este análisis se comprobaron mediante un estudio de recepción con personas ciegas e hipovidentes, cuyos resultados preliminares presentamos en esta comunicación.

Esta investigación se enmarca en el proyecto de investigación ITACA. Inclusión social, Traducción Audiovisual y Comunicación Audiovisual, ref. FFI2016-76054-P, financiado por el Ministerio de Economía y Competitividad de España (Programa Estatal de Fomento de la Investigación Científica y Técnica de Excelencia) durante el periodo 2016-2019.

* 232 - Producciones accesibles en entornos audiovisuales inmersivos: realidad virtual y videojuegos inclusivos - Ximo Granell - Universitat Jaume I - granell@uji.es y Laura Mejías Climent - Universitat Jaume I - lmejias@uji.es

El proyecto ITACA* parte del concepto de producción audiovisual accesible para proponer soluciones que mejoren el nivel de accesibilidad de las obras audiovisuales para personas con limitaciones sensoriales (sordera y ceguera). Para ello, se integran una serie de factores (semióticos y lingüísticos) desde los inicios del proceso de producción audiovisual para que sea más fácil hacerlos accesibles y traducirlos. Este proyecto, desarrollado entre 2016 y 2019, se ha centrado en llevar a cabo una investigación de carácter empírico y exploratorio acerca de las necesidades específicas de las personas con problemas visuales en diversos géneros audiovisuales de no ficción emitidos en televisión. Los resultados del proyecto han permitido extraer conclusiones acerca de algunos aspectos clave que contribuyen a incrementar el grado de accesibilidad de estos productos audiovisuales y establecer pautas para integrar la accesibilidad en las fases de preproducción, producción y posproducción de los productos audiovisuales.

Existen otros productos audiovisuales, además de los abarcados por el proyecto ITACA, en los que la necesidad de accesibilidad sensorial 
también es fundamental, tales como los videojuegos o entornos que hacen uso de la realidad virtual. Estos se caracterizan porque los usuarios no solo reciben información por medio de los canales audiovisuales, sino que deben interactuar con la obra en cuestión para que esta cobre sentido y pueda desarrollarse. Se trata de convertir a los espectadores en usuarios activos que dotan de sentido completo a la obra audiovisual interactiva, a través de una inmersión exitosa. Además, la información también se recibe por otros medios, como el canal táctil, mediante códigos hápticos, y pueden coexistir distintos canales de comunicación simultáneamente dentro del mismo producto. Para que la experiencia de los usuarios sea satisfactoria es necesario que la interacción y la inmersión proporcionadas por el juego o aplicación sean atractivas y plenamente funcionales. Este es el principal motivo por el que la interacción en el caso de discapacidad supone un reto especialmente difícil, ya que la interacción será únicamente posible a través del canal o canales para los cuales el receptor no padece discapacidad.

Esta investigación se enmarca en el proyecto de investigación ITACA. Inclusión social, Traducción Audiovisual y Comunicación Audiovisual, ref. FFI2016-76054-P, financiado por el Ministerio de Economía y Competitividad de España (Programa Estatal de Fomento de la Investigación Científica y Técnica de Excelencia) durante el periodo 2016-2019.

* 233 - La radio en el ecosistema mediático del siglo XXI - João Canavilhas - Universidade da Beira Interior/ LABCOM.IFP jc@ubi.pt

Desde que aparece la televisión, la muerte de la radio se anuncia como cercana. A pesar de todas las amenazas, la radio continúa viva e, incluso, gana nuevos públicos en un escenario hostil para un medio centenario. La realidad muestra que la radio transformó sus debilidades en fuerzas y se adaptó al nuevo ecosistema de una forma más rápida que cualquier otro medio. Las razones de esta rápida y exitosa adaptación están relacionadas con la simplicidad del soporte y con el lenguaje unisensorial usado, pero también con una capacidad inaudita para la adaptación a nuevas situaciones. En este trabajo se identifican las 
características que hacen de la radio un sobreviviente en el actual ecosistema mediático y se analiza la forma en que la radio remedió esas características y se adaptó al ecosistema, ilustrando cada caso con ejemplos de radios portuguesas.

* 234 - La migración de audiencias a nuevas plataformas de televisión y el rol de la publicidad - Carlos Jimenez-Prado carlose.jimenezp@utadeo.edu.co Universidad de Bogotá Jorge Tadeo Lozano

Esta ponencia propone identificar el rol de la publicidad frente a la migración de audiencias a plataformas de televisión, de acuerdo con las estrategias de los principales actores del mercado latinoamericano con énfasis en Colombia. Dentro de este panorama se propone identificar cómo la televisión abierta está enfrentando este nuevo contexto, los planteamientos de las plataformas de televisión latinoamericanas, así como si ha habido un cambio en formatos y cuáles son los de mayor acogida tanto en la televisión abierta como en las plataformas de televisión, para finalmente identificar las tendencias de la publicidad frente a este nuevo horizonte.

Para este propósito se usó una metodología de carácter cualitativo, bajo el paradigma histórico hermenéutico, orientando las acciones de investigación documental tanto científica como industrial y de la prensa especializada. El trabajo de campo se realizó a través de entrevistas semiestructuradas a los directivos de los principales canales privados en Colombia, Caracol, RCN y CityTV; a los directivos de plataformas regionales: Global Play y Vivo Play y al gremio Asotic.

Las plataformas de televisión han acostumbrado a la audiencia a acceder a un catálogo amplio de contenidos audiovisuales, a los cuales pueden acceder a través de una tarifa económica con un servicio enfocado a la calidad de la imagen y lo más importante, sin interrupciones comerciales. En este contexto la publicidad de las marcas debe ser relevante, no invasiva, apalancarse en recetas convencionales como el product placement y recurrir a la creatividad para encontrar nuevos espacios como el patrocinio para dar a conocer sus productos y mantener su reconocimiento entre la audiencia. 
* 235 - Transmedia en estrategias de comunicación de empresas de triple impacto - María Belén Barroso - Universidad de Málaga (España) - mbelenbarroso@uma.es, Claudia Gabriela Ardini - Universidad Nacional de Córdoba (Argentina) claudiaardini@gmail.com y Alfredo Caminos - Universidad Nacional de Córdoba (Argentina)-alfredocaminos@gmail.com

Desde los comienzos del movimiento ambiental entre los años 60 y 70, el concepto de sostenibilidad aplicado a la economía, la política, la sociedad y las organizaciones ha evolucionado hacia una visión integrada de las dimensiones sociales, económicas y ambientales en busca de generar estrategias que agreguen valor a la calidad de vida de las personas, el crecimiento del capital económico (y no sólo financiero) y la conservación de la naturaleza. Este viraje en el ámbito de los negocios hacia una perspectiva de triple impacto (concepto acuñado por Elkington en 1997) no es espontáneo, es producto de la reflexión sobre las enormes consecuencias de un modelo de producción, circulación y consumo del capitalismo lineal y no regenerativo que continúa marcando el compás de nuestro comportamiento y sus impactos. Es aquí donde podríamos pensar en la comunicación como parte del problema y también de la solución. Kahle y Gurel-Atay ya hablaron de esto en su libro "Communicating Sustainability for the Green Economy" (2013) cuando aseguraron por ejemplo que una de las razones del consumo insostenible son las estrategias de comunicación de marketing, de la publicidad y por ende de la comunicación.

En efecto, la gestión de la comunicación en estos nuevos modelos productivos alineados al triple impacto demanda una perspectiva tangencialmente diferente: simétrica y bidireccional, capaz de conversar en múltiples plataformas y medios, que estimule la cocreación de contenidos, flexible y dinámica navegando en contextos complejos. En definitiva, muchas de estas características convergen en la lógica de las narrativas transmedia (Scolari et al. 2012; Jenkins, 2003). En este marco, la presente investigación procura caracterizar la producción transmedia dentro de la estrategia de comunicación corporativa aplicando la técnica del análisis de contenido de los entornos digitales (sitio web y redes sociales) a un conjunto de 
empresas de triple impacto. En este caso forman parte de la muestra 30 compañías reconocidas como "Best for the world 2019" por la ONG Norteamericana B Lab por crear mayor impacto positivo social y ambiental. Estas empresas forman parte del movimiento global "B Corp" (y su versión latinoamericana Sistema B”) que aglutina más de 3.000 compañías en 150 industrias y 71 países. Los resultados de la investigación arrojan que la ampliación de los objetivos organizacionales hacia el triple impacto, y por ende, la extensión de la visión de los stakeholders hacia las comunidades, e incluso hacia la esfera pública; genera un escenario en el que las estrategias de transmedia fluyen en busca del encuentro de intereses y motivaciones para el bien común.

* 236 - Formación humana integral y aprendizaje cooperativo: Claves para un trabajo en proyectos integradores - Victoria Palacios M., PhD. - Pontificia Universidad Católica del Ecuador, Quito, Ecuador - vdpalacios@puce.edu.ec, Msc. Paulina Cisneros - Corporación para la educación audiovisual Francisco Xavier CEAFAX, Quito, Ecuador - Pciscneros45@hotmail.com y Narcisa MedrandaM., PhD. Universidad Politécnica Salesiana, Quito, Ecuador - nmedranda@ups.edu.ec

El proyecto integrador como estrategia didáctica se ha constituido en un elemento clave para la innovación educativa. Los beneficios de esta estrategia son del orden de: la integración de las diversas áreas temáticas que se trabajan dentro del sistema educativo; la resolución de problemas mediante la participación de la persona en su integralidad; y finalmente, el trabajar con otros, lo cual requiere del desarrollo de habilidades sociales. A través de la investigación documental, en este trabajo se aborda cuáles serían los requisitos para lograr un mejor trabajo por proyectos integradores y se plantea que los elementos de la formación humana integral y del aprendizaje cooperativo son clave para que la persona se comprometa de manera total en el proceso y que desarrolle capacidades de trabajar con otros de manera apropiada

* 237 - Sobreexposición en la comunicación política presidencial - Fernando Esquivel Lozano-Catedrático de la Facultad de 
Ciencias de la Comunicación, Universidad Autónoma de Nuevo León(UANL) - feresquivel@hotmail.com

El arribo a la Presidencia de la República de México por parte de Andrés Manuel López Obrador (AMLO), no solamente supuso el arribo del primer gobierno abiertamente socialista en la vida política moderna del país, sino también una nueva era en la comunicación política de un mandatario latinoamericano. El nuevo presidente mexicano incorporó en sus estrategias de marketing y comunicación política una fórmula que ya había utilizado con bastante éxito cuando fungió como Regente de la Ciudad de México: las diarias conferencias de prensa casi de madrugada, conocidas popularmente como "mañaneras". Esto lo ha convertido en el Presidente de la República más expuesto a nivel mundial, ya que todos los días de lunes a viernes, en punto de las 07:00 horas y en Palacio Nacional, se presenta ante los representantes de los medios de comunicación tradicionales y digitales, para responder, sin excepción, todas las interrogantes que le presenten.

Apenas una semana antes, la "mañanera" alcanzó las 359 mil 977 visitas, una cifra récord de este "diálogo circular" como le llama el primer mandatario mexicano, quien considera que con estas conferencias matutinas los ciudadanos se informan, participan más y van cambiando conductas en sus familias y en el trato comunitario y social. En la presente investigación se analizan las conferencias realizadas desde el primero de diciembre de 2018, día que AMLO inició su mandato, hasta el 31 de octubre de 2019, mediante una perspectiva analítica cuantitativa y cualitativa, para revisar los temas abordados y el impacto causado en la sociedad. Se busca que los resultados arrojen información contundente sobre esta estrategia de comunicación política inédita a nivel mundial.

* 238 - Frente al acoso sexual en el trabajo en Ecuador: una propuesta desde la comunicación - Belén Puñal Rama apunalr@unemi.edu.ec-Universidad Estatal de Milagro y Sergio Pena Dopico spenad@unemi.edu.ec - Universidad Estatal de Milagro 
Introducción. El acoso sexual en el trabajo (AST) es una problemática transversal a diferentes estratos y categorías laborales, que se ve atravesada por las relaciones de poder, no solo laborales sino también de género, como una muestra más de violencia hacia las mujeres. Objetivos. El objetivo de esta ponencia es exponer las directrices fundamentales de un plan de comunicación, dirigido a instituciones y corporaciones privadas, a directivos/as y a trabajadores y trabajadoras, que tiene como objetivo prevenir y llamar a la acción frente el AST. Método. Parte de una investigación previa, de carácter cualitativo, basado en el análisis de contenido y del discurso de 16 grupos de discusión con trabajadores/as realizados en Quito y Guayaquil, con el fin de análisis de las percepciones sobre el AST. A partir del árbol de problemas que se extrajo, se procedió a la elaboración del plan de comunicación. Resultados. En el imaginario sexista detectado se responsabiliza y culpabiliza a las mujeres, incidiendo en estereotipos tradicionales como el de la mujer tentadora y el hombre incapaz de controlar su deseo sexual. El AST se asume desde la perspectiva de la responsabilidad individual, sin apenas implicación de empresas e instituciones. El miedo a denunciar y la permisividad en las empresas son patrones recurrentes. Discusión y conclusiones: El estado del arte previo a este estudio muestra que el AST ha sido investigado desde una perspectiva fundamentalmente cuantitativa, lo que no ha permitido profundizar sobre el imaginario que lo alimenta. Los resultados obtenidos de este análisis cualitativo ratificaron la necesidad de incidir en las percepciones sobre el AST, concienciando sobre las desigualdades estructurales y las relaciones de poder que están en su raíz, así como en la importancia de la intervención colectiva.

* 239 - La discapacidad psicosocial en México: retos para su inclusión y comunicación - Sonia Esquivel Ochotorena Universidad Autónoma de Nuevo León, correo: sony_esq@hotmail.com t Lucila Hinojosa Córdova Universidad Autónoma de Nuevo León, correo: lucila.hinojosacr@uanl.edu.mx

Actualmente en México la discapacidad psicosocial sigue siendo una discapacidad poco conocida y atendida, con muchos vacíos de información y comunicación hacia la sociedad, y con grandes 
oportunidades de mejora para crear conciencia de la necesidad de su inclusión educativa, laboral y social. En este trabajo se presenta una revisión de la literatura que sobre los lineamientos tanto internacionales como nacionales y locales existen en la materia, con el propósito de hacer un análisis a profundidad de las leyes vigentes que existen hoy en día sobre la protección de los derechos humanos de las personas con discapacidad. Como resultado del análisis podemos ver que existen un número importante de leyes y acciones que se están tomando desde el nivel internacional, pasando por el nacional y aterrizando en el estatal, las cuales están a favor de la inclusión integral, educativa, laboral y social de las personas con discapacidad psicosocial; sin embargo hace falta una política pública que promueva su difusión y apropiación entre los distintos sectores de la población y en esto tienen un papel crucial los medios de comunicación. Es evidente que como sociedad nos falta conocer más a fondo estos lineamientos para ponerlos en práctica y fomentar y lograr una mejor inclusión. El trabajo se complementa con una reflexión final acerca de la situación actual de la salud mental que existe hoy en México, con el objetivo de dar a conocer un problema que crece día con día en nuestra población sin importar género ni edad y que se relaciona directamente con la problemática de la inclusión y la falta de atención e información entre la sociedad.

* 240 - La televisión local y su evolución en el ámbito latinoamericano - Kruzkaya Ordóñez - Universidad Técnica Particular de Loja - kordonez@utpl.edu.ec y Marlon Ramón Universidad Técnica Particular de Lojamgramon@utpl.edu.ec

En la actualidad la cantidad de información que se obtiene en el espacio digital permite que los medios tradicionales locales se revaloricen. El común diferenciador, son sus contenidos próximos que definen el rol de la televisión local. Estos medios, en el ámbito latinoamericano, se han convertido en lo que se denomina televisión espejo de la realidad local y social. Además, en cada nación latinoamericana, son relevantes en el marco de las estrategias de gobernalidad, debido a su acercamiento a la comunidad y la influencia que, estos medios de proximidad, ejercen en ellas. En este contexto, se plantea la presente investigación que realiza una revisión documental histórica de su 
desarrollo, así como del marco regulatorio que la sostiene. La metodología utilizada se fundamenta en el analisis cualitativo descriptivo y comprende la revisión de fuentes documentales, asi como del análisis de contenido de documentos legales. Entre las conclusiones más importantes se mencionan que las televisiones en los países Latinoamericanos son conglomerados en los que circulan grandes capitales que, sin duda, constituyen un considerable componente de los PIB nacionales, asi mismo las empresas televisivas han logrado ser lo que son gracias a su proyección y, finalmente, el negocio, al igual que la cultura y la política en dichos países, han estado y seguirán estando en la industria de la televisión.

* 241 - La comunicación digital institucional en la Educación Superior: aproximaciones a las propuestas curriculares de carreras de grado y de posgrado de Universidades Argentinas Dr. Alejandro, Álvarez Nobell - Universidad Nacional de Córdoba - aalvareznobell@unc.edu.ar, Lic. Lucía, Candelaria Casabella - Universidad Nacional de Córdoba lucia.casabella@gmail.com y Lic. María Belén, Iriarte Universidad Nacional de Córdoba - mabeleniriarte@gmail.com

La gestión de comunicación digital en las organizaciones ha irrumpido con fuerza en los últimos tiempos producto de la revolución digital y las nuevas prácticas de apropiación tecnosocial en contextos de ubicuidad. Ante estos desafíos, los últimos estudios sobre el desarrollo de la Comunicación Estratégica y las Relaciones Públicas en la región (Moreno, et al 2019) señalan la necesidad de desarrollar nuevas capacidades y competencias profesionales. El proyecto DigitalCom (SECYT-UNC - Línea Consolidar 2018/2021 - Cód: 33620180101035CB) radicado en la Universidad Nacional de Córdoba (Argentina) tiene por objetivo mapear la oferta de formación de grado y posgrado que las carreras de comunicación brindan en Argentina. Presentamos a continuación las primeras aproximaciones de los resultados que nos permiten conocer las asignaturas los principales ejes temáticos presentes en los programas de las Carreras que dictan las 46 dependencias universitarias nucleados en REDCOM (Red de Carreras de Comunicación Social) y FADECCOS (Federación Argentina de Carreras de Comunicación Social) en el año 2018-2019. Utilizamos una 
perspectiva metodológica cuantitativa a través de la técnica de revisión documental a fin de relevar datos básicos que aporten una descripción de lo antes mencionado a partir de la información publicada por los sitios oficiales de las dependencias universitarias. El objetivo será dar cuenta de la sistematización descriptiva obtenida y de las conclusiones iniciales a las que arribamos para empezar a construir el panorama de la situación de la enseñanza de la Comunicación Digital Institucional en la educación superior argentina. Las conclusiones preliminares nos sostienen que la mayoría de las carreras de grado cuenta con asignaturas que incluyen en su denominación los conceptos de comunicación digital, institucional u organizacional. $\mathrm{Y}$ también que la mayor parte de esas materias hacen referencia específicamente a "comunicación institucional", "comunicación organizacional" o a ambas. Por su parte, en el nivel de posgrado, llama la atención que aparecen más carreras vinculadas a la comunicación digital institucional en facultades que no están directamente ligadas a la enseñanza de la comunicación y no en aquéllas que por su especificidad deberían ofrecerlas.

* 242 - Las Relaciones Públicas y el consumo académico internacional - Yolanda López Lara -Universidad Autónoma de Nuevo León yolandalopezlara_uanl@hotmail.com, Asael Maceda- Universidad Autónoma de Nuevo León- Universidad Autónoma de Nuevo León- asaelmgz@gmail.com y Sergio Manuel de la Fuente Valdez-Universidad Autónoma de Nuevo Leónsermanfuen@yahoo.com

Cada vez se hace más notorio que estudiantes de educación superior tengan en su proyecto académico realizar el proceso de movilidad, para recibir enseñanza-aprendizaje en algunas unidades académicas que les favorecen en el área curricular profesional a partir del 6to. Semestre en adelante. Bajo estas circunstancias, el acompañamiento que se gestiona desde de las relaciones públicas universitarias cobra importancia y coadyuva a lograr expectativas no solo de los estudiantes, sino también a cubrir índices de calidad institucionales. La Universidad Autónoma de Nuevo León, consiente de este rubro, contempla en su Ley Orgánica la Dirección de Intercambio Académico, quien ejecuta minuciosamente todos las etapas de los procesos para cumplir eficientemente con esta importante función. Conforme a lo anterior, 
se determinó realizar un estudio de corte cualitativo con un alcance descriptivo y un diseño de investigación de caso intrínseco, cuya premisa indica: el consumo académico en instituciones universitarias a nivel internacional, favorece el índice de preparación y desarrollo universitario bajo la gestión y acompañamiento de las relaciones públicas. Las técnicas de recolección de datos fue la revisión de documentos institucionales como fuente de primera mano, después, la consulta bibliográfica impresa y posteriormente el apoyo de fuentes digitales. Algunos de los resultados obtenidos del semestre agosto diciembre de 2019 contemplan procesos de nuestros estudiantes de la Facultad de Ciencias de la Comunicación así como la recepción de estudiantes huéspedes de otras universidades a nivel nacional e internacional de y el acompañamiento de las relaciones publicas que está presente con nuestros estudiantes desde que se van al intercambio y regresan, así como, la inducción, procesos administrativos, y la la constante comunicación a través de medios formales y las redes sociales para estar siempre atentos en su bienestar y facilitarles la información necesaria en lo académico como en lo personal, desarrollada desde una planeación estratégica.

* 243 - Emoción en las redes sociales digitales como eje cognitivo del movimiento social de los Chalecos Amarillos (Gilets Jaunes) - Alberto José Luis Carrillo Canán - Université autonome de Puebla Mexico - acarrillo_mx@me.com y Jacques Ibanez Bueno - Université Savoie Mont-Blanc Laboratoire LLSETI Francia Jacques.Ibanez-Bueno@univ-smb.fr

El movimiento de los Chalecos Amarillos en Francia es notable en varios niveles. Lo que ocurre en el espacio público real (calles, rotondas, casetas de peaje) ha sido posible gracias a las interacciones en el "espacio" virtual la red social digital Facebook y sus sinergias con la matriz de medios de comunicación eléctricos (McLuhan). Partimos de las características visibles del movimiento para proponer el concepto de movilización digital, necesario para entender la dinámica del movimiento real en la vía pública. El análisis de la emoción en el análisis de los contenidos publicados en la red social permite captar los efectos sobre los participantes más activos, al margen de la información específica para la justificación de las acciones previstas. La emoción es 
el marco cognitivo para la reacción inmediata que es el patrón conductual dominante de los usuarios de la red social. La naturaleza cerrada y autoafirmativa de los contenidos publicados por los grupos militantes de Facebook alimenta la emotividad a través de acciones digitales específicas: publicar nuevos contenidos o tomar posturas emocionales, compartir contenidos comentando sobre ellos o participar directamente en transmisiones de vídeo en tiempo real durante eventos físicos. Una revisión contemporánea de la obra de McLuhan enriquece el análisis del funcionamiento de la red social digital, permitiendo entender el carácter emotivo del medio a partir de sus características tecnológicas.

* 244 - Internet, Redes Sociales y Entretenimiento Digital: Una mirada desde el Capital Social - Dr. Roberto Alejandro López Novelo - Centro de Investigación para la Comunicación Aplicada (CICA), Universidad Anáhuac México robertoa.lopez@anahuac.mx Mtro y Carlos Cienfuengos Alvarado - Universidad Anáhuac México carlos.cienfuegos@anahuac.mx

En el contexto actual, Internet se presenta como un espacio tecnosocial al que todos los días acuden millones de personas a realizar actividades vinculadas a la búsqueda de información, al uso de las redes sociales, al trabajo, al ocio y en los últimos años al entretenimiento. Asimismo, Internet permite la colaboración, la interacción y la relación social entre sus usuarios, posibilitando con ello la creación de capital social. Uno de los entornos en los que se puede observar el potencial que tiene Internet para la construcción y distribución de Capital Social son las redes sociales digitales, a través de las cuales los usuarios generan prácticas y formas de comunicación, si no nuevas si novedosas, basadas en la colaboración, la relación social, la interacción social, etc. El Capital Social es un concepto que en las últimas décadas ha cobrado suma importancia en el ámbito académico internacional, ya que en él, se concentran elementos como el capital, las relaciones sociales, el soporte social, la cohesión social, las normas, la confianza, la cooperación, etc. Aunado a lo anterior, el Capital Social se ha vinculado en los últimos años con las Tecnologías de Información y Comunicación (TIC), particularmente con Internet, que es 
considerado un ecosistema digital idóneo para la creación y distribución de entretenimiento. Así, el entretenimiento en Internet encuentra un potencial nunca antes visto, sustentado en los procesos de participación, colaboración e intercambio de información, que realizan las personas para generar nuevas ideas, plataformas, contenidos y estrategias de difusión.

* 245 - La propaganda política audiovisual de Alianza País en la segunda vuelta electoral de las elecciones presidenciales de 2017 en la plataforma digital Facebook - Rodrigo Esteban Alvarez Jarrín, Stephany Patricia Ibarra Bravo y Nina Lulushca Aguiar Mariño - Universidad Poitecnica Salesiana Quito Ecuador

Se estudió la propaganda política audiovisual de Alianza País en Facebook desde un enfoque metodológico mixto. A partir del enfoque cualitativo se realizó un análisis de discurso para comprender la capacidad persuasiva del audiovisual y posteriormente se llevó a cabo un análisis de contenido en la plataforma oficial de Facebook del entonces candidato presidencial Lenin Moreno, para comprobar, en términos cuantitativos, la influencia del discurso en la conformación de opinión pública. Se concibe a Facebook como un elemento mediador que faculta la reproducción del discurso porque crea un vínculo entre el interés político y el deseo de los espectadores, a través de la exposición mediática al mensaje ideológico.

* 246 - Las series de TV, como plataforma para descubrir música en la serie Girls - Cande Sánchez-Olmos - Universidad de Alicante - cande.sanchez@ua.es

Tanto en la producción de cine como de series de televisión destaca una figura que se denomina supervisor musical y que se encarga de proponer las canciones que forman parte de las bandas sonoras que escucharán en las series. Desde 2017, esta figura es reconocida por los premios Emmy como una categoría imprescindible para la creación de significado del discurso audiovisual. Además, esta sincronización ha supuesto el lanzamiento de nuevas canciones o artistas que antes de aparecer en una serie eran desconocidos Esta circunstancia justifica la necesidad de investigar esta figura. 
Esta comunicación tiene como objetivo principal analizar la música en las series de televisión como plataformas de descubrimiento de música pop. Para ello se analiza la supervisión musical como figura que crean experiencias memorables en la audiencia y a la vez promociona la canción sincronizada en la serie. Para ello se realiza un estudio de caso de la serie Girls con los siguientes objetivos específicos. En primer lugar, describir la figura de la supervisión musical. En segundo, se analizan y categorizan las canciones sincronizadas y la repercusión tanto de difusión como de promoción alcanzada por los artistas sincronizados.

Los resultados apuntan a que las series de televisión se han convertido en espacios para descubrir nuevas canciones y artistas, como lo ha sido la radio y los anuncios audiovisuales.

* 247 - La evolución y campos de actuación de las relaciones públicas en México - Marco-Tulio Flores Mayorga y Edgar Yeman García Turincio. (México)

Este estudio presenta un análisis reflexivo que tiene como propósito contribuir a la discusión sobre la posición actual de las relaciones públicas en el contexto mexicano al analizar sus antecedentes históricos y explorar sus campos de actuación hoy día en la docencia e investigación, centrándose en el ámbito profesional y entorno social, durante la época antigua, el Porfiriato, la Revolución Mexicana y el México contemporáneo hasta nuestros días.

Se destacan algunas acciones y sucesos relevantes considerados como parte de la disciplina, además de la influencia norteamericana en México con el comité Creel, a partir de la Primera Guerra Mundial. También se hace un breve recorrido de la enseñanza superior de la profesión que inició en 1960 con la inclusión de algunos cursos bajo el modelo polivalente de Ciencias de la Comunicación (periodismo, publicidad y relaciones públicas), introducido en 1965 por el Centro Internacional de Estudios Superiores de Comunicación para América Latina (CIESPAL) cuando intentaba reorientar las carreras de periodismo. Después de esta configuración de los estudios de 
comunicación, en los setentas se formaliza la creación de la carrera de comunicación y relaciones públicas.

En el ámbito organizacional se referencia la primera experiencia norteamericana en la aviación en la década de los treinta y de las primeras agencias de publicidad y relaciones públicas surgidas a mediados de los cuarenta, momento en el que también diferentes organismos públicos y privados empezaron a tomar en cuenta en sus estructuras a las relaciones públicas. Se hace un detenimiento especial sobre la destacada participación y contribución al desarrollo de la profesión de Federico Sánchez Fogarty, uno de sus máximos exponentes, no sólo del país, sino de América Latina. También se destaca la década de los noventa cuando se fortalecen las alianzas estratégicas comerciales con Estados Unidos y Canadá. En la actualidad, el enfoque que prevalece de las relaciones públicas en México tiende a orientarse a la mercadoctecnia y a los negocios en un contexto de desafíos económicos, politicos y sociales, en donde se enfrentan al constante desarrollo de la comunicación digital y las falsas noticias. Además de fortalecer la responsabilidad social e implementar acciones sustentables, gestionar una mayor transparencia y un diálogo con audiencias más activas, así como encarar los retos que suponen la comunicación global con diversos países y culturas, incluyendo la cuarta revolución.

Este análisis es una radiografía del acontecer histórico de las relaciones públicas que nos permite comprender cuáles han sido los cambios más significativos en los campos académico y profesional en México, concluye con un análisis de contenido de los sitios web e información oficial de 83 agencias de relaciones públicas con el fin de identificar hacía dónde se orientan los campos de actuación del sector tomando en cuenta el devenir de la profesión.

* 248 - Difusión Mediática Festividades Religiosas: San Judas Tadeo y Virgen de Guadalupe - Sergio Manuel de la Fuente Valdez - Facultad de Ciencias de la Comunicación - Universidad autónoma de Nuevo León - sermanfuen@yahoo.com, Yolanda López Lara.Yolandalopezlara_uanl@hotmail.com y Verónica Guajardo del Bosque. Facultad de Ciencias de la Comunicación. 
Universidad Autónoma de Nuevo León, México.

vguajardob@hotmail.com

Ha sido realizado un estudio mixto (cualitativo y cuantitativo), descriptivo, exploratorio, no experimental, relacionado con las tradiciones religiosas mexicanas, durante las festividades dedicadas a rendir culto a San Judas Tadeo y a la Virgen de Guadalupe. El universo es la población asistente a la Parroquia de San Judas Tadeo y a la Basílica de Guadalupe, en Monterrey, proveniente del área metropolitana. La muestra son los asistentes a esos dos recintos religiosos católicos. La selección de la muestra son los encuestados y entrevistados al azar, durante las celebraciones. Las razones de seleccionar este problema de investigación fueron la constante inquietud por saber los motivos que llevan a los asistentes y peregrinos a participar devotamente en estos destacados eventos masivos, sus consecuencias espirituales, familiares y sociales y los medios de difusión sobre la programación de múltiples eventos, cuyos actos constituyen un importante fenómeno social de mucha tradición en México. Sus implicaciones teóricas están basadas en teorías sociales como la Teoría Cultural y la Interpretativa teniendo además sus implicaciones prácticas y metodológicas. Los instrumentos de medición son un cuestionario, convertido en encuesta y un cuestionario-guía, utilizado para la discusión grupal. Principales hallazgos: los medios de difusión que contribuyeron a la asistencia y participación en distintas formas en festejos religiosos para los católicos son principalmente la comunicación interpersonal familiar, la televisión y la radio regiomontana, la comunicación organizacional parroquial, de la Basílica de Guadalupe y del Arzobispado de Monterrey. La tradición, las costumbres, los recuerdos y, en general, los valores de la religión católica inculcados en la familia, desde la niñez, a través de las generaciones, fueron las principales razones, causas o motivos por los durante muchos años han participado para rendir culto, agradecimiento, tributo o cumplimiento de una manda por favores concedidos y motivos a San Judas Tadeo y la Virgen de Guadalupe. 
Nota: este libro recoge todos los resúmenes recibidos hasta el momento de su cierre. Los recibidos después aparecen en la web del congreso

Edita: Sociedad Latina de Comunicación Social - La Laguna, Tenerife.

\section{Editores:}

Vanessa Rodríguez Breijo Milena Trenta

Alberto Ardèvol Abreu Ciro Hernández

Samuel Toledano Buendía Lucas Morales Domínguez

Alejandro Álvarez Nobell

Tatiana Hidalgo-Marí

Almudena Barrientos-Báez 


\section{Libro colectivo del $11^{\circ}$ Congreso Internacional Latina de Comunicación Social}

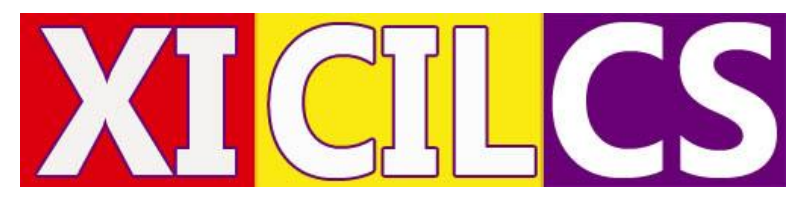

El CD adjunto contiene el libro colectivo originado en el $11^{\circ}$ Congreso Internacional Latina de Comunicación Social, celebrado en la Facultad de Ciencias Políticas, Sociales y de la Comunicación de la Universidad de La Laguna (Tenerife, Canarias; España) en diciembre de 2019.

Todos los trabajos contemplados en ese libro colectivo han sido previamente sometidos a evaluación por los moderadores de las correspondientes mesas de debate donde se presentaron.

Se trata del mismo documento que igualmente aparece en el sitio web: http://www.revistalatinacs.org/19SLCS/cac160.html

El disco está provisto de un pequeño programa de autoarranque: al ser introducido en la disquetera se abre por defecto la página http://www.revistalatinacs.org/19SLCS/libro-colectivo.html

En algunos sistemas puede que no funcione el autoarranque: en esos casos, una vez abierto el disco, hágase doble clic en el fichero http://www.revistalatinacs.org/19SLCS/libro-colectivo.html

Para localizar a un autor, hay que utilizar la herramienta "Buscar en esta página". Ese $\mathrm{CD}$, como obra colectiva, dispone de los siguientes registros, impresos en su carátula:

ISBN: 978-84-17314-10-1 y D.L.: TF- 997-2019

DOI: $10.4185 /$ CAC160 